$$
\text { ORNL/M- -5491 }
$$

\title{
1996 Structural Integrity Assessments for the Category C Liquid Low-Level Waste Tank Systems at Oak Ridge National Laboratory, Oak Ridge, Tennessee
}

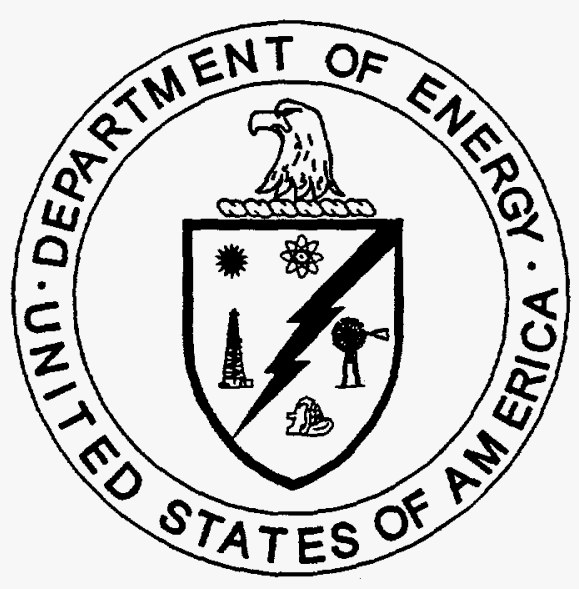

JAN 29 ค997

OSTI

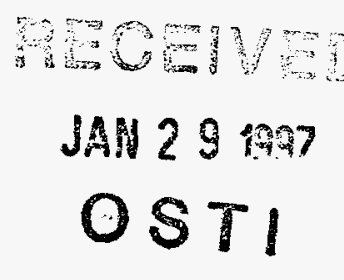

RISTEPTON OF THS DOOMEN IS UNLMTED

This document has been approved by the ORNL Technical Information Office

for release to the public. Date: $9 / 24 / 96$ 


\section{International Waste Management Systems and}

Vista Research, Incorporated

contributed to the preparation of this document and should not be considered eligible contractors for its review.

This report has been reproduced directly from the best available copy.

Available to DOE and DOE contractors from the Office of Scientific and Technical Information, P.O. Box 62, Oak Ridge, TN 37831; prices available from 423-5768401 (fax 423-576-2865).

Available to the public from the National Technical Information Service, U.S. Department of Commerce, 5285 Port Royal Rd., Springfield, VA 22161. 


\section{DISCLAIMER}

Portions of this document may be illegible in electronic image products. Images are produced from the best available original document. 


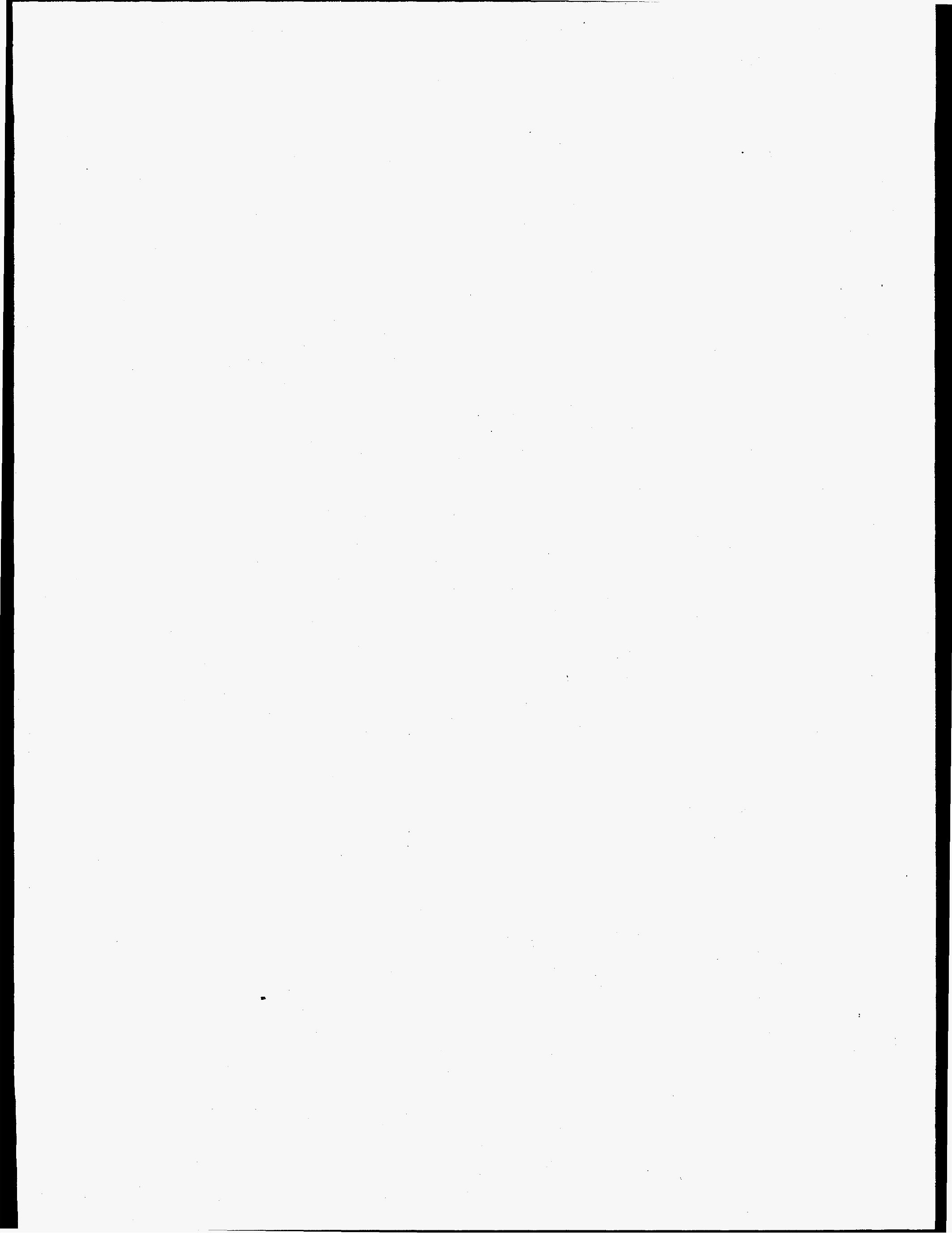




\section{DISCLAIMER}

This report was prepared as an account of work sponsored by an agency of the United States Government. Neither the United States Government nor any agency thereof, nor any of their employees, make any warranty, express or implied, or assumes any legal liability or responsibility for the accuracy, completeness, or usefulness of any information, apparatus, product, or process disclosed, or represents that its use would not infringe privately owned rights. Reference herein to any specific commercial product, process, or service by trade name, trademark, manufacturer, or otherwise does not necessarily constitute or imply its endorsement, recommendation, or favoring by the United States Government or any agency thereof. The views and opinions of authors expressed herein do not necessarily state or reflect those of the United States Government or any agency thereof. 


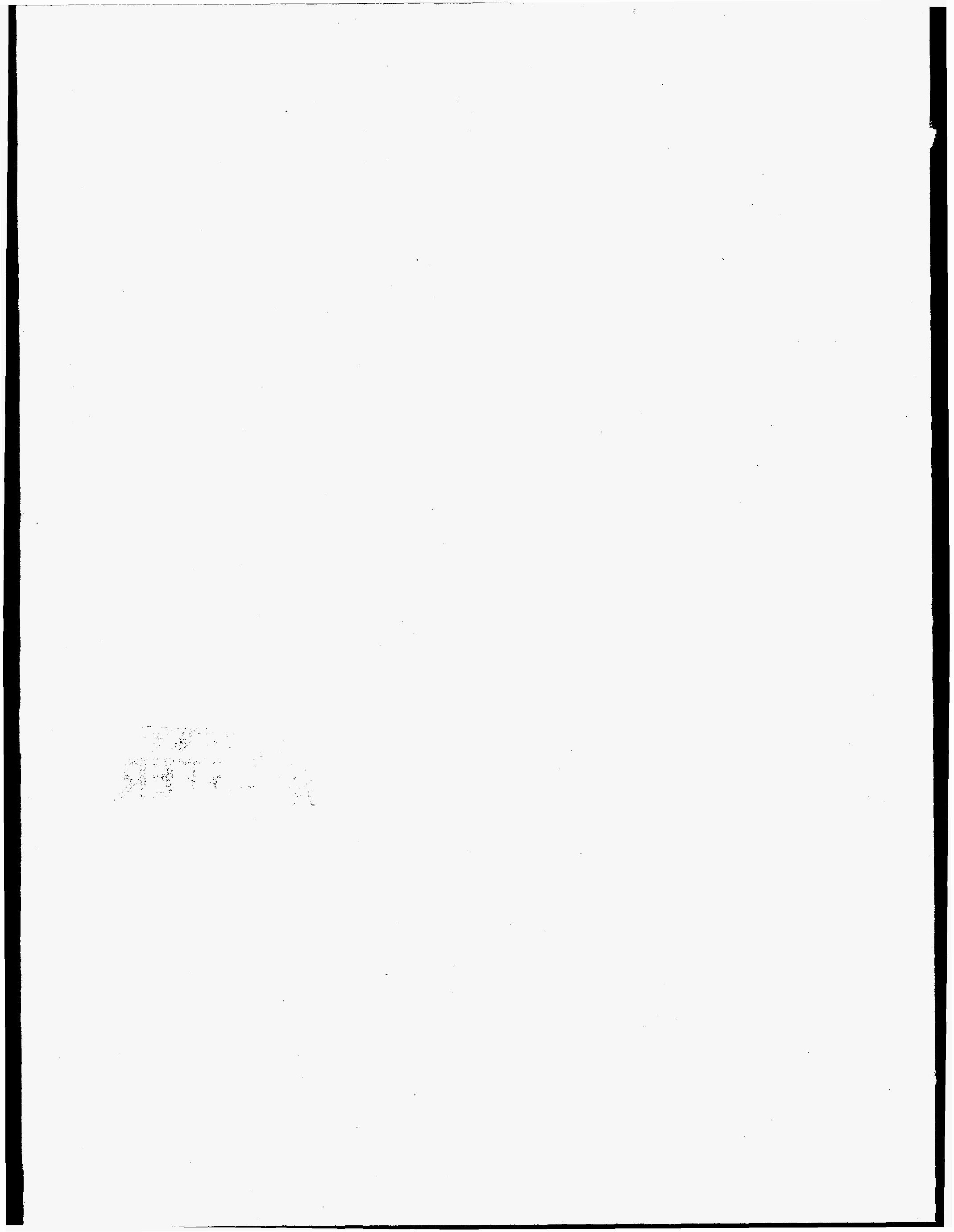


Energy Systems Environmental Restoration Program

\title{
1996 Structural Integrity Assessments for the Category C Liquid Low-Level Waste Tank Systems at Oak Ridge National Laboratory, Oak Ridge, Tennessee
}

Date Issued-September 1996

\author{
Prepared by \\ International Waste Management Systems \\ Knoxville, Tennessee \\ under subcontract 78X-SV914 \\ and \\ Vista Research, Incorporated \\ Mountain View, California \\ under subcontract 78X-SP750C
}

Prepared for the

U.S. Department of Energy

Office of Environmental Management

under budget and reporting code EW 20

Environmental Management Activities at the

OAK RIDGE NATIONAL LABORATORY

Oak Ridge, Tennessee 37831-6285

managed by

LOCKHEED MARTIN ENERGY SYSTEMS, INC.

for the

U.S. DEPARTMENT OF ENERGY

under contract DE-AC05-84OR21400 



\section{PREFACE}

This document summarizes the structural integrity certification of Category C Liquid Low Level WasteTank Systems at Oak Ridge National Laboratory, Oak Ridge, Tennessee in compliance with the requirements of the Federal Facility Agreement. This report is an update to the 1995 Structural Integrity Assessment (DOE/OR/01-1385\&D2). The work is being performed under Work Breakdown Structure 1.3.6.4.15.4 and Activity Data Sheet 3206. 


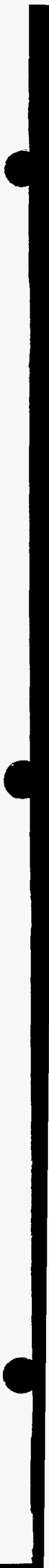




\section{TABLE OF CONTENTS}

PART I - SUPPLEMENTAL INFORMATION

PART II - STRUCTURAL INTEGRITY ASSESSMENTS FOR THE CATEGORY C LLLW TANK SYSTEMS 


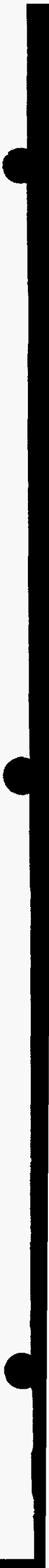




\section{PART I}

\section{SUPPLEMENTAL INFORMATION}




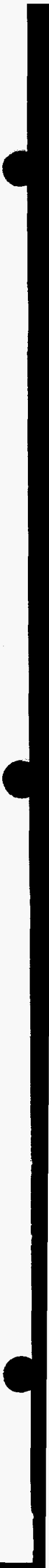




\section{SUPPLEMENTAL INFORMATION}

Part II provides the Structural Integrity Assessments for the Category C LLLW Tank Systems. These assessments of the structural integrity of the singly contained LLLW tanks and associated piping were conducted in accordance with Section IX.F and Appendix F of the Federal Facility Agreement (FFA). Part II is composed of a section for each of the 10 Category $\mathrm{C}$ tank system assessments and provides certification for each tank system component as warranted. This report represents the first annual reassessment of the structural integrity of the existing Category $\mathrm{C}$ tank systems and is an update of Structural Integrity Assessments for the Category C Liquid Low-Level Waste Tank Systems at the Oak Ridge National Laboratory [DOE/OR/01-1385\&D2] submitted in September 1995.

The following provides a summary of the findings of the structural integrity assessments. For the general types of system components which have not been certified, supplemental information is provided which describes the impact of the lack of certification. In addition, further detail is included for the HFIR (High Flux Isotopes Reactor) Tank System.

\section{SUMMARY OF ASSESSMENT FINDINGS}

Assessments were performed to determine the structural integrity of 10 tanks and their associated piping. The certifications of each component in the structural integrity assessments were based on the results of leak tests, a review of design drawings, and a qualitative corrosion assessment. A summary of the assessment findings for tanks and pipelines follows.

Tanks

Of the 10 tanks which were assessed, 8 were certified as having sufficient structural integrity to contain liquids up to the maximum levels achieved during leak testing. Two tanks, HFIR and WC-10, did not pass leak tests due to inflows into the respective tanks. A discussion of the HFIR Tank System is included below. Field investigations completed over the last two years indicate that inflows to Tank WC10 are entering the tank via a gravity drain line and that the source of the inflows appear to be non-LLLW from the Isotopes Circle area. Based on these investigations, an inactive pipeline leading to Tank WC-10 was cut and capped in April, 1996. A section of this inactive line was observed to contain two small holes. Since the repair was completed, the tank has passed two leak tests. These results will be documented in the 1997 update of the structural integrity assessments.

The certification statement for each tank that routinely passed monthly leak testing addresses a level up to which the tank has sufficient structural integrity to contain the liquids. This level is based on the highest level at which the tank passed leak testing. Based on an examination of the highest level reached in the tank over the assessment period and the highest level at which the tank passed leak testing, the testing program has been successful at testing at the volumes routinely reached in each tank. Monthly testing will be continued for the Category $\mathbf{C}$ tanks during the next annual re-assessment period. The monthly testing will continue to be conducted routinely on the first weekend of each month. In addition, DOE will actively monitor the levels in the tanks and will leak test the tanks if the liquid contents exceed the certification levels. In the event that certification levels are exceeded, DOE will notify TDEC that the certification levels were exceeded and will give the results of the leak tests. It should be noted that there are safety limits set for each tank which are not exceeded. 


\section{Pipelines}

There are 67 line segments which were identified as part of the Category $C$ tank systems. Of these 67 line segments, 53 segments are currently in use. These segments in use are approximately 13,184 feet in total length. Of this total length, $76 \%$, or 10,081 feet, was tested and therefore certified. The remaining lines were untestable. The untestable lines were discussed in the Detailed Leak Detection Test Plan and Schedule for Pipelines at ORNL, DOE/OR/01-1167\&D2. The pipelines which could not be tested were generally untestable due to one or more of the following circumstances:

1. Line is inaccessible (One end of the line cannot be accessed in order to pump water into the line for a volume balancing test.)

2. Line cannot be isolated (There are no isolation valves at the end of one or more segments of a piping system to permit a gas pressure decay test.)

3. Tank level measurement is inadequate to provide the accuracy and precision needed for an enhanced volume balancing leak test. When this situattion has occurred, it has been due to uncontrolled inflows into the tank which prevent a conclusive volume balancing test. However, volume balancing tests were performed (inlet line to Tank WC-10 and inlet line to HFIR Tank) in order to qualitatively assess the line condition.

The untestable pipelines generally include one or more of the following characteristics which indicate a mitigation of the risk of release to the environment or risk to the health and safety of workers or the public:

1. Line is a suction leg (additionally, in cases where there is an associated pump, the pump primes, indicating that the line is intact).

2. Line is not used.

3. Line is fully contained by a vault or runs through a vault for a portion of its length.

4. Line is short (often the untestable line is a segment of line existing between an isolation valve of a testable pipeline and a tank, pump, or steam jet).

The structural integrity assessments for each tank system list all of the line segments associated with each system. The assessment for each tank system discusses whether the lines are used or not, and the tank system diagram and tables provide information on length and type of line.

\section{HFIR TANK SYSTEM}

The HFIR Tank is currently used to collect LLLW from the ion exchange columns in the HFIR reactor building during re-generations. The tank also collects filter pit condensate and rain water infiltration into the filter pits. The HFIR Tank is scheduled to go out of service in September 1997. However, the HFIR portion of the Melton Valley LLLW Collection and Transfer Line Item construction project is currently scheduled to be complete by the Second Quarter FY 96. This project will eliminate the primary need for the tank, the drain lines from the filter pit and HFIR building to the tank and the 
pressurized line from the tank to the Diversion Box at Tanks T-1 and T-2. The filter pit contributes unsteady inflows into the tank and prevents the conclusive testing of the tank and the main portion of the gravity drain line from the building to the tank. The HFIR system Environmental Safety and Health (ES\&H) exemption is discussed in the FFA Plans and Schedules (ES/ER-17\&D1). The HFIR cannot be operated without access to the tank system.

HFIR is a primary producer of medical radioisotopes used in diagnosing and treating cancer throughout the United States. Many of these isotopes are short-lived, and continuity of production is vital. For example, HFIR is the sole provider of Palladium-103, which is used in the treatment of prostate cancer. Palladium has a half-life of only 17 days, thus production interruptions would severely impact its availability. HFIR is the western world's sole provider of transuranium isotopes, such as Californium- 252 . Used in the treatment of cervical cancer, Californium-252 has become an increasingly important medical tool over the last few years.

HFIR is also a key producer of Rhenium-188, which is used for radiolabeling antibodies for cancer treatment, and Osmium-191/Iridium-191m, which is used in evaluating heart disease. Although alternate sources can produce these isotopes, no other reactors can produce them efficiently, and without HFIR, the availability of these isotopes would be severely limited.

In additional to medical radioisotopes, isotopes for safety-related purposes are produced at HFIR. Californium-252 is used as the thermal neutron source in monitors that detect hidden explosives in luggage and packages. These monitors have been installed in several major airports in the United States and in Europe. No direct replacement for the Californium source is available. Also, systems designed by Los Alamos National Laboratory for assaying transuranic waste require a Californium source. Numerous international research projects depend upon continued availability of the HFIR reactor. These include the Magnetic Fusion Energy Materials Program, a joint United States/Japan project in which the United States has committed to irradiate several experiments. In addition, the United States, together with Japan, Russia, and the European Community, is engaged in a program in which HFIR is used to determine the effects of irradiation on candidate first-wall, shield, and insulator materials for the International Thermonuclear Experimental Reactor. Loss of the HFIR for support of these and other international projects would be costly and could potentially damage United States relations in the international community.

The shutdown of the HFIR would cause greater adverse societal impacts than would the benefits gained from the slightly decreased risk of environmental insult. The HFIR Tank has not been certified because variable inflows prevented successful leak testing, however, there are no indications that there are any outflows from the tank. The variable inflows also prevented leak testing of the drain line from the HFIR Building to the tank. The majority of the pressurized discharge piping between HFIR Tank and the Diversion Box at T-1 and T-2 (1947 feet out of 1985 feet) was successfully tested and certified. In addition, there are mitigating features of the piping not tested which lessens the impacts of a potential leak. A discussion of each untestable segment follows.

1. Line Segment 38 - This line segment is the suction piping for Pump A in the HFIR Tank Pump Pit and is $\mathbf{3 8}$ feet in length. The pump is capable of being primed prior to transfers indicating that the line is intact. In addition, the line is in the tank or in the concrete vault containing the pumps for approximately 25 feet out of the total pipe length of 38 feet. 
2. Line Segment 39 - This line segment is the suction piping for Pump B in the HFIR Tank Pump Pit and is $\mathbf{3 8}$ feet in length. The pump is capable of being primed prior to transfers indicating that the line is intact. In addition, the line is in the tank or in the concrete vault containing the pumps for approximately 25 feet out of the total pipe length of 38 feet.

3. Line Segment 76 - This line segment is a gravity drain line connecting the filter pit for Building 7920 to the drain line (line segment 75) to the filter pit for the HFIR (Building 7913) and is 20 feet in length. There is no access to either end of the line, rendering the line untestable by the enhanced volume balancing method or the gas pressure decay method.

4. Line Segment 75 - This line segment is a gravity drain line which connects the Building 7911 Stack to the Filter Pit (Building 7913) and is 22 feet in length. The line is inaccessible at each end, therefore it cannot be tested by the EVB or GPD method.

5. Line Segment 121 and Line Segment 77 - These line segments are connected in series and form the gravity drain line which connects the Filter Pit (Building 7913) to the HFIR Building and eventually to the HFIR Tank. The lines are 152 feet in length total. The lines are inaccessible and therefore, cannot be tested by the EVB or GPD method.

\section{CONCLUSION}

In summary, it is DOE's belief that the structural integrity assessments included in Part II of this document meet the intent of the FFA for allowing Category $\mathrm{C}$ tank systems to remain in service. 


\section{PART II}

STRUCTURAL INTEGRITY ASSESSMENTS

FOR THE CATEGORY C

LLLW TANK SYSTEMS 


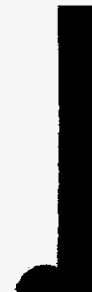




\section{6 \\ STRUCTURAL INTEGRITY ASSESSMENTS FOR THE \\ CATEGORY C LLLW TANK SYSTEMS}

Prepared by:

International Waste Management Systems

200 Tech Center Drive

Knoxville, TN 37912

Vista Research, Incorporated

100 View Street

P.O. Box 998

Mountain View, CA 94042

Prepared for:

Lockheed Martin Energy Systems

Oak Ridge National Laboratory

Oak Ridge, Tennessee

September 19, 1996 



\section{EXECUTIVE SUMMARY}

This document provides a report of the efforts made to satisfy the Federal Facility Agreement (FFA) for the structural integrity certification of ten Category C Liquid Low Level Waste (LLLW) tank systems on the Oak Ridge Reservation (ORR) in Oak Ridge, Tennessee.

This report is developed as an update to the 1995 Structural Integrity Assessment Report (DOE/OR/01-1385\&D2). DOE/OR/01-1385\&D2 included the assessment of 14 Category C tank systems. Four tank systems have since been removed from Category $\mathrm{C}$ classification. These systems include 2026A, F-201, WC-7, and WC-19. Each of these four systems has been removed from service and has been given a Category D classification.

Within this document, each Category $\mathrm{C}$ tank system is described including the associated pipeline segments evaluated as a part of those tank systems. A separate structural integrity assessment was conducted for each of the LLLW Tank Systems, four of which are located in Melton Valley, and six of which are located in Bethel Valley. The results of the structural integrity assessments are reported herein. The assessments are based on (1) a review of available tank design drawings, (2) a qualitative assessment of corrosion on the tank and pipelines, and primarily (3) leak testing program results.

Design plans and specifications were reviewed in 1995 for a general description of the tanks and associated pipelines. Information of primary significance included tank age, material of construction, tank design, and construction specifications. Design plans were also reviewed for the layouts and materials of pipeline constructions and ages of pipelines.

A generic corrosion assessment was conducted in 1995 for each tank system. Information was gathered, when available, related to the historical use of the tank and the likely contents. The corrosion assessments included a qualitative evaluation of the walls of each tank and pipelines associated with each tank, as well as the welds and joints of the systems. A general discussion of the stainless steel types encountered is included in Section 4.0 of this report. The potential for corrosion is evaluated within the sections on the individual tank systems.

The final information used to certify the tank systems were the results of leak testing performed on the tank systems. Category C tanks were tested monthly between January 1995 and December 1995. Annual leak testing of pipelines was conducted between August 1995 and September 1996. The results of these leak tests are presented in Section 7.0 of this report. A discussion of the untestable portion of the lines is also included in this section.

This assessment determined that all of the tank systems were generally designed and constructed with materials and methods appropriate to their intended usage. It was determined that controlling $\mathrm{pH}$ in nine of the ten Category $\mathrm{C}$ tank systems has significantly reduced the potential of corrosion. Nine of the ten Category $\mathrm{C}$ tanks have been leak tested. The untested tank has an uncontrollable inflow and cannot be leak tested. Of the nine that have been tested, eight routinely passed leak testing and have been certified. None of the tanks give any indication of an outflow, or leak. Most of the testable pipelines that require leak testing have been tested and certified. 

Certification results for each specific tank system are presented in the tank-specific subsections of Section 7.0, beginning with Section 7.1.4.3. Certification for each specific tank system is provided at the end of each tank section. 


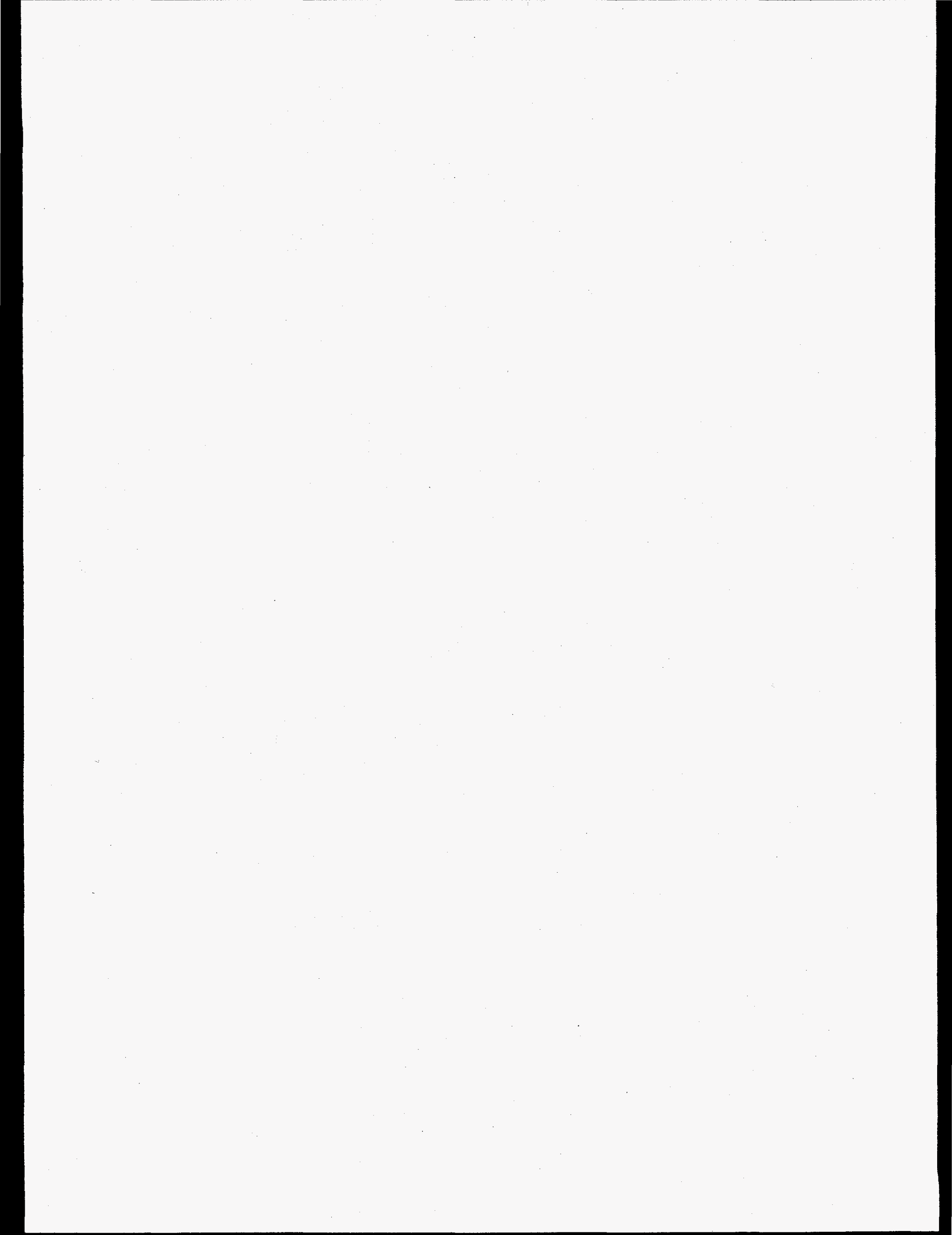




\section{EXECUTIVE SUMMARY}

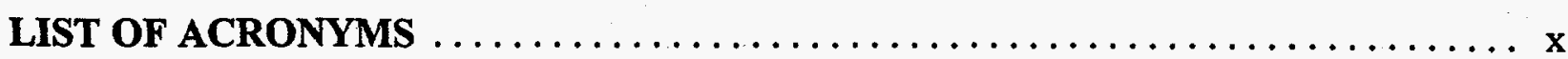

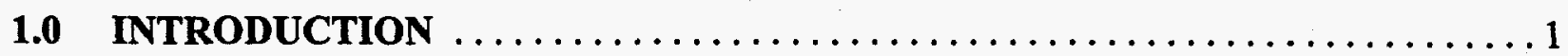

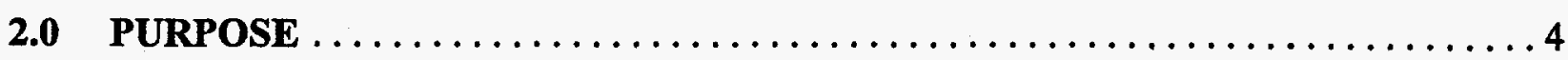

3.0 DESIGN DRAWING EVALUATION $\ldots \ldots \ldots \ldots \ldots \ldots \ldots \ldots \ldots \ldots \ldots$

4.0 GENERAL CORROSION ASSESSMENT OF THE CATEGORY C

TANK SYSTEMS $\ldots \ldots \ldots \ldots \ldots \ldots \ldots \ldots \ldots \ldots \ldots \ldots \ldots \ldots \ldots \ldots$

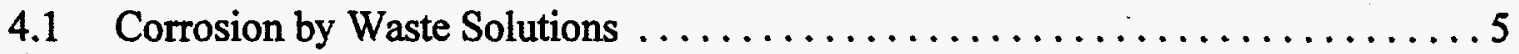

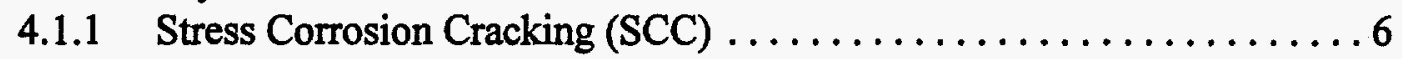

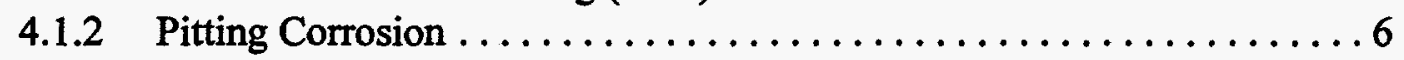

4.1.3 Crevice Corrosion ..............................6

4.1.4 Intergranular-Knife Line Attack ....................

4.1.5 Microbiologically Influenced Corrosion (MIC) $\ldots \ldots \ldots \ldots \ldots \ldots 7$

4.2 Soil Side Corrosion of ORNL Waste Systems $\ldots \ldots \ldots \ldots \ldots \ldots \ldots \ldots 7$

$5.0 \quad$ INTRODUCTION TO LEAK TESTING $\ldots \ldots \ldots \ldots \ldots \ldots \ldots \ldots$

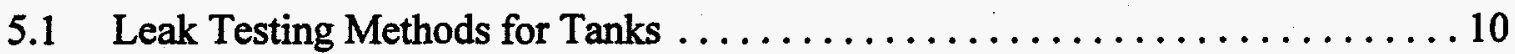

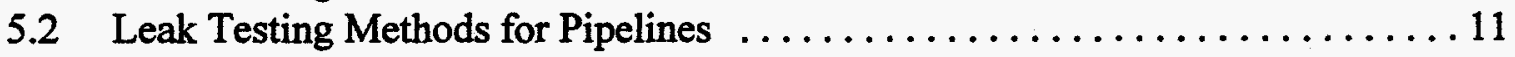

5.2.1 Leak Detection Method for Gravity-Fed Pipelines . . . . . . . . . 12

5.2.2 Leak Testing Methods for Pressurized Pipelines .............. 11

5.3 Determination of Expected Error Values for the Untestable Pipelines . . . . . 13

5.4 Data Analysis Based Upon the Kolomogorov-Smimov Test $\ldots \ldots \ldots \ldots \ldots 15$

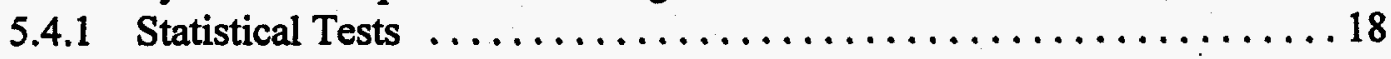

6.0 BASIS FOR TANK SYSTEM CERTIFICATION $\ldots \ldots \ldots \ldots \ldots \ldots \ldots \ldots \ldots \ldots \ldots \ldots$ 


\section{TABLE OF CONTENTS (cont'd)}

Section

Page

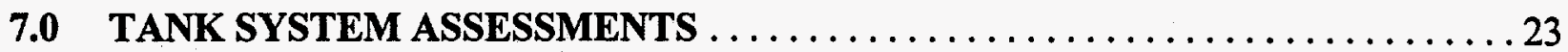

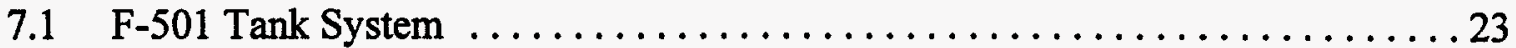

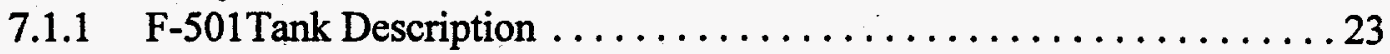

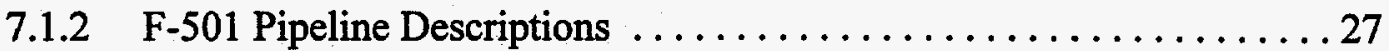

7.1.3 Corrosion Assessment of the F-501 Tank System . . . . . . . . . 28

7.1.4 Results of Leak Tests on the F-501 System ... . . . . . . . . . . 28

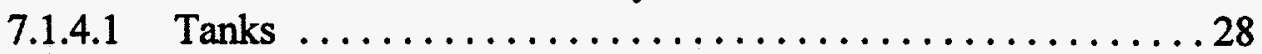

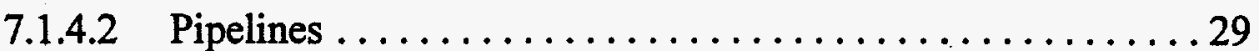

7.1.4.2.1 Testable Pipelines .................. 29

7.1.4.2.2 Untestable Pipelines ............... 30

7.1.4.3 Analysis of Leak Test Data . . . . . . . . . . . . 30

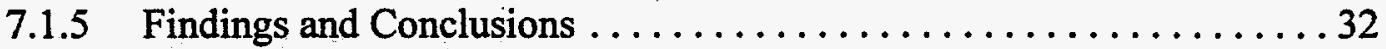

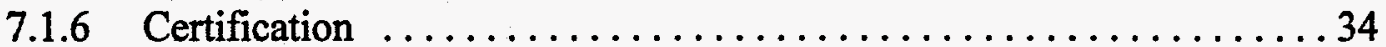

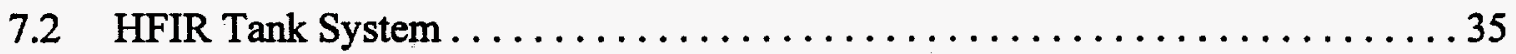

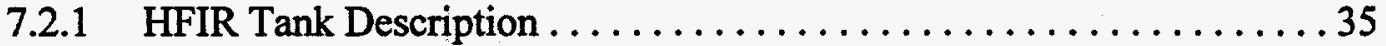

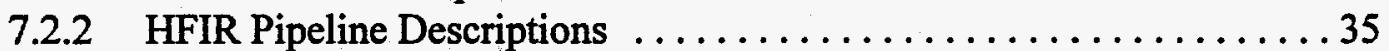

7.2.3 Corrosion Assessment of HFIR Tank System ............... 39

7.2.4 Results of Leak Tests on the HFIR System . . . . . . . . . . . 38

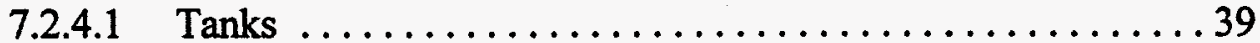

7.2.4.2 HFIR Pipelines . . . . . . . . . . . . . . . . 390

7.2.4.2.1 HFIR Testable Pipelines . . . . . . . . . . 40

7.2.4.2.2 HFIR Untestable Pipelines ........... 40

7.2.4.3 Analysis of HFIR Tank Leak Test Data . . . . . . . . . . 41

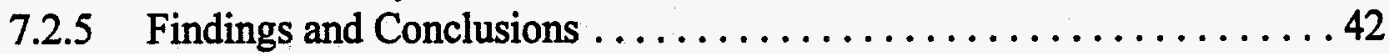

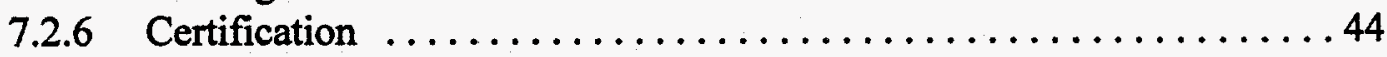

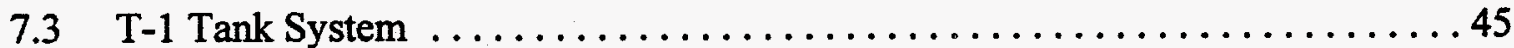

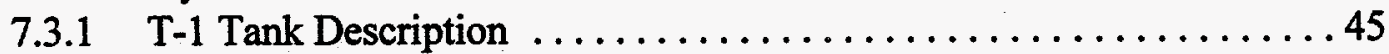

7.3 .2 T-1 Pipeline Descriptions . . . . . . . . . . . . . . . . 49

7.3.3 Corrosion Assessment of $\mathrm{T}-1$ Tank System . . . . . . . . . . . . . 49

7.3.4 Results of Leak Tests on the T-1 System .............. 50

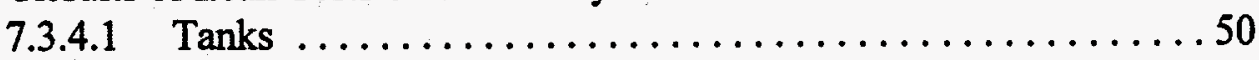

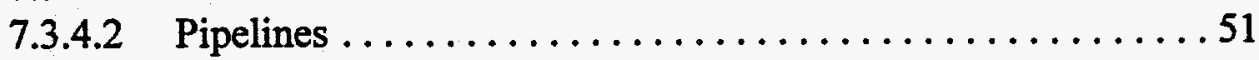

7.3.4.2.1 Testable Pipelines ................... 51

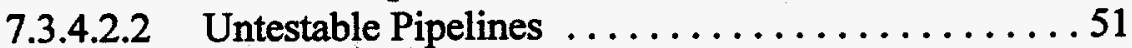

7.3.4.3 Analysis of Leak Testing Data . . . . . . . . . . 52

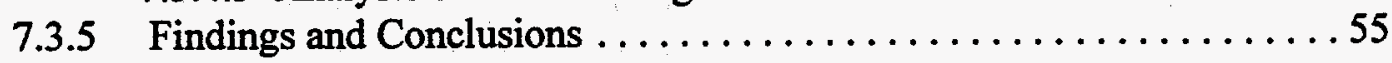




\section{TABLE OF CONTENTS (cont'd)}

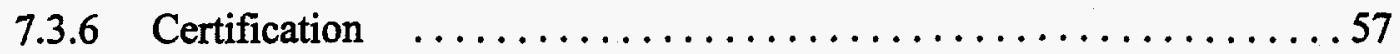

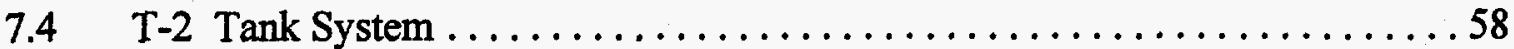

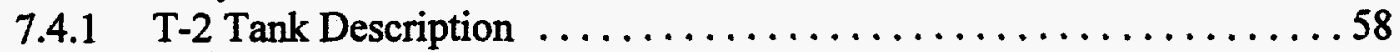

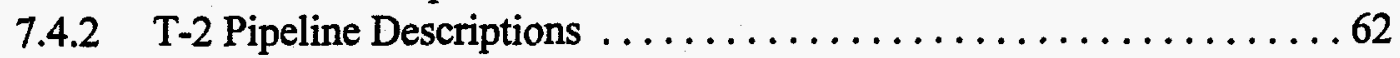

7.4.3 Corrosion Assessment of the T-2 Tank System ..............62 62

7.4.4 Results of Leak Tests on the T-2 System $\ldots \ldots \ldots \ldots \ldots \ldots \ldots \ldots$

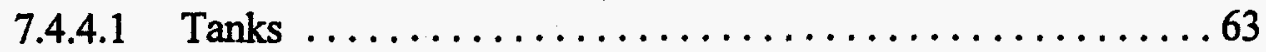

7.4.4.2 Pipelines .............................64

7.4.4.2.1 Untestable Pipelines . . . . . . . . . . . . . . 64

7.4.4.3 Analysis of Leak Test Data $\ldots \ldots \ldots \ldots \ldots \ldots \ldots \ldots 6 . \ldots 6$

7.4 .5 Findings and Conclusions $\ldots \ldots \ldots \ldots \ldots \ldots \ldots \ldots \ldots \ldots, \ldots, \ldots \ldots \ldots$

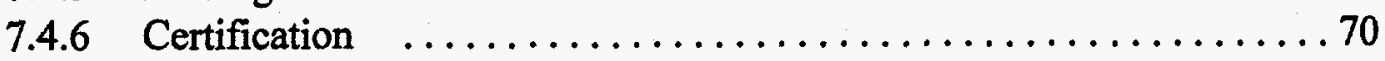

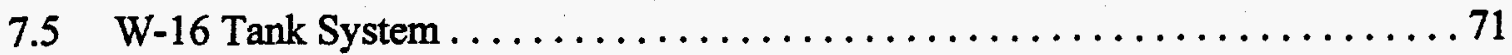

7.5.1 W-16 Tank Description .......................... 71

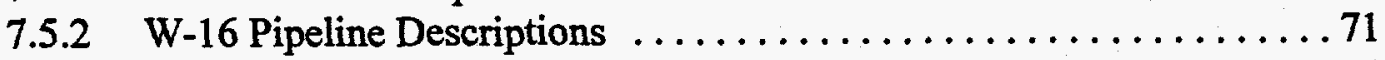

7.5.3 Corrosion Assessment of the W-16 Tank System ............74

7.5.4 Results of Leak Tests on the W-16 System $\ldots \ldots \ldots \ldots \ldots \ldots \ldots 75$

7.5.4.1 Tanks ................................. 75

7.5.4.2 Pipelines .............................. 76

7.5.4.2.1 Testable Pipelines $\ldots \ldots \ldots \ldots \ldots \ldots \ldots \ldots \ldots . \ldots \ldots$

7.5.4.2.2 Untestable Pipelines ................. 76

7.5.4.3 Analysis of Leak Test Data .................. 77

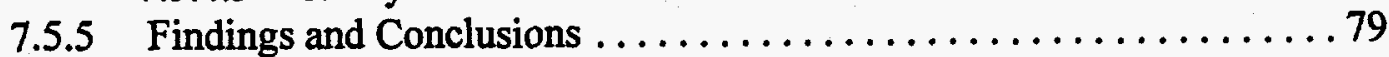

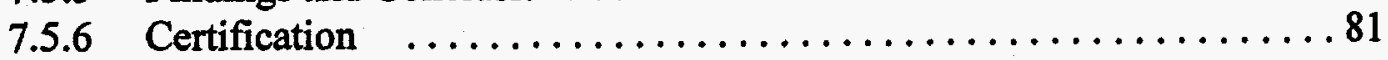

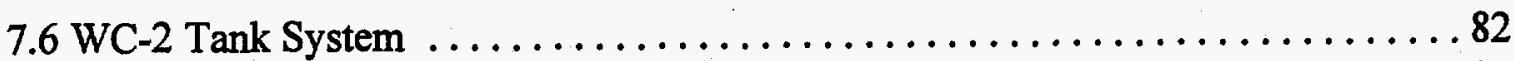

7.6.1 WC-2 Tank Description .......................... 82

7.6.2 WC-2 Pipeline Descriptions . . . . . . . . . . . . . . . . . . 85

7.6.3 Corrosion Assessment of the WC-2 Tank System . . . . . . . . . 86

7.6.4 Results of Leak Tests on the WC-2 System . . . . . . . . . . . . 86

7.6.4.1 Tanks ................................... 87

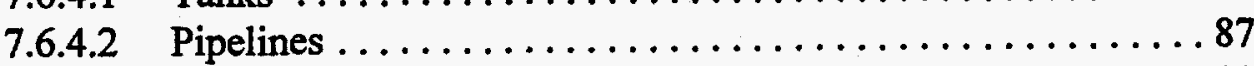

7.6.4.2.1 Testable Pipelines .................. 88

7.6.4.2.2 Untestable Pipelines . . . . . . . . . . . . . 88

7.6.4.3 Analysis of Leak Test Data $\ldots \ldots \ldots \ldots \ldots \ldots \ldots \ldots .68$

7.6.5 Findings and Conclusions $\ldots \ldots \ldots \ldots \ldots \ldots \ldots \ldots \ldots \ldots \ldots, \ldots \ldots \ldots$

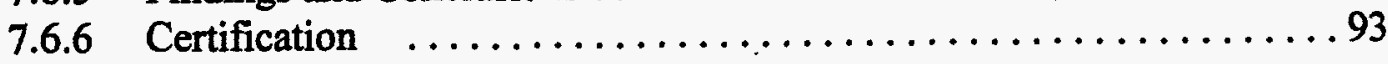




\section{TABLE OF CONTENTS (cont'd)}

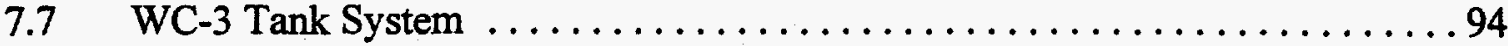

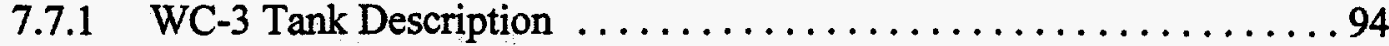

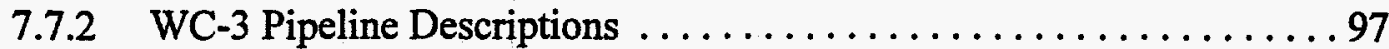

7.7.3 Corrosion Assessment of the WC-3 Tank System . . . . . . . . . . . . 98

7.7.4 Results of Leak Tests on the WC-3 System . . . . . . . . . . . . 98

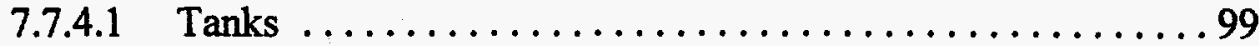

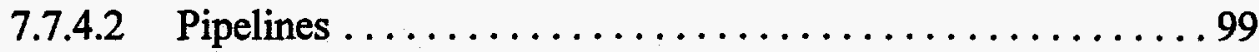

7.7.4.2.1 Testable Pipelines ................ 100

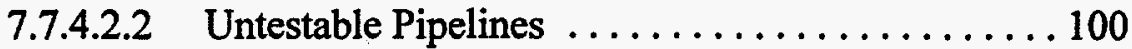

7.7.4.3 Analysis of Leak Test Data . . . . . . . . . . . . . . . 101

7.7.5 Findings and Conclusions ..................... 103

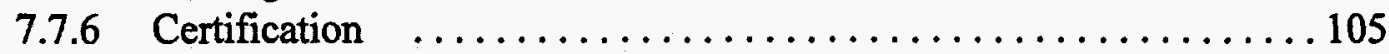

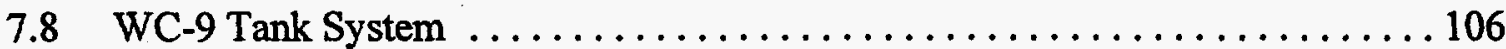

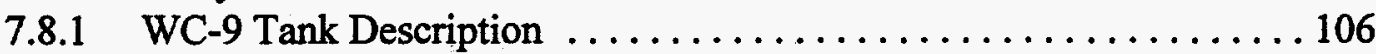

7.8.2 WC-9 Pipeline Descriptions ....................... 106

7.8.3 Corrosion Assessment of the WC-9 Tank System . . . . . . . . . . . 109

7.8.4 Results of Leak Tests on the WC-9 System . . . . . . . . . . . . 110

7.8.4.1 Tanks .......................... 110

7.8.4.2 Pipelines $\ldots \ldots \ldots \ldots \ldots \ldots \ldots \ldots \ldots \ldots \ldots \ldots \ldots$

7.8.4.2.1 Testable Pipelines .................. 111

7.8.4.2.2 Untestable Pipelines ............... 111

7.8.4.3 Analysis of Leak Test Data . . . . . . . . . . . . 111

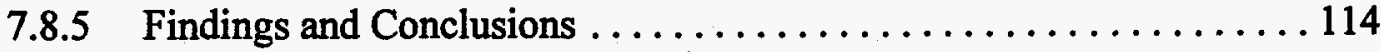

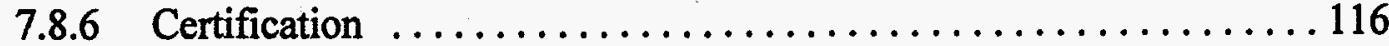

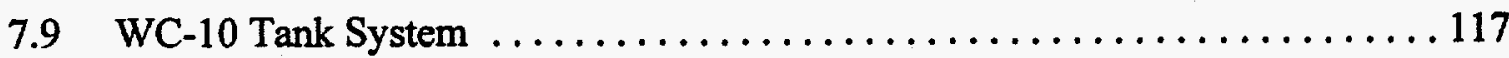

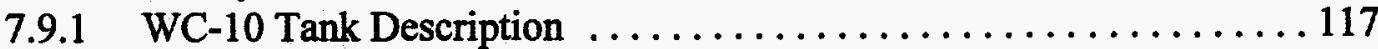

7.9.2 WC-10 Pipeline Descriptions ....................... 117

7.9.3 Corrosion Assessment of WC-10 Tank System . . . . . . . . . . . 122

7.9.4 Results of Leak Tests on the WC-10 System . . . . . . . . . . 122

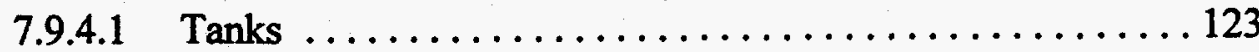

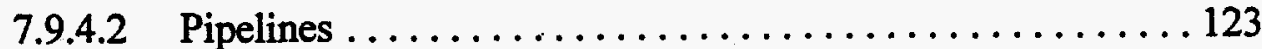

7.9.4.2.1 Testable Pipelines ................ 123

7.9.4.2.2 Untestable Pipelines ............... 125

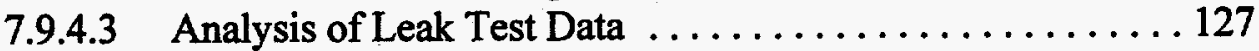

7.9.5 Findings and Conclusions ...................... 129

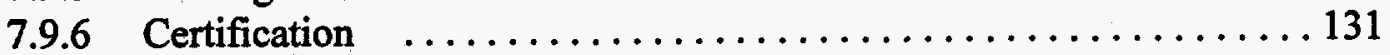




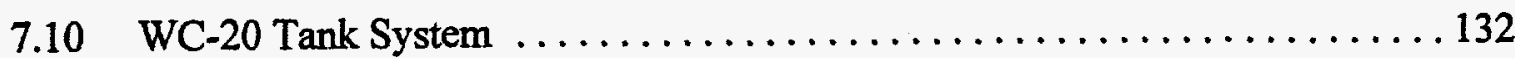

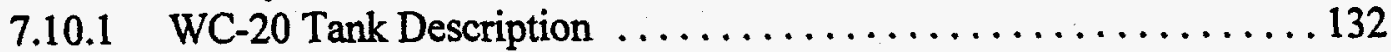

7.10 .2 WC-20 Pipeline Descriptions . . . . . . . . . . . . . . . . 132

7.10.3 Corrosion Assessment of WC-20 Tank System ............ 135

7.10 .4 Results of Leak Tests on the WC-20 System ............. 136

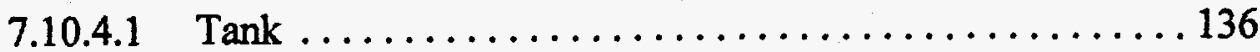

7.10.4.2 Pipelines ............................ 137

7.10.4.2.1 Testable Pipelines .................. 137

7.10.4.2.2 Untestable Pipelines . . . . . . . . . . . . . . 138

7.10.4.3 Analysis of Leak Test Data . . . . . . . . . . . . . 139

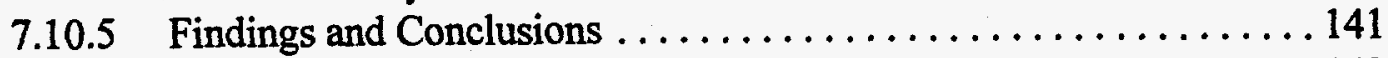

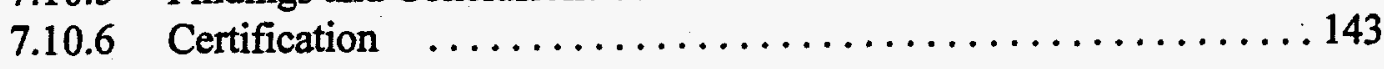




\section{TABLE OF CONTENTS (cont'd)}

\section{LIST OF FIGURES}

Figure

Page

1 Bethel Valley Category C LLLW Tank Systems $\ldots \ldots \ldots \ldots \ldots \ldots \ldots \ldots \ldots \ldots \ldots \ldots$

1A Melton Valley Category C LLLW Tank Systems $\ldots \ldots \ldots \ldots \ldots \ldots \ldots \ldots \ldots \ldots$

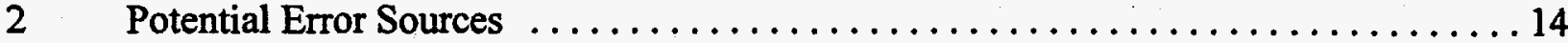

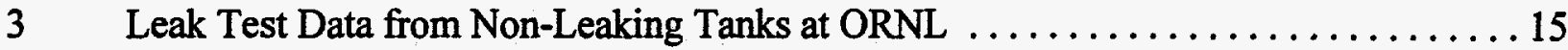

4 Histogram and Normal Probability Distribution Inferred from ORNL CVR Data . . . 16

5 Histogram and Gaussiam Distribution Inferred from Scaled Edison Evaluation Data . . 17

6 Distribution of ORNL CVR Data and Edison "Reference Data" .............. 18

7 Example of K-S Test, Showing the Reference CDF and the Test CDF $\ldots \ldots \ldots \ldots .21$

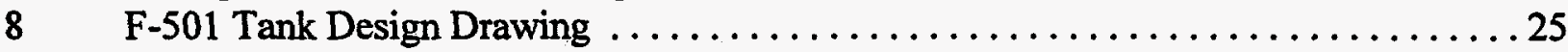

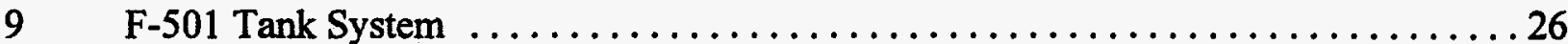

10 Time Series Plot of Leak Test CVRs from Tank F-501 ................. 30

11 Cumulative Frequency Distributions from Reference CVR Data and F501 CVR Data . 31

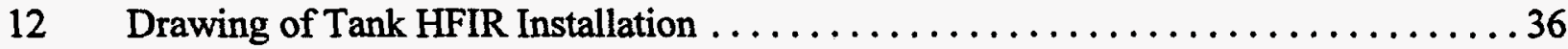

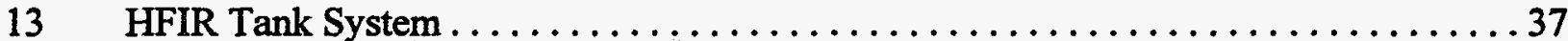

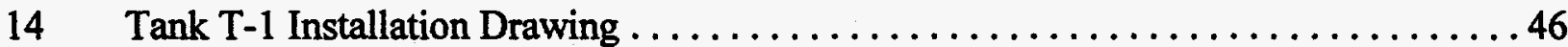

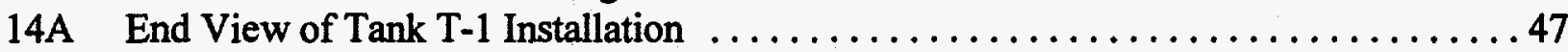

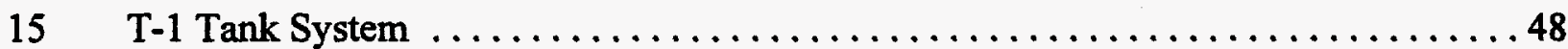

16 Time Series Plot of Leak Test CVRs from Tank T $-1 \ldots \ldots \ldots \ldots \ldots \ldots \ldots \ldots . \ldots . \ldots \ldots$

17 Cumulative Frequency Distribution from Reference CVR Data and T-1 CVR Data ...55

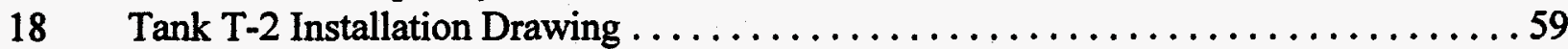

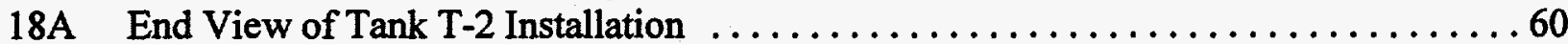

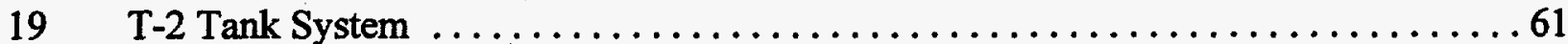

20 Time Series Plot of Leak Test CVRs from Tank T-2 ................66

21 Cumulative Frequency Distribution from Reference CVR Data and T-2 CVR Data . . 67

22 As-built Drawing of Tank W-16 Installation $\ldots \ldots \ldots \ldots \ldots \ldots \ldots \ldots \ldots \ldots \ldots \ldots 72$

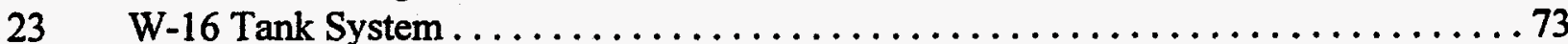

24 Time Series Plot of Leak Test CVRs from Tank W-16 . . . . . . . . . . . . 77

25 Cumulative Frequency Distribution from Reference CVR Data and W-16 Data . . . . 78

26 As-built Drawing of Tank WC-2 Installation $\ldots \ldots \ldots \ldots \ldots \ldots \ldots \ldots \ldots \ldots \ldots$

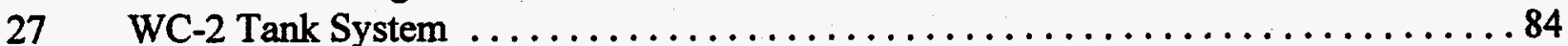

28 Time Series Plot of Leak Test CVRs from Tank WC- $2 \ldots \ldots \ldots \ldots \ldots \ldots \ldots$

29 Cumulative Frequency Distribution from Reference CVR Data and WC-2 Data . . . . 90

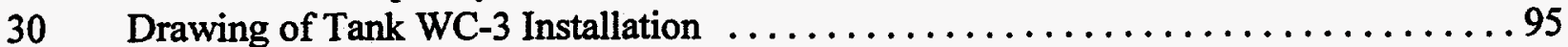

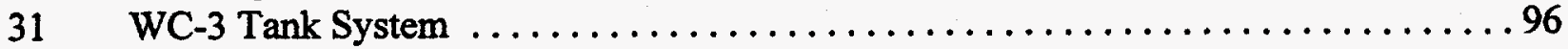




\section{LIST OF FIGURES}

Figure

Page

32 Time Series Plot of Leak Test CVRs from Tank WC-3 ................. 101

33 Cumulative Frequency Distribution from Reference CVR Data and WC-2 Data . . . . 102

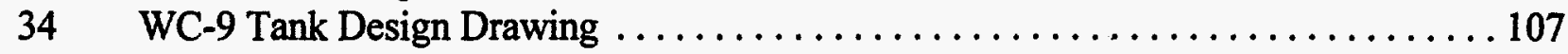

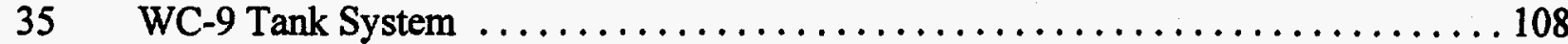

36 Time Series Plot of Leak Test CVRs from Tank WC-9 . . . . . . . . . . . . . . 112

37 Cumulative Frequency Distribution from Reference CVR Data and WC-9 Data . . . . 113

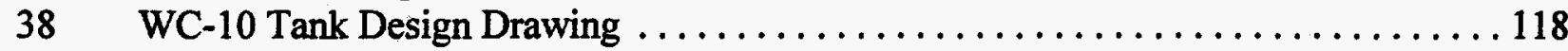

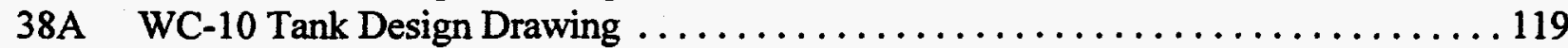

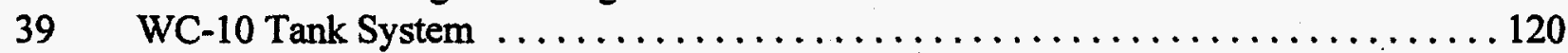

40 Time Series Plot of Leak Test CVRs from Tank WC-10 . . . . . . . . . . 127

41 Cumulative Frequency Distribution from Reference CVR Data and WC-10 Data . . . 128

42 As-built Drawing of Tank WC-20 Installation $\ldots \ldots \ldots \ldots \ldots \ldots \ldots \ldots \ldots \ldots \ldots \ldots$

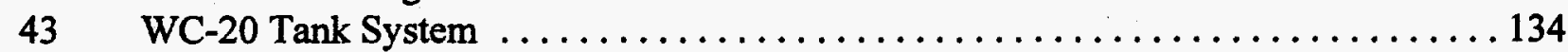

44 Time Series Plot of Leak Test CVRs from Tank WC-20 ................ 139

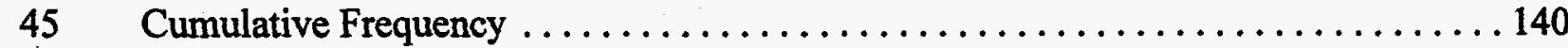




\section{TABLE OF CONTENTS (cont'd)}

\section{LIST OF TABLES}

Table

Page

1 Student's $t$-distribution for a Limited Range of N $\ldots \ldots \ldots \ldots \ldots \ldots \ldots \ldots \ldots$

2 Critical Statistics for the K-S "Goodness-of-Fit" Test ..................... 20

3 Characteristics of Line Segments Evaluated as a Part of Tank System F-501 . . . . . . . . 27

4 Summary of Leak Tests Conducted on Tank F-501 ..................... 29

5 Summary of Leak Test Results for the F-501 Testable Pipelines ............... 30

6 Summary of Statistical Analyses of F-501 CVR Data ................... 32

7 Summary of F-501 Tank System Testing and Certification ................... 33

8 Characteristics of Line Segments Evaluated as a Part of Tank System HFIR . . . . . . . 38

9 Summary of Leak Test Results for the HFIR Testable Lines ............... 40

10 Summary of Transfers Between HFIR and T-1 and T-2 During $1995 \ldots \ldots \ldots \ldots .41$

11 Summary of HFIR Tank System Testing and Certification ................. 43

12 Characteristics of Line Segments Evaluated as a Part of Tank System T-1 . . . . . . 49

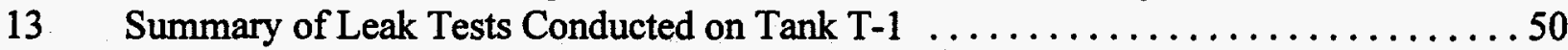

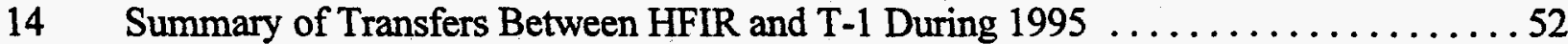

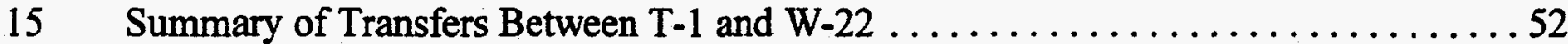

16 Summary of Statistical Analyses of T-1 CVR Data ..................... 54

17 Summary of T-1 Tank System Testing and Certification ................. 56

18 Characteristics of Line Segments Evaluated as a Part of Tank System T-2 . . . . . 62

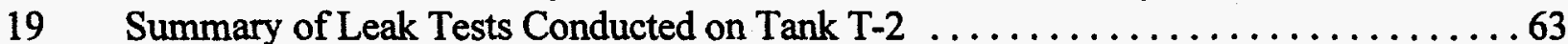

20 Summary of Transfers Between HFIR and T-1 during $1995 \ldots \ldots \ldots \ldots \ldots \ldots 6.66$

21 Summary of Transfers Between T-2 and W-22 during $1995 \ldots \ldots \ldots \ldots \ldots \ldots \ldots 65$

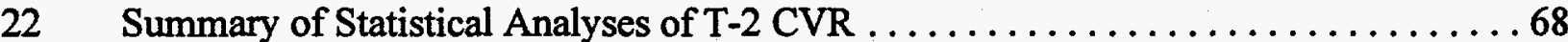

23 Summary of T-2 Tank System Testing and Certification ................6 69

24 Characteristics of Line Segments Evaluated as a Part of Tank System W-16 . . . . . . 74

25 Summary of Leak Tests Conducted on Tank W-16 .................... 75

26 Summary of Leak Tests Results for the W-16 Testable Lines

27 Summary of Statistical Analyses of W-16 CVR Data .................... 78

28 Summary of W-16 Tank System Testing and Certification ............... 80

29 Characteristics of Line Segments Evaluated as a Part of Tank System WC-2 . . . . 86

30 Summary of Leak Tests Conducted on Tank WC-2 ...................87 87

31 Summary of Leak Test Results for the WC-2 Testable Lines $\ldots \ldots \ldots \ldots \ldots \ldots \ldots 88$

32 Summary of Statistical Analyses of WC-2 Data $\ldots \ldots \ldots \ldots \ldots \ldots \ldots \ldots \ldots \ldots$

33 Summary of WC-2 Tank System Testing and Certification ................ 92

34 Characteristics of Line Segments Evaluated as a Part of Tank System WC-3 . . . . . 98 


\section{LIST OF TABLES}

\section{Table}

35 Summary of Leak Tests Conducted on Tank WC-3 .................... 99

36 Summary of Leak Test Results for the WC-3 Testable Lines . . . . . . . . . . . . . 100

37 Summary of Transfers between WC-3 and W-22 During $1995 \ldots \ldots \ldots \ldots \ldots \ldots$

38. Summary of Statistical Analyses of WC-3 CVR Data . . . . . . . . . . . . . . 102

39 Summary of Tank System Certification for Tank WC-3 . . . . . . . . . . . . . . 104

40 Characteristics of Line Segments Evaluated as a Part of Tank System WC-9 . . . . . 109

41 Summary of Leak Tests Conducted on Tank WC-9 ................... 110

42 Summary of Leak Test Results for the WC-9 Testable Lines . . . . . . . . . . . . 111

43 Summary of Statistical Analyses of WC-9 CVR Data .................. 113

44 Summary of WC-9 Tank System Testing and Certification $\ldots \ldots \ldots \ldots \ldots \ldots \ldots 114$

45 Characteristics of Line Segments Evaluated as a Part of Tank System WC-10 . . . . 121

46 Summary of Leak Tests Conducted on Tank WC-10 .................... 124

47 Summary of Leak Test Results for the WC-10 Testable Lines . . . . . . . . . . . . . . 125

48 Summary of Transfers between WC-10 and W-22 During $1995 \ldots \ldots \ldots \ldots \ldots \ldots$

49 Summary of Statistical Analyses of WC-10 CVR Data ................... 129

50 Summary of Tank System Certification for Tank WC-10 . . . . . . . . . . . 130

51 Characteristics of Line Segments Evaluated as a Part of Tank System WC-20 . . . 135

52 Summary of Leak Tests Conducted on Tank WC-20 ................. 136

53 Summary of Leak Test Results for the WC-20 Testable Lines . . . . . . . . . . . . 137

54 Summary of Transfers between WC-20 and W-22 During $1995 \ldots \ldots \ldots \ldots \ldots \ldots$

55 Summary of Statistical Analyses of WC-20 CVR ................... 140

56 Summary of WC-20 Tank System Testing and Certification $\ldots \ldots \ldots \ldots \ldots \ldots \ldots . \ldots \ldots 2$ 


\section{LIST OF ACRONYMS}

$\begin{array}{ll}\text { ASME } & \text { American Society of Mechanical Engineers } \\ \text { ASTM } & \text { American Society of Testing and Materials } \\ \text { CDF } & \text { Cumulative distribution function } \\ \text { CERCLA } & \text { Comprehensive Environmental Response, Compensation and Liability Act } \\ \text { CFR } & \text { Code of Federal Regulatons } \\ \text { CVR } & \text { Compensated volume rate } \\ \text { DOE } & \text { Department of Energy } \\ \text { DP } & \text { Differential pressure } \\ \text { EPA } & \text { Environmental Protection Agency } \\ \text { EVB } & \text { Enhanced volume balancing } \\ \text { FFA } & \text { Federal Facility Agreement } \\ \text { GPD } & \text { Gas pressure decay } \\ \text { HEPA } & \text { High Efficiency Particulate Air } \\ \text { H/V } & \text { Height to volume } \\ \text { HOG } & \text { Hot off-gas } \\ \text { K-S } & \text { Kolmogorov-Smirnov } \\ \text { LLLW } & \text { Liquid low level waste } \\ \text { LOC } & \text { Level of confidence } \\ \text { MDP } & \text { Modified differential pressure } \\ \text { MIC } & \text { Microbiologically influenced corrosion } \\ \text { NPS } & \text { Nominal pipe size } \\ \text { ORNL } & \text { Oak Ridge National Laboratory } \\ \text { ORR } & \text { Oak Ridge Reservation } \\ \text { PD } & \text { Probability of detection } \\ \text { PFA } & \text { Probability of false alarm } \\ \text { RTD } & \text { Resistance Thermal Detector } \\ \text { SARA } & \text { Superfund Amendment and Reauthorization Act } \\ \text { SCC } & \text { Stress corrosion cracking } \\ \text { SIA } & \text { Structural integrity assessment } \\ \text { SS } & \text { Stainless steel } \\ \text { TDEC } & \text { Tennessee Department of Environment and Conservation } \\ \text { UST } & \text { Underground Storage Tank } \\ \text { VDP } & \text { Volumetric differential pressure methods } \\ \text { WOCC } & \text { Waste Operations Control Center } \\ & \end{array}$




\subsection{INTRODUCTION}

The Superfund Amendment and Reauthorization Act (SARA) of the Comprehensive Environmental Response, Compensation, and Liability Act (CERCLA) required the Department of Energy (DOE) to execute a Federal Facility Agreement (FFA) with the Environmental Protection Agency (EPA) and the Tennessee Department of Environment and Conservation (TDEC) for the ORR.

The FFA distinguishes four categories of tank and pipeline systems:

- New systems (Category A),

- Doubly contained systems (Category B),

- Singly contained systems (Category C), and

- Inactive systems (Category D).

Section IX.F of the FFA specifically requires structural integrity assessments of the Category C LLLW systems. Results of the structural integrity assessments are to be submitted to the EPA Region IV and the TDEC to enable the continued use of the Category C tank systems, until next reassessment or removal from service, in accordance with FFA requirements.

The active portion of the Oak Ridge National Laboratory (ORNL) Liquid Low Level Waste (LLLW) system is distributed between the Bethel Valley and Melton Valley areas of the ORR. The active, singly contained portion of the LLLW system consists of ten tanks ranging in size from 400 to 15,000 gallons. These tank locations are shown in Figures 1 and 1A. The tanks are used to collect, and store liquid wastes.

The initial "Structural Integrity Assessments for the Category C LLLW Tank Systems" [DOE/OR/01-1385\&D2] was submitted to EPA and TDEC in September 1995. The results of the structural integrity assessments, for 14 tank systems classified as Category $\mathrm{C}$ were presented. Four tank systems, including Tanks F-201, 2026A, WC-7, and WC-19 were removed from service in FY96. Included herein is the first annual reassessment of the structural integrity for the ten tank systems that remain classified as Category C. 


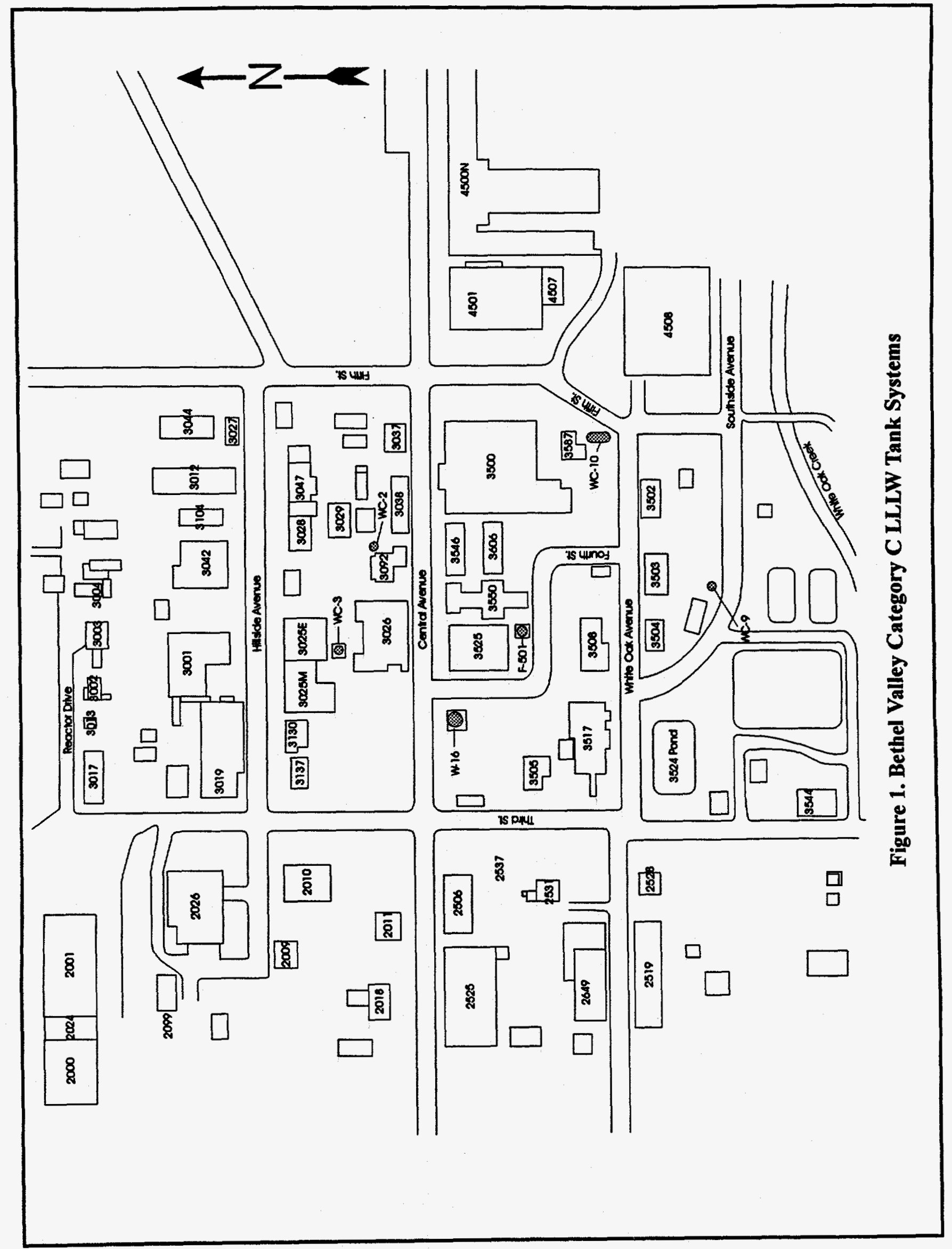




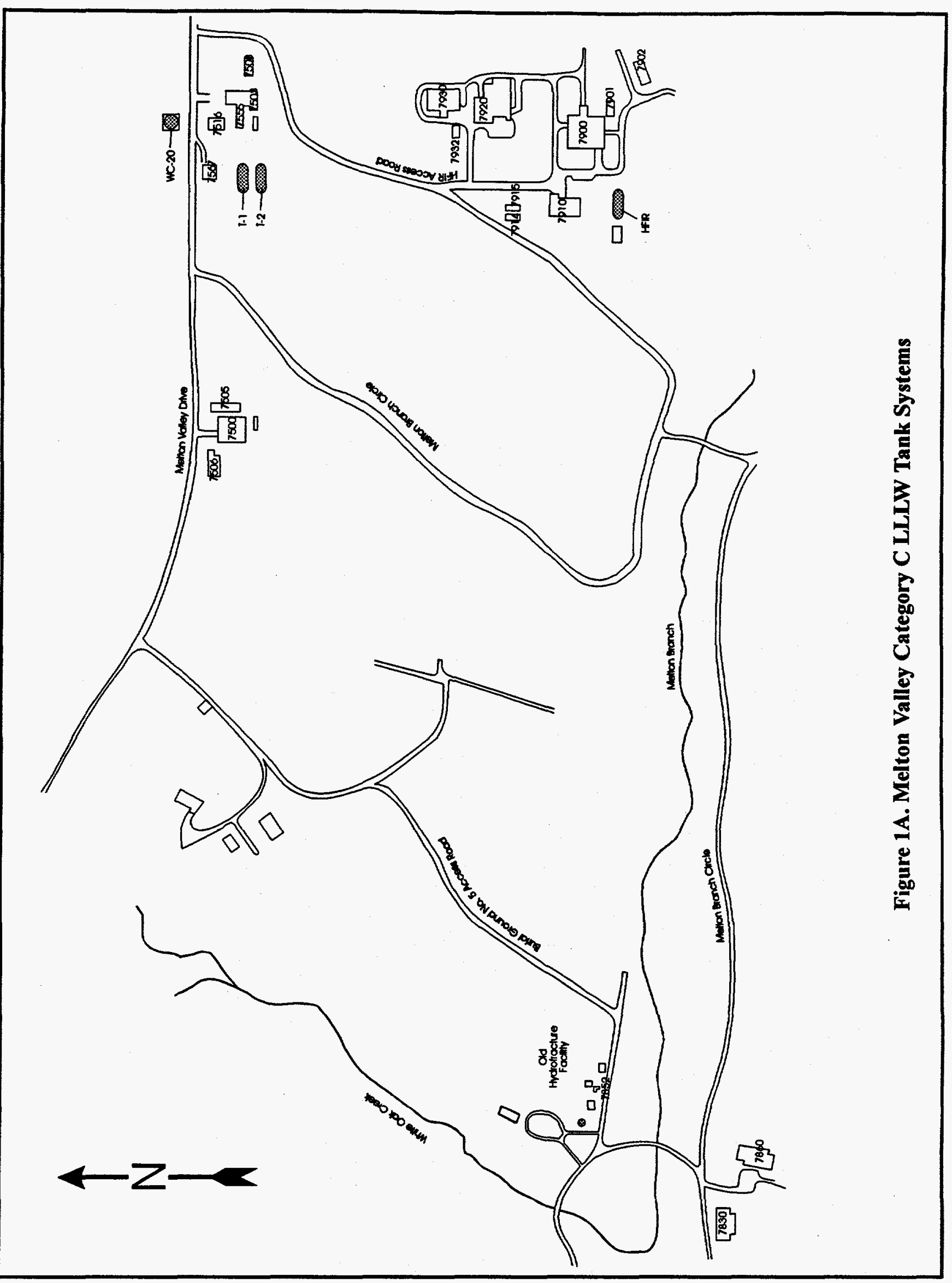




\subsection{PURPOSE}

This report presents the results of a series of evaluations to determine if the individual Category $\mathrm{C}$ tank systems retain sufficient structural integrity to continue being used. The approach used to reach the final certification/conclusion consisted of three phases, including:

- Review of the original engineering design drawings and construction materials to determine whether the tank and line systems were capable of containing liquids without leaking (and also to check that the construction materials were compatible with liquids that might have been placed in these systems). While drawings copied here in this report may be of poor quality, they are copies of the best available originals.

- A qualitative corrosion assessment conducted in 1995 that further evaluated both the potential internal corrosion effects of materials in the tank and in the potential external corrosion effects of the backfill and native soil at the Oak Ridge National Laboratory (ORNL).

- Performance of monthly leak tests on the tanks and annual leak tests on associated testable pipelines. This task was judged to be the most important criteria for determining structural integrity.

\subsection{DESIGN DRAWING EVALUATION}

Available design drawings and as-built drawings of the tanks were reviewed for the ten Category $\mathrm{C}$ tanks. In some cases, design drawings were generic for several tanks, and in some cases design drawings and/or as-builts were not available.

The drawings were reviewed for materials of construction, specifications, and any codes that were met by the tanks at the time of installation. Types of welds and the presence or absence of any extra flanges or ports were also noted. The information gained from review of the available drawings was used during the certification process for determining whether the tanks were suitable to contain LLLW at the time of installation, and to note any circumstances which may have contributed to deterioration of a tank's structural integrity. 


\subsection{GENERAL CORROSION ASSESSMENT OF THE CATEGORY C TANK SYSTEMS}

Most of the waste tanks and associated piping at ORNL are constructed of types 347 and $304 \mathrm{~L}$ stainless steel. Both of these stainless steel alloys nominally contain $18 \%$ chromium and $8 \%$ nickel and exhibit good corrosion resistance in many environments, particularly oxidizing ones. The corrosion resistance of 347 stainless steel is similar to that of 304L stainless steel. The carbon content in 347 stainless steel can be as high as $0.08 \%$, whereas in $304 \mathrm{~L}$ it is a maximum of $0.03 \%$. Both have an austenitic crystal structure and are easy to weld. Type 347 stainless steel is welded with 347 weld rod, and type $304 \mathrm{~L}$ stainless steel is welded with $308 \mathrm{~L}$ rod. The compositions of both weld rods are essentially the same as the base metal except that the chromium content is somewhat greater to compensate for chromium vaporization during welding. Generally, the corrosion resistance of the cast weld structure closely matches that of the base metal.

The stainless steels owe their stainless character to the presence of chromium. Depending on the environment, a minimum chromium content of 12 to $14 \%$ is required to produce a stainless alloy. In the temperature range of 480 to $870^{\circ} \mathrm{C}\left(900\right.$ to $\left.1600^{\circ} \mathrm{F}\right)$, the carbon in stainless steels that is in excess of $0.03 \%$ diffuses to grain boundaries, where it is precipitated as chromium carbide. Since the solid state diffusion rate of chromium is much less than carbon, the chromium content in a very thin layer at the edges of the grains is reduced to below the 12 to $14 \%$ level, and the metal in that thin layer is no longer a stainless steel. Stainless steel in such a condition is said to be sensitized, and in such conditions corrosion manifests itself by attacking along grain boundaries (intergranular corrosion) in some environments. If the alloy contains sufficient niobium (ten times the carbon content), as in 347 stainless steel, niobium carbide forms in preference to chromium carbide. The edges of the grains retain their chromium and the alloy is not subject to intergranular attack. Because of the niobium addition, 347 stainless steel is said to be stabilized; however, 304L stainless steel is stabilized by virtue of its low carbon content.

\subsection{Corrosion by Waste Solutions}

The ORNL waste solutions have varied compositions, and under some conditions may be highly corrosive to stainless steels. The corrosiveness of these solutions can be greatly reduced by adding caustic to make the solutions alkaline so that the $\mathrm{pH}$ is 13 to 14 . This is the current and past practice for most of the ORNL tanks, but there were unspecified periods when caustic was not added.

Corrosion failures seldom occur because of uniform attack (general wall thinning) but are much more likely to result from some form of localized attack. Several localized failure modes are briefly discussed below. None of these forms of attack are likely to occur if the solution $\mathrm{pH}$ is high; however, during periods when caustic was not added in the past or if the tank solutions are allowed to become only slightly alkaline or acidic in the future, localized attack may result. For the storage tanks, it is assumed that the temperature has never exceeded $25^{\circ} \mathrm{C}\left(77^{\circ} \mathrm{F}\right)$, that the concentration of radiolysis products in solution is insufficient to influence corrosion reactions, and that the solution composition is uniform throughout the tank. 


\subsubsection{Stress Corrosion Cracking (SCC)}

Austenitic stainless steels under tensile stress are susceptible to stress corrosion cracking (SCC) in the presence of chloride ions, but the minimum temperature required for cracking to occur is 50 to $60^{\circ} \mathrm{C}\left(122\right.$ to $\left.140^{\circ} \mathrm{F}\right)$, well above the assumed maximum temperature of the waste systems. Other agents can also produce SCC in stainless steel (e.g., caustic solutions, fluoride ions, and polythionic acids) but these require either higher temperature or fully sensitized microstructures which do not exist in the ORNL waste systems. Consequently, SCC does not represent a potential failure mode for these systems.

\subsubsection{Pitting Corrosion}

The austenitic stainless steels are subject to pitting in the presence of chloride ions. Under some conditions, chloride ions can initiate very localized corrosion on passive surfaces and at these sites pits may form. Once formed, a pit may continue to grow or spontaneously passivate. For a pit to form and continue to grow, the electrochemical potential of the metal must be above some minimum value which becomes lower as the chloride concentration and temperature increase. In addition, the presence of the other anions in a solution inhibits the pitting process [Lechkie 1966]. As an example, the minimum hydroxide ion concentration to prevent pitting of stainless steel in a solution with a given chloride concentration at $25^{\circ} \mathrm{C}\left(77^{\circ} \mathrm{F}\right)$ is given by the following equation:

$$
\log \left[\mathrm{Cl}^{-}\right]=1.62 \log \left[\mathrm{OH}^{-}\right]+1.84
$$

Similar relationships are given for other anions.

When a pit develops, the base of the pit is the anode and the surrounding area is the cathode of the corrosion cell. The solution within the pit is significantly different from the bulk solution and has a lower $\mathrm{pH}$ than the bulk solution. An active pit usually deepens at an appreciable rate, leading to relatively rapid penetration of vessel walls.

The alkaline solutions that presently exist in most ORNL waste tanks and the expected low chloride concentrations make growth of existing pits or formation of new ones very unlikely. However, if the $\mathrm{pH}$ of the solutions is allowed to become only slightly alkaline or acidic, pitting could lead to failure.

\subsubsection{Crevice Corrosion}

Crevice corrosion may occur under deposits, between metal flanges, and in other confined regions where the small volume of solution cannot readily mix with the bulk solution. Crevice corrosion often starts as a differential aeration cell, where corrosion processes consume the dissolved oxygen in the solution within the crevice and the potential of the metal in that region becomes more active than the surfaces outside of the crevice. Thus, an electrochemical cell is formed with the metal in the crevice region serving as a node. Once initiated, pitting and crevice corrosion proceeds by the same mechanism. 
Crevice corrosion is very improbable in solutions with $\mathrm{pH}$ values of 13 , but in only slightly alkaline or acidic solutions it represents a potential failure mode. A properly constructed system, however, without significant solids in the bottom, should provide few locations for crevice corrosion to begin.

\subsubsection{Intergranular-Knife Line Attack}

Since neither 347 nor $304 \mathrm{~L}$ stainless steels are subject to chromium carbide grain boundary precipitation, conventional intergranular attack is not to be expected. However, the niobium stabilization of 347 stainless steel produces one detrimental effect during welding that sometimes leads to "knife-line attack" [Shreir 1994, 3:56]. The metal immediately adjoining the fusion zone is subject to very high temperatures during welding, causing precipitated niobium carbide to go into solution. On reheating, as in multipass welding, carbide, possibly containing some chromium, may form. Thus, a very narrow band adjacent to the weld may be susceptible to intergranular attack in some environments. In contrast to knife-line attack, "weld decay" or "heat affected zone" corrosion that results from welding unstabilized stainless steel occurs a slight distance $(\sim 2 \mathrm{~mm})$ from the weld. In even moderately acidic and in alkaline solutions knife-line attack of 347 stainless steel at $250^{\circ} \mathrm{C}$ is improbable.

\subsubsection{Microbiologically Influenced Corrosion (MIC)}

It has only been in the last 10 to 20 years that the influence of microorganisms on corrosion processes has been recognized and understood by most corrosion engineers. There are many different microorganisms that can influence corrosion. Some operate under anaerobic conditions while others thrive in aerated environments. Under favorable conditions, doubling times of 60 to 120 minutes are possible, so a small number of microorganisms originally present can form large colonies in relatively short times [Sherier 1994, 2:87-97]. Before MIC can begin, the microorganisms must colonize on a metal surface. Colonization is not possible when the solution flows rapidly past a metal surface; however, metals exposed to slow-moving or stagnant solutions are prime candidates for MIC.

While there is presently no evidence that MIC has been involved in corrosion of either the interior or exterior surfaces of the LLLW waste system, MIC appears possible and needs to be considered a possible failure mechanism in slightly acidic, neutral, or slightly alkaline solutions; however, at a $\mathrm{pH}$ of $13, \mathrm{MIC}$ is highly improbable.

\subsection{Soil Side Corrosion of ORNL Waste Systems}

Many of the ORNL waste tanks and essentially all associated piping are buried directly in soil. These tanks and pipes were not coated, nor has cathodic protection been applied on any of the tanks or much of the singly contained piping. Consequently, there is concern about the condition of the stainless steel after more than 40 years in the soil. There are two reports of testing programs and experience at the Savannah River Plant that suggest damage is probably not severe at ORNL. 
The most extensive study of stainless steel corrosion by soils was conducted by Romanoff of the National Bureau of Standards [Romanoff]. Pipe sections of 304 stainless steel ( $0.05 \%$ and $0.08 \%$ carbon) were buried for up to 14 years in different soils across the United States. Chloride, sulfate, and $\mathrm{pH}$ values ranged from zero to $10,000 \mathrm{ppm}, 12$ to $10,500 \mathrm{ppm}$, and 4.8 to 9.4 respectively. In all cases, uniform attack was negligible. In soils containing low concentrations of chloride and sulfate, such as at ORNL, maximum pit depths were 0.006 inches in 14 years. In a subsequent study, many 304 stainless steel specimens $(0.05 \%$ and $0.06 \% \mathrm{C})$ were exposed in different soils for up to eight years. Only a few very shallow (unmeasured) pits were reported [Gerhold 1981].

Many underground stainless steel pipelines at the Savannah River Plant are neither coated nor cathodically protected. These lines were installed in the early $1950 \mathrm{~s}$, and as of about five years ago, not a single failure had been observed [Ondrejcin 1991]. On the other hand, underground stainless steel lines at the Hanford Reservation, installed during World War II, began leaking in 1947. Penetrations were caused by localized pitting which was probably initiated by MIC [Bucholz 1960]. Installation of cathodic protection on all buried lines stopped the failures. One major difference between the soils at Hanford and Savannah River (and ORNL) is the porosity. Hanford has an alluvial soil with about $30 \%$ porosity, whereas the porosity at Savannah River and ORNL is much less.

In spite of the Hanford experience, the data obtained by Romanoff and the observation at Savannah River, combined with the apparent lack of failure in the ORNL waste system after more than 40 years, implied that stainless steel corrosion by ORNL soils is minimal and is unlikely to contribute significantly to any possible future failures. Evidence to support this theory was found when a section of stainless steel piping installed as a part of the W-16 Tank System in 1951 was purposely unearthed in May 1995. The section had sustained very little external corrosion or damage and appeared to be structurally sound. 


\subsection{INTRODUCTION TO LEAK TESTING}

The LLLW tank systems are comprised of several components, including the tanks and several different types of pipelines. Different types of components, or similar components with significantly different volume capacities or other characteristics, require different leak testing methods. This is a consequence of the existing instrumentation or performance requirements, actual configuration of the system, environmental effects, operational constraints, or a combination of these factors.

The Category C LLLW system can be divided into three distinct types of components: tanks, pressurized pipelines, and gravity-fed pipelines. The pipelines can be further divided according to whether they are capable of being isolated from the remainder of the system (i.e., whether they are valved or unvalved). Each component type and their subdivisions present distinctly different technical problems for leak testing.

The pipelines at ORNL were divided into two classifications based on the mode of transportation of the liquids within the pipelines: pressurized and gravity-fed. None of the gravity-fed lines could be isolated from the remainder of the system; therefore, they could not be pressurized. Enhanced Volume Balancing (EVB) was employed as the test method for these gravity-fed lines. This method uses a controlled addition of minimal volumes of water to the line being tested. The pressurized pipelines were tested by a volumetric gas pressure decay (GPD) method (followed by a tracer technique when required). The choice of method for a given line depended upon whether that line could be isolated by means of valves.

The LLLW tanks are tested using another volumetric method. This method precisely measures the change in liquid volume over time. The protocol for using this method is slightly different depending upon the size of the tank. For the larger tanks (over 3,000 gallons in capacity) the volume data is collected over a longer period of time, to improve the precision of the method.

Singly contained tanks with volumes between 3,000 gallons and 15,000 gallons (referred to as large tanks) were tested by a method based upon the differential-pressure sensors, but using a modified test protocol. The large tanks are distinguished from the small tanks by their heightto-volume $(\mathrm{H} / \mathrm{V})$ ratios. The tanks considered to be large have $\mathrm{H} / \mathrm{V}$ ratios in excess of 100 $\mathrm{gal} / \mathrm{in}$. (at mid-tank), while the small tanks have $\mathrm{H} / \mathrm{V}$ ratios significantly less than $100 \mathrm{gal} / \mathrm{in}$. Tank Systems T-1, T-2, HFIR, and WC-20 are classified as large tanks in this report, with the remainder of the ten tank systems classified as small tanks.

The LLLW tanks are tested monthly, while the pipelines are tested annually. The performance of all of the leak testing methods employed at ORNL has been evaluated, and all meet the basic performance requirements described in the Underground Storage Tank (UST) regulations. The tank methods have been shown to be capable of detecting a leak of $0.2 \mathrm{gal} / \mathrm{hr}$ with a probability of detection (PD) of at least $95 \%$, and with a probability of false alarm (PFA) of no more than $5 \%$. The pipeline methods have a performance sufficient to detect leaks that are 
full-use equivalent to $0.1 \mathrm{gal} / \mathrm{hr}$, with a PD of at least $95 \%$ and a PFA of no more than $5 \%$.

As part of the certification process, the leak test methods, protocol, and evaluation procedures and documents were examined for accuracy and applicability to ORNL's LLLW system. These efforts showed that the methods used were consistent with the LLLW components tested, that the methods used were consistent with the evaluation approach, and that leak tests at ORNL were conducted in accordance with the test procedures and protocols appropriate to the method used.

These leak tests resulted in one of several test decisions. A PASS decision indicates that the absolute value of the measured volume rate of the component tested was less than a specified test threshold value. A FAIL decision indicates a negative volume rate that exceeded the threshold, suggesting a leak in the system. An INCONCLUSIVE result indicates that the data quality was too poor to make a decision, or that there were known factors rendering the test unreliable. For the LLLW tanks, two other test decisions are possible: EMPTY and INFLOW. An EMPTY result indicates that the liquid level is at or below the bottom of the dip leg of the level sensor and therefore, the liquid level cannot be recorded. An INFLOW result occurs when the measured rate of volume change is greater than expected, suggesting that liquid is flowing into the tank from external sources.

Because the vault sumps in some of the tank pits collect runoff during rainfall events, data collected during rain events occurring during leak tests were analyzed to determine whether rainfall affected the test. Suspected inflows due to rain cause an INCONCLUSIVE or INFLOW test result.

\subsection{Leak Testing Methods for Tanks}

The tanks were tested by a method based upon differential pressure (DP) measurement of the liquid level in the tank, using an instrument called a DP cell. The DP cell measures liquid level by sensing the head pressure produced by the liquid with respect to the pressure in the vapor space of the tank. As the liquid depth increases, the pressure increases. The output of the DP cell is proportional to the measured pressure. The liquid level can be determined from a measurement of the output with a calibrated sensor.

As configured at ORNL, the DP cell infers the tank liquid level by measuring the mass of the liquid in a vertical column above the outlet of a bubbler tube that is placed into the tank. In a container with constant cross-sectional area, and where the bubbler tube extends to the bottom of the container, the output of the DP cell is independent of level (volume) changes that result from thermally induced expansion and contraction of the liquid. That is, the DP cell is selfcompensating for thermally produced volume changes in the liquid, and eliminates the need to compensate for the liquid volume changes due to temperature fluctuations.

Before a leak test is initiated, it is important to minimize external factors that can affect the test results. Accordingly, the testing protocol begins with a waiting period, during which all 
tank activity is suspended until after the end of the leak test. During this period, the operators/owners using the tank are asked to suspend additions to and transfers from the tank. In addition, outside activities such as air sparging to clear the level gauge air lines, are also suspended. This waiting period gives the tank and its contents an opportunity to stabilize, thereby maximizing the quality of the leak test data.

After the waiting period, a data collection period is initiated. Tanks with volumes less than 3,000 gallons were tested for one or two consecutive trial periods of 24 hours each. Tanks with volumes between 3,000 and 15,000 gallons were tested for one or two single trial periods of 48 hours each. Data from these trials were used to derive a decision on the leak tests. If the decision is inconclusive or indicates that the tank is empty or experiencing an inflow, another test is scheduled as soon as possible.

\subsection{Leak Testing Methods for Pipelines}

The gravity-fed pipelines generally transport only small volumes of waste (e.g., fractions of a gallon to a few tens of gallons) at any given time, carrying the liquid from a hot cell to a collection tank. The gravity-fed lines typically contain no liquid other than during a deliberate transfer of waste or when liquids accumulate in low spots at the bottom of a horizontally oriented pipe. Such transfers are infrequent and none of these lines could be isolated from the tank for a pressure test. These lines were tested using a variation of the volume balancing method, in which a known volume of liquid introduced into a pipeline is compared to the volume that actually reaches the collection tank.

The pressurized pipelines generally carry a larger volume than do gravity-fed lines. Some of the pressurized lines could be isolated from their respective tanks by valves and were therefore pressure tested. The remainder of the pressurized lines could not be isolated, due to lack of isolation valves, and were not pressure tested.

\subsubsection{Leak Detection Method for Gravity-Fed Pipelines}

Gravity-fed pipelines were tested using a variation of the volume balancing method. Traditional volume balancing methods were not used to test gravity lines at ORNL because the lines are used infrequently and tend to dry out between uses (and are likely to be dry before a test). With dry pipes, an unknown portion of an added volume is lost due to "wetting" of the walls of the pipe, and some additional unknown portion can "pool" or accumulate in low spots in the line. Thus, the volume added to the line and the volume received by the tank would generally never balance, and it would not be known if the volume loss was due to wetting and pooling or to a leak in the line. A further difficulty with traditional volume balancing is that it requires that a large volume of liquid be added at the inlet end of the line so that, in the case of a small leak, the observed volume difference will be large enough to be measured accurately with the existing sensors. This creates additional waste liquids that must be processed and is therefore not encouraged. 
These problems were addressed at ORNL through a variation on the traditional volume balancing method, in which the rate of flow of liquid added at the inlet end of the line is compared to the rate of flow of liquid collected in the tank. This is referred to as an "enhanced volume balancing" method, or EVB. Once a steady rate of flow has been established at the inlet and another steady rate of flow is observed in the collection tank, the line has been wetted and low spots have been filled. After known environmental effects have been compensated for, and within the uncertainties of the method, the difference between the flow rate at which liquid is being added to the line and the flow rate being recorded in the tank is a direct measure of the leak rate of the pipeline.

Successful use of the EVB method requires: (1) that the collection tank is nonleaking (so any measured volume rate can be attributed to the pipeline), (2) that the precision of the pump used to add water at the inlet be at least an order of magnitude better than the leak rate to be detected, and (3) that the height-to-volume ratio of the collection tank is known precisely. These requirements are met by (1) ensuring that the collection tank is tight prior to leak testing the pipeline, (2) using a precise and calibrated metering pump, together with a closed loop pump speed controller, and (3) measuring the height-to-volume correction factor as part of the EVB test protocol.

\subsubsection{Leak Testing Methods for Pressurized Pipelines}

The LLLW pressurized pipelines were tested using a gas pressure decay (GPD) method, followed by a helium tracer technique if necessary.

In the GPD test, the pipeline is first drained or purged of liquid and then pressurized with nitrogen (or air). The line is then isolated from the pressure source while the line pressure is monitored and recorded for a specified period of time. After a short waiting period to allow adiabatic effects to subside, the recorded data are processed in such a way that the rate of change of pressure in the line is converted into an equivalent liquid loss rate. The data are then compared to a detection threshold. Within the allowable noise of the method, a pressure drop in the line can be attributable to losses in the line caused by either a "hole" in the line or poorly seated valves that allow the gas to pass through the internal piping of the valve into the downstream piping. If a GPD test results in a PASS decision, the line is considered tight. If the GPD test results in a FAll decision, a helium tracer technique is employed so that the failure can either be verified (and the leak located or localized) or the GPD result can be declared a false alarm.

When the helium tracer technique is employed following a GPD test, a helium purge is first used to ensure a $100 \%$ helium atmosphere in the pipeline. Following the helium purge, the line is pressurized with helium and continuous pressure is maintained for the duration of the measurement period. After a short waiting period (which allows helium to begin to diffuse upward from the buried line, if a hole in the line exists), a helium detector is walked along the surface of the ground directly above and parallel to the surveyed location of the pipeline. Gas samples are collected at frequent intervals along the line, from small accumulator locations that 
have been "punched" into the soil (or drilled into the roadway); these data are then recorded. The process is repeated so that the helium has sufficient time to reach the surface, even in soils with low permeability.

Successful helium tracing of the pressurized line requires that: (1) the isolation valves can be closed sufficiently to enable pressure buildup, (2) the location of the line is well known, (3) frequent sample intervals are used to maximize the chance of detecting any helium that might be escaping from a hole in the line, and (4) escaping helium remains confined within a few feet laterally of the pipeline. At ORNL, these requirements are met by (1) replacing valves that are not operable, (2) surveying the location of the line from the "as built" drawings, backed up with the line locator measurement, (3) punching or drilling helium accumulator pockets at eight to ten foot intervals along the surveyed location. The fourth requirement should be met because of the expectation that leaking helium will remain within the confines of the pipeline trench.

\subsection{Determination of Expected Error Values for the Untestable Pipelines}

Although some pipelines in the LLLW system cannot be tested for leaks, a rough assessment of their integrity can be inferred if liquid transfers are made through these lines during the assessment period, and if the volumes "sent" from the sending tank and the volumes "received" by the receiving tank are recorded for each transfer. This assessment can be made by subjecting the difference between the two volumes to an error analysis, based upon the errors expected to be observed given the measuring instruments and other factors. The sources of error included in this analysis are: (1) the precision of the level sensor and (2) the accuracy of the measurement, which depends on strapping table error, signal conditioning accuracy, level sensor accuracy, and the influence of temperature changes in the liquid that are not compensated for. The foregoing sources of error are quantified either through estimates provided in the manufacturer's specifications or through analysis of the data. The resulting numbers are then combined statistically to obtain a numerical value for the expected error. The discrepancy between the input and output volumes is considered significant if its absolute value is greater than the expected error. Sources likely to contribute to this error were considered, and are presented in Figure 2. 
Precision of the level sensor. The first step is to determine the precision of the level sensor, $P_{R}$, for each tank. $P_{R}$ is based on the noise observed in the data. The process can be expressed by:

$$
P_{R}=\sqrt{\left(2 * \sigma^{2}\right)}
$$

where $\sigma$ is the standard deviation. It is assumed

that

$\sigma$ before transfer $\approx \sigma$ after transfer $=\sigma$.

Accuracy of the measurement. The accuracy of the measurement, $\mathrm{P}_{A}$, is then determined for each tank. There are four components to $P_{A}$.

- S (strapping table error). $S=0.5 \%$ of full scale, based upon an engineering estimate made from manufacturer specifications.

- G (Action Pak accuracy). G $=0.1 \%$ of full scale, based on manufacturer specifications.

- A (sensor accuracy). $A=0.2 \%$ of full scale, based on manufacturer specifications for the 823 DP cell.

- $U$ (uncompensated temperature influence). $U=0.1 \%$ of full scale, as determined from the data.

The values of S, G, A and U, once calculated, are converted to volume (in gallons) based on the height-to-volume ratios at the two levels (before and after a transfer). In the horizontal tanks, $P_{A}$ may vary between transfers due to the fact that a tank's height-to-volume ratio can vary according to the level of liquid. The numbers are then combined statistically, according to

$$
P_{A}=(1 / 3) \sqrt{S_{\text {level 1 }}^{2}+G_{l e v e l ~ 1}^{2}+A_{\text {level 1 }}^{2}+U_{\text {level 1 }}^{2}+S_{\text {level 2 }}^{2}+G_{\text {level 2 }}^{2}+A_{\text {level 2 }}^{2}+U_{\text {level 2 }}^{2}}
$$

(These are all $3 \sigma$ numbers, so the $1 / 3$ factor converts each to a $1 \sigma$ number.)

When the errors from all the above sources have been considered, the error for an individual tank, $P$ (a 10 number), can be determined. Since the $P_{A}$ values are all given as a percent of full scale, they are dependent on the volume transferred:

$$
P=\sqrt{2 *\left(P_{R}\right)^{2}+\left(\frac{V_{T}}{V_{F S}}\right)^{2} *\left(P_{A}^{2}-P_{R}^{2}\right)}
$$

where $V_{\mathrm{T}}$ is the volume transferred and $\mathrm{V}_{\mathrm{FS}}$ is the total volume capasity of the tank. In this scenario, as one approaches zero volume transferred,

$$
P \rightarrow \sqrt{2 * P_{R}^{2}}
$$

and as one approaches full volume transferred,

$$
\mathrm{P} \rightarrow \sqrt{P_{R}^{2}+P_{A}^{2}}
$$

Based on the following equation, the expected error (a $3 \sigma$ number) can now be calculated for a specific transfer between two tanks:

$$
\text { Expected Error }=3 * \sqrt{P_{\text {tank } 1}^{2}+P_{\text {tank } 2}^{2}}
$$

\section{Figure 2 Potential Error Sources}




\subsection{Statistical Analysis and Hypothesis Testing}

The key portion of the analysis performed to support the 1995 structural integrity assessments (SIA) for the Category C LLLW systems is statistical analysis and hypothesis testing on the compensated volume rate (CVR) data collected that year. In this analysis, a null hypothesis test is used to test the mean of the data, and another null hypothesis test is used to test the variance of the data. As described in the "analysis" sections of the first SIA document [DOE/OR/01-1385\&D2], the purpose of the analysis is to determine whether the data "...was consistent with data expected from a non-leaking tank, with the evaluated performance of a calibrated leak testing method used as the comparator."

In drafting the analysis reports for this 1995 SIA document, the hypothesis testing (using an F-test) indicated that the variance of some of the 1995 CVR populations was different from the expected population. Examination showed, however, that in most of these cases the "differences" were created by one or two isolated CVRs. These few data points, although passing all the data quality checks designed to reject "bad data" and must therefore be considered "good" and admitted into the analysis set, were nonetheless anomalous in terms of the type of hypothesis testing being conducted. One explanation for the test and reference data to appear "different" was that the CVR data might not be normally (gaussian) distributed, which is an implied requirement of the data in applying the F-test. Examination of a large body of the ORNL CVR data shows that, indeed, the data does diverge from gaussian behavior, particularly in the tails of the distribution'. This is illustrated in the figure below. Figure 3 shows a time series plot of all of the CVR data from the six LLLW tanks at ORNL that, after more than three years of frequent testing, have proven that they are both non-leaking and free of inflows. (These tanks are: 2026A, F-501, W-16, WC-2, WC-3, and WC-9.)

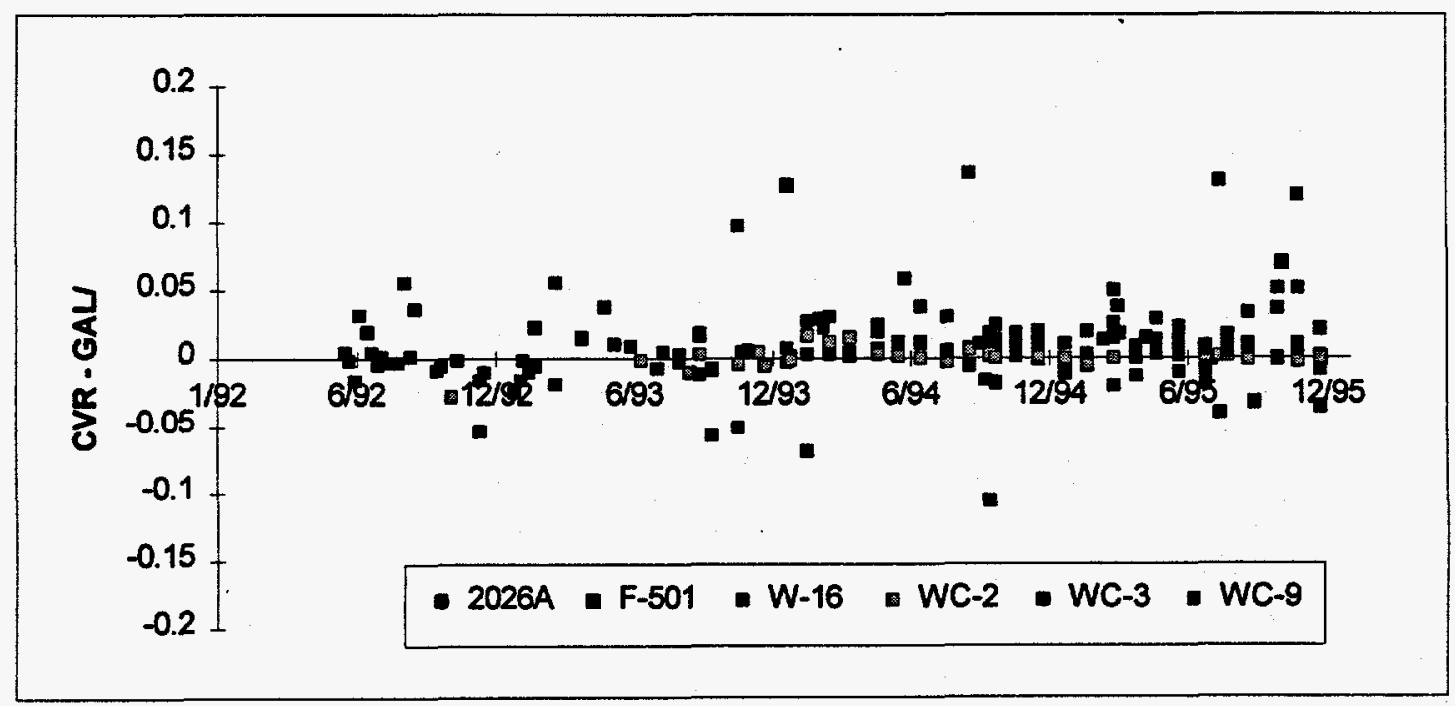

Figure 3. Leak test data from non-leaking tanks at ORNL, over a $31 / 2$-year period.

\footnotetext{
${ }^{1}$ Non-gaussian tails are not unexpected. These tails are usually due to extraneous sources.
} 
The data from these six tanks, 190 CVR measurements taken over the three and half year period from June 1992 through December 1995, provide a good estimate of the "noise" in the measurements in actual field conditions at $\mathrm{ORNL}^{2}$.

The grey-shaded plot in Figure 4 shows a histogram of the CVR data shown in Figure 3. This data shows that the central mean of the CVR values is very close to zero gal $/ \mathrm{h}$ (about 0.007 $\mathrm{gal} / \mathrm{h}$ ), and that the bulk of the data has a fairly narrow distribution, with most of the values falling between -0.02 and $+0.03 \mathrm{gal} / \mathrm{h}$, with a slight skew of the histogram toward positive CVR values. It is seen in this figure, however, that there are a significant number of CVR values that fall well-beyond the "spread" that one would normally associate with the central histogram; these values range from about $-0.1 \mathrm{gal} / \mathrm{h}$ to about $+0.14 \mathrm{gal} / \mathrm{h}$. The gaussian probability distribution function corresponding to the mean and standard deviation of the CVR data set $(0.007 \mathrm{gal} / \mathrm{h}$ and $0.028 \mathrm{gal} / \mathrm{h}$, respectively) is also shown in Figure 4; as the solid smooth line. It seemed that this implied distribution really is not a good fit to the actual distribution: it is too wide in the central portion of the data (due to the influence of the tails of the histogram on the standard deviation), and not wide enough in the limits to encompass the tails of the histogram.

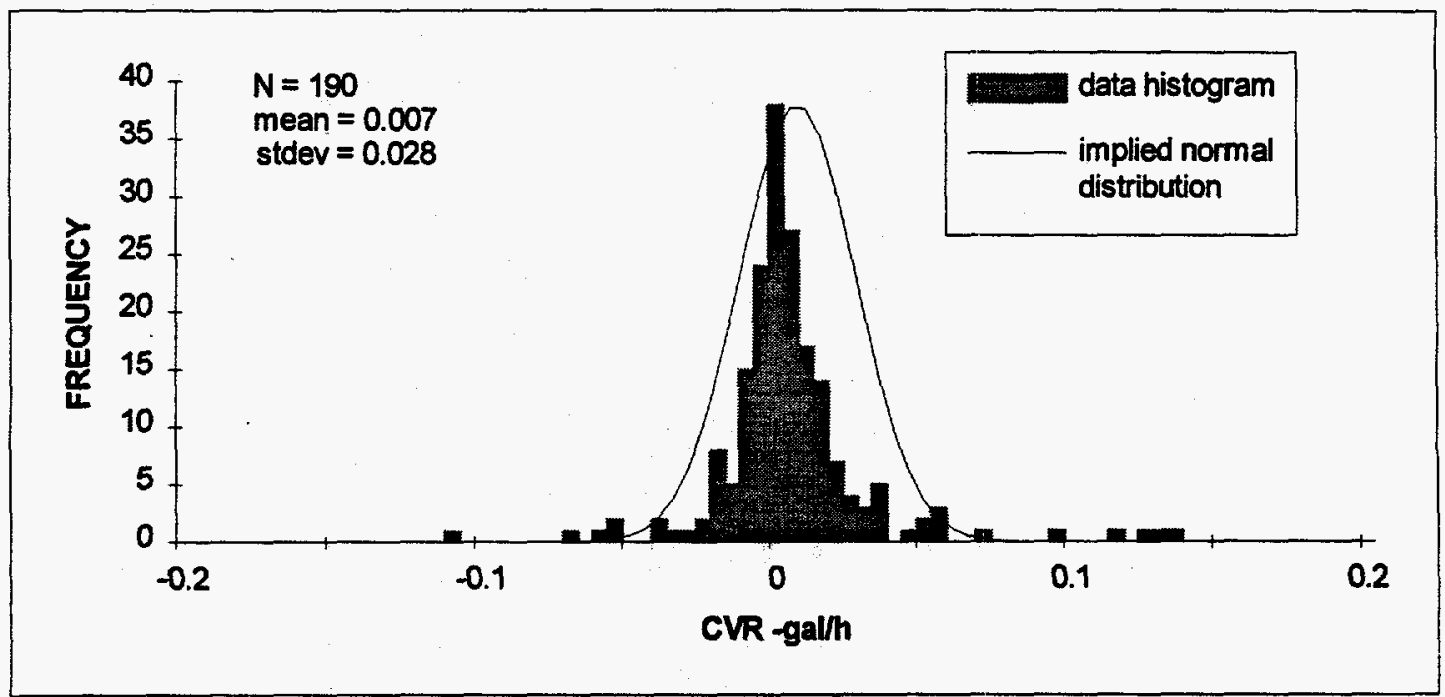

Figure 4. Histogram (grey) and normal probability distribution (line) inferred from ORNL CVR data.

To assess the consequence of "testing" these data as done in the previous SIA report [DOE/OR/01-1385\&D2], we can scale the CVRs from the Edison evaluation data [Douglas, et. al., 1992] by the height-to-volume $(H / V)$ values of the six ORNL tanks. Effectively, this results in the comparison data that was used in the F-test of the SIA report. Figure 5 shows a histogram of these scaled data (17 evaluation points $\times 6 \mathrm{H} / \mathrm{Vs}=102$ points), together with the gaussian distribution that would be inferred from the mean and standard deviation of the scaled data. It is seen that, except for slight bias caused by four small positive CVR values, the gaussian fit (the

${ }^{2}$ Two CVR values were removed from the WC-3 data set; these CVRs were determined to be due to an INFLOW to the tank, for unknown reasons, possibly operator error. They were edited from this data because they are obviously anomalous and do not represent typical data from non-leaking tanks at ORNL. 
smooth line) is a good representation of the scaled data.

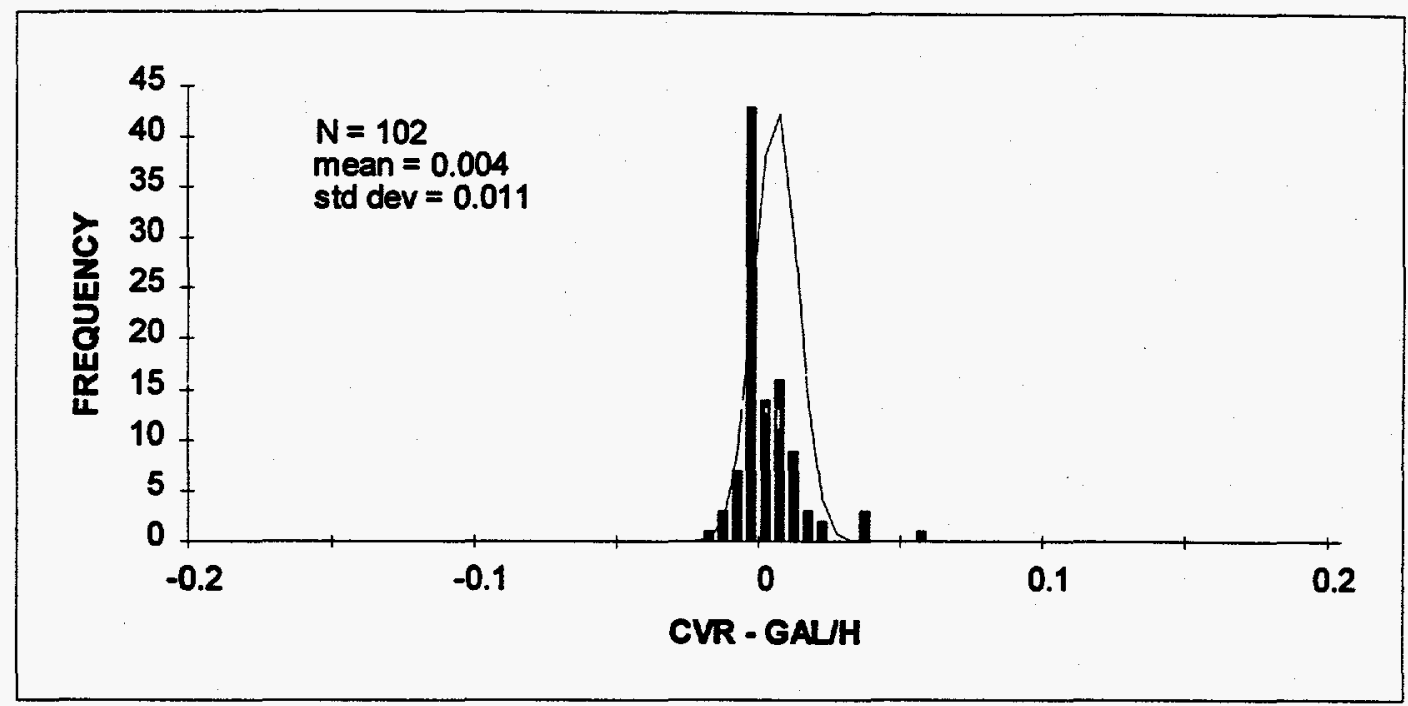

Figure 5. Histogram and gaussian distribution inferred from scaled Edison evaluation data.

By overlaying the (scaled) Edison evaluation data of Figure 5 (the "reference data," here) with the ORNL test data from Figure 4, we can get a direct comparison. This is shown in Figure 6. This figure shows that, while the (Edison) reference data (the smooth curve with the square markers) is a very good approximation for the central body of the ORNL-data histogram (except for a slight bias), it significantly underestimates the tails of the actual data distribution. This provides a qualitative reason why, in the earlier SIA report [DOE/OR/01-1385\&D2], some of the tanks failed the $F$-test null hypothesis that "... the variance of the two populations were equivalent." Simply stated, except for the central gaussian-like features of the ORNL CVR distribution, the two populations are different.

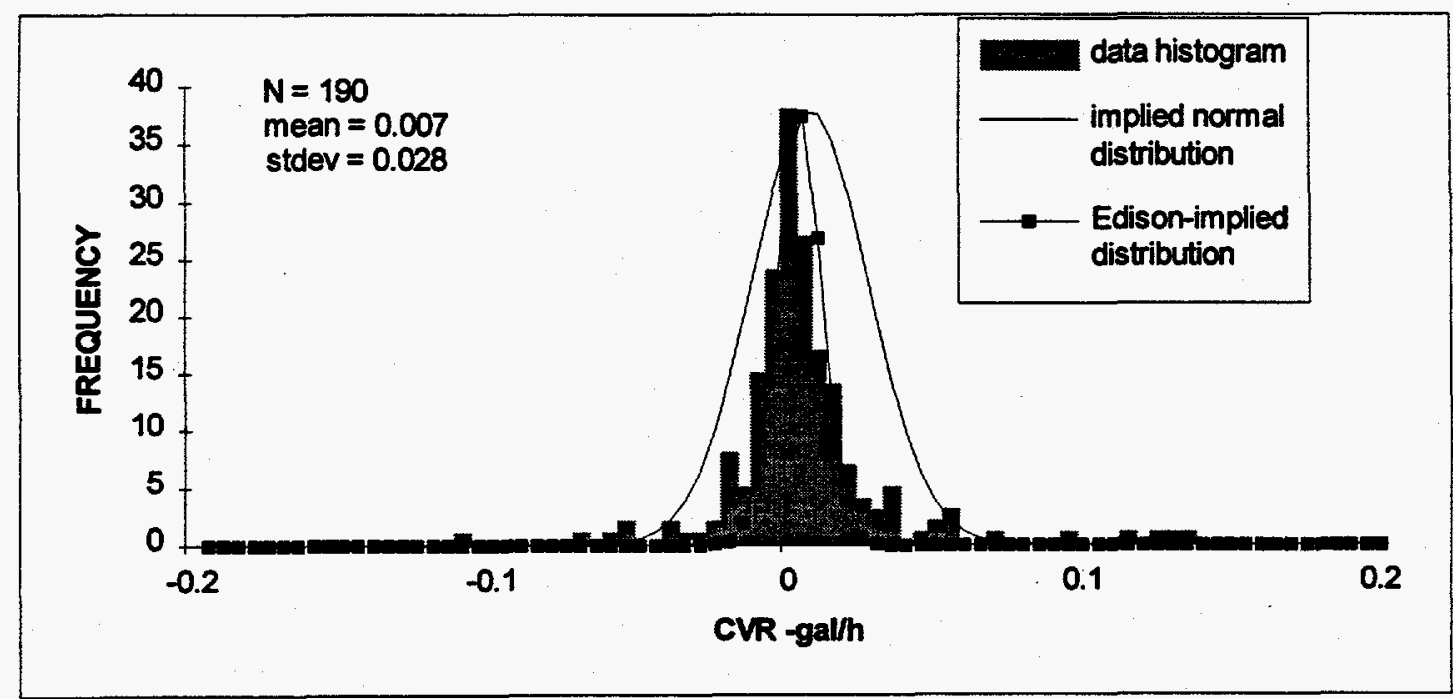

Figure 6. Distributions of ORNL CVR data and Edison "reference data". 
The consequence of the information presented above is that, while hypothesis testing of the ORNL CVR data should continue as an aide to technical consensus, continued use of the Ftest will result in anomalous equivalent distribution hypothesis test "failures" from time to time. Since these "failures" would not be indicative of any process or integrity problems in the tank(s) being tested, they would be counter-productive to the goals and objectives of the SIA effort. Accordingly, iests that can account for the tails of the actual ORNL data distribution are needed to test the mean and variance of the data. Such tests are discussed in Section 5.4.1

\subsubsection{Statistical tests}

The hypothesis testing utilized a Student's-t test to test the means of the CVR data, and an F-test to test the variance of the CVRs. Each of these tests calculates a test statistic that is compared to a critical value, for a specified level of confidence (LOC). If the test statistic is greater than the critical value, then the null hypothesis is rejected. The LOC chosen for this analysis is $99 \%$ in order to minimize the chances of incorrectly rejecting the nuil hypothesis-that is, that declare the mean or variance of a set of CVRs to be "different than expected from a non-leaking tank," when in fact it was not different. Table 1 shows the critical values used in the Student's $t$-test for a LOC of $99 \%$, as a function of the number of degrees of freedom, df, in the data set. Here, $\mathrm{df}$ is $(\mathrm{N}-1)$, where $\mathrm{N}$ is the number of $\mathrm{CVR}$ values in the data set to be tested.

Table 1. Student's-t distribution for a limited range of $\mathrm{N}(\mathrm{df}=\mathrm{N}-1)$.

\begin{tabular}{llll}
\hline \hline df & $T_{\text {critical (99\%) }}$ & df & $T_{\text {critica (99\%) }}$ \\
\hline 5 & 4.032 & 11 & 3.106 \\
6 & 3.707 & 12 & 3.055 \\
7 & 3.499 & 13 & 3.012 \\
8 & 3.355 & 14 & 2.977 \\
9 & 3.250 & 15 & 2.947 \\
10 & 3.169 & 16 & 2.921 \\
\hline Abstracted from [Mendenhall, 1992])
\end{tabular}


The t-statistic is calculated as:

$$
t_{\text {stat }}=\sqrt{N} \frac{m}{s}
$$

where $\mathrm{N}$ is the number of points in the (CVR) data set, $\mathrm{m}$ is the mean of the $\mathrm{N}$-points of data, and $s$ is the standard deviation of the data. The F-statistic is calculated as:

$$
F_{\text {stat }}=\frac{s^{2}}{s_{\text {ref }}^{2}}
$$

where $s_{\text {ref }}$ is the standard deviation of the reference data. It can be seen by inspecting these two equations that while the t-statistic uses the standard deviation of the data in the calculation, the Fstatistic includes the ratio of two variances, where each variance is the square of the standard deviation of the test or reference data. As a result, the F-test is much more sensitive to changes in the spread of a population than the t-test.

The discussion above indicates that, while the Student's $t$-test can be retained to test the means of the CVR data, another test is needed to test the variance of the data. Although there are several tests that could be used, the Kolmogorov-Smirnov (K-S) "goodness-of-fit" test not only meets the requirement for handling non-gaussian data but is also very simple and direct. The $\mathrm{K}$ $S$ test examines the deviations between a hypothesized cumulative distribution function (CDF), $F_{X}(x)$, and the observed cumulative histogram, $F^{*}\left(X^{(1)}\right)=I / n$, in which $X^{(1)}$ is the ith largest observed value in the random sample of size $N$. (In this case, $F_{X}(x)$ would be represented as the cumulative distribution of a set of reference CVRs, and $F^{*}\left(X^{(1)}\right)$ would be represented by the cumulative distribution of the CVRs from a particular tank that is being "tested.") The K-S test statistic is expressed algebraically as:

$$
K S_{\text {stat }}=\max _{i=1}^{N}\left[\left|F^{*}\left(X^{(i)}\right)-F_{X}\left(X^{(i)}\right)\right|\right]
$$

$\mathrm{KS}_{\text {stat }}$ is the largest of the absolute values of the $\mathrm{N}$ differences between the reference $\mathrm{CDF}^{4}$ and the CDF of the data under test.

${ }^{3}$ The K-S test could be used to test both the mean and variance of the CVR populations. In this analysis, the mean was tested with the Student's t-test and the variance was tested using the K-S test.

4 In this analysis the reference is the set of CVR values obtained from the ORNL tests for the six tanks described above, from the beginning of the leak testing program up to, but not including, the data in the current analysis period. As more leak test data is obtained, it is expected that future K-S tests will utilize same-tank data as the reference. Once 40 to $50 \mathrm{CVRs}$ for a particular tank have been obtained from earlier tests, that data will be as the reference for that tank. This eliminates the need for height-to-volume scaling and provides a direct comparison of the data sets. 
Procedurally, the K-S test is performed in this analysis by first calculating the reference set of CVRs that is scaled to the appropriate height-to-volume (H/V) of the test tank. The mean of the scaled CVRs is then subtracted and the CDF is calculated to obtain the "reference," $F_{x}(x)$. The test set is obtained by subtracting the mean of the data being tested, and the CDF of the test data, $\mathrm{F}^{*}\left(\mathrm{X}^{(\mathrm{I})}\right)$ is calculated. The test statistic is then calculated as the largest ordinal (i.e., vertical) difference between the two CDFs. The critical statistic is determined from a table of values for the K-S test. Table 2 shows the K-S critical values for a LOC of $99 \%$, for a range of $\mathrm{N}$ that spans the data considered here. (When the means are subtracted from the data, the number of degrees of freedom is reduced by one; accordingly, the "sample size" used must be reduced by one. For example, if a tank has 11 conclusive CVR values over the 12-month period being considered, the $\mathrm{K}-\mathrm{S}$ critical value is 0.49 ). Just as for the t-test, if the K-S test statistic is less than the K-S critical value, the null hypothesis is accepted. If the test statistic is greater than the critical value, the null hypothesis is rejected.

Table 2. Critical statistic for the K-S "goodness-of-fit" test

\begin{tabular}{ll}
\hline \hline Sample size & K-S $_{\text {critical (99\%) }}$ \\
\hline 5 & 0.67 \\
10 & 0.49 \\
15 & 0.40 \\
20 & 0.35 \\
25 & 0.32 \\
30 & 0.29 \\
40 & 0.25 \\
Large $\mathrm{N}$ & $1.63 /(\mathrm{N})^{1 / 2}$ \\
(abstracted from [Benjamin and Cornell, 1970])
\end{tabular}

Figure 7 illustrates the K-S test. After removing the means from both the data to be tested and the scaled reference set of data, the cumulative distribution functions of both sets are calculated and plotted. The bold solid line in the figure shows the CDF calculated from the set of CVRs to be tested, while the light dashed line shows the CDF calculated from the reference set of CVRs. The two distributions are differenced over the range of the data and the maximum difference is obtained; here, the maximum difference, $\mathrm{KS}_{\text {stat }}$ is 0.33 and occurs at a CVR $=0.025$ $\mathrm{gal} / \mathrm{h}$. The set of CVRs being tested had 11 values in the set; since the mean was removed, reducing the number of degrees of freedom by one, a "sample size" of $(11-1)=10$ is used to look up the K-S critical value in Table 2; here, $\mathrm{KS}_{\text {crit }}=0.49$. Since $\mathrm{KS}_{\text {stat }}$ is smaller than $\mathrm{KS}_{\text {crit }}$, we fail to reject the null hypothesis that ..."there is no statistical difference between the two populations." Thus, the two populations are deemed equivalent. 


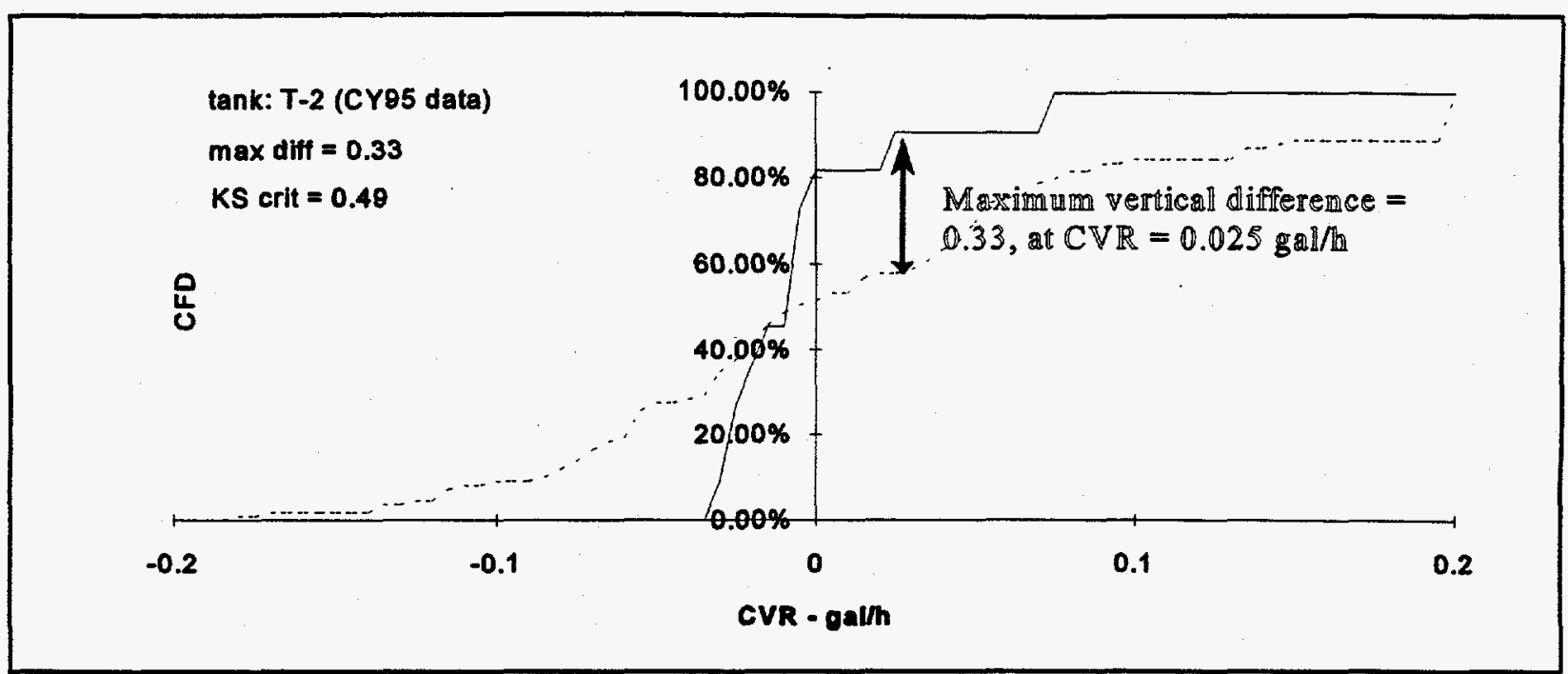

Figure 7. An example of the K-S test, showing the reference CDF (light dashed line) and the test CDF (bold solid line). 


\subsection{BASIS FOR TANK SYSTEM CERTIFICATION}

Tank certification in this effort was based on three specific areas where data were available. Design drawings for each tank system were available for review. A corrosion evaluation of each system provided limited, but useful, information concerning remaining structural integrity. The major data set upon which the structural integrity assessment was based was the leak test information. For example, a leak test with a pass result is sufficient to determine that the remaining structural integrity of the tank is adequate to hold the liquid, at the time of the test.

Line tests provide a similar method by which the remaining integrity of the line can be assessed and a determination made concerning the avility of the line to contain fluid. However, for gravity lines, this certification is valid only up to the flow rate under which the EVB was conducted and for the date and time of testing. GPD testing provides sufficient information to certify the entire pressurized line segment at full capacity for the date and time of testing.

With such a significant reliance on leak detection methods to certify the tank and its ability to successfully retain liquids, it is important that the testing results meet the agreed upon requirements, which have their foundation in 40 CFR Part 280 . Included are the requirements of greater than $95 \%$ PD of detecting a leak of $0.2 \mathrm{gal} / \mathrm{hr}$ and less than 5\% PFA. Results which successfully demonstrate that they meet or exceed these requirements are accepted as a PASS and used as a basis for certification of the tank. Certification applies only to that portion of the tank which was wetted during the leak test. This limiting value can be stated either as a depth of liquid in the tank or as a percent of total tank capacity. In many cases each tank has been tested on multiple occasions. The successful test with the greatest depth or percent of total capacity is accepted as the certification limit. If a future leak test is conducted with a greater volume in the tank and the result is pass, certification may be extended to the greater volume upon reevaluation.

A review of the design drawings for each of the tank systems must demonstrate and validate that the tank systems were properly designed to retain the liquid wastes placed in them. Each tank and its associated lines were evaluated. The resultant certification, based on available data, should not be construed as a guarantee that leaks have not occurred in the tank or lines, in the past, nor that they will not leak in the future. 


\subsection{TANK SYSTEM ASSESSMENTS}

This section of the report details the actual leak testing performed, and the corresponding certification results, for each of the ten Category C LLLW tank systems. Throughout this section, individual pipelines are referred to using a unique "line segment number" and "index number." These line segment and index numbers are in accordance with previous numbering in "Detailed Leak Detection Test Plan and Schedule for the Oak Ridge National Laboratory Liquid Low-Level Waste Active Pipelines" [DOE/OR/01-1167\&D2]. While each pipeline has a line segment number, only testable lines were assigned index numbers.

\subsection{F-501 Tank System}

The F-501 Tank System is located just south of Building 3525, as shown in Figure 1. The system collects LLLW from Building 3525 . The waste is transferred by truck from F-501 to the Evaporator Complex. The tank system is made up of Tank F-501 and three pipelines connected to the system. Because the lines and tank do not meet the requirements for secondary containment, the tank system has been given the classification of Category $\mathrm{C}$, according to the FFA.

\subsubsection{F-501 Tank Description}

Tank F-501 is a 400-gallon tank located in an unlined, reinforced concrete vault. Installed in 1962, Tank F-501 is mounted vertically on four 3" x 3" x 5/16" L legs anchored to the floor of the vault. The tank is constructed of $304 \mathrm{~L}$ stainless steel and has a wall thickness of $1 / 4$ " with ASME standard 304L stainless steel flanged dished heads. The outside diameter of the tank is $48^{\prime \prime}$ with a length of $46^{\prime \prime}$. The working volume of the tank is stated as 192 gallons. The drawing for Tank F-501 is provided as Figure 8.

The tank is equipped with four 1" diameter nozzles, two 2" diameter nozzles, and one 3 "diameter flange on the top of the tank. Six of the nozzles are located around a 18" radius from the center of the tank. The flanged nozzle is located $12^{\prime \prime}$ from the center of the tank with a 1" offset from the tank centerline. One 4" diameter nozzle is located on the side of the tank, 4-1/2" below the weld of the top flanged dished head. Another 3" diameter nozzle is located 6-1/5" below the weld of the top flanged dished head on the opposite side of the tank of the 4 " diameter nozzle. All nozzles are 304L stainless steel. Two lifting lugs are positioned on opposite edges of the top flanged dish head.

The unlined reinforced concrete vault has interior dimensions of 7'-6" x 6'-6" and walls 12 " thick. The top of the vault is constructed to receive inwardly stepped plugs used to allow inspection and maintenance. The floor of the vault is sloped to a 1'-0" $\times 11^{\prime}-0^{\prime \prime} \times 1^{\prime}-0^{\prime \prime}$ sump. The outside of the vault has a membrane waterproofing followed by a $1 / 2$ " fiber board to within $4^{\prime}-0^{\prime \prime}$ of the top of the vault. 
Tank F-501 is capable of receiving material from two sources. The sources originate in Building 3525 and Tank F-201. Tank F-201 is no longer in service. The liquids generated in Building 3525 are gravity-fed into Tank F-501. A schematic of the tank system with numbered line segments is shown in Figure 9. 


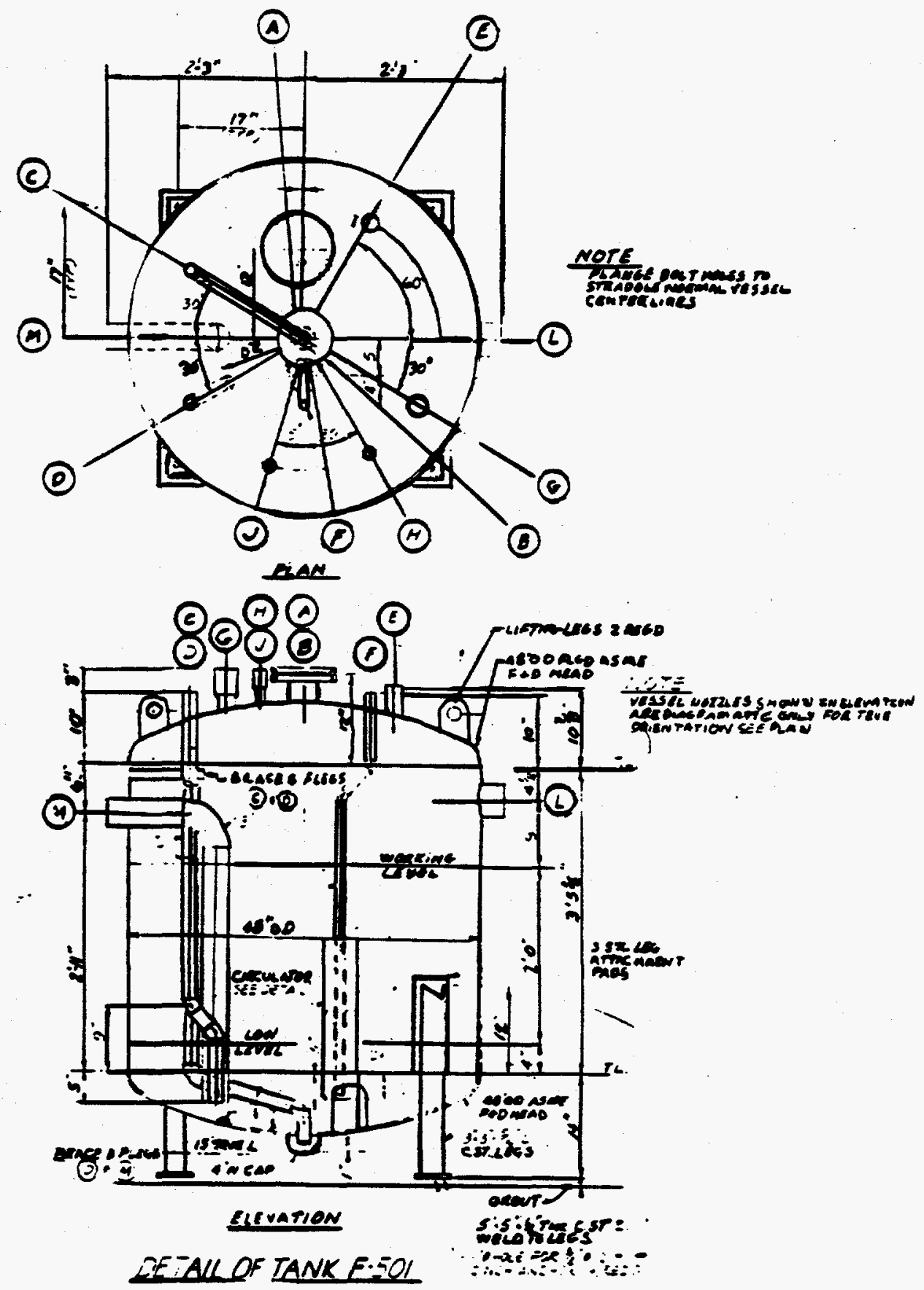

Figure 8. F-501 Tank Design Drawing 


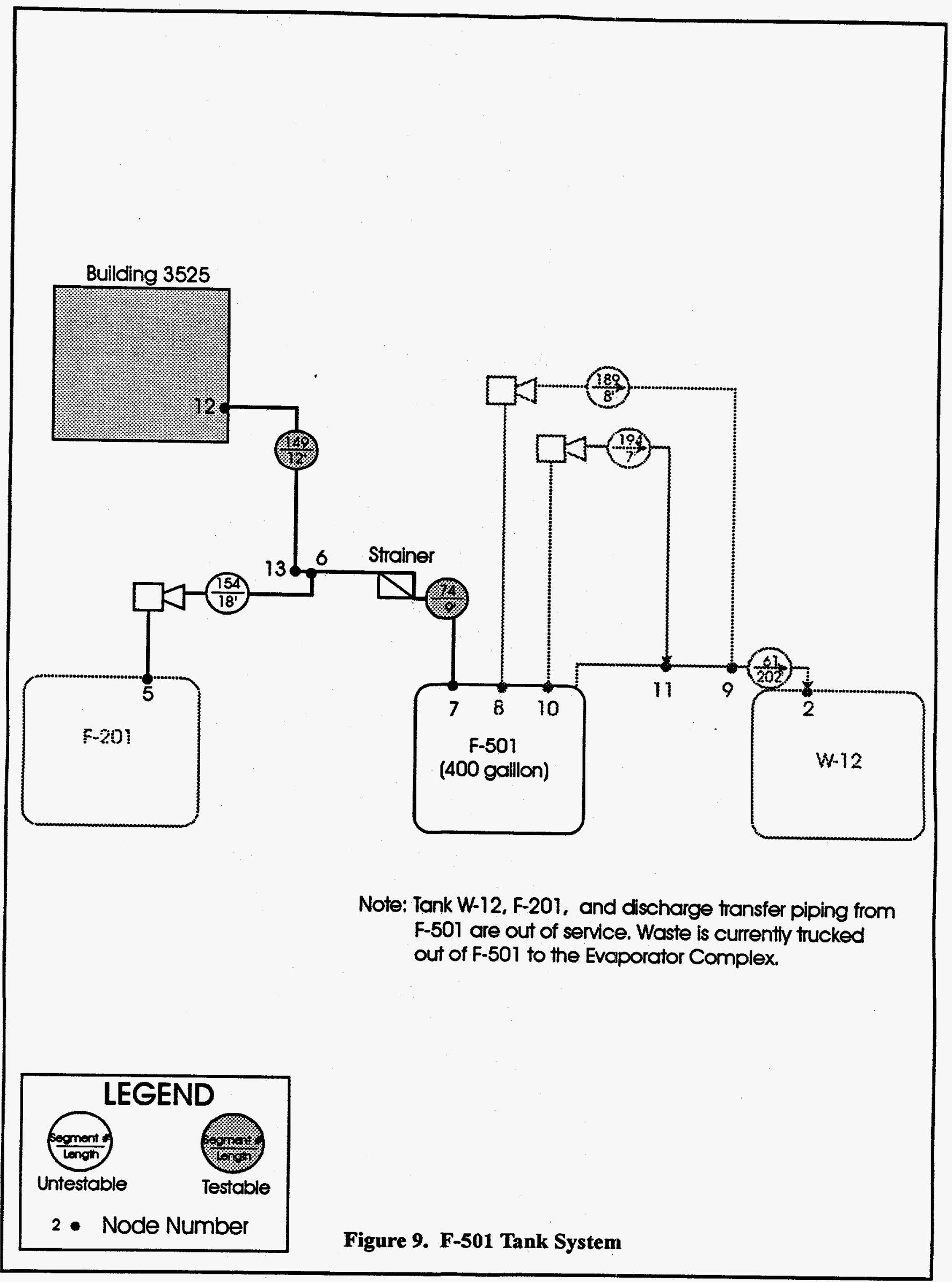




\subsubsection{F-501 Pipeline Descriptions}

The F-501 system has three pipelines, each of which is made up of multiple line segments. The first pipeline, identified as Index No. G30 (node 12 to node 7 in Figure 10), has $2 "$ and 4" diameter segments, and is constructed of 304L stainless steel. This line, made up of two line segments, is a gravity-fed line connecting a cell header in Building 3525 with Tank F501. The first segment, Line Segment 149, is a $12^{\prime}$ long segment that leaves the cell header in Building 3525 as a 2" diameter line constructed of 304L stainless steel (node 12 to node 6). The second segment, Line Segment 74, is a 4" diameter line, and is 9' long (node 6 to node 7).

The second pipeline is a portion of the transfer line connecting Tank F-201 to Tank F501. This segment, Line Segment 154, is $18^{\prime}$ long, with a 1-1/2" diameter, and is constructed of 304L SS. This segment extends from Tank F-201 to the 4" diameter segment described above as Line Segment 74 (node 6 to node 7).

The third element of the F-501 Tank System is the matrix of discharge transfer lines leading from Tank F-501 to Tank W-12. Even though described here, these discharge lines are no longer in service. Waste is trucked from Tank F-501 to the Evaporator Complex. This element is comprised of three line segments, all constructed of $304 \mathrm{~L}$ stainless steel. The first, Line Segment 189 (node 8 to node 9), is $8^{\prime}$ long, has a 1" diameter. This segment transfers liquid from Tank F-501, via steam jet to Line Segment 61 which leads to Tank W-12. The second, Line Segment 194 (node 10 to node 11 ), is 7' long, with a 1" diameter. Segment 194 previously transferred liquids from Tank F-501, via steam jet to Line Segment 61. The third, Line Segment 61 (node 9 to node 2), is 202' long, with a 3" diameter. Table 3 contains a summary of the F-501 Tank System pipeline characteristics.

Table 3. Characteristics of Line Segments Evaluated as a Part of Tank System F-501

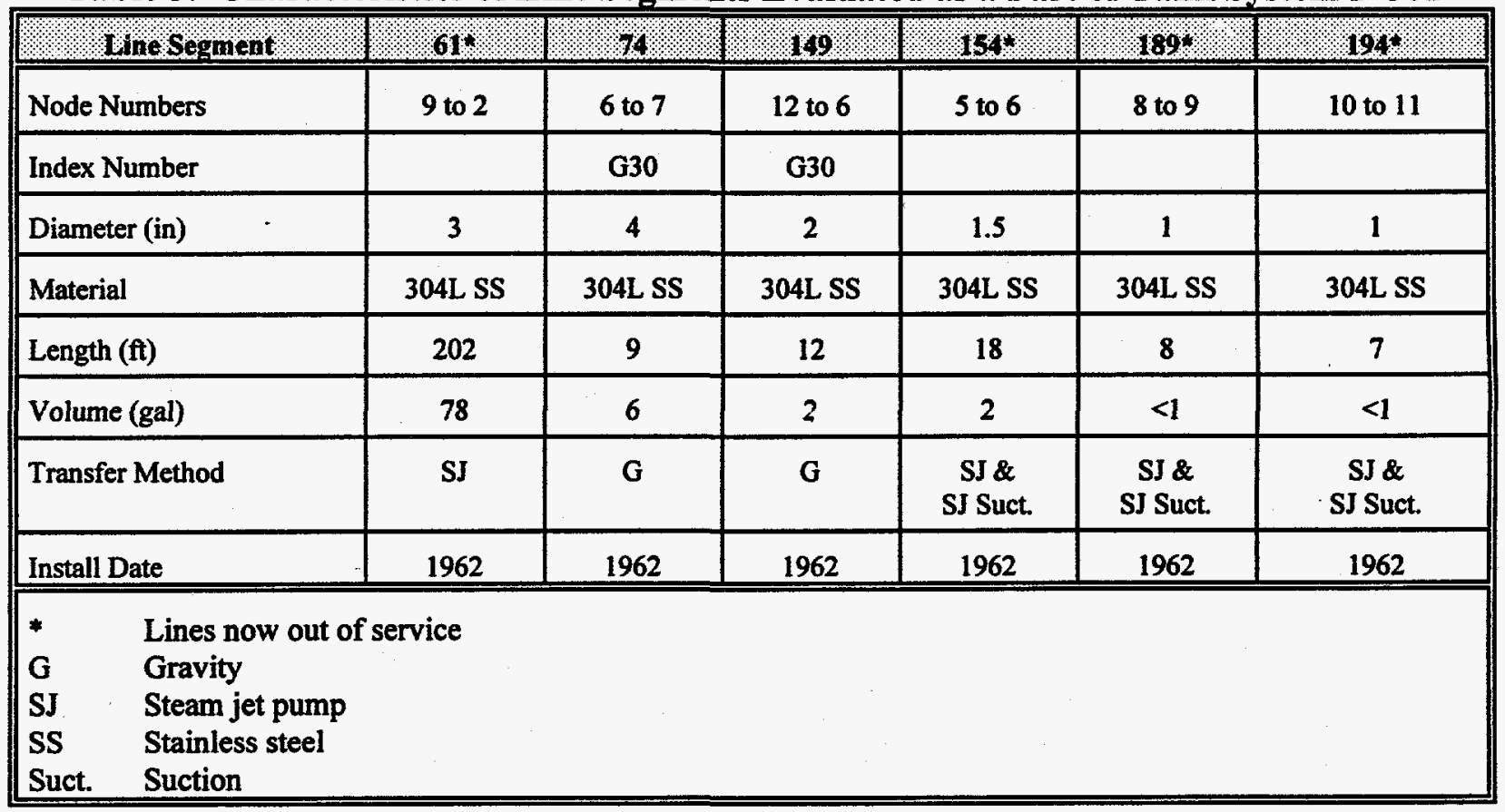




\subsubsection{Corrosion Assessment of F-501 Tank System}

Tank F-501 is an active tank used to collect liquid waste from Building 3525 . Solutions collected in the tank include acids (including $\mathrm{HCl}$ and $\mathrm{HF}$ ), bases, salts, and detergent solutions used for decontamination. No effort is made to maintain the tank solution at a high $\mathrm{pH}$, and the solution may have a high or low $\mathrm{pH}$ depending on what was most recently added to the tank.

Because of the unknown and variable composition of the tank solution, pitting and crevice corrosion as well as a high general corrosion rate must be considered possible. It is not possible to estimate the present condition of the tank.

Since the tank is situated in a concrete vault, external corrosion is not a concern. Some of the stainless steel piping is buried and is subject to corrosion by soil. However, based on information cited in Section 4.0, corrosion of stainless steel by ORNL soil is not believed to be severe.

\subsubsection{Results of Leak Tests on the F-501 System}

This section summarizes the results of the leak detection tests conducted on Tank System F-501. Each element in the system was tested with a method appropriate for that element. Each method used has been demonstrated to detect a specified leak rate $(0.2 \mathrm{gal} / \mathrm{hr}$ for tank methods; $0.1 \mathrm{gal} / \mathrm{hr}$ for pipeline methods) with a PD no less than $95 \%$ and a PFA no greater than $5 \%$. The test method used for each component of the system is shown in Section 7.1.5.

\subsubsection{Tanks}

Leak testing of Tank F-501 for this assessment period began in February 1995 and continued at frequent intervals through December 1995, with a total of 23 leak test attempts on the tank during this reporting period. The results of these tests are summarized in Table 4, which shows the date of each test, the volume of LLLW in the tank at the time of the test, the percent of Tank F-501's total volume the test represented ${ }^{5}$, the test result, and comments pertinent to particular tests. The table shows that Tank F-501 recorded PASS results for six of the 23 leak tests conducted during this reporting period, with INCONCLUSIVE results comprising the remainder of the tests. The reason for the inconclusive results appears to be a problem with the DP cell temperature sensor circuit that is part of the method. The resistance thermal detector (RTD) transmitter was replaced and all results since the repair were pass, as shown in the last three entries in the table. The maximum volume for which the tank passed the leak testing during this reporting period was 130 gallons, or $68 \%$ of the total capacity. This is slightly less than the previously certified level of 139 gallons (72\%) for this tank [DOE/OR/01-1385\&D2].

${ }^{5}$ Although the LLLW tank documentation and drawings show that F-501 has a 400 gallon capacity, an overflow drain limits the actual capacity to 192 gallons. The look up table used by the tank liquid level monitoring system uses a $100 \%$ capacity of 192 gallons for Tank F-501. Since the leak tests are based upon data from the level monitoring system, the percent of capacity here is based on a 192 gallon capacity; these values are rounded to the nearest percent. 
Table 4. Summary of Leak Tests Conducted on Tank F-501

\begin{tabular}{|c|c|c|c|c|}
\hline Date & \# or Gallons: & $\%$ Capacity & Test Result & Comment \\
\hline $02 / 03 / 95$ & 68 & 34 & PASS & \\
\hline $03 / 10 / 95$ & N/A & $\mathrm{N} / \mathrm{A}$ & INCONCLUSIVE & RTD problem \\
\hline $04 / 07 / 95$ & N/A & N/A & INCONCLUSIVE & RTD problem \\
\hline $04 / 21 / 95$ & N/A & N/A & INCONCLUSIVE & RTD problem \\
\hline $04 / 28 / 95$ & N/A & N/A & INCONCLUSIVE & RTD problem \\
\hline $05 / 05 / 95$ & N/A & N/A & INCONCLUSIVE & RTD problem \\
\hline $06 / 02 / 95$ & 61 & 30 & PASS & \\
\hline $07 / 07 / 95$ & 43 & N/A & INCONCLUSIVE & DQ - data shift \\
\hline $07 / 14 / 95$ & 54 & 27 & PASS & \\
\hline $07 / 21 / 95$ & N/A & N/A & INCONCLUSIVE & RTD problem \\
\hline $08 / 04 / 95$ & N/A & N/A & INCONCLUSIVE & RTD problem \\
\hline $08 / 11 / 95$ & N/A & N/A & INCONCLUSIVE & RTD problem \\
\hline $0 / 18 / 95$ & N/A & N/A & INCONCLUSIVE & RTD problem \\
\hline $08 / 25 / 95$ & 109 & N/A & INCONCLUSIVE & DQ - additions? \\
\hline $09 / 01 / 95$ & N/A & N/A & INCONCLUSIVE & RTD problem \\
\hline $09 / 08 / 95$ & N/A & N/A & INCONCLUSIVE & RTD problem \\
\hline $09 / 15 / 95$ & N/A & $\mathrm{N} / \mathrm{A}$ & INCONCLUSIVE & RTD problem \\
\hline $09 / 22 / 95$ & N/A & N/A & INCONCLUSIVE & RTD problem \\
\hline $09 / 29 / 95$ & N/A & N/A & INCONCLUSIVE & RTD problem \\
\hline $10 / 06 / 95$ & N/A & N/A & INCONCLUSIVE & RTD problem \\
\hline $10 / 13 / 95$ & 50 & 26 & PASS & RTD TX replaced \\
\hline $11 / 03 / 95$ & 43 & 22 & PASS & \\
\hline $12 / 01 / 95$ & 130 & 68 & PASS & \\
\hline
\end{tabular}

The six usable CVR data from these leak tests were analyzed (1) to verify that the test method was performing properly in this application and (2) to confirm that during this assessment period the leak testing process had remained nominal; that is, that the use of, or performance of, the method as applied to this particular tank was not deteriorating. This analysis included a statistical examination of the CVR data, as well as a comparison of this year's assessment data with prior data. The analysis and the results are described in Section 7.1.4.3.

\subsubsection{F-501 Pipelines}

The results of the leak detection tests on the testable portion of the F-501 pipeline is summarized in Section 7.1.4.2.1. As described in Section 7.1.4.2.2, all other portions of the F501 piping system have been taken out of service and thus no longer require leak testing.

\subsection{F-501 Testable Pipelines}

The testable portion of the F-501 pipeline system is comprised of a single gravity-fed inlet line leading from Building 3525 to Tank F-501 (see Figure 9). This line was tested in early March 1996 and achieved a PASS result. Table 5 summarizes the results of this test. 
Table 5. Summary of Leak Test Results for the F-501 Testable Pipelines

\begin{tabular}{|c|c|c|c|c|}
\hline Inder Nunber & Eine Segment & Test Date & Test Result & Comment \\
\hline G30 & 74,149 & 7-Mar-96 & PASS & \\
\hline
\end{tabular}

\subsection{F-501 Untestable Pipelines}

The untestable portion of the F-501 system included a portion of a no-longer-used line leading from Tank F-201 to Tank F-501, and the discharge line leading from Tank F-501 to Tank W-12. Tank W-12 was taken out of service on October 15, 1995. Since LLLW is being trucked from F-501, instead of using the transfer piping, there are no longer any parts of the F-501 discharge piping that require leak testing.

\subsubsection{Analysis of Tank F-501 Leak Test Data}

During this assessment period, a total of 23 leak tests were attempted on Tank F-501; of these, six tests resulted in conclusive decisions. Figure 10 shows a time series plot of the CVR data obtained from each of the useable test results. It can be seen from the plot that all six of the CVR values are within the INFLOW and OUTFLOW decision thresholds, and are thus consistent with the PASS results obtained from these tests.

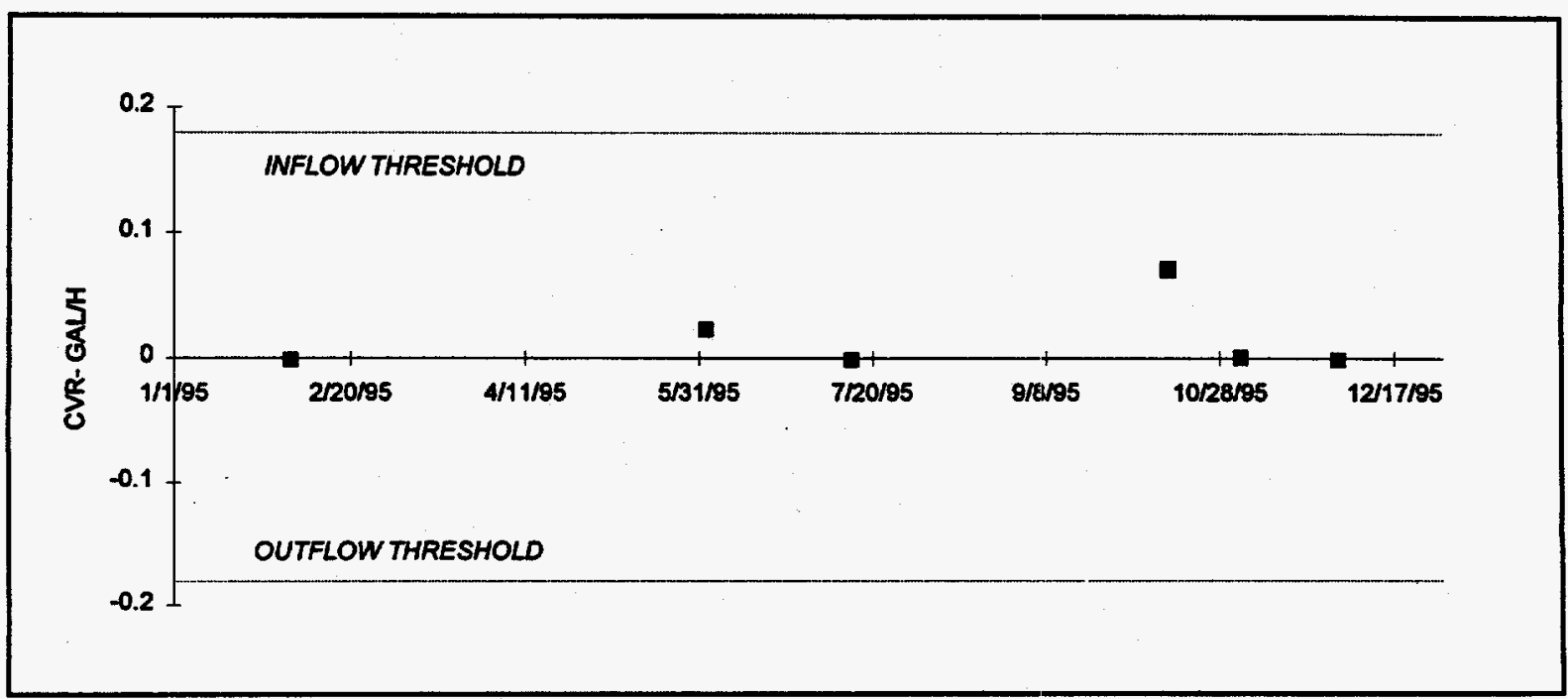

Figure 10. Times series plot of leak test CVRs from Tank F-501.

A comparative analysis of the data shown in Figure 10 was performed. The analysis included using the Student's $t$ - [Mendenhall, 1992], and the K-S [Benjamin and Cornell, 1970] statistical tests. The Student's t-test is used to determine the significance of the mean of the CVR data. The K-S analysis is used to determine if the population of CVR values from F-501 is significantly different than a reference set of CVRs. These statistical tests are fully described in Section 5.4. 
Applying the $t$-test to the six data values shown in Figure 10 results in a t-statistic, $t_{\text {stat }}$ of 1.27 , while the critical value, $t_{\text {crit }}$, is 4.03 , for a $99 \%$ level of confidence. Applying the K-S "goodness-of-fit" test to the F-501 CVR data, using a H/V weighted set of reference CVRs, results in a maximum ordinal difference, $\mathrm{KS}_{\text {stat }}$ of 0.57 , while the critical value, $\mathrm{KS}_{\text {crit }}$, is 0.67 , for a $99 \%$ level of confidence. Based upon this analysis, we conclude that both the mean and fluctuation of the 1995 CVR data from Tank F-501 are entirely consistent with data expected from a non-leaking tank.

Figure 11 graphically illustrates the K-S test applied to the F-501 data. The bold solid line in the figure shows the cumulative distribution function (CDF) obtained from the CVR data shown in Figure 10, after removing the mean from the data. The light dashed line in the figure shows the CDF obtained from the reference set of CVR values (See Section 5.4), after removing the mean from that data and scaling those values by the H/V coefficient of F-501 (7.77 gal/in.), divided by the $\mathrm{H} / \mathrm{V}$ of the (mean-removed) reference set (14.72 $\mathrm{gal} / \mathrm{in}$.).

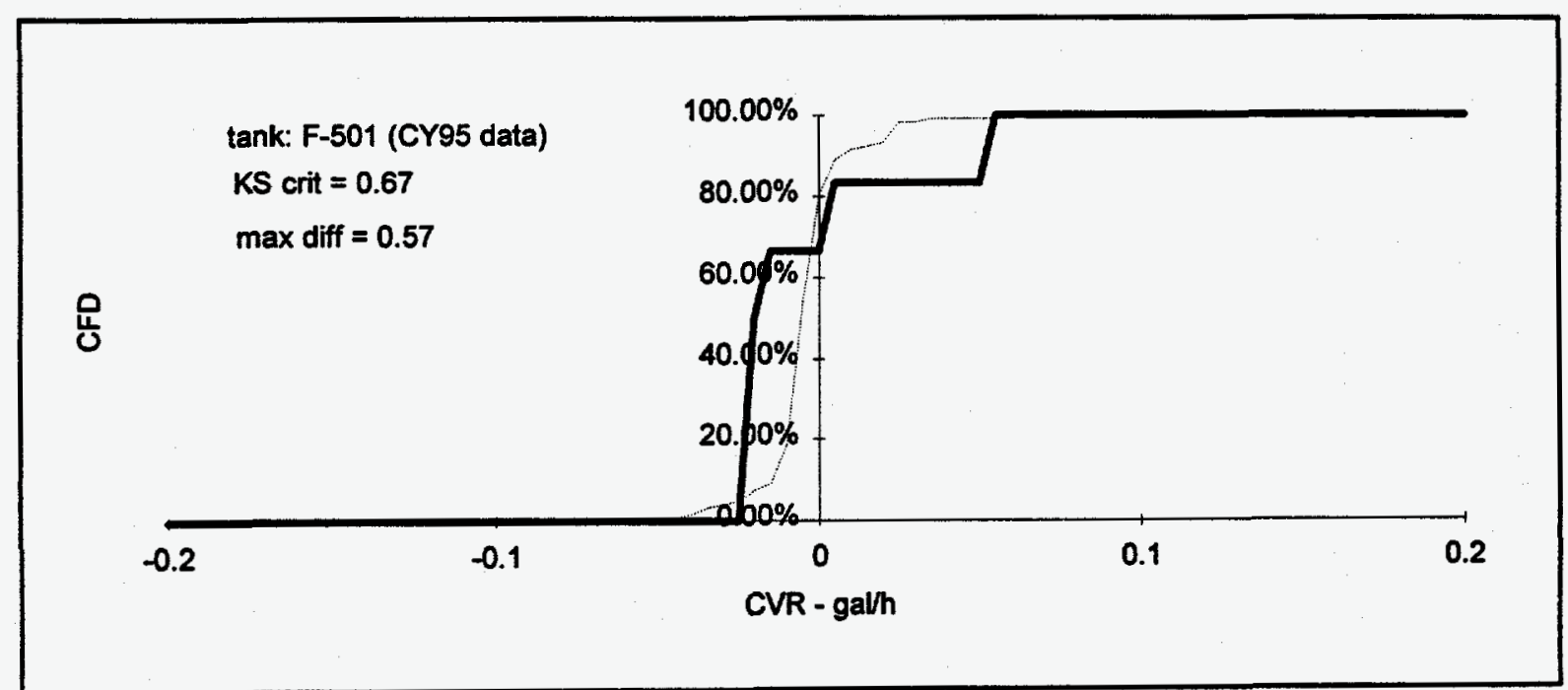

Figure 11. Cumulative frequency distributions from reference CVR data (light dashed line) and F-501 CVR data (CY95) (bold solid line).

The similarity of the data sets defined by the two lines illustrated in Figure 11 is "tested" with the K-S "goodness-of-fit" test. Here, the test statistic, $\mathrm{KS}_{\text {stat }}$ is 0.57 , while the critical value, $\mathrm{KS}_{\text {crit }}$ is 0.67 . Since the maximum ordinal difference, $\mathrm{KS}_{\text {stat }}$, is less than $\mathrm{KS}_{\text {crit }}$, the two populations are deemed to be equivalent.

Table 6 summarizes the statistical analyses of the Tank F-501 CVR data. The table shows that the mean of the CY95 test data is equivalent to zero $\mathrm{gal} / \mathrm{h}$, and that the population of the CY95 CVR values is not different than the population of CVR values in the reference, or comparison, data set. 
Table 6. Summary of Statistical Analyses of F-501 CVR Data (H/V=7.77 gal/in)

\begin{tabular}{|c|c|c|}
\hline & Reference CVR data & '95 CVR data \\
\hline $\mathbf{N}$ & 118 & 6 \\
\hline Mean (gal/h) & 0.002 & 0.015 \\
\hline $\begin{array}{l}\text { Standard Deviation } \\
(\mathrm{gal} / \mathrm{h})\end{array}$ & 0.016 & 0.029 \\
\hline t-statistic & & 1.27 \\
\hline t-critical ( $1 \%)$ & & 4.03 \\
\hline t-test Inference & & Same as zero mean \\
\hline KS-statistic & & 0.57 \\
\hline KS-critical (1\%) & & 0.67 \\
\hline KS-test Inference & & $\begin{array}{c}\text { Same population as } \\
\text { reference set }\end{array}$ \\
\hline
\end{tabular}

\subsubsection{Findings and Conclusions}

The findings of this report are based on (1) a review of available tank design drawings, (2) a qualitative assessment of corrosion on the tank and pipelines, and (3) leak testing results from the tank and testable pipelines.

Review of the design drawings indicated that the tank was designed in accordance with acceptable practices defined by ASTM and ASME. The design drawings revealed a sound design of the F-501 Tank.

The corrosion assessment determined that with the present and past uses of the tank system, all forms of corrosion on the interior walls of the tank and associated piping may be considered possible.

Leak testing of Tank F-501 was successfully completed by the DP method in six tests. The tank passed each of the six tests.

One testable pipeline exists for this tank system (G30). This line passed the EPA and TDEC approved test method.

All untestable lines associated with Tank F-501 have been removed from service and do not require certification.

All of these factors were considered in determining certification of the F-501 Tank System components. Table 7 summarizes the elements of the tank system which were certified and the conditional limits on their certifications. 
Table 7. Summary of F-501 Tank System Testing and Certification

\begin{tabular}{|c|c|c|c|c|c|c|c|}
\hline \multicolumn{2}{|c|}{ System } & 1 ength & $\begin{array}{l}\text { Tested } \\
\text { (Yes(No) }\end{array}$ & $\begin{array}{l}\text { Leak Test } \\
\text { Method }\end{array}$ & Test & Certification & Certinication \\
\hline \multicolumn{2}{|c|}{ Tank F-501 } & & Yes & DP & PASS & Yes & $68 \%$ \\
\hline \multicolumn{2}{|c|}{ LS-61* } & 202 & No & $\mathrm{N} / \mathrm{T}$ & $\mathrm{N} / \mathrm{T}$ & No & $\mathrm{N} / \mathrm{T}$ \\
\hline \multicolumn{2}{|c|}{ LS-74 } & 9 & Yes & EVB & PASS & Yes & $32 \mathrm{gph}$ \\
\hline \multicolumn{2}{|c|}{ LS-149 } & 12 & Yes & EVB & PASS & Yes & $32 \mathrm{gph}$ \\
\hline \multicolumn{2}{|c|}{ LS-189* } & 8 & No & $\mathrm{N} / \mathrm{T}$ & $\mathrm{N} / \mathrm{T}$ & No & $\mathrm{N} / \mathrm{T}$ \\
\hline \multicolumn{2}{|c|}{ LS-194* } & 7 & No & $\mathrm{N} / \mathrm{T}$ & $\mathrm{N} / \mathrm{T}$ & No & $\mathrm{N} / \mathrm{T}$ \\
\hline \multicolumn{2}{|c|}{ LS-154* } & 18 & No & $\mathrm{N} / \mathrm{T}$ & $\mathrm{N} / \mathrm{T}$ & No & $\mathrm{N} / \mathrm{T}$ \\
\hline $\begin{array}{l}\text { DP } \\
\text { EVB } \\
\text { gph } \\
\text { LS } \\
\text { N/T }\end{array}$ & \multicolumn{3}{|c|}{$\begin{array}{l}\text { Not in use } \\
\text { Differential Pressure } \\
\text { Enhanced volume balancing } \\
\text { Gallons per hour } \\
\text { Line segment } \\
\text { Not testable } \\
\end{array}$} & & & & r. \\
\hline
\end{tabular}




\subsubsection{Certification}

Based on the results of the design drawings review, the qualitative corrosion assessment and the results of the leak testing program, it is my professional opinion that Tank F-501 retains sufficient structural integrity to contain liquids at operating levels up to the maximum level which achieved a PASS during the testing program. Also, based upon the results of the pipeline tests, it is my professional opinion that Line Segments 74 and 149 retain sufficient integrity to contain liquids up to a flow rate of $32 \mathrm{gph}$. Table 7 provides a summary description of the certifications for the F-501 Tank System. If future testing is conducted at larger pipeline flows and greater tank levels, then certification levels may also increase.

It is recommended that leak detection and line testing be continued using EPA and TDEC approved methods, to support annual certification, until this system has been removed from operation or replaced.

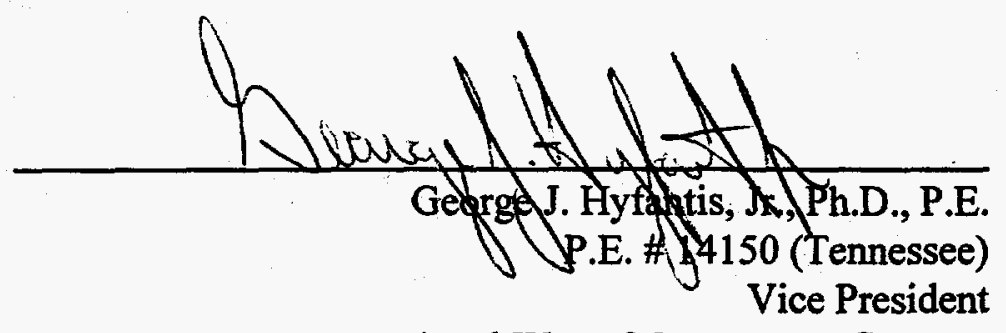

International Waste Management Systems

a Division of Environmental Systems Corporation 


\subsection{HFIR Tank System}

The HFIR Tank System is located west of the HFIR (Building 7900) as shown in Figure 1A. The tank system is made up of the HFIR tank and nine line segments connected to the tank. Because the lines and tank are all singly contained, the tank system has been classified as Category C, according to the FFA. This tank system is scheduled to be replaced by the Melton Valley LLLW Collection and Transfer Line Item Construction Project, which is scheduled to be completed in FY97.

\subsubsection{HFIR Tank Description}

The HFIR tank is a 13,000 gallon, buried, singly contained tank. Installed in 1961, the HFIR tank is mounted horizontally and is encased in reinforced concrete. The tank is constructed of stainless steel with an undetermined wall thickness and has dished heads at both ends. The working volume of the tank is recorded by WOCC as 9,148 gallons. The design drawing for the HFIR Tank System is shown in Figure 12.

The tank is equipped with two flanged nozzles and a 18" diameter manhole. Both nozzles and the manhole are located on top of the tank aligned along the tank centerline. The manhole contains one 6" diameter and two 2" diameter nozzles which extend down into the tank. The tank also contains one 6" diameter-flanged nozzle on the bottom and near the end of the tank. This nozzle has been closed using a 150 pound, $304 \mathrm{~L}$ stainless steel blind flange.

The tank is located in an earthen pit that is trapezoidal in cross-section. Concrete completely surrounds and covers the tank except for the tip nozzles and manhole. A network of \#5 rebar surrounding the tank provides reinforcement. Earth backfill was placed over the concrete. The tank is buried to a depth of $18^{\prime}-6^{\prime \prime}$ to the top of the tank.

The HFIR tank system is used to collect LLLW from the HFIR reactor in Building 7900, R\&D laboratories, the off-gas stack from Building 7911, and filter pit wastes from Buildings 7913 and 7920. A schematic of the tank system with numbered line segments is provided in Figure 13.

\subsubsection{HFIR Pipeline Descriptions}

There are two testable pipeline elements associated with the HFIR tank system. The first consists of only one segment, Line Segment 60 (node 26 to node 28 in Figure 13). This segment is a 1,947' long, 3" diameter, cast iron, pressurized portion of the discharge pipeline connecting the HFIR Tank to the Diversion Box for Tanks T-1 and T-2. The second testable element is a 400 ' long, gravity-fed pipeline leading from Building 7900 to the HFIR Tank (node 17 to node 21). This element is made up of two line segments. The first segment, identified as Line Segment 78, is a 190', 3" diameter cast-iron line segment that leads from Building 7900 to a sump containing a 6 " diameter $\times 3$ " diameter pipeline reducer (node 17 to node 20 in Figure 13). The second segment, identified as Line Segment 79, is a 210' long, 6" diameter stainless steel segment connecting the reducer to the HFIR Tank (node 20 to 21). 

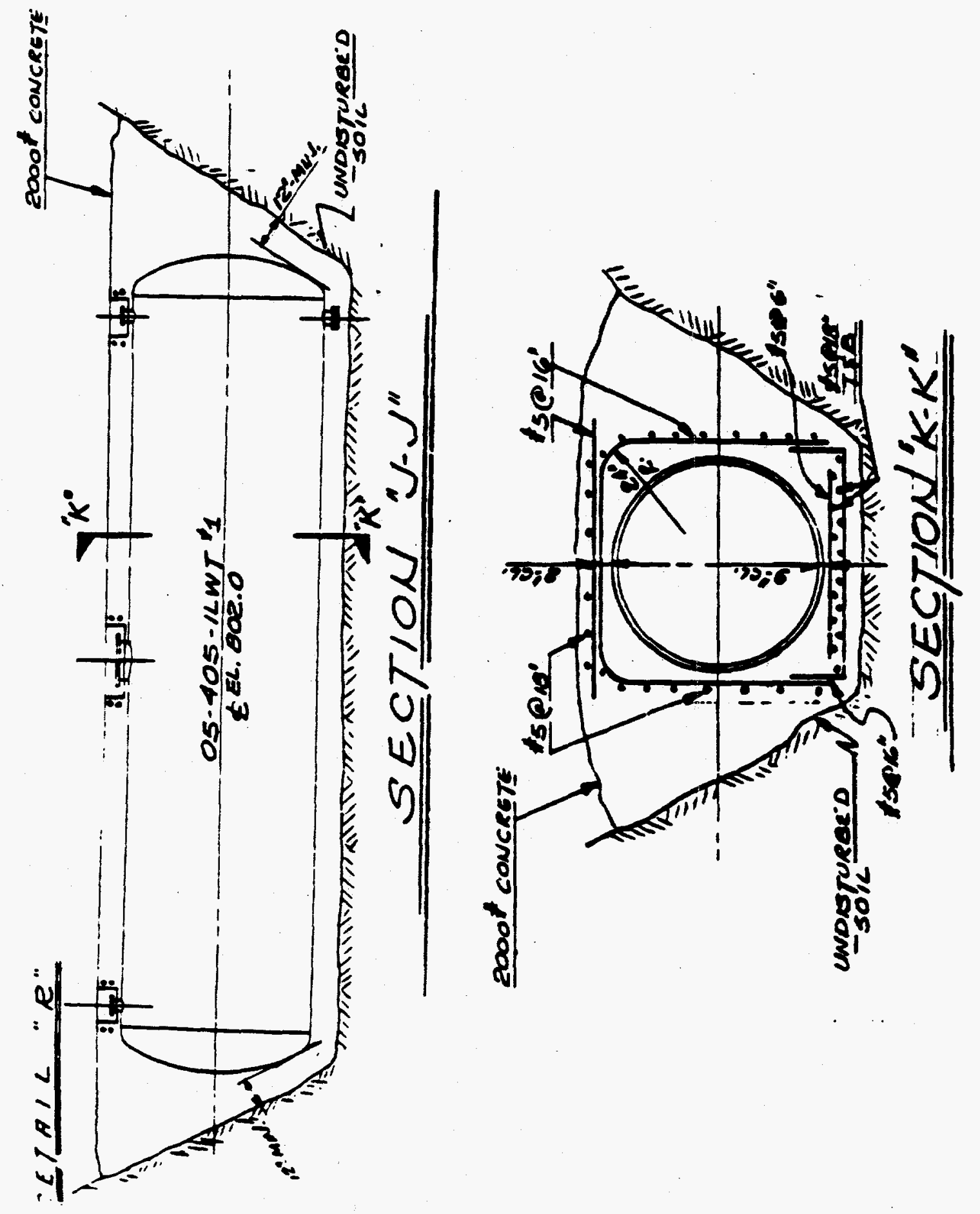

告 


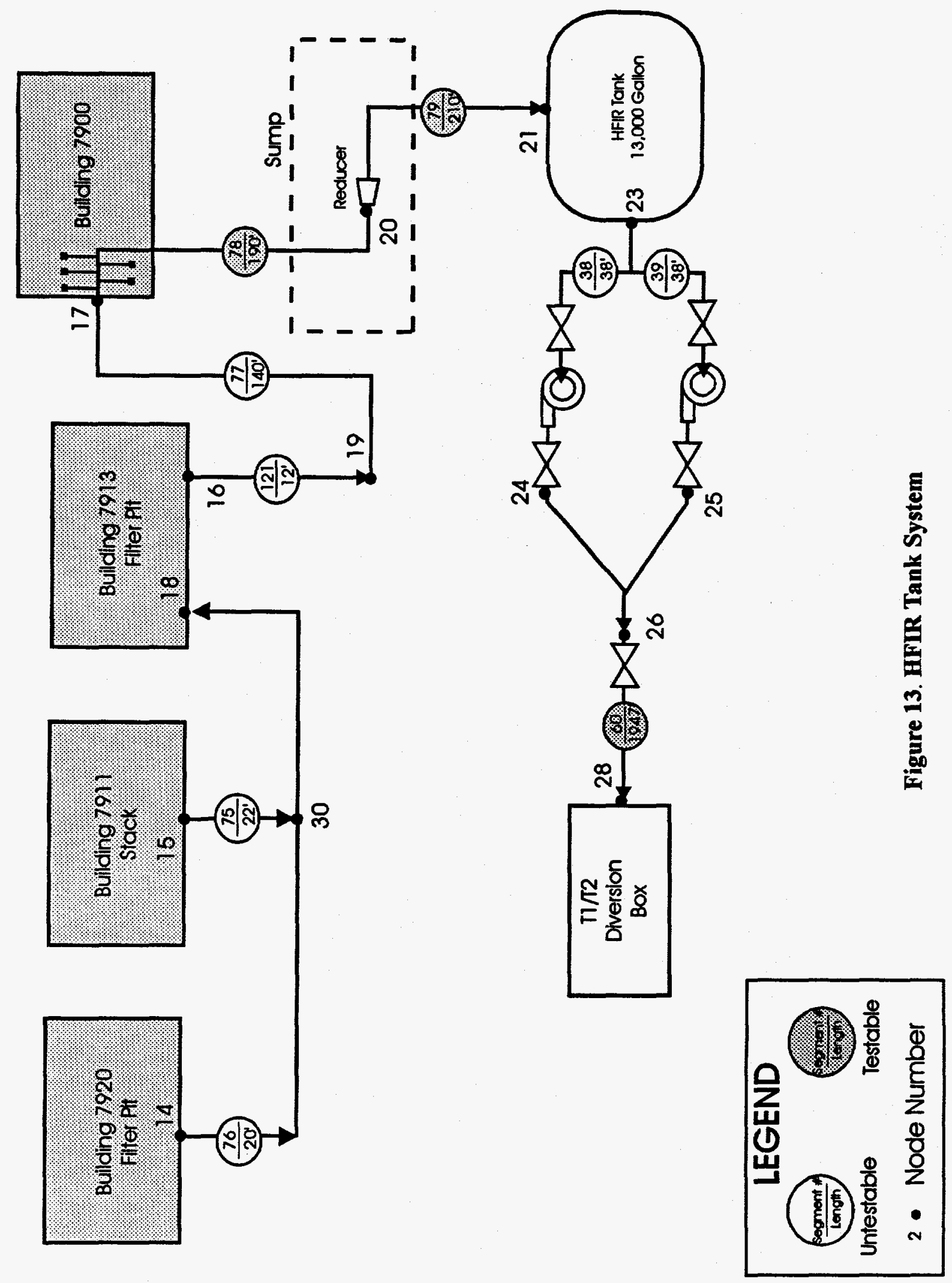


The HFIR Tank System has five pipeline elements that cannot be tested for leaks because they lack physical access. The first two untestable elements are two segments of suction lines connecting the HFIR Tank to the HFIR transfer pumps known as Pump A and Pump B. Each of these line segments are $38^{\prime}$ in length, $2^{\prime \prime}$ diameter, and constructed of stainless steel. These two segments are identified as Line Segments 38 and 39 (node 23 to node 24 and node 23 to node 25, respectively). A third untestable element is made up of two segments, Line Segments 121 (node 16 to node 19) and 77 (node 19 to node 17). This pipeline element is a gravity-fed line leading from the Building 7913 filter pit to Building 7900. This element is a total of 152' long, has a 3" diameter, and is made of cast iron. The fourth untestable pipeline, Line Segment 76, (node 14 to node 30) is a portion of the gravity-fed line from the Building 7920 filter pit to the line leading to the Building 7913 Filter Pit. This line segment is $20^{\prime}$ long with a 2" diameter and is made of cast iron. The fifth untestable pipeline, Line Segment 75 (node 15 to node 18) is a portion of the gravity-fed line from the Building 7911 Stack to the Building 7913 Filter Pit. This line segment is 22 ' long with a 2" diameter, and is made of cast iron. Characteristics of line segments associated with the HFIR tank are summarized in Table 8.

Table 8. Characteristics of Line Segments Evaluated as a Part of HFIR Tank System

\begin{tabular}{|c|c|c|c|c|c|c|c|c|c|c|}
\hline \multicolumn{2}{|l|}{ Segnent } & 38 & 39 \% & 60 & 75. & 76 & 77 & 78 & 79 . & $121 \%$ \\
\hline \multicolumn{2}{|c|}{ Node Number } & 23 to 24 & 23 to 25 & 26 to 28 & $\begin{array}{c}15 \text { to } \\
18\end{array}$ & 14 to 30 & 19 to 17 & 17 to 20 & 20 to 21 & 16 to 19 \\
\hline \multicolumn{2}{|l|}{$\begin{array}{l}\text { Index } \\
\text { Number }\end{array}$} & - & $*$ & P1 & & & & G16 & G16 & \\
\hline \multicolumn{2}{|c|}{ Diameter (in) } & 2 & 2 & 3 & 3 & 2 & 3 & 3 & 6 & 3 \\
\hline \multicolumn{2}{|l|}{ Material } & 304L SS & 304L SS & $\mathrm{CI}$ & CI & CI & $\mathrm{CI}$ & $\mathrm{CI}$ & 304L SS & $\mathrm{Cl}$ \\
\hline \multicolumn{2}{|l|}{ Length (ft) } & 38 & 38 & 1,947 & 22 & 20 & 140 & 190 & 210 & 12 \\
\hline \multicolumn{2}{|c|}{ Volume (gal) } & 7 & 7 & 748 & 9 & 8 & 54 & 73 & 315 & 5 \\
\hline \multicolumn{2}{|l|}{$\begin{array}{l}\text { Transfer } \\
\text { Method }\end{array}$} & CP Suct. & CP Suct. & $\mathrm{CP}$ & G & G & G & G & G & G \\
\hline \multicolumn{2}{|l|}{ Install Date } & 1961 & 1961 & 1961 & 1961 & 1961 & 1961 & 1961 & 1961 & 1961 \\
\hline \multicolumn{11}{|c|}{$\begin{array}{ll}- & \text { Transfer records available } \\
\text { CI } & \text { Cast iron } \\
\text { CP } & \text { Centrifugal Pump } \\
\text { G } & \text { Gravity } \\
\text { SJ } & \text { Steam jet pump } \\
\text { SS } & \text { Stainless Steel } \\
\text { Suct. } & \text { Suction }\end{array}$} \\
\hline
\end{tabular}

\subsubsection{Corrosion Assessment of the HFIR Tank System}

The HFIR tank receives solution from regeneration of ion exchange resins used to purify the HFIR and pool waters as well as small amounts of resin fines. Until 1991, new anion resin was purchased in the chloride form and was converted to the hydroxide form with $5 \%$ sodium hydroxide. The cation resin was purchased in the sodium form and was converted to the 
hydrogen form with $4 \%$ nitric acid. Excess sodium hydroxide was always used so that the $\mathrm{pH}$ of the liquid added to the tank was 13 or greater and contained sodium nitrate, sodium chloride, small amounts of resin fines, and sodium hydroxide. The same procedure was used to regenerate depleted resins, except chloride ions were not present in the waste stream. Since 1991, resins were purchased in the hydrogen and hydroxide forms, and chlorides have not been added to the tank.

One interesting feature of this system is that an underground cast iron pipe line connects the HFIR tank to the T-1/T-2 Diversion Box. Cast iron generally has much poorer corrosion resistance to aqueous environments than SS. In highly alkaline solutions, such as the waste solution, corrosion resistance by cast iron should be adequate, but if the $\mathrm{pH}$ becomes seven or less, rapid general corrosion would be expected.

Assuming that the tank conditions have always been as described above, attack on the stainless steel tank should be very low even with chloride in solution. During short periods when the solution may have been slightly acidic, enough nitrate ions were probably present to prevent any damaging or pitting.

External corrosion of the tank should be minimal. The concrete encasing the tank should not enhance corrosion; in fact, the presence of concrete may actually protect most of the stainless steel surface from soil and ground water and increase the $\mathrm{pH}$ of any water that may come in contact with the stainless steel through cracks or pores in the concrete. Underground stainless steel piping in direct contact with the soil is unlikely to have experienced serious corrosion based on information cited in General Aspect of Corrosion at ORNL (Section 4).

\subsubsection{Results of Leak Tests on the HFIR System}

This section summarizes the results of the leak detection tests conducted on the HFIR Tank System. Each element in the system was tested with a method appropriate for that element. Each method used has been demonstrated to detect a specified leak rate $(0.2 \mathrm{gal} / \mathrm{hr}$ for tank methods; $0.1 \mathrm{gal} / \mathrm{hr}$ for pipeline methods) with a PD no less than $95 \%$ and a PFA no greater than $5 \%$. The methods used for each element are shown in Section 7.2.5.

\subsubsection{Tanks}

Due to the uncontrolled inflows into the HFIR tank, no leak tests have been conducted to date. However, liquid level data have been collected regularly during this assessment period to estimate the inflows to the tank. These data show that, excluding the periods of high use of the tank, the HFIR tank has an average continuous inflow of about $2.8 \mathrm{gal} / \mathrm{h}$, with a standard deviation of about $1.4 \mathrm{gal} / \mathrm{h}$. This inflow is thought to come from condensation in a hot off-gas filter pit. The HFIR tank cannot be conclusively leak tested until this inflow is mitigated.

\subsubsection{HFIR Pipelines}

The results of the leak detection test on the testable portion of the HFIR pipelines are 
summarized in Section 7.2.4.2.1. An assessment of the HFIR pipelines that cannot be tested for leaks with existing approved methods is summarized in Section 7.2.4.2.2.

\subsection{HFIR Testable Pipelines}

The testable portion of the HFIR pipeline system is comprised of two elements: a pressurized portion of the discharge pipeline connecting the HFIR tank to the Diversion Box (designated Index No. P1, Line Segment 60), and a gravity pipeline leading from Building 7900 to the HFIR Tank (designated Index No. G16, Line Segments 78 and 79.) As illustrated in Table 9, the pressurized line was leak tested on April 9, 1996, achieving a PASS result. The variable inflow into the HFIR tank prevented a leak test of the gravity-fed segment.

Table 9. Summary of Leak Test Results for the HFIR Testable Pipelines

\begin{tabular}{|c|c|c|c|c|}
\hline Kndex Number & Line Segment & Test Date & Test Result & Comment \\
\hline $\mathrm{Pl}$ & 60 & 9-Apr-96 & PASS & \\
\hline G16 & 78.79 & $N / A$ & N/A & variable inflo \\
\hline
\end{tabular}

\subsection{HFIR Untestable Pipelines}

The HFIR Tank System has five untestable pipeline elements, three gravity-fed line segments and two suction segments. The untestable gravity-fed lines include a segment from the Building 7911 stack to the Building 7913 filter pit (node 15 to node 18), a segment from the Building 7920 filter pit to the Building 7913 filter pit (node 14 to node 18), and a segment from the Building 7913 filter pit to the HFIR Building (7900). (A portion of the node 14 to node 18 segment is concurrent with the node 15 to node 18 segment.) These gravity-fed segments cannot be tested because they cannot be accessed, and the integrity of these lines cannot be assessed using transfer records because there are none available. The entire system is scheduled to be removed from service in FY97.

The untestable suction lines are line segments numbers 38 and 39. These lines comprise the tank suction leg and two short parallel branch lines connecting the HFIR tank to the HFIR transfer pumps, Pump A and Pump B. Together with the testable portion of the discharge line that is in series with these untestable suction legs, these lines carry transfers from the HFIR tank to Tanks T-1 and T-2. Since the volume in the HFIR, T-1, and T-2 tanks are measured and recorded by the Waste Operations Control Center (WOCC), the transfer differences data can be used to form a statistical assessment of the integrity of the untestable segments.

Transfer logs show that during Calendar Year 1995, there were 12 transfers made from the HFIR tank to either Tank T-1 or Tank T-2. These transfers are summarized in the first four columns of Table 10. The differences between the volume sent (column 3 ) and the volume received (column 4) are shown in column 5 . For these transfers, the expected transfer errors (based upon the uncertainty of each measurement as described in Section 5.3) are given in column 6. As seen in column 7, about half of the transfer differences exceeded the expected error, and are thus considered significant transfer differences. As described in the previous 
structural integrity report [DOE/OR/01-1385\&D2], the suspected cause of these transfer differences is inaccuracy in the HFIR strapping table, a look-up table which is used by the WOCC to convert liquid level in the tank to volume.

Table 10. Summary of Transfers Between HFIR and T-1 and T-2 During 1995

\begin{tabular}{|c|c|c|c|c|c|c|}
\hline Transier & Transfer & $\begin{array}{l}\text { Yolume } \\
\text { sent }\end{array}$ & $\begin{array}{l}\text { Rolinie } \\
\text { Recived } \\
(\mathrm{gal})\end{array}$ & Difference & $\begin{array}{l}\text { Maximum } \\
\text { Erroected } \\
\text { (gal) }\end{array}$ & $\begin{array}{l}\text { Girference } \\
\text { Greater } \\
\text { Than }\end{array}$ \\
\hline $01 / 13 / 95$ & HFIR to T-1 & 5188 & 4945 & 243 & 100 & Yes \\
\hline $01 / 13 / 95$ & HFIR to T-2 & 665 & 665 & 0 & 58 & No \\
\hline $02 / 08 / 95$ & HFIR to T-1 & 5079 & 5051 & 28 & 98 & No \\
\hline $03 / 17 / 95$ & HFIR to T-2 & 5451 & 4906 & 545 & 104 & Yes \\
\hline $04 / 24 / 95$ & HFIR to T-2 & 2517 & 2438 & 79 & 68 & Yes \\
\hline 05/30/95 & HFIR to $T-2$ & 4669 & 4569 & 100 & 95 & See Note 1 \\
\hline $07 / 21 / 95$ & HFIR to T-2 & 4558 & 4352 & 206 & 93 & Yes \\
\hline $08 / 21 / 95$ & HFIR to T-2 & 3420 & 3356 & 64 & 77 & No \\
\hline 09/01/95 & HFIR to T-2 & 4088 & 3835 & 253 & 86 & Yes \\
\hline $11 / 07 / 95$ & HFIR to T-2 & 5318 & 5295 & 23 & 103 & No \\
\hline $12 / 01 / 95$ & HFIR to $T-2$ & 5055 & 5274 & (219) & 98 & See Note 2 \\
\hline $12 / 02 / 95$ & HFIR to T-1 & 6930 & 6904 & 26 & 125 & No \\
\hline
\end{tabular}

Note 1: Prime water was added to line; unable to assess significance of difference

Note 2: negative difference-possible data entry error; disregard

\subsubsection{Analysis of HFIR Tank Leak Test Data}

Analysis of the HFIR tank monthly leak test data was not performed because no leak testing was accomplished during this reporting period as a result of the inflows to the tank, as reported earlier. 


\subsubsection{Findings and Conclusions}

The findings of this report are based on (1) a review of available tank design drawings, (2) a qualitative assessment of corrosion on the tank and pipelines, and (3) leak testing results from the tank and testable pipelines. The design drawings revealed a sound design of the HFIR tank.

During the corrosion assessment it was determined that with the present use of the tank system, all forms of corrosion on the interior walls of the tank and associated piping including cast iron segments, should be nonexistent. Corrosion damage that may have occurred when the tank was used in past environments cannot be assessed. Furthermore, an analysis of the general aspects of corrosion at ORNL revealed that corrosion of stainless steel by ORNL soil is not believed to be severe.

Leak testing of the HFIR tank was not completed due to the inflow present in the tank.

One of the testable line segments passed leak testing by one of the methods discussed previously. The other testable line segments did not pass the volume balancing leak test due to uncontrolled inflows into the HFIR tank.

Transfer logs were used to qualitatively assess the pipelines which are untestable by currently approved methods. Transfer logs reveal that of 12 transfers made, seven show input/output volume differences greater than the expected measurement errors. The suspected cause of these differences is inaccuracy in the HFIR tank strapping table, which is used to convert liquid level in the tank to volume. The volume of these transfers along with the latest qualitative assessment of the pipelines are reported to EPA and TDEC in the "Quarterly Highlights for LLLW Tank System Activities." Although a limited evaluation of the untestable pipelines can be made using transfer logs, this method of assessment, due to its limited accuracy, is not deemed valid for certification purposes.

All of these factors were considered in determining certification of the HFIR Tank

System components. Table 11 summarizes the elements of the tank system which were certified and the conditional limits on their certifications. 
Table 11. Summary of HFIR Tank System Testing and Certification

\begin{tabular}{|c|c|c|c|c|c|c|c|}
\hline \multicolumn{2}{|c|}{ 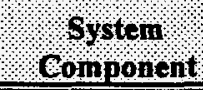 } & $\begin{array}{l}\text { tength } \\
\text { (nt) }\end{array}$ & $\begin{array}{l}\text { rested } \\
\text { (res ANo) }\end{array}$ & Weal Test & Result & Certification & $\begin{array}{l}\text { ertification } \\
\text { Level }\end{array}$ \\
\hline \multicolumn{2}{|c|}{ Tank HFIR } & & No & $\mathrm{N} / \mathrm{T}$ & $\mathrm{N} / \mathrm{T}$ & No & $\mathrm{N} / \mathrm{T}$ \\
\hline \multicolumn{2}{|l|}{ LS-38 } & 38 & No & $\mathrm{N} / \mathrm{T}^{*}$ & $\mathrm{~N} / \mathrm{T}$ & No & $\mathrm{N} / \mathrm{T}$ \\
\hline \multicolumn{2}{|l|}{ LS-39 } & 38 & No & $\mathrm{N} / \mathrm{T}^{*}$ & $\mathrm{~N} / \mathrm{T}$ & No & $\mathrm{N} / \mathrm{T}$ \\
\hline \multicolumn{2}{|l|}{ LS-60 } & 1947 & Yes & GPD & PASS & Yes & Full flow \\
\hline \multicolumn{2}{|l|}{ S-75 } & 22 & No & $\mathrm{N} / \mathrm{T}$ & $\mathrm{N} / \mathrm{T}$ & No & $\mathrm{N} / \mathrm{T}$ \\
\hline \multicolumn{2}{|l|}{ LS-76 } & 45 & No & $\mathrm{N} / \mathrm{T}$ & $\mathrm{N} / \mathrm{T}$ & No & $\mathrm{N} / \mathrm{T}$ \\
\hline \multicolumn{2}{|l|}{ LS-77 } & 140 & No & $\mathrm{N} / \mathrm{T}$ & $\mathrm{N} / \mathrm{T}$ & No & $\mathrm{N} / \mathrm{T}$ \\
\hline \multicolumn{2}{|l|}{ LS-78 } & 190 & No & $\mathrm{N} / \mathrm{T}$ & $\mathrm{N} / \mathrm{T}$ & No & $\mathrm{N} / \mathrm{T}$ \\
\hline \multicolumn{2}{|l|}{ LS-79 } & 210 & No & $N / T$ & $\mathrm{~N} / \mathrm{T}$ & No & $\mathrm{N} / \mathrm{T}$ \\
\hline \multicolumn{2}{|l|}{ LS-121 } & 12 & No & $\mathrm{N} / \mathrm{T}$ & $\mathrm{N} / \mathrm{T}$ & No & $\mathrm{N} / \mathrm{T}$ \\
\hline $\begin{array}{l}* \\
\text { EVB } \\
\text { GPD } \\
\text { INC } \\
\text { LS } \\
\text { N/T } \\
\text { VDP }\end{array}$ & \multicolumn{7}{|c|}{$\begin{array}{l}\text { Transfer records available } \\
\text { Enhanced volume balancin } \\
\text { Gas pressure decay } \\
\text { Inconclusive } \\
\text { Line segment } \\
\text { Not testable } \\
\text { Volumetric DP Methods }\end{array}$} \\
\hline
\end{tabular}




\subsubsection{Certification}

The HFIR tank cannot be certified at this time. Based on the results of the design drawings review, the qualitative corrosion assessment and the results of the leak testing program, it is my professional opinion that Line Segment 60 retains sufficient integrity to contain liquids up to the full flow potential of this line segment. Table 11 provides a summary description of the certifications for the HFIR Tank System.

It is recommended that efforts to test the HFIR Tank continue. It is also recommended that line testing be continued using EPA and TDEC approved methods, to support annual certification, until this system has been removed from operation or replaced.

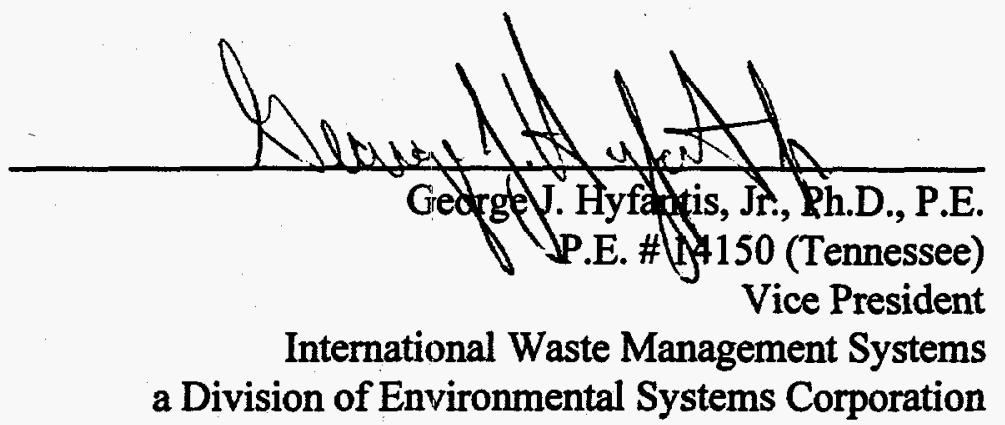




\subsection{T-1 Tank System}

The T-1 Tank System is located near Building 7567 as shown in Figure 1A. The T-1 Tank System collects LLLW from the HFIR tank prior to transferring it to the Evaporator Complex in Bethel Valley. The system is made up of Tank T-1 and two pipeline segments connected to the system. Because the lines and tank are all singly contained, the tank system has been classified as Category $\mathrm{C}$, according to the FFA.

\subsubsection{T-1 Tank Description}

Tank T-1 is a 15,000 gallon, buried, singly contained tank. The tank is constructed of 304L stainless steel and has a wall thickness of 1/4" with ASME standard 3/8" thick 304L stainless steel flanged dished heads. The outside diameter of the tank is $10^{\prime}-0^{\prime \prime}$ with a total length of $27^{\prime}-5^{\prime \prime}$.

Installed in 1963, Tank T-1 is mounted horizontally on two reinforced concrete $3^{\prime}-6^{\prime \prime}$ pillars, anchored to $12^{\prime}-0^{\prime \prime}$ x 7'-0" x 2'-0" footings. Tank T-1 has a 3-1/4" x 1/4" 304L stainless steel strap over the top, bolted to a 1-1/4" diameter 304L stainless steel anchor cast into the concrete supports.

Tank T-1 is contained in an earthen pit, along with Tank T-2. The pit has bottom dimensions of 34'-0" x 29'-0". The long axes of the tanks are parallel to the shorter bottom dimension of the pit. The tanks are separated by a reinforced concrete wall $37^{\prime}-0^{\prime \prime} \times 9^{\prime}-0^{\prime \prime} \times 1^{\prime}-0^{\prime \prime}$ supported on a continuous $3^{\prime}-0^{\prime \prime} \times 1^{\prime}-0$ " footing. On either side of the concrete dividing wall and supported by the wall footing is a dry well constructed of a 12 " diameter vitrified clay pipe extending vertically to the surface. The pit is backfilled with 1 " diameter gravel to the centerline of the tanks. A layer of polyethylene covers the gravel, with the remaining pit volume backfilled with earth to an elevation of 6'-6" above the top of the tanks. The design drawings for Tank T-1 are shown in Figure 14 and Figure 14A.

The tank is equipped with nine 2" diameter Schedule 40 stainless steel welded nozzles, two 1" diameter Schedule 40 stainless steel welded nozzles, one 4" diameter Schedule 40 stainless steel welded nozzle, and one 18" diameter manhole. All measurements are on centers of the nozzles or the manhole. All materials, fabrication, welding and inspection are in accordance with ORNL specification XSP-56.

Tank T-1 has only one inlet line and one outlet line. Tank T-1 is capable of receiving material from one source, the HFIR Tank. The liquids generated in Building 7900 are transferred directly into the tank identified as HFIR. LLLW is transferred from the HFIR Tank to Tank T-1 prior to being transferred to the Evaporator Complex in Bethel Valley. A schematic of the tank system with numbered line segments is shown in Figure 15. 


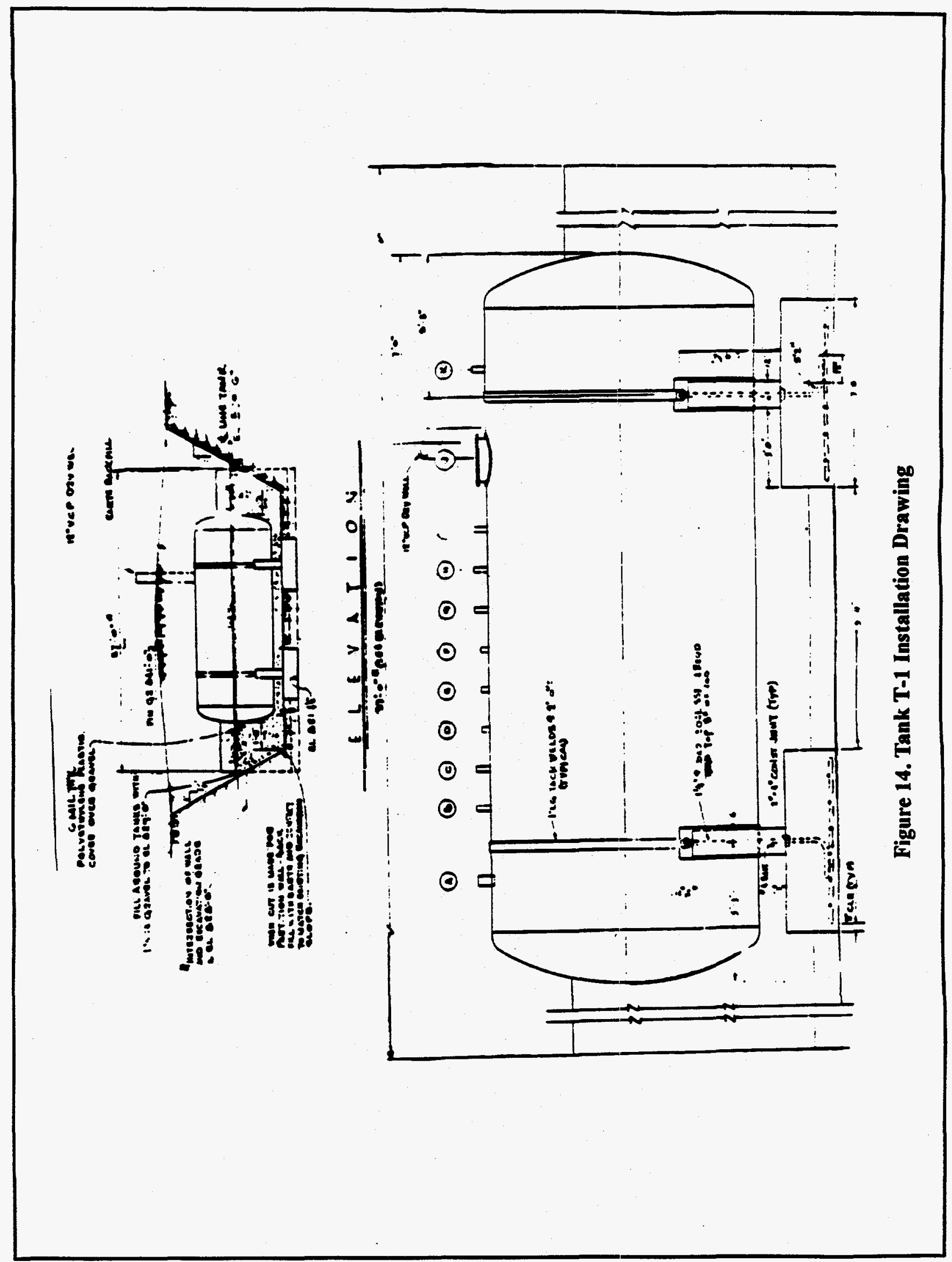




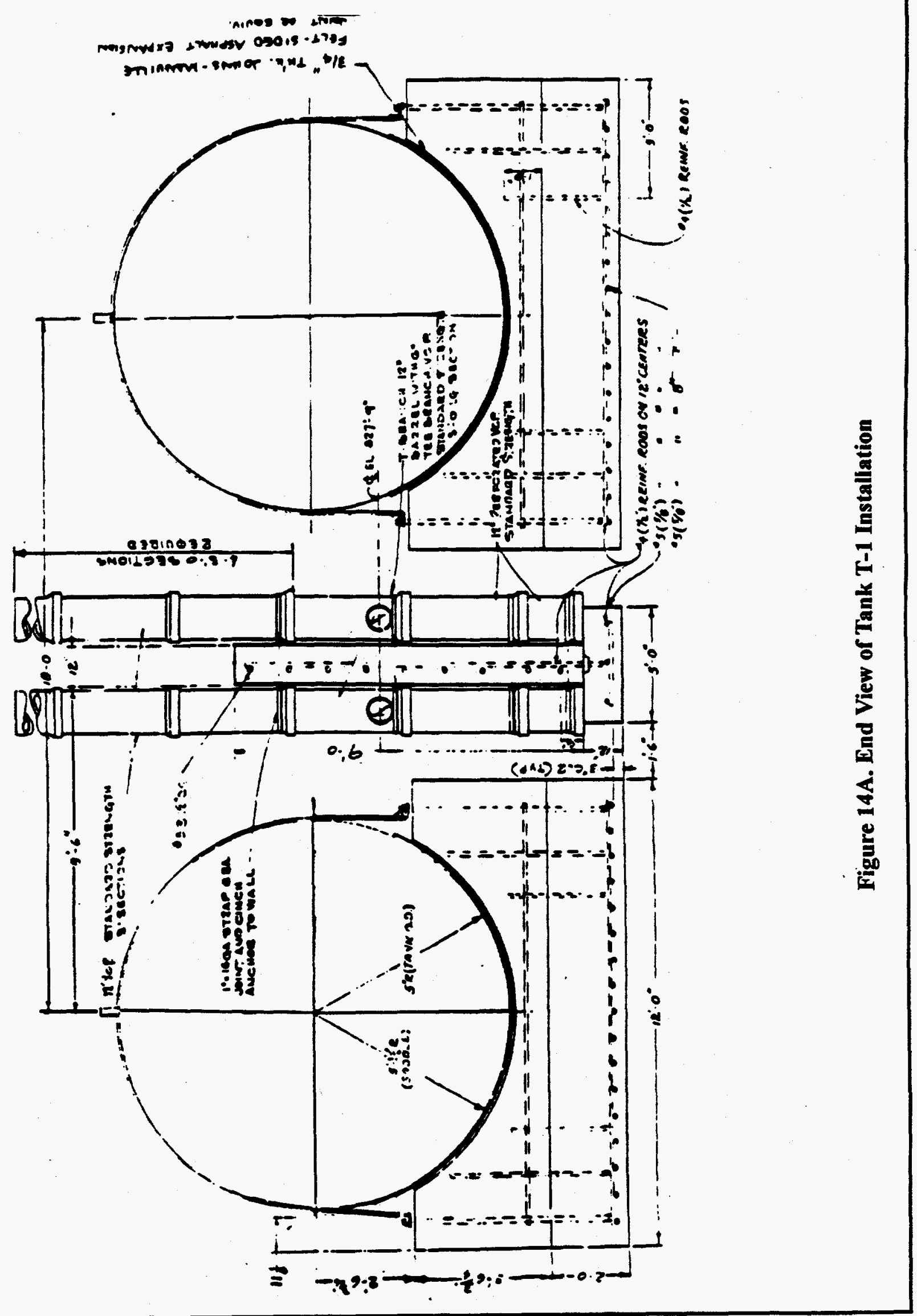



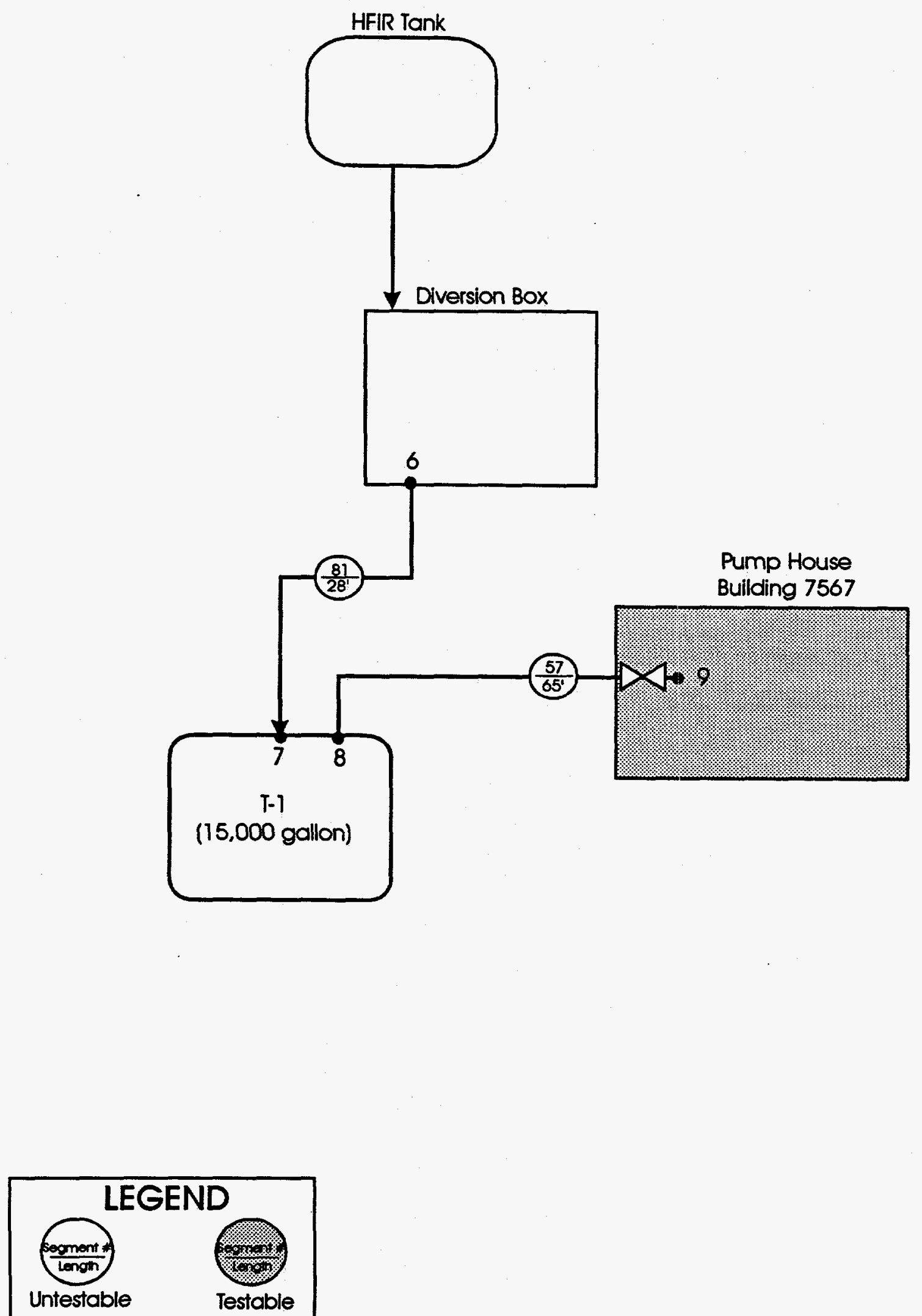

2 - Node Number

Figure 15. T-1 Tank System 


\subsubsection{T-1 Pipeline Descriptions}

The T-1 Tank System has two pipeline segments. Line Segment 81 (node 6 to node 7 in Figure 16) is a $28^{\prime}$ long, 4" diameter, 304L stainless steel section of piping connecting the T1/T2 Diversion Box with Tank T-1. Line Segment 57 is a singly contained suction pipeline running between Tank T-1 and the Building 7567 Pump House. This segment (node 8 to node 9), is 65' long, with a 2" diameter, and is made of 304L stainless steel. Both lines are used regularly, with transfers from the HFIR tank through the diversion box piping to Tank T-1 and subsequent flow through the suction piping to the Building 7567 transfer pumps. The main section of the transfer line from the HFIR tank to the diversion box is tested and covered in the structural integrity assessment for the HFIR tank. The main segment of the transfer line from Building 7567 Pump House to the Evaporator Complex is tested and covered in the structural integrity assessment for Tank WC-20. Table 12 contains a summary of the T-1 Tank System line characteristics.

Table 12. Characteristics of Line Segments Evaluated as a Part of Tank System T-1

\begin{tabular}{|c|c|c|c|}
\hline \multicolumn{2}{|c|}{ Line Segment } & 81 & 57 \\
\hline \multicolumn{2}{|c|}{ Node Number } & 6 to 7 & 8 to 9 \\
\hline \multicolumn{2}{|c|}{ Index Number } & $*$ & $*$ \\
\hline \multicolumn{2}{|c|}{ Diameter (in) } & 4 & 2 \\
\hline \multicolumn{2}{|c|}{ Material } & 304L SS & 304L SS \\
\hline \multicolumn{2}{|c|}{ Length (ft) } & 28 & 65 \\
\hline \multicolumn{2}{|c|}{ Volume (gal) } & 18 & 11 \\
\hline \multicolumn{2}{|c|}{ Transfer Method } & $\mathrm{CP}$ and $\mathrm{SJ}$ & CP Suct. \\
\hline \multicolumn{2}{|c|}{ Install Date } & 1963 & 1963 \\
\hline $\begin{array}{l}* \\
\text { CP } \\
\text { SJ } \\
\text { SS } \\
\text { Suct. }\end{array}$ & \multicolumn{3}{|c|}{$\begin{array}{l}\text { Transfer records availab } \\
\text { Centrifugal Pump } \\
\text { Steam Jet Pump } \\
\text { Stainless Steel } \\
\text { Suction }\end{array}$} \\
\hline
\end{tabular}

\subsubsection{Corrosion Assessment of the T-1 Tank System}

Since 1976, Tank T-1 has collected only waste from the HFIR tank, which may include small amounts of liquids from filter pits (rain water). Consequently, the environment in Tank T-1 is essentially the same as in the HFIR Tank: sodium nitrate, sodium hydroxide, traces of radionuclides and a few resin fines, with a pH of about 13. Prior to 1976, Tank T-1 also collected alkaline waste from the Transuranium Processing Facility, but in 1976 Tank WC-20 was placed in service and since then all transuranic wastes have been collected in that tank. All indications are that the liquid environment in Tank T-1 has always been alkaline, and if true, corrosion damage to the interior of the tank should not be very significant. 
Tank T-1 and most of its associated piping are buried directly in soil. As with other tank systems, stainless steel would be expected to have reasonably good corrosion resistance to soil at ORNL. This system has been underground only since 1963 , whereas other stainless steel tanks have been buried in similar soil since 1951 without evidence of leakage.

\subsubsection{Results of Leak Tests on the T-1 System}

This section summarizes the results of the leak detection tests conducted on Tank System T-1 (the tank and its associated pipelines). Each element in the system was tested with a method appropriate for that element. Each method used has been demonstrated to detect a specified leak rate $(0.2 \mathrm{gal} / \mathrm{hr}$ for tank methods; $0.1 \mathrm{gal} / \mathrm{hr}$ for pipeline methods) with a PD no less than $95 \%$ and a PFa no greater than $5 \%$.

\subsubsection{Tanks}

Leak testing of Tank T-1 for this assessment period began in February 1995 and continued at monthly intervals through December 1995, with a total of 14 leak test attempts on the tank during this reporting period. The results of these tests are summarized in Table 13, which shows the date of each test, the volume of LLLW in the tank at the time of the test, the percent of Tank T-1's total volume the test represented, the test result, and comments pertinent to particular tests. The table shows that Tank T-1 recorded PASS results for nine of the 14 leak tests, with INCONCLUSIVE results comprising the remainder of the tests. The reasons for the inconclusive results include spurious noise and two protocol errors. These errors were a "blowdown" that was performed during a test period, and a transfer that occurred during a test period. The maximum volume for which the tank passed the leak testing during this reporting period was 3,612 gallons, or $24 \%$ of the total capacity. This is less than the previously certified level of 8,258 gallons (55\%) for this tank [DOE/OR/01-1385\&D2].

Table 13. Summary of Leak Tests Conducted on Tank T-1

\begin{tabular}{|c|c|c|c|c|c|}
\hline Date & f of Gallons & \% Capacity & Test Result & Comment \\
\hline $02 / 03 / 95$ & 3,962 & 26 & INCONCLUSIVE & spurious noise \\
\hline $02 / 17 / 95$ & 3,441 & 23 & INCONCLUSIVE & spurious noise \\
\hline $03 / 03 / 95$ & 3,361 & 22 & PASS & \\
\hline $04 / 07 / 95$ & 3,448 & 23 & INCONCLUSIVE & noise \\
\hline $04 / 28 / 95$ & 3,493 & 23 & PASS & \\
\hline $05 / 05 / 95$ & 3,443 & 23 & INCONCLUSIVE & "blowdown" during test \\
\hline $06 / 02 / 95$ & 3,359 & 22 & PASS & \\
\hline $07 / 07 / 95$ & 3,553 & 24 & PASS & \\
\hline $08 / 04 / 95$ & 3,419 & 23 & PASS & \\
\hline $09 / 01 / 95$ & 3,459 & 23 & PASS & \\
\hline $10 / 06 / 95$ & 3,427 & 23 & PASS & \\
\hline $11 / 03 / 95$ & 3,612 & 24 & PASS & \\
\hline $12 / 01 / 95$ & 3,138 & 21 & INCONCLUSIVE & transfer during test \\
\hline $12 / 15 / 95$ & 3,094 & 21 & PASS & \\
\hline
\end{tabular}


The nine usable CVR data values from these leak tests were analyzed (1) to verify that the test method was performing properly in this application and (2) to confirm that during this assessment period the leak testing process had remained nominal; that is, that performance of the method as applied to this particular tank was not deteriorating. This analysis included a statistical examination of the CVR data, as well as a comparison of this year's assessment data with prior data. The analysis and the results are described in Section 7.3.4.3.

\subsubsection{T-1 Pipelines}

There are two pipelines associated with the T-1 tank system: Line Segments 81 and 57. Neither of these lines can be leak tested. Line Segment 81 cannot be tested because it is not accessible, and Line Segment 57 cannot be tested because there is no isolation valve at the tank end of the line. An assessment of the integrity of these lines based upon transfer records is summarized in Section 7.3.4.2.2.

\subsection{T-1 Testable Pipelines}

There are no testable pipelines in the T-1 tank system.

\subsection{T-1 Untestable Pipelines}

The untestable portion of the T-1 tank system (Line Segments 81 and 57) consists of the inlet line connecting the HFIR/WC-20 Diversion Box with Tank T-1, and the suction pipeline between Tank T-1 and the Building 7567 Pump House. The untestable inlet line is a part of the transfer line from the HFIR tank to Tank T-1; the volume in both of these tanks is measured and recorded by Waste Operations Control Center (WOCC). The untestable suction line is a part of the T-1 tank to W-22 tank transfer line; the volume in W-22 tank is also measured and recorded by WOCC. Transfer logs show that during the period from January 1995 through December 1995 , three transfers were made from HFIR tank to T-1 tank and three transfers were made from T-1 tank to W-22 tank. Table 14 summarizes the transfers from HFIR tank to T-1 tank, and Table 15 summarizes those from T-1 tank to W-22 tank. The data from the transfer logs are shown in the first four columns of each table. The difference between the volume sent (Column 3 ) and the volume received (Column 4) for each transfer is shown in Column 5. For both the HFIR-to-T-1 and T-1-to-W-22 transfers, the expected errors are shown in Column 6.

Of the three recorded HFIR-to-T-1 transfers, only one shows an input/output volume difference greater than the maximum error expected for each transfer. Since this difference is negative, a measured loss of volume is indicated. However, as discussed in Section 7.3.4.2.2 for the HFIR Tank System, the suspected cause of the transfer difference is inaccuracy in the HFIR tank strapping table, which is used to convert liquid level in the tank to volume. 
Table 14. Summary of Transfers between HFIR Tank and T-1 Tank from January 1995 to December 1995

\begin{tabular}{|c|c|c|c|c|c|c|}
\hline Transfer & Transfer $10 \mathrm{~g}$ & $\begin{array}{l}\text { rolume } \\
\text { sent } \\
\left(\mathrm{Gall}^{\prime}\right.\end{array}$ & $\begin{array}{l}\text { rolume } \\
\text { recelved } \\
(\mathrm{Cal})\end{array}$ & Difference & $\begin{array}{l}\text { Yaximum } \\
\text { Expected } \\
\text { Error } \\
(\mathrm{Gal})\end{array}$ & $\begin{array}{l}\text { Is difference } \\
\text { greater fhan } \\
\text { expected } \\
\text { error? }\end{array}$ \\
\hline $1 / 13 / 95$ & HFIR to T-1 & 5188 & 4945 & -243 & 100 & Yes \\
\hline $2 / 8 / 95$ & HFIR to T-1 & 5079 & 5051 & -28 & 100 & No \\
\hline $12 / 2 / 95$ & HFIR to T-1 & 6930 & 6904 & -26 & 126 & No \\
\hline
\end{tabular}

Table 15. Summary of Transfers between T-1 Tank and W-22 Tank from January 1995 to December 1995

\begin{tabular}{|c|c|c|c|c|c|c|}
\hline Transfer & Transfer log & $\begin{array}{l}\text { Volume } \\
\text { Sent } \\
(\text { Gai) }\end{array}$ & $\begin{array}{l}\text { Yolums } \\
\text { Recerved }\end{array}$ & $\begin{array}{l}\text { Eifference } \\
\text { (Gall }\end{array}$ & $\begin{array}{l}\text { Maximum } \\
\text { Expected } \\
\text { Error } \\
\text { (Gai) }\end{array}$ & $\begin{array}{l}\text { Is difference } \\
\text { greater than } \\
\text { expected }\end{array}$ \\
\hline $1 / 13 / 95$ & T-1 to W-22 & 6552 & 7170 & 618 & 187 & Yes \\
\hline 2/9/95 & T-1 to W-22 & 5085 & 6037 & 952 & 173 & Yes \\
\hline $12 / 2 / 95$ & $T-1$ to $W-22$ & 7443 & 8380 & 937 & 201 & Yes \\
\hline
\end{tabular}

All three of the recorded T-1 tank to W-22 tank transfers (Table 15) show input/output volume differences greater than the maximum error expected. All differences were positive, indicating that more liquid was measured going into Tank W-22 than was measured leaving Tank T-1; these results suggest numerical errors in the volume balance, or unrecorded flush or prime water that was added to the system.

\subsubsection{Analysis of Tank T-1 Leak Test Data}

During this assessment period, a total of 14 leak tests were attempted on Tank T-1; of these, nine tests resulted in conclusive decisions. Figure 16 shows a time series plot of the CVR data obtained from each of the useable test results. It can be seen from the plot that all nine of the CVR values are within the INFLOW and OUTFLOW decision thresholds, and are thus consistent with the PASS results obtained from these tests. 


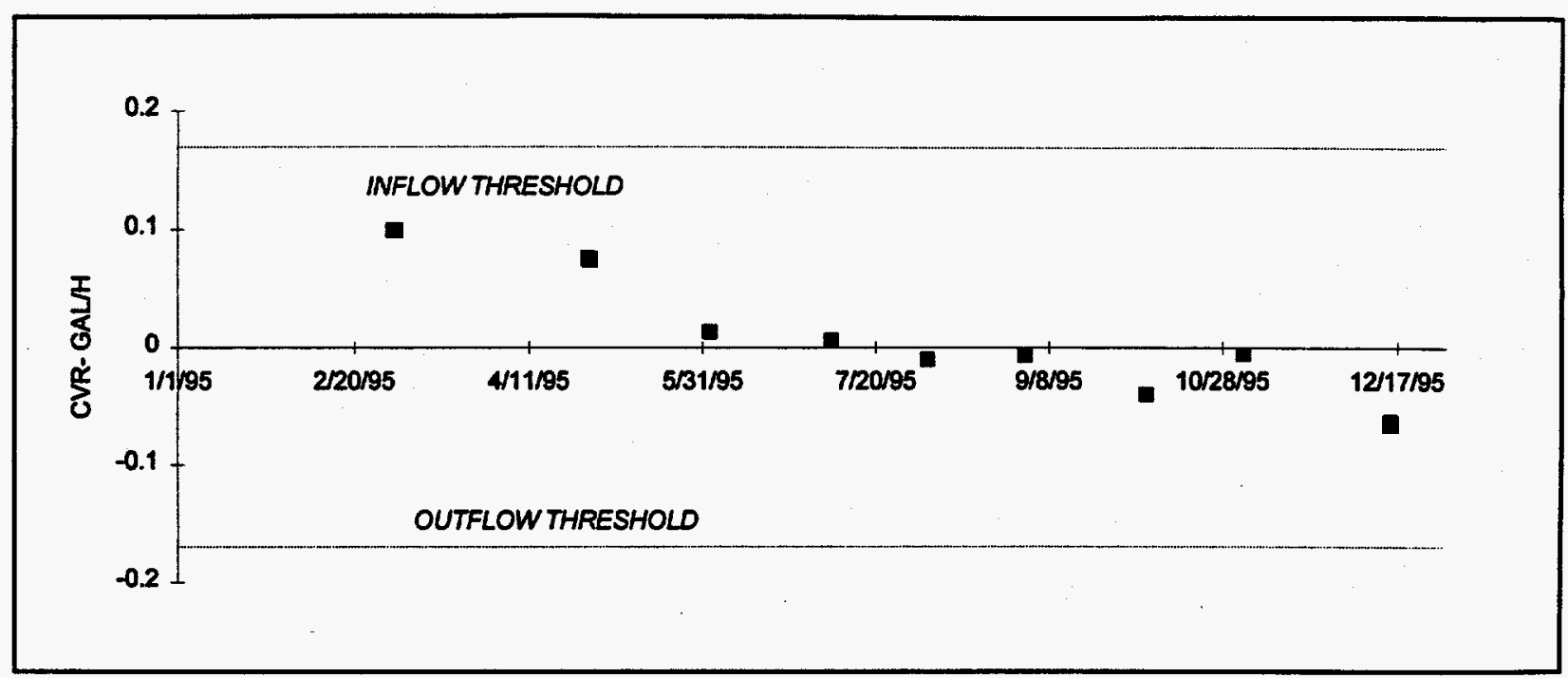

Figure 16. Time Series Plot of Leak Test CVRs from Tank T-1

A comparative analysis of the data shown in Figure 16 was performed. The analysis included using the Student's $t$ - [Mendenhall, 1992], and the K-S [Benjamin and Cornell, 1970] statistical tests. The Student's $t$-test is used to determine the significance of the mean of the CVR data. The K-S analysis is used to determine if the population of CVR values from T-1 tank is significantly different than a reference set of CVRs. These statistical tests are fully described in Section 5.4.

As shown below, applying the t-test to the nine data values shown above results in a tstatistic, $t_{\text {stat }}$ of 0.46 , while the critical value, $t_{\text {crit }}$ is 3.36 , for a $99 \%$ level of confidence. Applying the K-S "goodness-of-fit" test to the Tank T-1 CVR data, using a H/V weighted set of reference CVRs, results in a maximum ordinal difference, $\mathrm{KS}_{\text {stat }}$ of 0.25 , while the critical value, $\mathrm{KS}_{\text {crit, }}$ is 0.53 , for a $99 \%$ level of confidence. Based upon this analysis, we conclude that both the mean and the fluctuations of the CY95 CVR data from Tank T-1 CVR are entirely consistent with data expected from a non-leaking tank.

Figure 17 graphically illustrates the K-S test applied to the T-1 data. The bold solid line in the figure shows the CDF obtained from the CVR data shown in Figure 16, after removing the mean from the data. The light dashed line in the figure shows the CDF obtained from the reference set of CVR values (See Section 5.4), after removing the mean from that data and scaling those values by the $H / V$ coefficient of $T-1$ ( $164 \mathrm{gal} / \mathrm{in}$.), divided by the $\mathrm{H} / \mathrm{V}$ of the (mean-removed) reference set (14.72 gal/in.). 


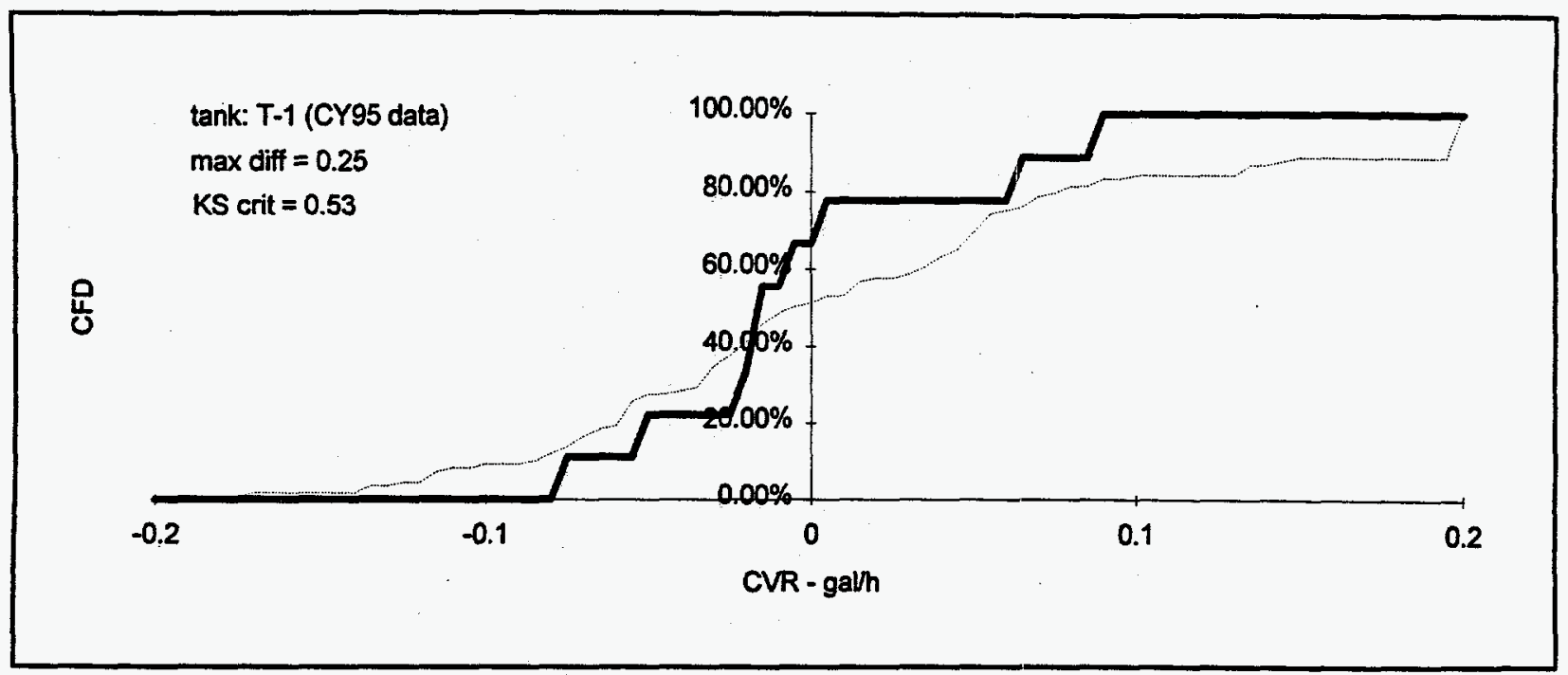

Figure 17. Cumulative frequency distributions from reference CVR data (light dashed line) and T-1 CVR data (CY95) (bold solid line).

The similarity of the data sets defined by the two lines illustrated in Figure 17 is "tested" with the $\mathrm{K}-\mathrm{S}$ "goodness-of-fit" test. Here, the test statistic, $\mathrm{KS}_{\text {stat, }}$ is 0.25 , while the critical value, $\mathrm{KS}_{\text {crit }}$ is 0.53 . Since the maximum ordinal difference, $\mathrm{KS}_{\text {stat }}$, is less than $\mathrm{KS}_{\text {crit }}$, the two populations are deemed to be equivalent.

Table 16 summarizes the statistical analyses of the Tank T-1 CVR data. The table shows that the mean of the CY95 test data is equivalent to zero $\mathrm{gal} / \mathrm{h}$, and that the population of the CY95 CVR values is not different than the population of CVR values in the reference, or comparison, data set.

Table 16. Summary of Statistical Analyses of T-1 CVR Data (H/V=164 gal/in)

\begin{tabular}{|c|c|c|}
\hline & Reference CVR data & '95 CVR data \\
\hline $\mathbf{N}$ & 118 & 9 \\
\hline Mean (gal/h) & 0.036 & 0.008 \\
\hline $\begin{array}{c}\text { Standard Deviation } \\
(\mathrm{gal} / \mathrm{h})\end{array}$ & 0.245 & 0.051 \\
\hline t-statistic & & 0.46 \\
\hline t-critical (1\%) & & 3.36 \\
\hline t-test Inference & & Same as zero mean \\
\hline KS-statistic & & 0.25 \\
\hline KS-critical (1\%) & & 0.53 \\
\hline KS-test Inference & & $\begin{array}{l}\text { Same population as } \\
\text { reference set }\end{array}$ \\
\hline
\end{tabular}




\subsubsection{Findings and Conclusions}

The findings of this report are based on (1) a review of available tank design drawings, (2) a qualitative assessment of corrosion on the tank and pipelines, and (3) leak testing results from the tank and testable pipelines.

Review of the design drawings indicated that the tank was designed in accordance with acceptable practices defined by ASTM and ASME. One concern noted was an abundance of inlets into the tank that were not connected to pipelines. However, because the unused inlets are located on the top of the tank, there is no concern that leakage could occur at those locations as long as the tank is operating at less than full capacity. The design drawings revealed a sound design of the T-1 Tank.

The corrosion assessment determined that, with the present use of the tank system, all forms of corrosion on the interior walls of the tank and associated piping should be nonexistent. Corrosion damage that may have occurred when the tank was used in past environments cannot be assessed. Furthermore, an analysis of the general aspects of corrosion at ORNL revealed that corrosion of stainless steel by ORNL soil is not believed to be severe.

Leak testing of Tank T-1 was completed by the Modified DP method in 14 tests. The tank passed nine tests and had inconclusive results in five tests.

The T-1 Tank System consists of two line segments, neither of which were testable by the current methods. Transfer logs were used to qualitatively assess the pipelines which are untestable by currently approved methods. These transfer logs reveal that three transfers were made between HFIR Tank and Tank T-1 and three transfers were made between Tank T-1 and Tank W-22. One of the transfers between HFIR Tank and Tank T-1 exceeded the maximum expected difference between the recorded volume sent and the recorded volume received. It is suspected that the cause of these recorded differences is due to inaccuracy in the strapping tables which are used to convert liquid levels in the tanks to volume. The three transfers between Tank T-1 and Tank W-22 also exceeded the expected difference. However, in each of the three transfers, the volume received was greater than the volume sent, indicating unrecorded prime or flush water was present. The volume of these transfers along with the latest qualitative assessment of the pipelines are reported to EPA and TDEC in the "Quarterly Highlight for LLLW Tank System Activities." Although a limited evaluation of the untestable pipelines can be made using transfer logs, this method of assessment, due to its limited accuracy, is not deemed valid for certification purposes.

All of these factors were considered in determining certification of the T-1 System components. Table 17 summarizes the elements of the tank systems which were certified and the conditional limits on their certifications. 
Table 17. Summary of T-1 Tank System Testing and Certification

\begin{tabular}{|c|c|c|c|c|c|c|c|}
\hline \multicolumn{2}{|c|}{ Systen } & length: & Tested & $\begin{array}{l}\text { Leak } \\
\text { Test } \\
\text { Method }\end{array}$ & Result & Certification & Certification \\
\hline \multicolumn{2}{|c|}{ Tank T-1 } & & Yes & MDP & PASS & Yes & $24 \%$ \\
\hline \multicolumn{2}{|l|}{ LS-57 } & 65 & No & $N / T^{*}$ & $\mathrm{~N} / \mathrm{T}$ & No & $\mathrm{N} / \mathrm{T}$ \\
\hline \multicolumn{2}{|l|}{ LS-81 } & 28 & No & $\mathrm{N} / \mathrm{T}^{*}$ & $\mathrm{~N} / \mathrm{T}$ & No & $\mathrm{N} / \mathrm{T}$ \\
\hline $\begin{array}{l}\text { LS } \\
\text { MDP } \\
\text { N/A } \\
\text { N/T }\end{array}$ & \multicolumn{7}{|c|}{$\begin{array}{l}\text { Transfer records available } \\
\text { Line segment } \\
\text { Modified Differential Pressure } \\
\text { Not applicable } \\
\text { Not testable }\end{array}$} \\
\hline
\end{tabular}




\subsubsection{Certification}

Based on the results of the design drawings review, the qualitative corrosion assessment and the results of the leak testing program, it is my professional opinion that Tank T-1 retains sufficient structural integrity to contain liquids at operating levels up to the maximum level which achieved a PASs during the testing program. Table 17 provides a summary description of the certifications for the T-1 Tank System. If future testing is conducted at greater tank levels, then certification levels may also increase.

It is recommended that leak detection be continued, to support annual certification, until this system has been removed from operation or replaced.

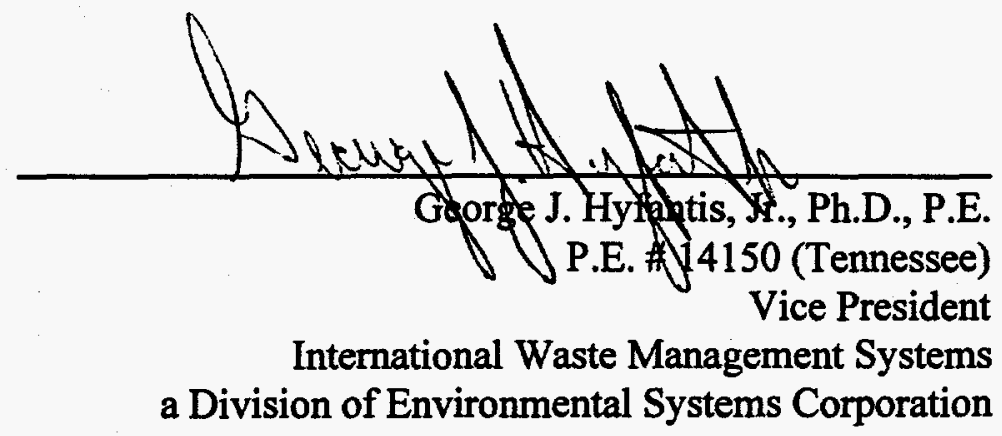





\subsection{T-2 Tank System}

The T-2 Tank System is located near Building 7567 as shown in Figure 1A. Tank System T-2 collects Melton Valley LLLW prior to transferring it to the Evaporator Complex in Bethel Valley. The T-2 Tank System is made up of Tank T-2 and two pipeline segments connected to the system. Because the lines and tank are all singly contained, the tank system has been classified as Category $\mathrm{C}$, according to the FFA.

\subsubsection{T-2 Tank Description}

Tank T-2 is a 15,000 gallon, buried, singly contained tank. Installed in $1963, T-2$ is mounted horizontally on two reinforced concrete $3^{\prime}-6^{\prime \prime}$ pillars, anchored to $12^{\prime}-0^{\prime \prime}$ × $7^{\prime}-0^{\prime \prime}$ x $2^{\prime}-0^{\prime \prime}$ footings. Tank T-2 has a 3-1/4" x 1/4" 304L stainless steel strap over the top bolted to a 1-1/4" diameter 304L stainless steel anchor cast into the concrete supports. The tank is constructed of $304 \mathrm{~L}$ stainless steel and has a wall thickness of 1/4" with ASME standard 3/8" thick 304L stainless steel flanged dished heads. The outside diameter of the tank is $10^{\prime}-0^{\prime \prime}$ with a total length of $27^{\prime}-5^{\prime \prime}$. The design drawings for T-2 tank are given as Figure 18 and Figure 18A.

The tank is equipped with nine 2 " diameter Schedule 40 NS stainless steel welded nozzles, two 1" diameter Schedule 40 NS stainless steel welded nozzles, one 4" diameter Schedule 40 NS stainless steel welded nozzle, and one 18" diameter manhole. All measurements are on centers of the nozzle or the manhole. All materials, fabrication, welding, and inspection are in accordance with ORNL specification XSP-56.

Tank T-2 is contained in an earthen pit, along with Tank T-1. The pit has bottom dimensions of 34'-0" $\times 29^{\prime}-0^{\prime \prime}$. The long axes of the tanks are parallel to the shorter bottom dimension of the pit. The tanks are separated by a reinforced concrete wall 37'-0" $\times 9^{\prime}-0^{\prime \prime} \times 1^{\prime}-0^{\prime \prime}$ supported on a continuous $3^{\prime}-0^{\prime}$ x $1^{\prime}-0^{\prime \prime}$ footing. On either side of the concrete dividing wall and supported by the wall footing is a dry well constructed of a 12" diameter vitrified clay pipe extending vertically to the surface. The pit is backfilled with 1 " diameter gravel to the centerline of the tanks. A layer of polyethylene covers the gravel, with the remaining pit volume backfilled with earth to an elevation of $6^{\prime}-6^{\prime \prime}$ above the top of the tanks.

Tank T-2 has only one inlet line and one outlet line. Tank T-2 is capable of receiving material from one source, the HFIR Tank. The liquids generated in Building 7900 are transferred directly into the tank identified as HFIR. LLLW is transferred from the HFIR Tank to Tank T-2 prior to being transferred to the Evaporator Complex in Bethel Valley. A schematic of the tank system with numbered line segments is shown in Figure 19. 


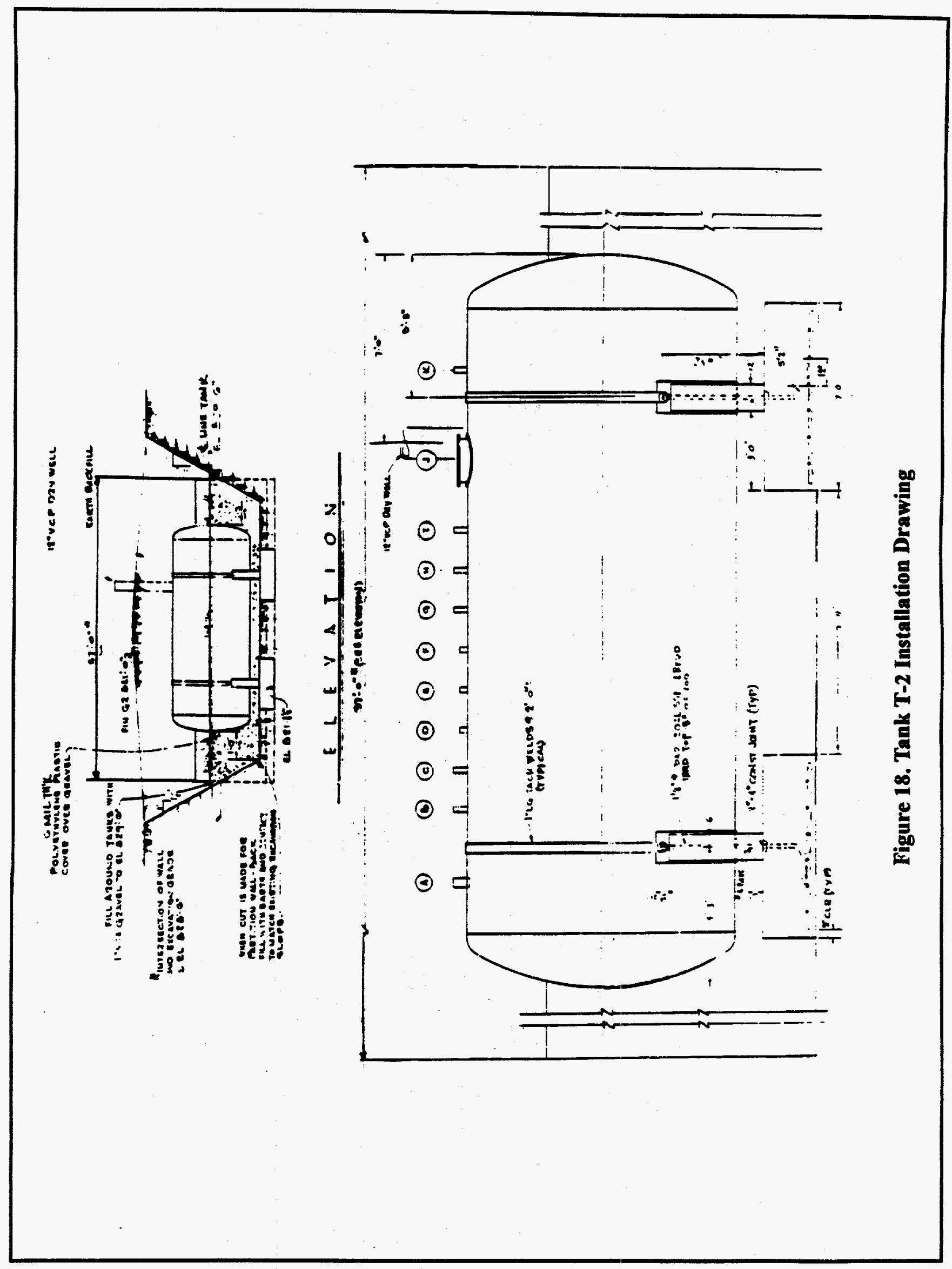




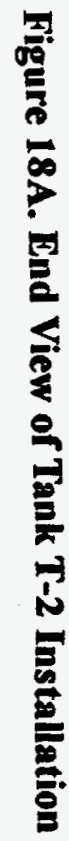
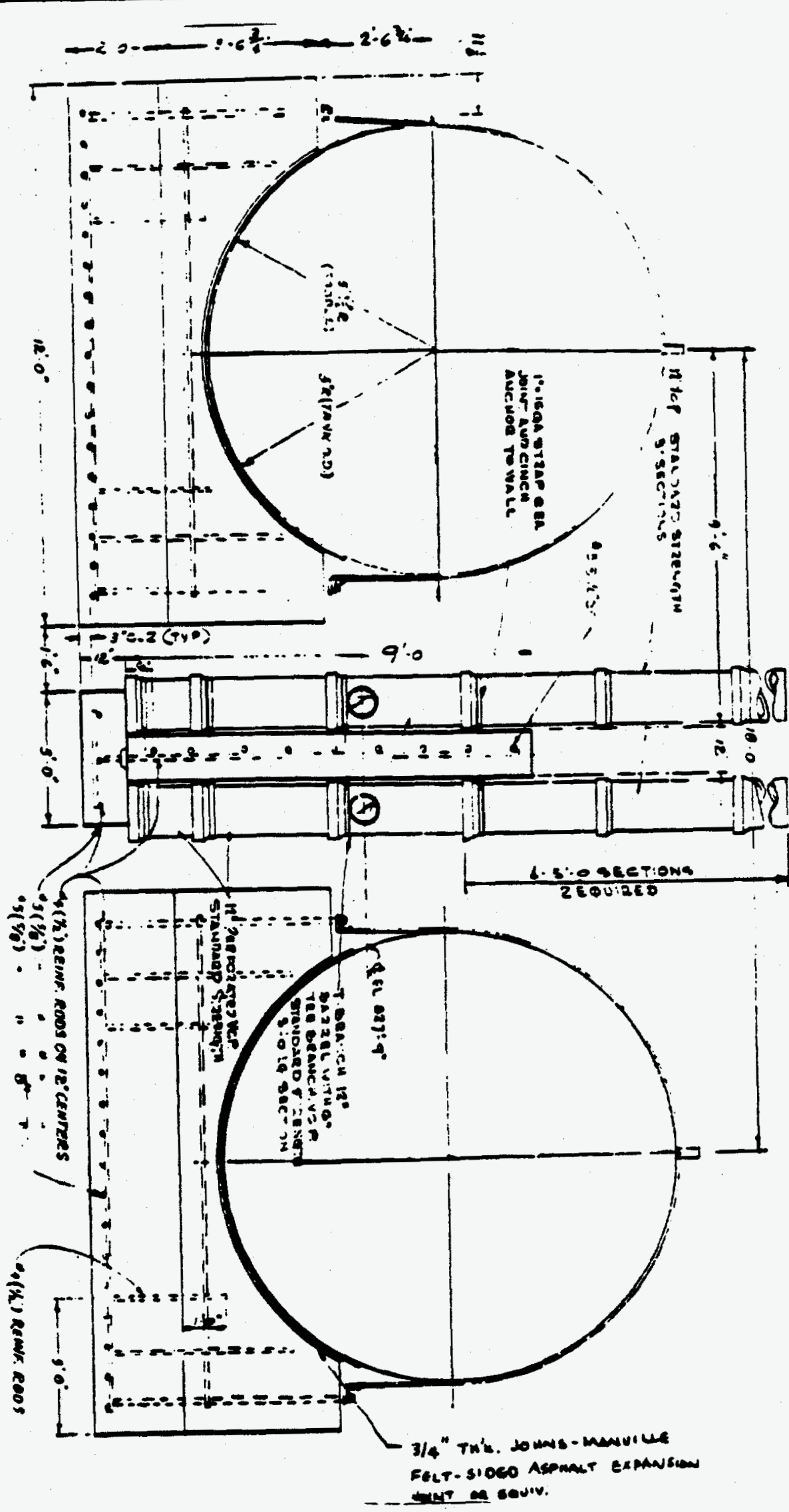

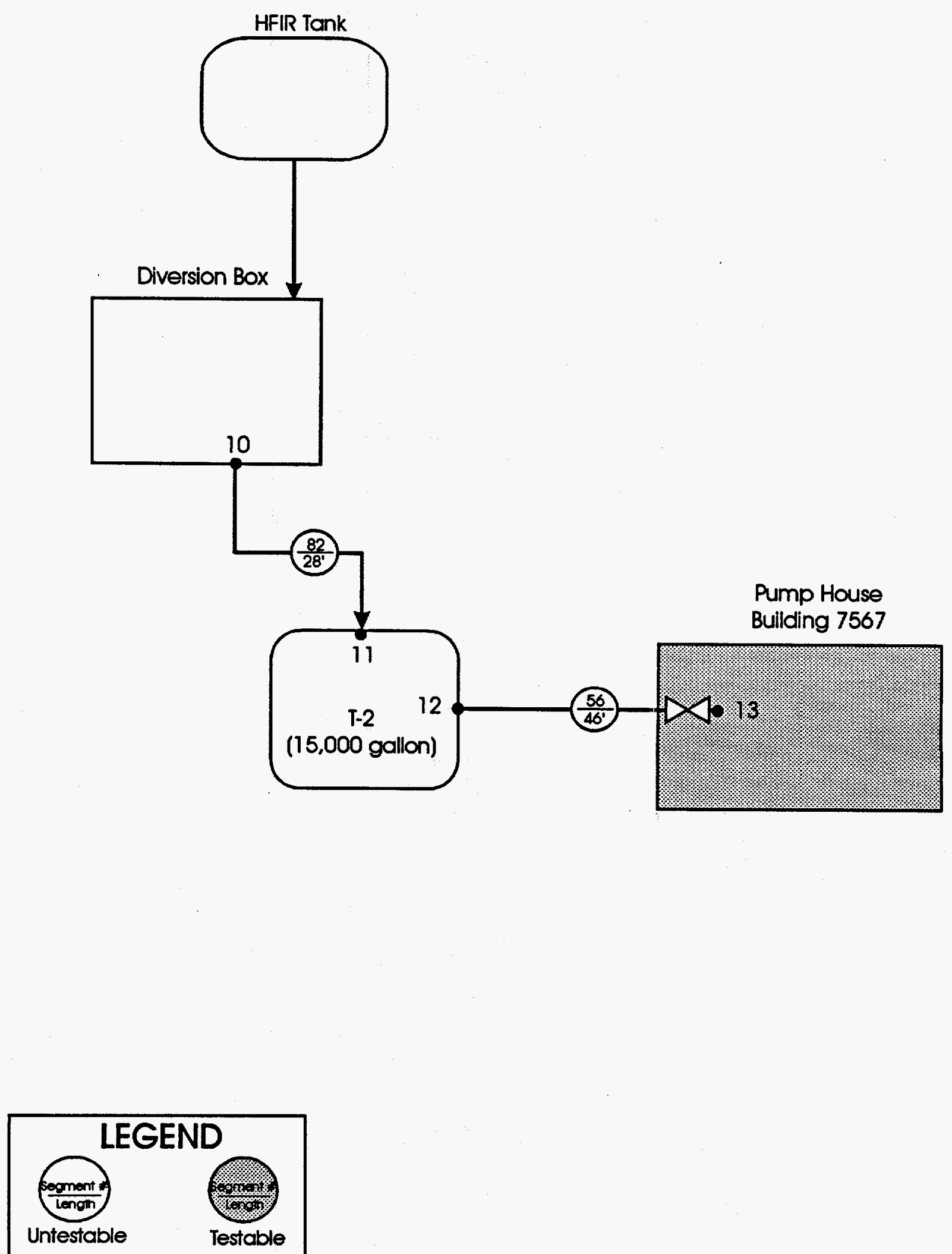

2 - Node Number

Figure 19. T-2 Tank System 


\subsubsection{T-2 Pipeline Descriptions}

The T-2 System has two pipeline segments. One segment is a $28^{\prime}$ long, 4" diameter, 304L stainless steel section of piping connecting the T1/T2 Diversion Box with Tank T-2. This line is identified as Line Segment 82 (node 10 to node 11 in Figure 20). The second segment is a singly contained suction pipeline between Tank T-2 and the Building 7567 Pump House. This line, index number 56 (node 12 to node 13), is 46' long, has a 2" diameter, and is made of 304L SS. Both of these lines are used regularly, with transfers through the diversion box piping to T2 tank and subsequent flow through the suction piping to the Building 7567 Transfer Pumps. The transfer line from the HFIR tank to the diversion box is tested and covered in the structural integrity assessment for the HFIR tank. The main segment of the transfer line from Building 7567 Pump House to the Evaporator Complex is tested and covered in the structural integrity assessment for Tank WC-20. Table 18 contains a summary of the T-2 Tank System line characteristics.

Table 18. Characteristics of Line Segments Evaluated as a Part of Tank System T-2

\begin{tabular}{|c|c|c|c|}
\hline \multicolumn{2}{|c|}{ Line Segment } & 56 & 82 \\
\hline \multicolumn{2}{|c|}{ Node Numbers } & 12 to 13 & 10 to 11 \\
\hline \multicolumn{2}{|c|}{ Index Number } & * & $*$ \\
\hline \multicolumn{2}{|c|}{ Diameter (in) } & 2 & 4 \\
\hline \multicolumn{2}{|c|}{ Material } & 304L SS & 304L SS \\
\hline \multicolumn{2}{|c|}{ Length (ft) } & 46 & 28 \\
\hline \multicolumn{2}{|c|}{ Volume (gal) } & 8 & 18 \\
\hline \multicolumn{2}{|c|}{ Transfer Method } & CP Suct. & $\mathrm{CP}$ and $\mathrm{SJ}$ \\
\hline \multicolumn{2}{|c|}{ Install Date } & 1963 & 1963 \\
\hline \multicolumn{4}{|c|}{$\begin{array}{ll}* & \text { Transfer records available } \\
\text { CP } & \text { Centrifugal Pump } \\
\text { SJ } & \text { Steam Jet Pump } \\
\text { SS } & \text { Stainless Steel } \\
\text { Suct. } & \text { Suction } \\
\end{array}$} \\
\hline
\end{tabular}

\subsubsection{Corrosion Assessment of the T-2 Tank System}

Since 1976, Tank T-2 has collected only waste from the HFIR Tank, which may include small amounts of liquids from filter pits (rain water). Consequently, the environment in Tank T-2 is essentially the same as in the HFIR Tank: sodium nitrate, sodium hydroxide, traces of radionuclides and a few resin fines, with a pH of about 13. Prior to 1976, Tank T-2 also collected alkaline waste from the Transuranium Processing Facility, but in 1976, Tank WC-20 was placed in service and since then all transuranic wastes have been collected in that tank. All indications are that the liquid environment in Tank T-2 has always been alkaline, and if true, corrosion damage to the interior of the tank should not be very significant. 
Tank T-2 and most of its associated piping are buried directly in soil. As with other tank systems, stainless steel would be expected to have reasonably good corrosion resistance to soil at ORNL. This system has been underground only since 1963, whereas other stainless steel tanks have been buried in similar soil since 1951 without evidence of leakage.

\subsubsection{Results of Leak Tests on the T-2 System}

This section summarizes the results of the leak detection tests conducted on Tank System T-2 (the tank and its associated pipelines). Each element in the system was tested with a method appropriate for that element. Each method used has been demonstrated to detect a specified leak rate $(0.2 \mathrm{gal} / \mathrm{hr}$ for tank methods; $0.1 \mathrm{gal} / \mathrm{hr}$ for pipeline methods) with a PD no less than $95 \%$ and a PFA no greater than $5 \%$.

\subsubsection{T-2 Tank}

Leak testing of Tank T-2 for the current assessment period began in February 1995 and continued at routine intervals through December 1995, with a total of 15 leak test attempts on the tank during this reporting period. The results of these tests are summarized in Table 19, which shows the date of each test, the volume of LLLW in the tank at the time of the test, the percent of Tank T-2's total volume the test represented, the test results, and comments pertinent to particular tests. The table shows that Tank T-2 recorded PASS results for 11 of the 15 leak tests, with INCONCLUSIVE results for the remaining four tests. The reasons for the inconclusive results include spurious noise, missing data in the WOCC record, and a protocol error caused by a transfer that occurred during the test period. The maximum volume for which the tank passed the leak testing during this reporting period was 4,908 gallons, or $33 \%$ of the total capacity. This is less than the previously certified level of 7,084 gallons (47\%) for this tank [DOE/OR-011385\&D2].

Table 19. Summary of Leak Tests Conducted on Tank T-2

\begin{tabular}{|c|c|c|c|c|}
\hline Date & 4 of Gallors & $\%$ Capacity & Testresults & Conment \\
\hline $02 / 03 / 95$ & 3,803 & N/A & INCONCLUSIVE & spurious noise \\
\hline $02 / 17 / 95$ & 4,834 & N/A & INCONCLUSIVE & spurious noise \\
\hline $03 / 03 / 95$ & 4,908 & 33 & PASS & \\
\hline $04 / 07 / 95$ & 3,398 & 23 & PASS & \\
\hline $04 / 21 / 95$ & 3,215 & 21 & PASS & noise \\
\hline $05 / 05 / 95$ & 3,343 & 22 & PASS & "blowdown" during test \\
\hline $06 / 02 / 95$ & 3,365 & 22 & PASS & . \\
\hline $07 / 07 / 95$ & 3,437 & 23 & PASS & \\
\hline $08 / 04 / 95$ & 4,282 & 28 & PASS & \\
\hline $09 / 01 / 95$ & 3,305 & $22^{\prime}$ & PASS & \\
\hline
\end{tabular}




\begin{tabular}{||c|c|c|c|c|}
\hline Date & \# of Gallons & \% Capacity & Test Results . & ( I Comment \\
\hline $10 / 06 / 95$ & 4,165 & 28 & PASS & \\
\hline $11 / 03 / 95$ & 3,122 & N/A & INCONCLUSIVE & missing WOCC data \\
\hline $11 / 17 / 95$ & 2,880 & 19 & PASS & \\
\hline $12 / 01 / 95$ & 3,170 & N/A & INCONCLUSIVE & transfer during test \\
\hline $12 / 15 / 95$ & 3,279 & 22 & PASS & \\
\hline
\end{tabular}

The 11 usable CVR data values from these leak tests were analyzed (1) to verify that the test method was performing properly in this application and (2) to confirm that during this assessment period the leak testing process had remained nominal; that is, the performance of the method as applied to this particular tank was not deteriorating. This analysis included a statistical examination of the CVR data, as well as a comparison of this year's assessment data with prior data. The analysis and the results are described in Section 7.4.4.3.

\subsubsection{T-2 Pipelines}

There are two pipelines associated with the T-2 Tank System: Line Segments 82 and 56. Neither of these lines can be leak tested. As assessment of the integrity of these lines based upon transfer records is summarized in Section 7.4.2.2.

\subsection{Untestable Pipelines}

The untestable portion of the T-2 Tank System (Line Segments 82 and 56) consists of the inlet line connecting the HFIR Diversion Box with Tank T-2, and the suction pipeline between Tank T-2 and the Building 7567 Pump House. The untestable inlet line is a part of the transfer line from the HFIR tank to Tank T-2; the volume in both of these tanks is measured and recorded by WOCC. The untestable suction line is a part of the Tank T-2 to Tank W-22 transfer line; the volume in Tank W-22 is also measured and recorded by WOCC. Transfer logs show that during the period from January 1995 through December 1995, nine transfers were made from HFIR Tank to Tank T-2 and eleven transfers were made from Tank T-2 to Tank W-22. Table 20 summarizes the transfers from HFIR Tank to Tank T-2, and Table 21 summarizes those from Tank T-2 to Tank W-22. The data from the transfer logs are shown the first four columns of each table. The difference between the volume sent (column 3) and the volume received (column 4) for each transfer is shown is Column 5. For both the HFIR tank-to-T-2 tank and T-2 tank to W-22 tank transfers, the expected errors are shown in Column 6. 
Table 20. Summary of Transfers between HFIR Tank and T-2 Tank from January 1995 to December 1995

\begin{tabular}{|c|c|c|c|c|c|c|}
\hline Transfer & Transferlog. & $\begin{array}{l}\text { Volume } \\
\text { Sent } \\
\text { (Gal) }\end{array}$ & $\begin{array}{l}\text { Yolune } \\
\text { Recelved } \\
(\mathrm{Gal})\end{array}$ & Difference & $\begin{array}{l}\text { Maximum } \\
\text { Expected } \\
\text { Error } \\
(\mathrm{Gal})\end{array}$ & $\begin{array}{l}\text { Is difference } \\
\text { greater than } \\
\text { expected } \\
\text { enror? }\end{array}$ \\
\hline $01 / 13 / 95$ & HFIR to T-2 & 665 & 665 & 0 & 58 & No \\
\hline $03 / 17 / 95$ & HFIR to T-2 & 5451 & 4906 & -545 & 102 & Yes \\
\hline $04 / 24 / 95$ & HFIR to T-2 & 2517 & 2438 & -79 & 70 & Yes \\
\hline $05 / 30 / 95$ & HFIR to T-2 & 4669 & 4569 & -100 & 94 & Yes \\
\hline $07 / 21 / 95$ & HFIR to T-2 & 4558 & 4352 & -206 & 92 & Yes \\
\hline $08 / 21 / 95$ & HFIR to T-2 & 3420 & 3356 & -64 & 79 & No \\
\hline $09 / 01 / 95$ & HFIR to T-2 & 4088 & 3835 & -253 & 86 & Yes \\
\hline $11 / 07 / 95$ & HFIR to T-2 & 5318 & 5295 & -23 & 103 & No \\
\hline $12 / 01 / 95$ & HFIR to T-2 & 5055 & 5274 & 219 & 101 & Yes \\
\hline
\end{tabular}

Table 21. Summary of Transfers between T-2 Tank and W-22 Tank from January 1995 to December 1995

\begin{tabular}{|c|c|c|c|c|c|c|}
\hline Transfer & Transfer $10 \mathrm{~g}$. & $\begin{array}{l}\text { Volume } \\
\text { Sent }(\text { Gall. }\end{array}$ & $\begin{array}{l}\text { volume } \\
\text { received } \\
(\text { Gan) }\end{array}$ & Difference & $\begin{array}{l}\text { Maximuni } \\
\text { Expected } \\
\text { Error } \\
\text { (Ga) }\end{array}$ & $\begin{array}{l}\text { is difference } \\
\text { greater than } \\
\text { expected } \\
\text { errot? }\end{array}$ \\
\hline $01 / 14 / 95$ & $\mathrm{~T}-2$ to $\mathrm{W}-22$ & 2102 & 2500 & 398 & 147 & Yes \\
\hline $03 / 18 / 95$ & $T-2$ to $W-22$ & 6951 & 8190 & 1239 & 197 & See Note 1 \\
\hline $04 / 25 / 95$ & $T-2$ to $W-22$ & 2968 & 2845 & -123 & 150 & No \\
\hline $05 / 31 / 95$ & $T-2$ to $W-22$ & 1200 & 1200 & 0 & 142 & No \\
\hline $05 / 31 / 95$ & $T-2$ to $W-22$ & 5126 & 5210 & 84 & 168 & No \\
\hline $07 / 23 / 95$ & $\mathrm{~T}-2$ to $\mathrm{W}-22$ & 4133 & 5756 & 1623 & 168 & See Note 2 \\
\hline $09 / 02 / 95$ & $T-2$ to $W-22$ & 671 & 671 & 0 & 141 & No \\
\hline $09 / 02 / 95$ & $\mathrm{~T}-2$ to $\mathrm{W}-22$ & 8589 & 8589 & 0 & 208 & No \\
\hline $11 / 11 / 95$ & $\mathrm{~T}-2$ to $\mathrm{W}-22$ & 1140 & 1140 & 0 & 142 & No \\
\hline $11 / 11 / 95$ & $\mathrm{~T}-2$ to $\mathrm{W}-22$ & 8030 & 9802 & 1772 & 216 & Yes \\
\hline $12 / 02 / 95$ & $\mathrm{~T}-2$ to $\mathrm{W}-22$ & 5247 & 5550 & 303 & 171 & Yes \\
\hline
\end{tabular}

Note 1) 1300 gallons of flush alloys transferred

Note 2) 1623 gallons rinse 
Of the nine recorded HFIR Tank to Tank T-2 transfers, six show an input/output volume difference greater than the maximum error expected for each transfer. Since all but one of these differences are negative, a measured loss of volume is indicated. However, as discussed in Section 7.4.4.2.2 for the HFIR Tank System, the suspected cause of the transfer difference is inaccuracy in the HFIR Tank strapping table, which is used to convert liquid level in the tank to volume.

Five of the eleven recorded Tank T-2 to Tank W-22 transfers (Table 21) show input/output volume differences greater than the maximum error expected. All differences were positive, indicating that more liquid was measured going into Tank W-22 than was measured leaving Tank T-2; these results suggest numerical errors in the volume balance, or unrecorded flush or prime water that was added to the system.

\subsubsection{Analysis of Tank T-2 Leak Test Data}

During this assessment period, a total of 15 leak tests were attempted on Tank T-2; of these, 11 tests resulted in conclusive results. Figure 20 shows a time series plot of the CVR data obtained from each of the useable test results. It can be seen from the plot that all 11 of the CVR values are within the INFLOW and OUTFLOW decision thresholds, and are thus consistent with the PASS results obtained from these tests.

A comparative analysis of the data show in Figure 20 was performed. The analysis included using the Student's $t$ - [Mendenhall, 1992], and the K-S [Benjamin and Cornell, 1970] statistical tests. The Student's $t$-test is used to determine the significance of the mean of the CVR data. The K-S analysis is used to determine if the population of CVR values from T-2 is significantly different than a reference set of CVRs. These statistical tests are fully described in Section 5.4.

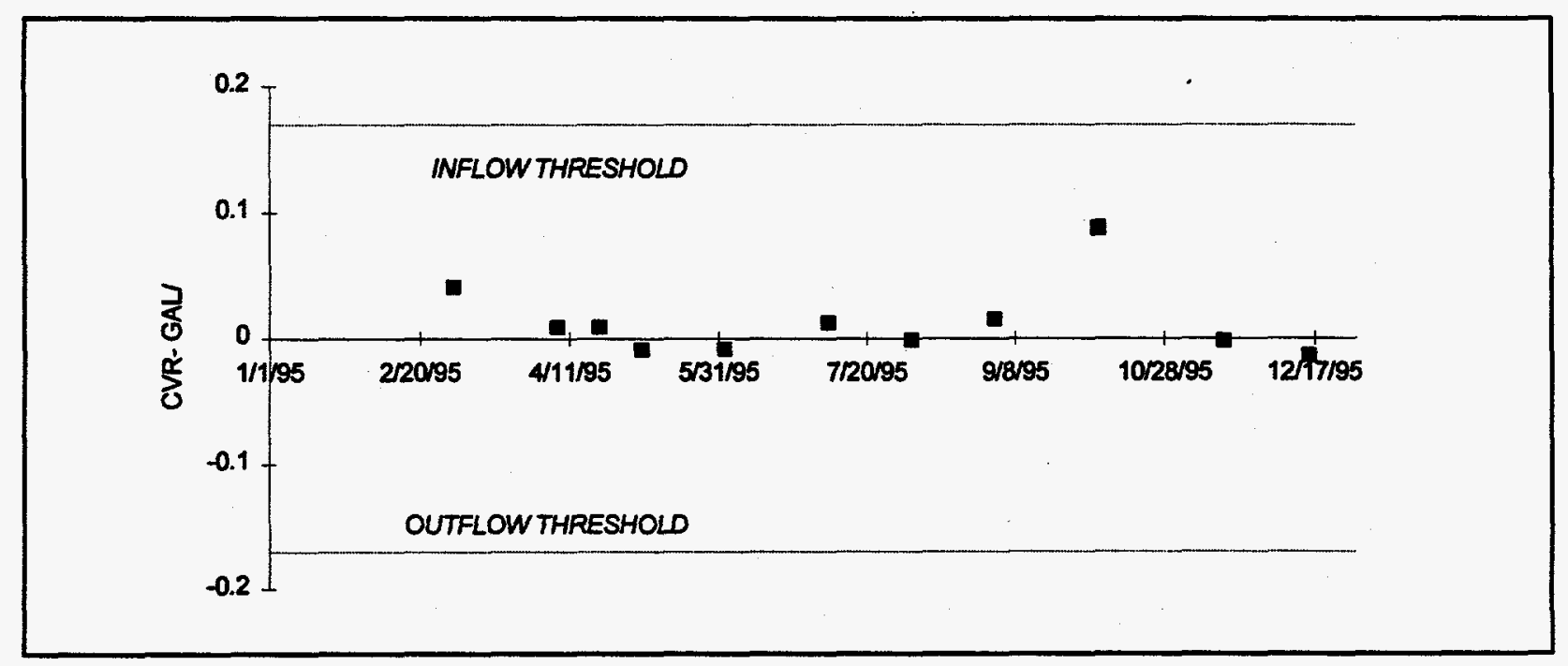

Figure 20. Time Series Plot of Leak Test CVRs from Tank T-2 
As shown below, applying the t-test to the 11 data values shown above results in a tstatistic, $t_{\text {stat }}$ of 1.44 , while the critical value, $t_{\text {crit }}$ is 3.17 , for a $99 \%$ level of confidence. Applying the K-S "goodness-of-fit" test to the T-2 CVR data, using a H/V weighted set of reference CVRs, results in a maximum ordinal difference, $\mathrm{KS}_{\text {stat }}$ of 0.33 , while the critical value, $\mathrm{KS}_{\text {crit }}$ is 0.49 , for a $99 \%$ level of confidence. Based upon this analysis, we conclude that both the mean and fluctuations of the 1995 CVR data from Tank T-2 are entirely consistent with data from a non-leaking tank.

Figure 21 graphically illustrates the K-S test applies to the T-2 data. The bold solid line in the figure show the CDF obtained from the CVR data shown in Figure 21, after removing the mean from the data. The light dashed line in the figure shows the CDF obtained from the reference set of CVR values (See Section 5.4), after removing the mean from that data set and scaling those values by the H/N coefficient of T-2 tank (164 gal/in.), divided by the $\mathrm{H} / \mathrm{V}$ of the (mean-removed) reference set (14.72 gal/in.).

The similarity of the data set defined by the two lines illustrated in Figure 21 is "tested" with the K-S "goodness-of-fit" test. Here the test statistic, $\mathrm{KS}$ stut is 0.33 , while the critical value, $\mathrm{KS}_{\text {crit, }}$, is 0.49 . Since the maximum ordinal difference, $\mathrm{KS}_{\text {stat, }}$ is less than $\mathrm{KS}_{\text {crit, }}$, the two populations are deemed to be equivalent.

Table 22 summarizes the statistical analysis of the Tank T-2 CVR data. The table shows that the mean of the CY95 test data is equivalent to zero $\mathrm{gal} / \mathrm{h}$, and that the population of the CY95 CVR values is not different than the population of CVR values in the reference, or comparison, data set.

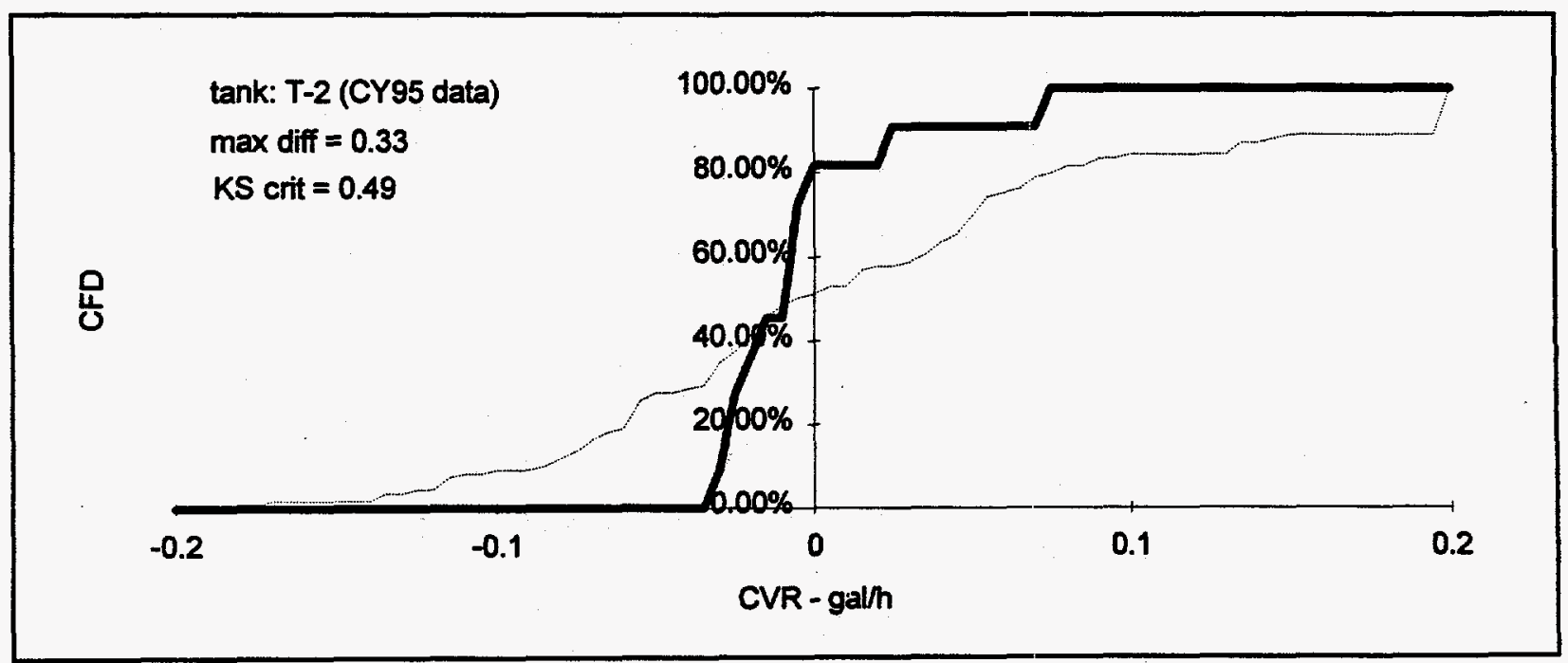

Figure 21. Cumulative frequency distributions from reference CVR data (light dashed line) and T-2 CVR data (CY95) (bold solid line). 
Table 22. Summary of Statistical Analyses of T-2 CVR Data (H/V=164 gal/in)

\begin{tabular}{|c|c|c|}
\hline & Reference CVR data & '95 CVR data \\
\hline $\mathbf{N}$ & 118 & 11 \\
\hline Mean (gal/h) & 0.036 & 0.013 \\
\hline $\begin{array}{c}\text { Standard Deviation } \\
(\mathrm{gal} / \mathrm{h})\end{array}$ & 0.245 & 0.029 \\
\hline t-statistic & & 1.44 \\
\hline t-critical (1\%) & & 3.17 \\
\hline t-test Inference & . & Same as zero mean \\
\hline KS-statistic & & 0.33 \\
\hline KS-critical (1\%) & & 0.49 \\
\hline KS-test Inference & & $\begin{array}{c}\text { Same population as } \\
\text { reference set }\end{array}$ \\
\hline
\end{tabular}

\subsubsection{Findings and Conclusions}

The findings of this report are based on (1) a review of available tank design drawings, (2) a qualitative assessment of corrosion on the tank and pipelines, and (3) leak testing results from the tank and testable pipelines.

Review of the design drawings indicated that the tank was designed in accordance with acceptable practices defined by ASTM and ASME. One concern noted was an abundance of nozzles into the tank which were not connected to pipelines. However, because the unused nozzles are located on the top of the tank, there is no concern that leakage could occur at those locations as long as the tank is operating at less than full capacity. The design drawings revealed a sound design of the T-2 tank.

During the corrosion assessment it was determined that with the present use of the tank system, all forms of corrosion on the interior walls of the tank and associated piping should be nonexistent. Corrosion damage that may have occurred when the tank was used in past environments cannot be assessed. Furthermore, an analysis of the general aspects of corrosion at ORNL revealed that corrosion of stainless steel by ORNL soil is not believed to be severe.

Leak testing of Tank T-2 was completed by the Modified DP method in 15 tests. The tank had a PASS results for eleven of the tests and had INCONCLUSIVE results in four tests. 
The T-2 Tank System consists of two line segments, neither of which were testable by the current methods. Transfer logs were used to qualitatively assess the pipelines which are untestable by currently approved methods. These transfer logs reveal that nine transfers were made between HFIR Tank and Tank T-2, and eleven transfers were made between Tank T-2 and Tank W-22. Six of the transfers between the HFIR tank and the Tank T-2 exceeded the maximum expected difference between the recorded volume sent and the recorded volume received. It is suspected that the cause of these recorded differences is due to inaccuracy in the strapping tables which are used to convert liquid levels in the tanks to volume. Five transfers between Tank T-2 and Tank W-22 also exceeded the expected difference. However, in each of the three transfers, the volume received was greater than the volume sent, indicating unrecorded prime or flush water was present. The volume of these transfers along with the latest qualitative assessment of the pipelines was reported to EPA and TDEC in the "Quarterly Highlight for LLLW Tank System Activities." Although a limited evaluation of the untestable pipelines can be made using transfer logs, this method of assessment, due to its limited accuracy, is not deemed valid for certification purposes.

All of these factors were considered in determining certification of the T-2 system components. Table 23 summarizes the elements of the tank systems which were certified and the conditional limits on their certifications.

Table 23. Summary of T-2 Tank System Testing and Certification

\begin{tabular}{|c|c|c|c|c|c|c|c|}
\hline \multicolumn{2}{|c|}{ Component } & $\begin{array}{l}\text { Length? } \\
\text { (fin) }\end{array}$ & $\begin{array}{l}\text { Tested } \\
\text { Ges/No. }\end{array}$ & $\begin{array}{l}\text { Leal Test } \\
\text { Method }\end{array}$ & Result & Certinication & certincation \\
\hline \multicolumn{2}{|c|}{ Tank T-2 } & & Yes & MDP & PASS & Yes & $33 \%$ \\
\hline \multicolumn{2}{|l|}{ LS-56 } & 46 & No & $\mathrm{N} / \mathrm{T}^{*}$ & $\mathrm{~N} / \mathrm{T}$ & No & $\mathrm{N} / \mathrm{T}$ \\
\hline \multicolumn{2}{|l|}{ LS-82 } & 28 & No & $\mathrm{N} / \mathrm{T}^{*}$ & $\mathrm{~N} / \mathrm{T}$ & No & $\mathrm{N} / \mathrm{T}$ \\
\hline $\begin{array}{l}\text { LS } \\
\text { MDP } \\
\text { N/T }\end{array}$ & $\begin{array}{l}\text { Tran } \\
\text { Line } \\
\text { Modi } \\
\text { Not t }\end{array}$ & $\begin{array}{l}\text { ecords av } \\
\text { ient } \\
\text { Different } \\
\text { le }\end{array}$ & ressure & & & & \\
\hline
\end{tabular}




\subsubsection{Certification}

Based on the results of the design drawings review, the qualitative corrosion assessment, and the results of the leak testing program, it is my professional opinion that Tank T-2 retains sufficient structural integrity to contain liquids at operating levels up to the maximum level which achieved a PASS during the testing program. Table 23 provides a summary description of the certifications for the T-2 Tank System. If future testing is conducted at larger tank volumes, then certification volumes may also increase.

It is recommended that leak testing using the EPA and TDEC approved methods be continued to support annual certification, until this system has been removed from operation or replaced.

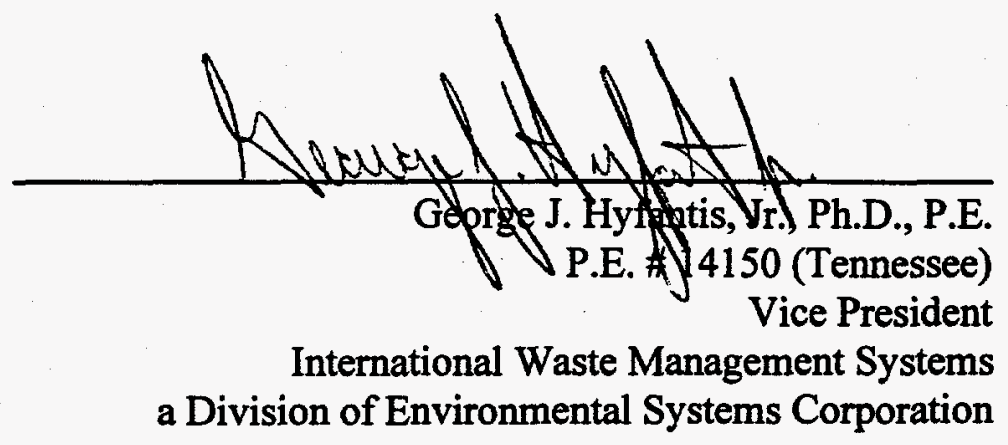




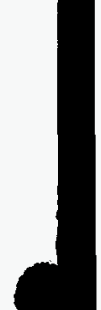


The W-16 Tank System is located near the South Tank Farm, as shown in Figure 1. The tank system previously collected LLLW waste from Building 3026 and discharged these liquids by steam jet to Valve Box 1 at the Central Waste Collection Header. The system is made up of Tank W-16 and nine line segments connected to the tank system. Because the lines and tank are all singly contained, the tank system has been classified as Category $\mathrm{C}$, according to the FFA.

\subsubsection{W-16 Tank Description}

Tank W-16 is a 1,000 gallon, buried, singly contained tank on a concrete pad. Installed in 1951, Tank W-16 is mounted vertically on 3/8" thick stainless steel angle legs welded to the side of the tank near the base and bolted to an 8 " thick concrete pad. The tank is constructed of 347 stainless steel and has a wall thickness of 1/4". The outside diameter of the tank is 66", with a length of 88". The working volume of the tank is 700 gallons. The drawing for Tank W16 is provided as Figure 22.

The tank is equipped with ten nozzles and one float gauge on the top of the tank. All the nozzles are located around an unknown radius of the tank center, and the float gauge is located in the center of the tank. Four lifting lugs are positioned symmetrically around the edges near the top of the tank. The tank is located below ground. The excavation pit was backfilled with crushed stone to the top of the tank. A schematic of the tank system with numbered line segments provided as Figure 23.

\subsubsection{W-16 Pipeline Descriptions}

Nine separate lines make up the portion of the LLLW pipeline system belonging to Tank W-16. Characteristics of the nine lines are listed in Table 24, and the line segments are shown in Figure 23. All pipelines associated with the W-16 Tank System are constructed of 347 stainless steel and were installed in 1951.

As shown in Figure 23, W-16 has one inlet, and one discharge pipeline. The remaining eight line segments are not directly connected to Tank W-16.

Line Segment 145 is the pipeline that transports waste into Tank W-16. Line Segment 145 is a gravity-fed, 200', 3" diameter stainless steel line that connects Building 3026D to Tank W-16. The remaining eight pipelines are all components of the tank discharge pipeline system. Line Segment 163 is a 14' long section of 1 " diameter suction line leading from the tank to a steam jet. Line Segments 181, 181A, 181B, and 181C are each 4' long sections of 2" diameter line that make up a manifold system for the discharge of Tanks W-16, W-17 and W-18 (nodes 4 to 11,11 to 13,12 to 13 and 14 to 13 respectfully). The line leaving the discharge manifold, Line Segment 24, is a 55' section of 2" diameter line. Each of these lines are pressurized by steam jet, which is used to transfer the liquids. 


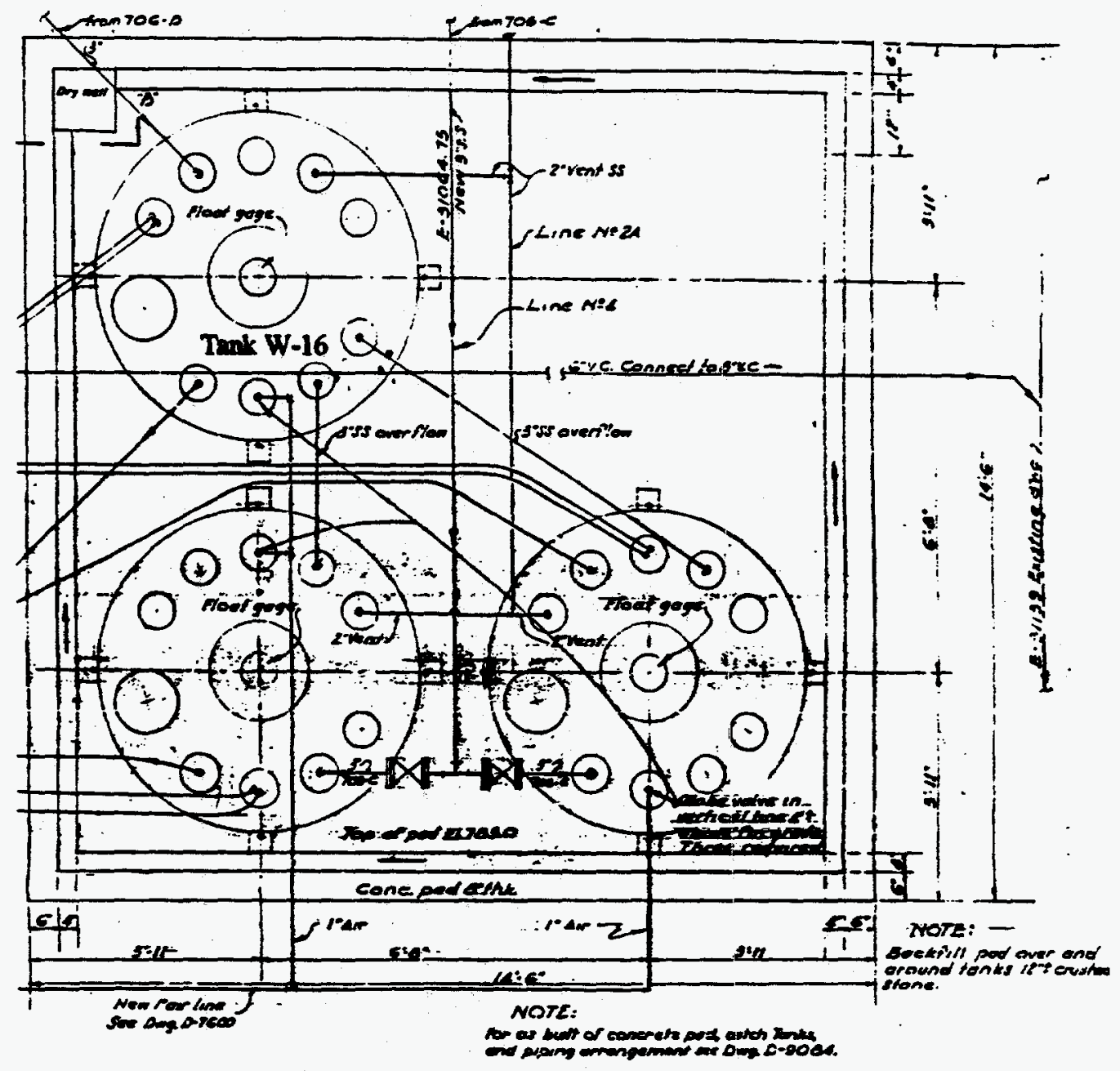

Figure 22. As-built Drawing of Tank W-16 Installation 


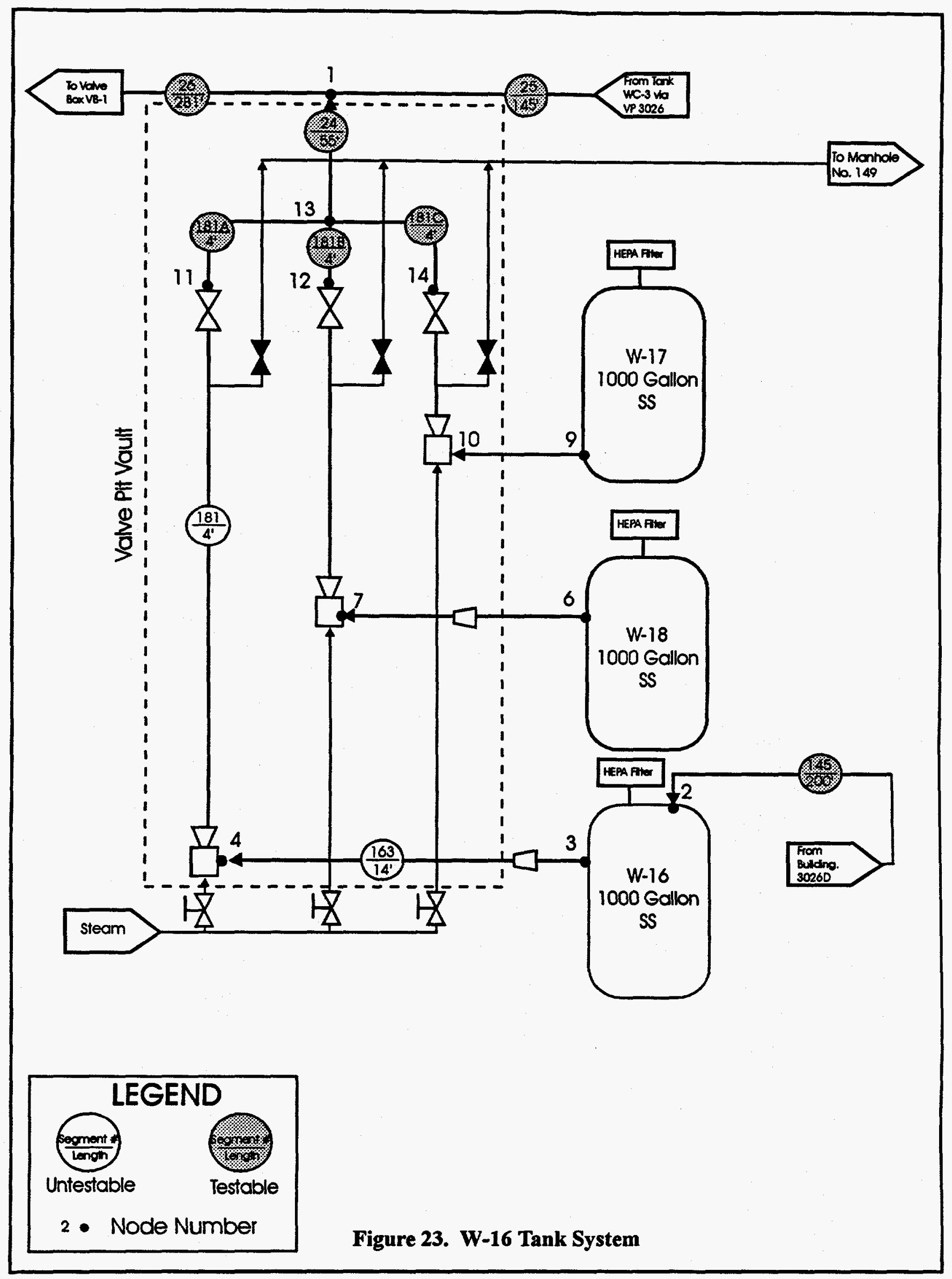


Line Segment 24 connects to a pipeline leading from the discharge of Tanks WC-3 and WC-19 and continues to Valve Box No. 1 (VB-1). Two segments of 2" diameter line make up this pipeline. Line Segment 25 is a 145' long, pressurized line that runs from the WC-19 discharge connection to the connection with Line Segment 24. Line Segment 26 is a 281' long pressurized line that runs from the Segment 24 connection to VB-1.

Line Segments 24, 25, 26, and 181A, 181B and 181C are all designated as Tank W-16 lines. These lines are not isolated from Tank WC-3 and Tank WC-19 discharge piping, all of which are denoted as P37. Therefore, these six lines were leak tested with the WC-3 Tank System. The line segments which are part of P37 but defined as part of the W-16 Tank System are shown in Table 24. Leak test results are included in Section 7.5.4.

Table 24. Characteristics of Line Segments Evaluated as a Part of Tank System W-16

\begin{tabular}{|c|c|c|c|c|c|c|c|c|c|}
\hline tofne Segment & 24 & 25 & 26 & 145 & 163 & 181 & $181 \mathrm{~A}$ & $181 \mathrm{~B}$ & 1810 \\
\hline $\begin{array}{l}\text { Node } \\
\text { Numbers }\end{array}$ & 13 to 1 & $\begin{array}{c}\text { VP } 3026 \\
\text { to } 1\end{array}$ & $\begin{array}{l}1 \text { to } \\
\text { VB-1 }\end{array}$ & $\begin{array}{c}3026 \text { to } \\
2\end{array}$ & 3 to 4 & 4 to 11 & 11 to 13 & $\begin{array}{c}12 \text { to } \\
13\end{array}$ & 14 to 13 \\
\hline Index Number & P37 & P37 & P37 & $\mathrm{G} 17$ & & & P37 & P37 & P37 \\
\hline Diameter (in) & 2 & 2 & 2 & 3 & 1 & 2 & 2 & 2 & 2 \\
\hline Material & 347 SS & $347 \mathrm{SS}$ & 347 SS & 347 SS & 347 SS & $347 \mathrm{SS}$ & $347 \mathrm{SS}$ & & 347 SS \\
\hline Length ( $f$ ) & 55 & 145 & 281 & 200 & 14 & 4 & 4 & 4 & 4 \\
\hline Volume (gal) & 10 & 25 & 49 & 77 & 2 & 1 & 1 & 1 & 1 \\
\hline $\begin{array}{l}\text { Transfer } \\
\text { Method }\end{array}$ & SJ & SJ & SJ & G & SJ Suct. & SJ & SJ & SJ & SJ \\
\hline Install Date & 1951 & 1951 & 1951 & 1951 & 1951 & 1951 & 1951 & 1951 & 1951 \\
\hline \multicolumn{10}{|l|}{$\begin{array}{l}\text { G } \\
\text { SJ } \\
\text { Suct. } \\
\text { SS } \\
\end{array}$} \\
\hline
\end{tabular}

\subsubsection{Corrosion Assessment of the W-16 Tank System}

Tank W-16 formerly collected waste from Building 3026D, but the tank has not been used for that purpose since at least 1990 . The $\mathrm{pH}$ of the tank solution is maintained at about 13, and corrosion damage since at least 1990 should have been very slight. Corrosion damage that may have occurred when the system was used for its intended purpose (radioisotope production and decontamination) cannot be assessed.

Some of the stainless steel piping is buried and is subject to corrosion by soil. However, based on information cited in Section 4.0, corrosion of stainless steel by ORNL soil is not believed to be severe. 


\subsubsection{Results of Leak Tests on the W-16 System}

This section summarizes the results of the leak detection tests conducted on Tank System W-16 (the tank and its associated pipelines). Each element in the system was tested with a method appropriate for that element. Each method used has been demonstrated to detect a specified leak rate ( $0.2 \mathrm{gal} / \mathrm{hr}$ for tank methods; $0.1 \mathrm{gal} / \mathrm{hr}$ for pipeline methods) with a PD no less than $95 \%$ and a Pfa no greater than $5 \%$. The test method used for each element is shown in Section 7.5.5.

\subsubsection{Tank}

Leak testing of Tank W-16 for the current assessment period began in February 1995 and continued at routine intervals through December 1995, with a total of 13 leak test attempts on the tank during this reporting period. The results of these tests are summarized in Table 25, which shows the date of each test, the volume of LLLW in the tank at the time of the test, the percent of Tank W-16's total volume the test represented ${ }^{6}$, the test result, and comments pertinent to particular tests. The table shows that Tank W-16 recorded PASS results for 12 of the 13 leak tests, with one INCONCLUSIVE result. Anomalous low frequency noise in the data record caused the inconclusive result. The maximum volume for which the tank passed the leak testing during this reporting period was 177 gallons, or $15 \%$ of the total capacity. This is less than the previously certified level of 382 gallons (33\%) for this tank [DOE/OR/01-1385\&D2].

Table 25. Summary of Leak Tests Conducted on Tank W-16

\begin{tabular}{|c|c|c|c|c|}
\hline Date & H.or Gallons & of capacity & Test Result & Comment \\
\hline $02 / 03 / 95$ & 122 & 11 & PASS & \\
\hline $03 / 10895$ & 121 & 11 & PASS & \\
\hline $03 / 14 / 95$ & 124 & 11 & PASS & \\
\hline $04 / 07 / 95$ & N/A & N/A & INCONCLUSIVE & low freq noise \\
\hline $04 / 21 / 95$ & 151 & 13 & PASS & \\
\hline $05 / 05 / 95$ & 152 & 13 & PASS & \\
\hline $06 / 02 / 95$ & 152 & 13 & PASS & \\
\hline $07 / 07 / 95$ & 162 & 14 & PASS & \\
\hline $08 / 04 / 95$ & 171 & 15 & PASS & \\
\hline $09 / 01 / 95$ & 177 & 15 & PASS & \\
\hline $10 / 06 / 95$ & 175 & 15 & PASS & \\
\hline $11 / 03 / 95$ & 176 & 15 & PASS & \\
\hline $12 / 01 / 95$ & 168 & 15 & PASS & \\
\hline
\end{tabular}

${ }^{6}$ WOCC look-up tables show $100 \%$ capacity for W-16 as 1,148 gal. The percent capacity shown in the table is based on this number. 
The 12 usable CVR data values from these leak tests were analyzed (1) to verify that the test method was performing properly in this application and (2) to confirm that during this assessment period the leak testing process had remained nominal; that is the performance of the method as applied to this particular tank was not deteriorating. This analysis included a statistical examination of the CVR data, as well as a comparison of this year's assessment data with prior data. The analysis and the results are described in Section 7.5.4.3.

\subsubsection{W-16 Pipelines}

The results of the leak detection test on the testable W-16 pipelines are summarized in Section 7.5.4.2.1. An assessment of the integrity of these lines based upon transfer records is summarized in Section 7.5.4.2.2.

\subsection{W-16 Testable Pipelines}

There are two testable pipelines associated with the W-16 Tank System. One is a gravity-fed line leading from Building 3026D to Tank W-16. This pipeline (index no. G17, segment no. 145) was last tested in June 1994, with an INCONCLUSIVE result. The line is not scheduled to be used until the Isotopes Facility Deactivation project in FY98. The line will be tested again prior to its next use.

The second testable pipeline in the W-16 System is a discharge line that joins W-16 to the WC-3 discharge line (index no. P37) and cannot be isolated from that system. This element, comprised of six separate segments, was tested in September 1996 and passed the gas pressure decay test,

Table 26. Summary of Leak Test Results for the WC-16 Testable Lines.

\begin{tabular}{|c|c|c|c|c|c|}
\hline Element No & Line Segment & Test Date & Trest Result & Comment \\
\hline P37 & 24 & $09 / 05 / 96$ & PASS & \\
\hline P37 & 25 & $09 / 05 / 99$ & PASS & \\
\hline P37 & 26 & $09 / 05 / 96$ & PASS & \\
\hline P37 & $181 \mathrm{~A}$ & $09 / 05 / 96$ & PASS & \\
\hline P37 & $181 \mathrm{~B}$ & $09 / 05 / 96$ & PASS & \\
\hline P37 & $181 \mathrm{C}$ & $09 / 05 / 96$ & PASS & \\
\hline G17 & 145 & NT & NA & $\begin{array}{c}\text { Not currently in } \\
\text { use will be tested } \\
\text { prior to reuse }\end{array}$ \\
\hline
\end{tabular}

\subsection{W-16 Untestable Pipelines}

The untestable portion of the W-16 System (Line Segments 181 and 163) carried transfers from Tank W-16 through VB-1 to Tank W-22. WOCC transfer records show that 
during the period from January 1995 through December 1995, there were no transfers made from W-16 to W-22. Thus, in the case of the W-16 Tank System, no assessment can be made based on the transfer data.

\subsubsection{Analysis of Tank W-16 Leak Test Data}

During this assessment period, a total of 13 leak tests were attempted on Tank W-16; of these, 12 tests resulted in conclusive results. Figure 24 shows a time series plot of the CVR data obtained from each of the useable test results. It can be seen from the plot that all 12 of the CVR values are within the INFLOW and OUTFLOW decision thresholds, and are thus consistent with the PASS results obtained from these tests.

A comparative analysis of the data shown in Figure 24 was performed. The analysis included using the Student's $t$ - [Mendenhall, 1992], and the K-S [Benjamin and Cornell, 1970] statistical tests. The Student's t-test is used to determine the significance of the mean of the CVR data. The K-S analysis is used to determine if the population of CVR values from W-16 is significantly different than a reference set of CVRs. These statistical tests are fully described in Section 5.4.

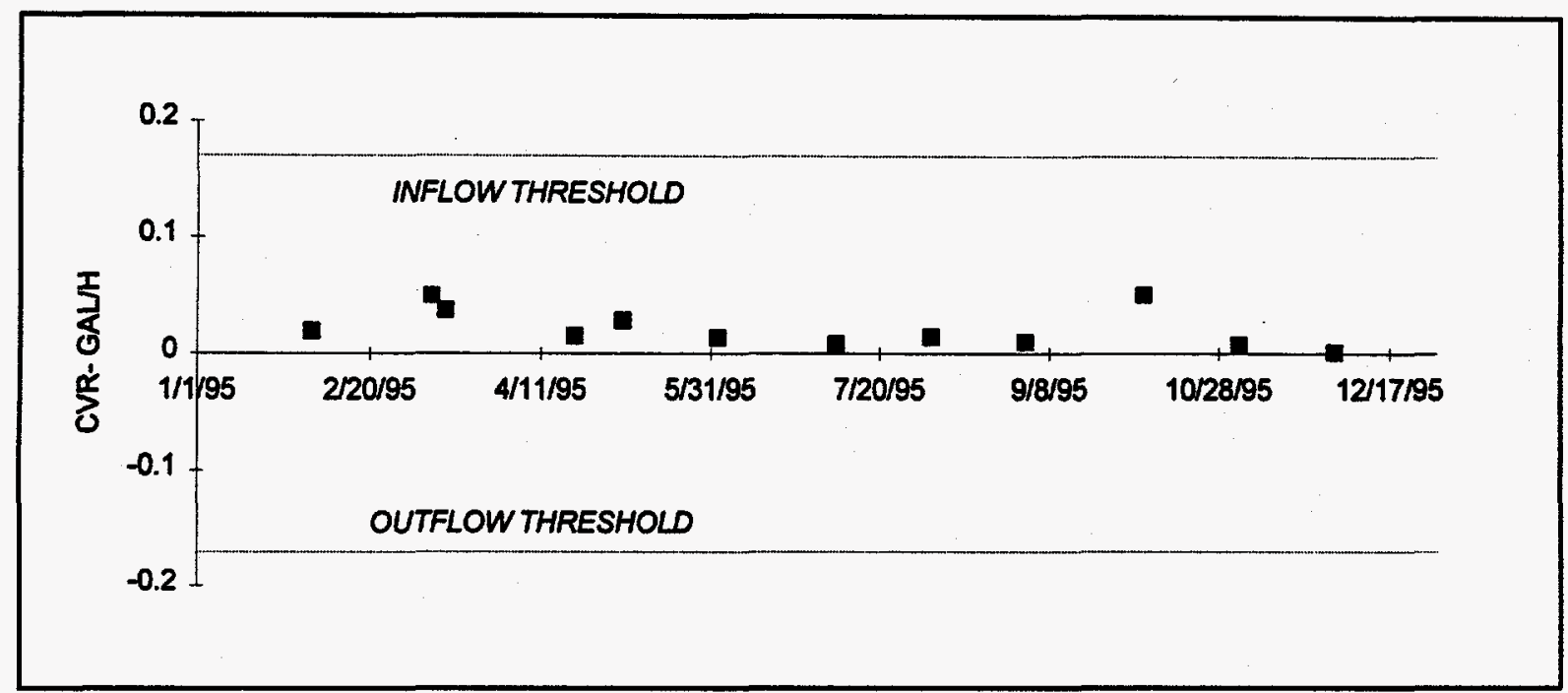

Figure 24. Time series plot of leak test CVRs from Tank W-16.

As shown below, applying the t-test to the 12 data values shown above results in a $t-$ statistic, $t_{\text {stat }}$ of 4.52 , while the critical value, $t_{\text {crit }}$, for a $99 \%$ level of confidence, is 3.11 . Applying the K-S "goodness-of-fit" test to the W-16 CVR data, using a H/V weighted set of reference CVRs, results in a maximum ordinal difference, $\mathrm{KS}_{\text {stat }}$ of 0.26 , while the critical value, $\mathrm{KS}_{\text {crit, }}$ is 0.47 . for a $99 \%$ level of confidence. Based upon this analysis, we conclude that while the spread of the CY95 CVR values is not different than the reference population, the mean of the CY95 CVR data from tank W-16 is not equivalent to zero gal/h, and is consistent with the plot that shows a slight inflow into the tank. All of the results, however, are within the acceptance criteria.

Figure 25 graphically illustrates the K-S test applied to the W-16 data. The bold solid 
line in the figure shows the CDF obtained from the CVR data shown in Figure 24, after removing the mean from the data. The light dashed line in the figure shows the CDF obtained from the reference set of CVR values (See Section 5.4), after removing the mean from that data and scaling those values by the $\mathrm{H} / \mathrm{V}$ coefficient of $\mathrm{W}-16(14.72 \mathrm{gal} / \mathrm{in}$.), divided by the $\mathrm{H} / \mathrm{V}$ of the (mean-removed) reference set (14.72 gal/in.).

The similarity of the data sets defined by the two lines illustrated in Figure 25 is "tested" with the K-S "goodness-of-fit" test. Here, the test statistic, $\mathrm{KS}_{\text {sut }}$, is 0.26 , while the critical value, $\mathrm{KS}_{\text {crit }}$ is 0.47 . Since the maximum ordinal difference, $\mathrm{KS}_{\text {stat }}$, is less than $\mathrm{KS}_{\text {crit }}$, the two populations are deemed to be equivalent.

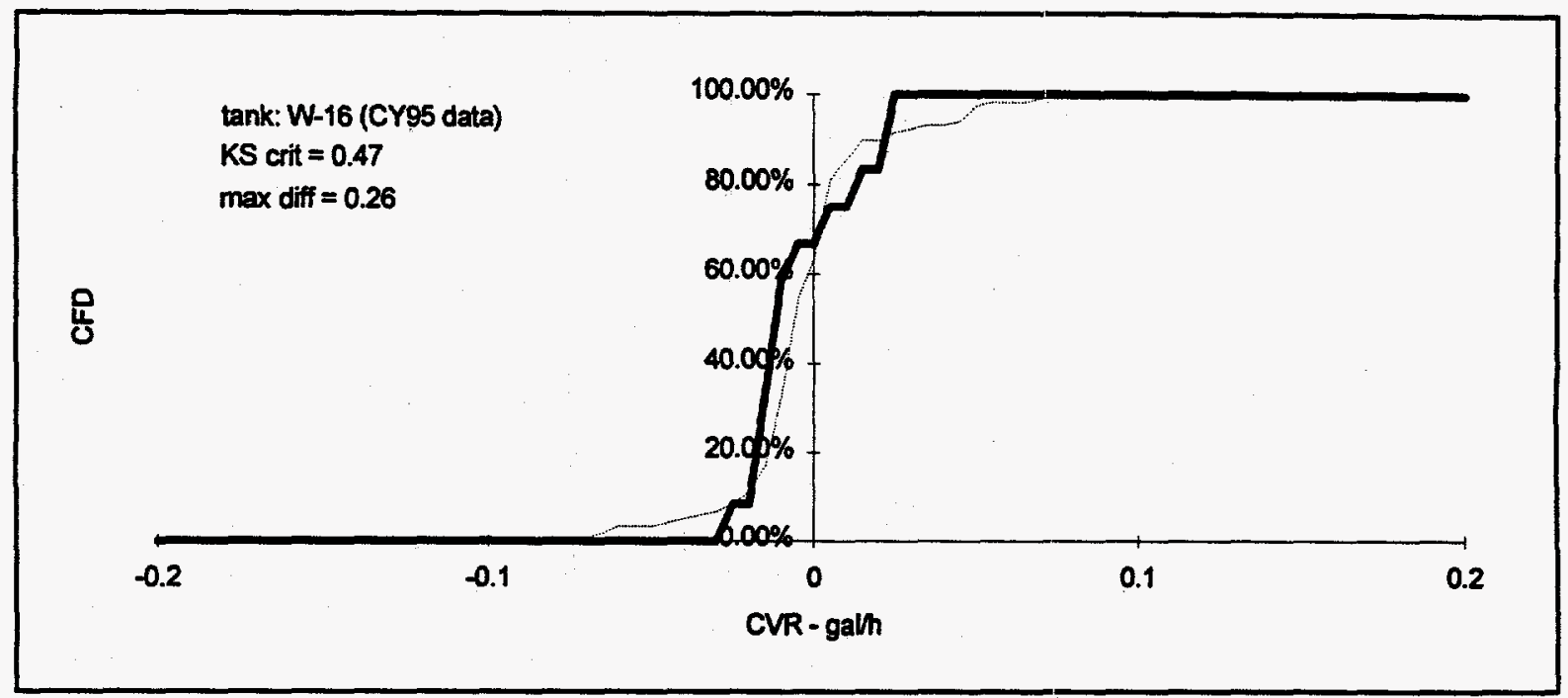

Figure 25. Cumulative frequency distributions from reference CVR data (light dashed line) and W-16 CVR data (CY95) (bold solid line).

Table 27 summarizes the statistical analyses of the Tank W-16 CVR data. The table shows that the mean of the CY95 test data is indicative of a weak. inflow. The population of the CY95 CVR values, however, is not different than the population of CVR values in the reference, or comparison, data set. 
Table 27. Summary of Statistical Analyses of W-16 CVR Data (H/V=14.72 gal/in)

\begin{tabular}{|c|c|c|}
\hline & Reference CVR data & '95 CVR data \\
\hline $\mathbf{N}$ & 118 & 12 \\
\hline Mean (gal/h) & 0.005 & 0.021 \\
\hline $\begin{array}{c}\text { Standard Deviation } \\
(\mathrm{gal} / \mathrm{h})\end{array}$ & 0.031 & 0.016 \\
\hline t-statistic & & 4.52 \\
\hline t-critical (1\%) & & 3.11 \\
\hline t-test Inference & & mean is significant \\
\hline KS-statistic & & 0.26 \\
\hline KS-critical (1\%) & & 0.47 \\
\hline KS-test Inference & & $\begin{array}{c}\text { Same population as } \\
\text { reference set }\end{array}$ \\
\hline
\end{tabular}

\subsubsection{Findings and Conclusions}

The findings of this report are based on (1) a review of available tank design drawings, (2) a qualitative assessment of corrosion on the tank and pipelines, and (3) leak testing results from the tank and testable pipelines. Review of the design drawings revealed an abundance of nozzles into the tank that were not connected to pipelines. However, because the unused nozzles are located on the top of the tank, there is no concern that leakage could occur at those locations as long as the tank is operating at less than full capacity. The design drawings revealed a sound design of the W-16 Tank.

During the corrosion assessment, it was determined that with the present use of the tank system, all forms of corrosion on the interior walls of the tank and associated piping should be nonexistent. Corrosion damage that may have occurred when the tank was used in past environments cannot be assessed. Furthermore, an analysis of the general aspects of corrosion at ORNL revealed that corrosion of stainless steel by ORNL soil is not believed to be severe.

Leak testing of Tank W-16 was completed by the DP method in 13 tests. The tank passed 12 of the tests and had inconclusive results in one test. The inconclusive result was explained by excessive noise in the liquid level measurement device.

Six of the seven testable line segments have passed leak testing. The seventh line segment is a pipeline that is not scheduled for use until the Isotopes Facility Deactivation project in FY98. The line will be re-tested before use. Although a limited evaluation of the untestable pipelines can be made using transfer logs, no transfers were made from this tank during the reporting period. 
All of these factors were considered in determining certification of the W-16 Tank System components. Table 28 summarizes the elements of the tank system which were certified and the conditional limits on their certifications.

Table 28. Summary of W-16 Tank System Testing and Certification

\begin{tabular}{|c|c|c|c|c|c|c|}
\hline $\begin{array}{l}\text { Systern } \\
\text { Component }\end{array}$ & length & Trested & $\begin{array}{l}\text { leak Test? } \\
\text { Method }\end{array}$ & Result & Certification. & Certification \\
\hline Tank W-16 & & Yes & DP & PASS & Yes & $15 \%$ \\
\hline LS-24 & 55 & Yes & GPD & PASS & Yes & Full Flow \\
\hline LS-25 & 145 & Yes & GPD & PASS & Yes & Full Flow \\
\hline LS-26 & 281 & Yes & GPD & PASS & Yes & Full Flow \\
\hline LS-145* & 200 & No & $\mathrm{N} / \mathrm{T}$ & $\mathrm{N} / \mathrm{T}$ & No & $\mathrm{N} / \mathrm{T}$ \\
\hline LS-163 & 14 & No & $\mathrm{N} / \mathrm{T}$ & $\mathrm{N} / \mathrm{T}$ & No & $\mathrm{N} / \mathrm{T}$ \\
\hline LS-181 & 4 & No & $\mathrm{N} / \mathrm{T}$ & $\mathrm{N} / \mathrm{T}$ & No & $\mathrm{N} / \mathrm{T}$ \\
\hline LS-181A & 4 & Yes & GPD & PASS & Yes & Full Flow \\
\hline LS-181B & 4 & Yes & GPD & PASS & Yes & Full Flow \\
\hline LS-181C & 4 & Yes & GPD & PASS & Yes & Full Flow \\
\hline \multicolumn{7}{|c|}{$\begin{array}{ll}\text { * } & \text { Not currently in use } \\
\text { DP } & \text { Differential Pressure } \\
\text { EVB } & \text { Enhanced volume balancing } \\
\text { GPD } & \text { Gas pressure decay } \\
\text { INC } & \text { Inconclusive } \\
\text { LS } & \text { Line segment } \\
\text { N/T } & \text { Not testable } \\
\end{array}$} \\
\hline
\end{tabular}




\subsubsection{Certification}

Based on the results of the design drawings review, the qualitative corrosion assessment, and the results of the leak testing program, it is my professional opinion that Tank W-16 retains sufficient structural integrity to contain liquids at operating levels up to the maximum level which achieved a PASS during the testing program. Also, based upon the results of pipeline tests, it is my professional opinion that Line Segments 24, 25, 26, 181A, 181B, and 191C retain sufficient structural integrity to contain liquids up to the full flow potential of the lines. Table 28 provides a summary description of the certifications for the W-16 Tank System. If future testing is conducted at greater tank levels, then certification levels may also increase.

It is recommended that leak detection and line testing be continued using EPA and TDEC approved methods, to support annual certification, until this system has been removed from operation or replaced.

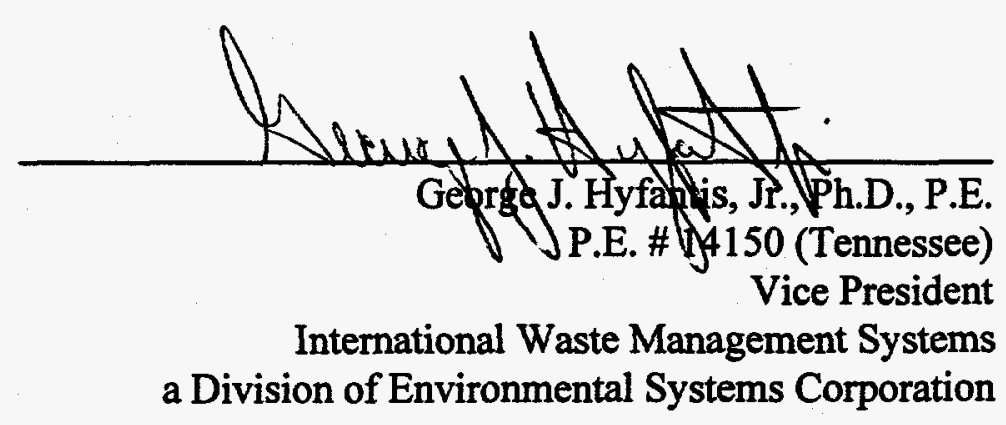




\subsection{WC-2 Tank System}

The WC-2 Tank System is located near the northeast corner of Building 3092, as shown in Figure 1. The WC-2 Tank System collects LLLW from Buildings 3038 and hot off-gas (HOG) duct condensate from a HOG drain trap in Isotope Circle. The tank system is made up of Tank WC-2 and nine line segments connected to the system. Because the lines and tank are all singly contained, the tank system has been classified as Category $\mathrm{C}$, according to the FFA.

\subsubsection{WC-2 Tank Description}

Tank WC-2 is a 1,000 gallon, buried, singly contained tank. Installed in 1951, WC-2 is mounted vertically to an $8^{\prime}-0^{\prime \prime} \times 8^{\prime}-0^{\prime \prime} \times 0^{\prime}-8^{\prime \prime}$ concrete pad. The tank is constructed of 347 stainless steel and was designed with a 1/4" wall thickness. All materials welded to the tank are also 347 stainless steel. The tank is constructed with 3/8" thick ASME flanged dished heads on top and $1 / 4$ " thick ASME flanged dished heads on the bottom. The outside diameter of the tank is $5^{\prime}-6^{\prime \prime}$, with a total height of $77^{\prime} 4-1 / 4^{\prime \prime}$. The design drawing for Tank WC-2 is provided in Figure 26.

The tank is equipped with nine $3 "$ diameter flanged nozzles, one 8" diameter flanged nozzle, and one 16" diameter manhole opening. The flanged nozzles are located around a 2'-0" radius of the tank center, and the manhole is located in the center of the tank. Each of the 3" diameter flanges are fitted to be secured by four $5 / 8$ " diameter bolts, and the manhole is fitted to be secured by sixteen $3 / 4$ " diameter bolts. All flanges are slip on welding type. All of the necessary welds on the tank are specified in accordance with code from the ASTM for unfired pressure vessels. At the time of construction, the welds were specified to provide substantially the same composition as adjacent unwelded metal.

The pit containing the tank was constructed with a one and half foot deep earthen sump located on the northeast corner of the tank pad. An 8" diameter vitrified clay pipe, installed 6" from the bottom of the sump, extended to the surface of the backfilled tank pit and is currently used as a tank pit sample point.

During the tank installation, the tank pit was backfilled with 1-1/2" diameter stone to a minimum depth of one foot above the concrete pad. The remainder of the tank pit was backfilled with earthen materials.

Tank WC-2 was designed to receive material from four sources, which originated in Buildings 3038 and 3028, an isotope off-gas duct condensate drain in Building 3092, and in a pump pit used to contain any spills or leaks that may occur within the vault containing the pump that discharges the liquids from the tank. The tank no longer receives waste from Building 3028. A schematic of the tank system with numbered line segments is provided in Figure 27. 


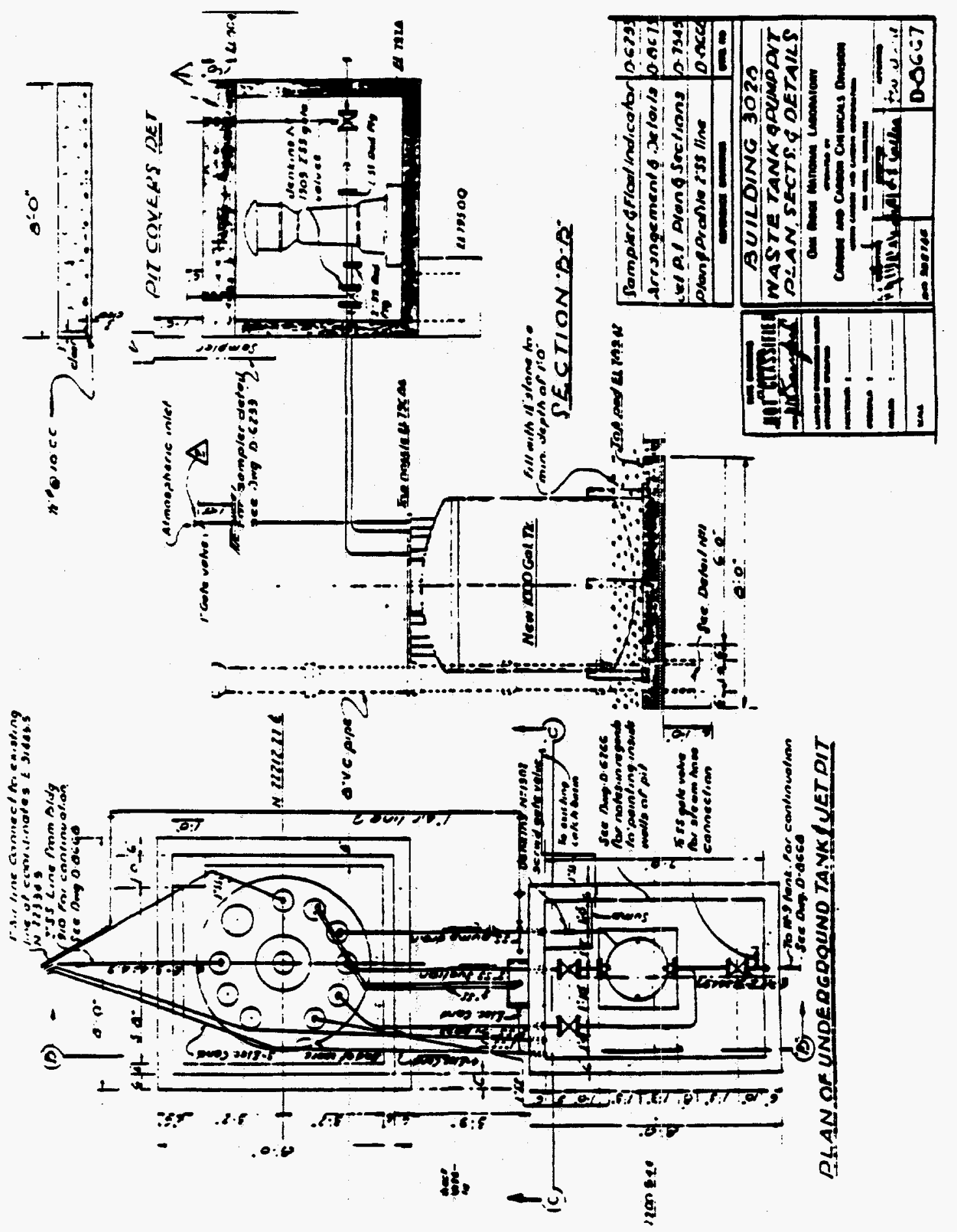

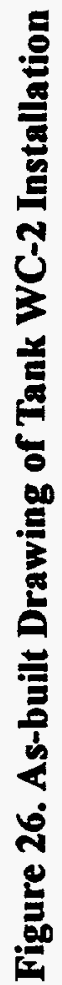




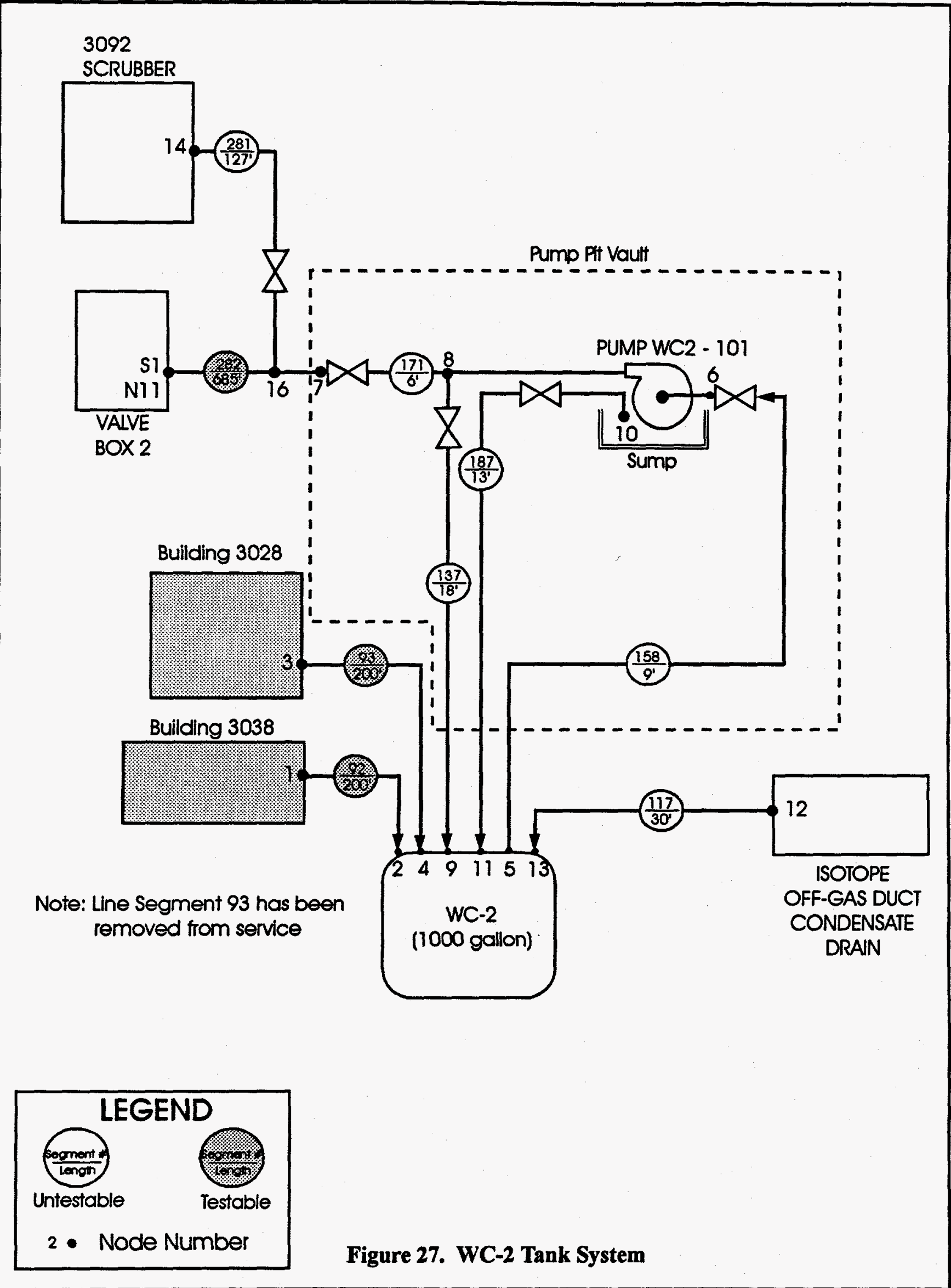




\subsubsection{WC-2 Pipeline Descriptions}

Nine separate lines make up the portion of the LLLW pipeline system belonging to Tank WC-2. Characteristics of these nine lines are listed in Table 29, and line segments are shown in Figure 27. All pipelines associated with the WC-2 Tank System are constructed of 347 stainless steel and were installed in 1951.

As shown in Figure 27, WC-2 has five inlet pipelines and one discharge pipeline. The remaining three line segments are not directly connected to Tank WC-2. Two of the gravity drain lines to the tank were originally testable and the main section of the pressurized discharge pipeline is testable.

Line Segments 92 and 93 are inlets for waste coming into Tank WC-2. Line Segment 92 is a $200^{\prime}$ long, 2" diameter gravity-fed pipeline leading from Building 3038 to Tank WC-2 (node 1 to node 2 in Figure 28). This line was blocked during construction activities in FY96 and could not be leak tested. Line Segment 93 is a 200' long, 2" diarneter gravity-fed pipeline leading from Building 3028 to Tank WC-2 (node 3 to node 4). This line has been taken out of service and no future use is planned. The remaining inlets into the tank are made up of Line Segments 117, 137, and 187. Line Segments 117 and 137 are 2" diameter inlets and Line Segment 187 is a $1^{\prime \prime}$ diameter inlet. Line Segment 117 is a $30^{\prime}$ long gravity-fed element that drains a hot off gas (HOG) duct condensate trap (node 12 to node 13). Line Segment 137 is a $18^{\prime}$ long recirculation line for the WC-2/101 pump back into WC-2 (node 8 to node 9). Line Segment 187 is a $13^{\prime}$ long gravity-fed line that drains the WC-2/101 pump pit drain to WC-2 (node 10 to node 11). Line Segments 117 and 187 are not accessible, therefore leak testing was not possible on these two line segments. Line Segment 137 is untestable due to the lack of an isolation valve at the point where the line enters the tank.

Line Segment 281 is a $127^{\prime}$ long, 2" diameter line comprised of suction and jet discharge transfer piping that jets waste from the Building 3092 scrubber into the WC-2 transfer piping (node 14 to node 16). There is no valve at the scrubber end of this segment to serve as an isolation point, and thereby rendering this line untestable by existing approved methods.

Line Segment 158 is part of the primary tank discharge line (node 5 to node 6). This segment is a 9' long, 2" diameter section of suction piping that extends from Tank WC-2 to the inlet of centrifugal pump WC2-101. Line Segment 158 lacks a second valve and cannot be isolated or tested. Flow into Line Segment 171 begins at the discharge of pump WC-2-101 and extends to a valve known as V-WC-2-104 (node 6 to node 7). Line Segment 171 is 6 ' in length and has a diameter of $2 "$. The pump sits in a concrete vault with a stainless steel gate valve located on either side of the pump. The pump vault, which is not a part of the tested line system, has a $4.5 \mathrm{ft}^{3}$ collection sump extending two foot below the floor elevation of the vault.

The third testable element, Line Segment 282, is a pressurized $685^{\prime}$ long, $2^{\prime \prime}$ diameter stainless steel portion of the discharge between Tank WC-2 (at valve V-WC2-104) and Valve Box No. 2 (node 7 to S1 Node 11). 
Line Segment 282 was tested by the gas pressure decay method described in Section 3.2.2. Leak test results are included in Section 7.6.4.

Table 29. Characteristics of Line Segments Evaluated as a Part of Tank System WC-2

\begin{tabular}{|c|c|c|c|c|c|c|c|c|c|c|}
\hline \multicolumn{2}{|c|}{ 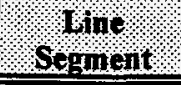 } & 92 & 93 & 117 & 137 & 158 & 17 & 187 & 281 & 287 \\
\hline \multicolumn{2}{|l|}{$\begin{array}{l}\text { Node } \\
\text { Numbers }\end{array}$} & 1 to 2 & 3 to 4 & $\begin{array}{c}12 \text { to } \\
13\end{array}$ & 8 to 9 & 5 to 6 & 8 to 7 & $\begin{array}{l}10 \text { to } \\
11\end{array}$ & $\begin{array}{c}14 \text { to } \\
16\end{array}$ & $\begin{array}{c}16 \text { to } \\
\text { S1-N11 }\end{array}$ \\
\hline \multicolumn{2}{|l|}{$\begin{array}{l}\text { Index } \\
\text { Number }\end{array}$} & G14 & G3 & & & & & & & P16 \\
\hline \multicolumn{2}{|l|}{$\begin{array}{l}\text { Diameter } \\
\text { (in) }\end{array}$} & 2 & 2 & 2 & 2 & 2 & 2 & 1 & 2 & 2 \\
\hline \multicolumn{2}{|l|}{ Material } & $347 \mathrm{SS}$ & 347 SS & $347 \mathrm{SS}$ & $347 \mathrm{SS}$ & $347 \mathrm{SS}$ & $347 \mathrm{SS}$ & $347 \mathrm{SS}$ & 347 SS & $347 \mathrm{SS}$ \\
\hline \multicolumn{2}{|l|}{ Length $(f t)$} & 200 & 200 & 30 & 18 & 9 & 6 & 13 & 127 & 685 \\
\hline \multicolumn{2}{|l|}{$\begin{array}{l}\text { Volume } \\
\text { (gal) }\end{array}$} & 35 & 35 & 5 & 3 & 2 & 1 & 1 & 22 & 119 \\
\hline \multicolumn{2}{|l|}{$\begin{array}{l}\text { Transfer } \\
\text { Method }\end{array}$} & $\mathbf{G}$ & $\mathrm{G}$ & G & $\mathrm{CP}$ & $\begin{array}{c}\text { CP } \\
\text { Suct. }\end{array}$ & $\mathrm{CP}$ & $\mathbf{G}$ & $\begin{array}{l}\text { SJ \& } \\
\text { Suct. }\end{array}$ & $C P$ \\
\hline \multicolumn{2}{|c|}{ Install Date } & 1951 & 1951 & 1951 & 1951 & 1951 & 1951 & 1951 & 1951 & 1951 \\
\hline \multicolumn{11}{|c|}{$\begin{array}{ll}\text { CP } & \text { Centrifugal Pump } \\
\text { G } & \text { Gravity } \\
\text { SJ } & \text { Steam jet pump } \\
\text { Suct. } & \text { Suction } \\
\text { SS } & \text { Stainless Steel } \\
\end{array}$} \\
\hline
\end{tabular}

\subsubsection{Corrosion Assessment of the WC-2 Tank System}

For the last few years, all waste solutions going into Tank WC-2 were those used to decontaminate the hot cells in Buildings 3028 and 3038 in preparation for decommissioning these buildings. Investigations indicated that surfactants have been used, and the volume added to the tank has only averaged ten to twenty gallons per week. If acid must be used in the future, based on information obtained from ORNL, only nitric acid would be considered. Type 347 stainless steel is compatible with both of these environments. Furthermore, the solution in the tank is maintained at a pH of approximately 13. With the present use, all forms of corrosion on the interior 347 stainless steel walls of the tank and associated piping should be essentially nil. Corrosion damage that may have occurred when the system was used with other environments cannot be assessed.

Some of the stainless steel piping is buried and is subject to corrosion by soil. However, based on information cited in Section 4.0, corrosion of stainless steel by ORNL soil is not believed to be severe.

\subsubsection{Results of Leak Tests on the WC-2 System}

This section summarizes the results of the leak detection tests conducted on Tank 
System WC-2 (the tank and its associated pipelines). Each element in the system was tested with a method appropriate for that element. Each method used has been demonstrated to detect a specified leak rate $(0.2 \mathrm{gal} / \mathrm{hr}$ for tank methods; $0.1 \mathrm{gal} / \mathrm{hr}$ for pipeline methods $)$ with a $\mathrm{PD}$ no less than $95 \%$ and a PFA no greater than $5 \%$.

\subsubsection{Tank}

Leak testing of Tank WC-2 for the current assessment period began in March 1995 and continued at routine intervals through December 1995, with a total of 12 leak test attempts during this reporting period. The results of these tests are summarized in Table 30, which shows the date of each test, the volume of LLLW in the tank at the time of the test, the percent of Tank WC-2's total volume the test represented ${ }^{7}$, the test result, and comments pertinent to particular tests. The table shows that Tank WC-2 recorded PASS results for all 12 leak tests. The maximum volume for which the tank passed the leak testing during this reporting period was 368 gallons, or $32 \%$ of the total capacity. This is less than the previously certified level of 519 gallons (45\%) for this tank [DOE/OR/01-1385\&D2].

Table 30. Summary of Leak Tests Conducted on Tank WC-2

\begin{tabular}{|c|c|c|c|c|}
\hline Date & \# or Gallons: & $\%$ Capacity. & TrstResult: & Comment \\
\hline $03 / 02 / 95$ & 302 & 26 & PASS & \\
\hline $03 / 10 / 95$ & 306 & 27 & PASS & \\
\hline $04 / 07 / 95$ & 306 & 27 & PASS & \\
\hline $05 / 05 / 95$ & 306 & 27 & PASS & \\
\hline $01 / 02 / 95$ & 322 & 28 & PASS & \\
\hline $07 / 07 / 95$ & 321 & 28 & PASS & \\
\hline $07 / 25 / 95$ & 280 & 24 & PASS & \\
\hline $08 / 04 / 95$ & 322 & 28 & PASS & \\
\hline $09 / 01 / 95$ & 367 & 32 & PASS & \\
\hline $10 / 06 / 95$ & 367 & 32 & PASS & \\
\hline $11 / 03 / 95$ & 368 & 32 & PASS & \\
\hline $12 / 01 / 95$ & 368 & 32 & PASS & \\
\hline
\end{tabular}

The 12 usable CVR data values from these leak tests were analyzed (1) to verify that the test method was performing properly in this application and (2) to confirm that during this assessment period the leak testing process had remained nominal; that is, the performance of the method as applied to this particular tank was not deteriorating. This analysis included a statistical examination of the CVR data, as well as a comparison of this year's assessment data with prior data. The analysis and the results are described in Section 7.6.4.3.

\subsubsection{WC-2 Pipelines}

The results of the leak detection test on the testable WC-2 pipelines are summarized in

${ }^{7}$ WOCC look-up tables show $100 \%$ capacity for WC-2 as 1,148 gal. The percent capacity shown in the table is based on this number. 
Section 7.6.4.2.1. An assessment of the integrity of the WC-2 pipelines that cannot be tested for leaks with existing approved methods is summarized in Section 7.6.4.2.2.

\subsection{WC-2 Testable Pipelines}

There are three testable pipelines associated with the WC-2 tank system: two gravity lines and one pressurized discharge line. One gravity line leads from Building 3028 to Tank WC-2 (Segment 93) and the second leads from Building 3038 to WC-2 (Segment 92). The discharge line connects Tank WC-2 with VB-2 (Segment 282). The discharge line was leak tested in December 1995 and the line passed that test. Line Segment 92 was blocked during construction and could not be leak tested. Line Segment 93 is not used and therefore not scheduled for leak testing. Table 31 shows the results of the leak tests conducted on the WC-2 pipelines.

Table 31. Summary of Leak Test Results for the WC-2 Testable Lines.

\begin{tabular}{|c|c|c|c|c|}
\hline Blement No & Une Segment & Test Date & Test Result & . Comment \\
\hline G3 & 93 & N/T & N/A & line not used \\
\hline G14 & 92 & N/T & N/A & $\begin{array}{c}\text { blockage } \\
\text { prevented testing }\end{array}$ \\
\hline P16 & 282 & Dec. 95 & PASS & \\
\hline
\end{tabular}

\subsection{WC-2 Untestable Pipelines}

The untestable portion of the WC-2 system (Line Segments 158 and 171) carries transfers from Tank WC-2 through VB-2 to Tank W-22. WOCC transfer logs show that during the period from February 1995 through December 1995, there were no transfers through these pipelines.

\subsubsection{Analysis of Tank WC-2 Leak Test Data}

During this assessment period, a total of 12 leak tests were attempted on Tank WC-2; of these, 12 tests resulted in conclusive decisions. Figure 28 shows a time series plot of the CVR data obtained from each of the useable test results. It can be seen from the plot that all 12 of the CVR values are within the INFLOW and OUTFLOW decision thresholds, and are thus consistent with the PASS results obtained from these tests.

A comparative analysis of the data shown in Figure 28 was performed. The analysis included using the Student's $t$ - [Mendenhall, 1992], and the K-S [Benjamin and Cornell, 1970] statistical tests. The Student's $t$-test is used to determine the significance of the mean of the CVR data. The K-S analysis is used to determine if the population of CVR values from WC-2 tank is significantly different than a reference set of CVRs. These statistical tests are fully described in Section 5.4. 


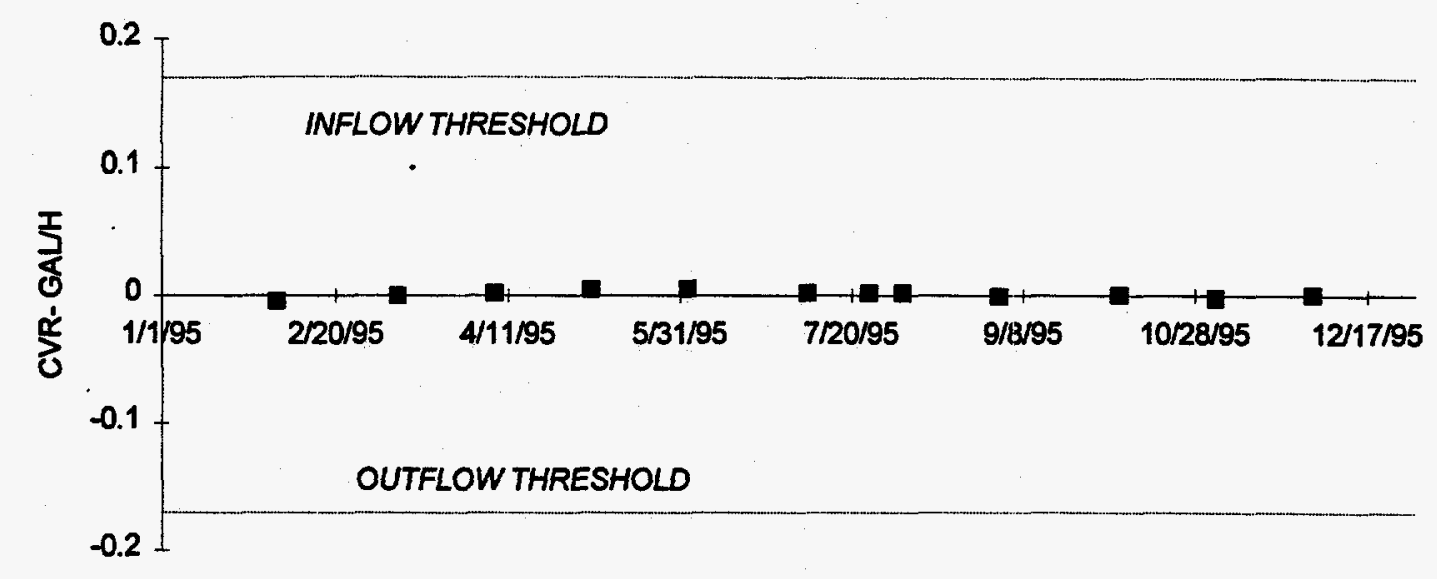

Figure 28. Time series plot of leak test CVRs from Tank WC-2.

As shown below, applying the t-test to the 12 data values shown above results in a tstatistic, $t_{\text {stat }}$, of 1.03 , while the critical value, $t_{\text {crit }}$, is 3.11 , for a $99 \%$ level of confidence. Applying the K-S "goodness-of-fit" test to the WC-2 CVR data, using a H/V weighted set of reference CVRs, results in a maximum ordinal difference, $\mathrm{Ks}_{\text {stat }}$ of 0.37 , while the critical value, $\mathrm{KS}_{\text {crit }}$, is 0.47 , for a $99 \%$ level of confidence. Based upon this analysis, we conclude that the mean and the fluctuations of the 1995 CVR data from Tank WC-2 are entirely consistent with data expected from a non-leaking tank.

Figure 29 graphically illustrates the K-S test applied to the WC-2 data. The bold solid line in the figure shows the CDF obtained from the CVR data shown in Figure 28, after removing the mean from the data. The light dashed line in the figure shows the CDF obtained from the reference set of CVR values (See Section 5.4), after removing the mean from that data and scaling those values by the H/V coefficient of WC-2 (14.72 gal/in.), divided by the H/V of the (mean-removed) reference set (14.72 gal/in.).

The similarity of the data sets defined by the two lines illustrated in Figure 29 is "tested" with the K-S "goodness-of-fit" test. Here, the test statistic, $\mathrm{KS}_{\text {stat, }}$ is 0.37 , while the critical value, $\mathrm{KS}_{\text {erit, }}$ is 0.47 . Since the maximum ordinal difference, $\mathrm{KS}_{\text {stat }}$, is less than $\mathrm{KS}_{\text {erit }}$, the two populations are deemed to be equivalent.

Table 32 summarizes the statistical analyses of the Tank WC-2 CVR data. The table shows that the mean of the CY95 test data is equivalent to zero gal/h, and that the population of CY95 CVR values is not different than the population of CVR values in the reference, or comparison, data set. 


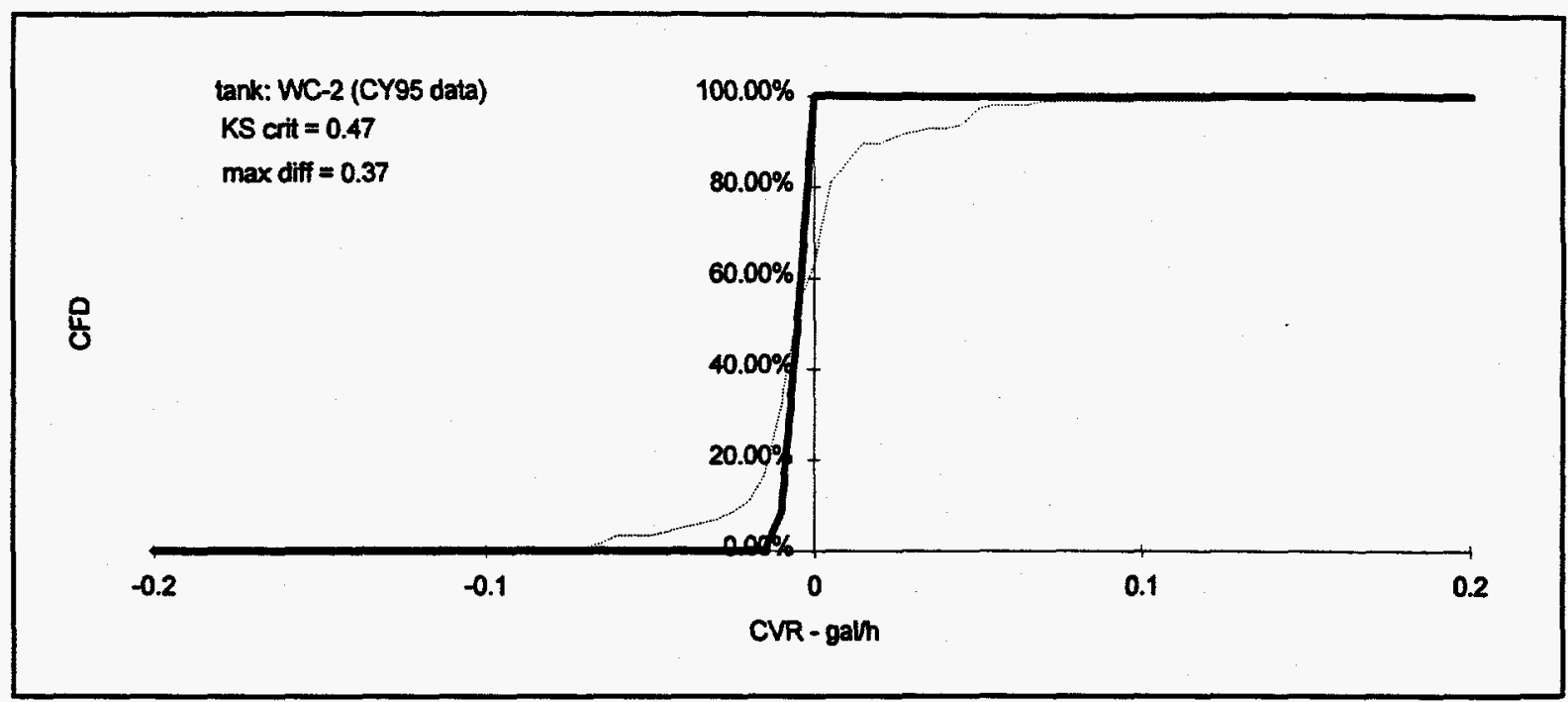

Figure 29. Cumulative frequency distribution from reference CVR data (light dashed line) and WC-2 data (CY95) (bold solid line).

Table 32. Summary of Statistical Analyses of WC-2 CVR Data (H/V=14.72 gal/in)

\begin{tabular}{|c|c|c|}
\hline & Reference CVR data & '95 CVR data \\
\hline $\mathbf{N}$ & 118 & 12 \\
\hline Mean (gal/h) & 0.005 & 0.001 \\
\hline $\begin{array}{c}\text { Standard Deviation } \\
(\mathrm{gal} / \mathrm{h})\end{array}$ & 0.031 & 0.003 \\
\hline t-statistic & & 1.03 \\
\hline t-critical (1\%) & & 3.11 \\
\hline t-test Inference & & mean is same as $0 \mathrm{gal} / \mathrm{h}$ \\
\hline KS-statistic & & 0.37 \\
\hline KS-critical (1\%) & & 0.47 \\
\hline KS-test Inference & & $\begin{array}{l}\text { Same population as } \\
\text { reference set }\end{array}$ \\
\hline
\end{tabular}




\subsubsection{Findings and Conclusions}

The findings of this report are based on (1) a review of available tank design drawings, (2) a qualitative assessment of corrosion on the tank and pipelines, and (3) leak testing results from the tank and testable pipelines.

Review of the design drawings indicated that the tank was designed in accordance with acceptable practices defined by ASTM and ASME. One concern noted was an abundance of inlets into the tank that were not connected to pipelines. However, because the unused inlets are located on the top of the tank, there is no concern that leakage could occur at those locations as long as the tank is operating at less than full capacity. The design drawings revealed a sound design of the WC-2 tank.

During the corrosion assessment, it was determined that with the present use of the tank system, all forms of corrosion on the interior walls of the tank and associated piping should be nonexistent. Corrosion damage that may have occurred when the tank was used in past environments cannot be assessed. Furthermore, an analysis of the general aspects of corrosion at ORNL revealed that corrosion of stainless steel by ORNL soil is not believed to be severe.

Leak testing of Tank WC-2 was completed by the DP method in 12 tests. The tank received PASS results for all twelve tests.

One of three testable line segments passed leak testing by methods discussed previously. Blockage prevented testing of the second testable segment. The third testable line segment is not used and will not be tested. Although a limited evaluation of the untestable pipelines can be made using transfer logs, no transfers occurred during this reporting period.

All of these factors were considered in determining certification of the WC-2 Tank System components. Table 33 summarizes the elements of the tank system which were certified and the conditional limits on their certifications. 
Table 33. Summary of WC-2 Tank System Testing and Certification

\begin{tabular}{|c|c|c|c|c|c|c|}
\hline $\begin{array}{l}\text { Systen } \\
\text { Component }\end{array}$ & I length & $\begin{array}{l}\text { Tested } \\
\text { (YesiNo) }\end{array}$ & $\begin{array}{l}\text { Leal } \\
\text { Test } \\
\text { Method } \\
\end{array}$ & Result & Certification & Certincation \\
\hline Tank WC-2 & & Yes & DP & PASS & Yes & $32 \%$ \\
\hline LS-92 & 200 & No & $\mathrm{N} / \mathrm{T}$ & $\mathrm{N} / \mathrm{T}$ & No & $\mathrm{N} / \mathrm{T}$ \\
\hline LS-93 & 200 & No & $\mathrm{N} / \mathrm{T}$ & $\mathrm{N} / \mathrm{T}$ & No & $\mathrm{N} / \mathrm{T}$ \\
\hline LS-117 & 30 & No & $\mathrm{N} / \mathrm{T}$ & $\mathrm{N} / \mathrm{T}$ & No & $\mathrm{N} / \mathrm{T}$ \\
\hline LS-137 & 18 & No & $\mathrm{N} / \mathrm{T}$ & $\mathrm{N} / \mathrm{T}$ & No & $\mathrm{N} / \mathrm{T}$ \\
\hline LS-158 & 9 & No & $\mathrm{N} / \mathrm{T}$ & $\mathrm{N} / \mathrm{T}$ & No & $\mathrm{N} / \mathrm{T}$ \\
\hline LS-171 & 6 & No & $\mathrm{N} / \mathrm{T}$ & $\mathrm{N} / \mathrm{T}$ & No & $\mathrm{N} / \mathrm{T}$ \\
\hline LS-187 & 13 & No & $\mathrm{N} / \mathrm{T}$ & $\mathrm{N} / \mathrm{T}$ & No & $\mathrm{N} / \mathrm{T}$ \\
\hline LS-281 & 127 & No & $\mathrm{N} / \mathrm{T}$ & $\mathrm{N} / \mathrm{T}$ & No & $\mathrm{N} / \mathrm{T}$ \\
\hline LS-282 & 685 & Yes & GPD & PASS & Yes & Full flow \\
\hline \multicolumn{7}{|c|}{$\begin{array}{ll}\text { DP } & \text { Differential Pressure } \\
\text { EVB } & \text { Enhanced volume balancing } \\
\text { gph } & \text { Gallons per hour } \\
\text { LS } & \text { Line segment } \\
\text { N/T } & \text { Not testable }\end{array}$} \\
\hline
\end{tabular}




\subsubsection{Certification}

Based on the results of the design drawings review, the qualitative corrosion assessment, and the results of the leak testing program, it is my professional opinion that Tank WC-2 retains sufficient structural integrity to contain liquids at operating levels up to the maximum level which achieved a PASS during the testing program. Also, based upon the results of the pipeline tests, it is my professional opinion that Line Segment 282 retains sufficient integrity to contain liquids up to the full flow potential of this line segment. Table 33 provides a summary description of the certifications for the WC-2 Tank System. If future testing is conducted at greater tank levels, then certification levels may also increase.

It is recommended that leak detection and line testing be continued using EPA and TDEC approved methods, to support annual certification, until this system has been removed from operation or replaced.

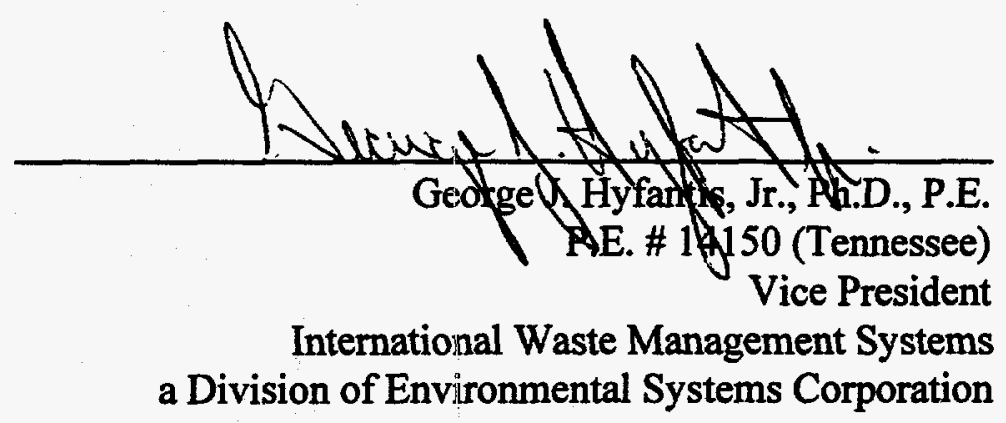




\subsection{WC-3 Tank System}

The WC-3 Tank System is located directly south of Building 3025, as shown in Figure 1. The tank system is made up of Tank WC-3 and eight line segments connected to the tank system. The WC-3 Tank System collects waste from the gravity-fed pipeline system in Building 3025. These wastes are transferred by steam-jet from WC-3 to the Evaporator Complex via Valve Pit 3026 (VP-3026) and Valve Box No 1. Because the lines and tank are all singly contained, the tank system has been given the classification of Category $\mathrm{C}$, according to the FFA.

\subsubsection{WC-3 Tank Description}

Tank WC-3 is a 1,000 gallon, buried, singly contained tank. Installed in 1951, WC-3 is mounted vertically to a $7^{\prime}-6^{\prime \prime} \times 7^{\prime}-6^{\prime \prime} \times 11^{\prime}-3^{\prime \prime}$ concrete pad. The tank is constructed of 347 stainless steel and was designed with a 1/4" wall thickness. All materials welded to the tank are also 347 stainless steel. The tank is constructed with a 3/8" thick ASME flanged dished head on top and a 1/4" thick ASME flanged dished head on the bottom. The outside diameter of the tank is $5^{\prime}-6^{\prime \prime}$, with a total height of 7'-4-1/4". The design drawing for Tank WC-3 is provided as Figure 30.

The tank is equipped with nine $3 "$ diameter flanged nozzles, one 8" diameter flanged nozzle, and one 16" diameter manhole opening. The flanged nozzles are located around a 2'-0" radius of the tank center, and the manhole is located in the center of the tank. Each of the 3" diameter flanges are fitted to be secured by four $5 / 8$ " diameter bolts, and the manhole is fitted to be secured by sixteen $3 / 4^{\prime \prime}$ diameter bolts. All flanges are slip on welding type. All of the necessary welds on the tank are specified in accordance with codes from the ASTM for unfired pressure vessels. At the time of construction, the welds were specified to provide substantially the same composition as adjacent, unwelded metal. The tank is ventilated to the atmosphere through an HEPA filter.

The pit containing the tank was constructed with an 8" diameter vitrified pipe dry well in the southeast corner, extending to just above ground surface. A jet pit which houses an earthen sump is located to the direct south of the tank pit. The sump is located in the northwest corner of the jet pit.

Building 3025 is the only source of waste which enters Tank WC-3. A schematic of the tank system with numbered line segments is shown in Figure 31. 


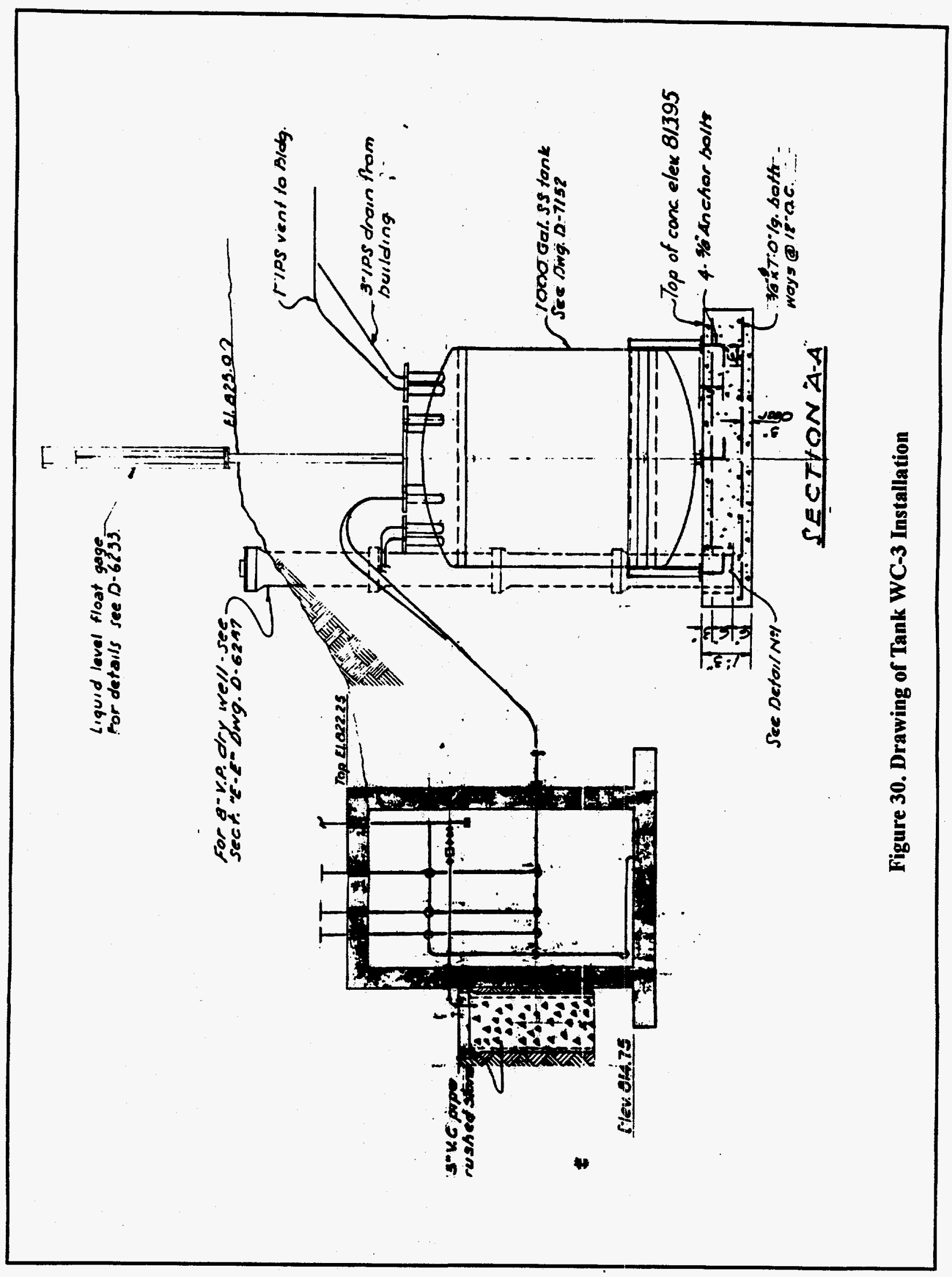




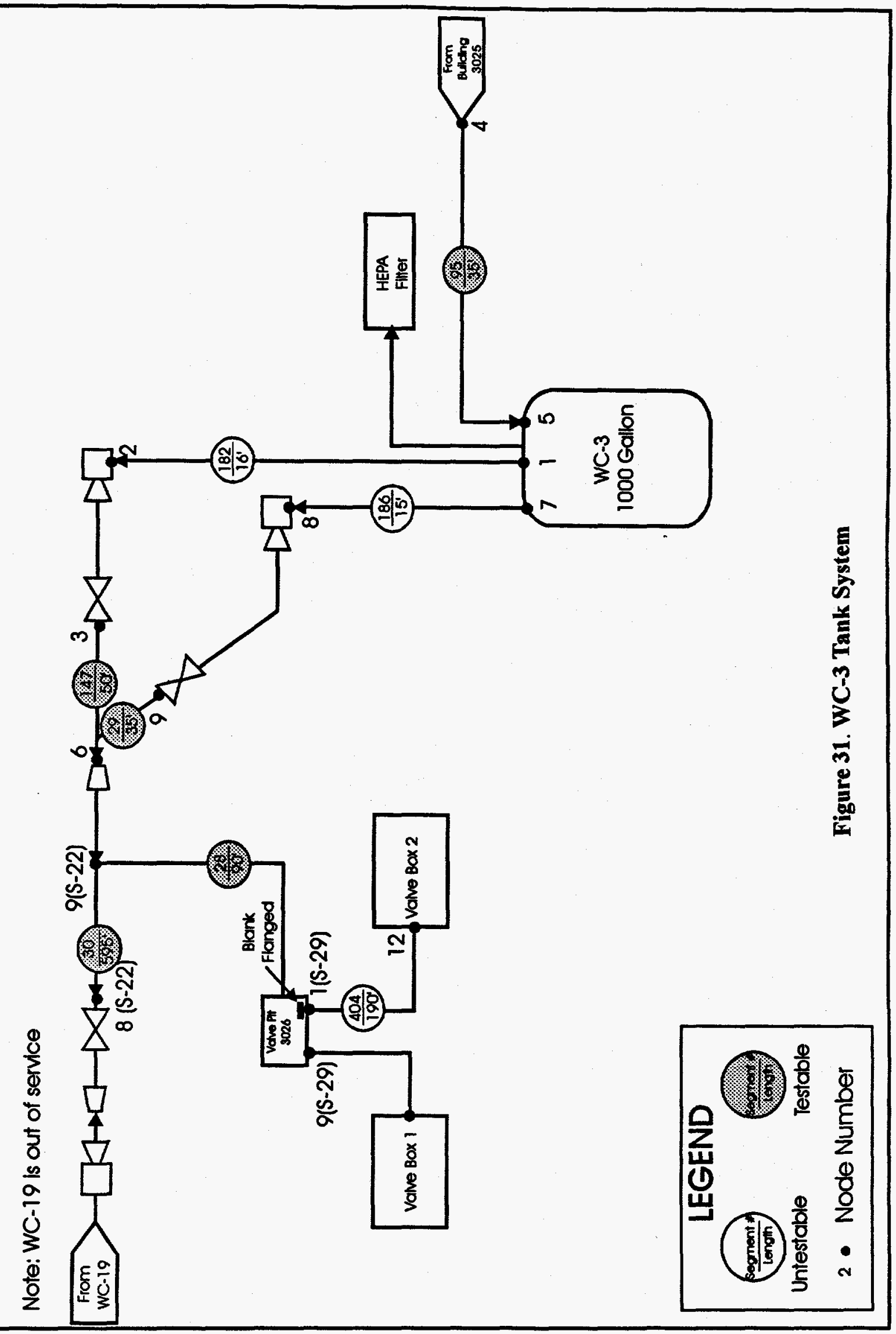




\subsubsection{WC-3 Pipeline Descriptions}

Eight separate lines make up the portion of the LLLW pipeline system belonging to Tank WC-3. Details of these lines are listed in Table 33, and line segment numbers are shown in Figure 31. All pipelines associated with the WC-3 Tank System are constructed of 347 stainless steel and were installed in 1951. Materials are transferred through pipelines of WC-3 tank by either a steam jet pump (SJ), or a suction steam jet pump (SJ Suct.). As shown in Figure 31, WC-3 tank has one inlet line and two outlet lines. The remaining five line segments are not directly connected to Tank WC-3.

Of the eight pipelines associated with Tank System WC-3, there are three testable pipeline elements made up of five separate line segments. The first is a gravity-fed line that drains from Building 3025 into Tank WC-3. This line, identified as Line Segment 95 is a 35' long gravity-fed line with a 3" diameter (Building 3025 to node 5 in Figure 31).

A second testable pipeline element, P37, is a pressurized piping network leading from Tank WC-19 and Tank WC-3 to Valve Box 1 via Valve Pit 3026 and Tank W-16. Element P37 consists of four line segments defined as belonging to WC-3, identified as Line Segments 147, 29, 30, and 28. Line Segments 28, 29, 147, and 30 all intersect at a manifold. Line Segment 28 (nodes 9S-22 to VP-3026) is a 2" diameter line carrying LLLW from lines 29, 147, and 30 to valve pit VP-3026. Line Segment 29 (nodes 9 to 6) extends $35^{\prime}$ from the isolation valve to the reducer, and intersects with Line Segment 147. Line Segment 30 (nodes 9S-22 to 8S-22) extends $595^{\prime}$ from a reducer connecting to the WC-19 pipeline system.

The third testable pipeline element associated with Tank System WC-3 is a pressurized, 2 " diameter, 190' long segment leading from VP-3026 to Valve Box 2. This element is made up of Line Segment 404, which is no longer used and is therefore not scheduled for testing. All of these previously described lines are made of 347 stainless steel.

The two outlet lines from the tank have index numbers 182 and 186. These lines are $16^{\prime}$ and $15^{\prime}$ long, respectively, and neither of these $1^{\prime \prime}$ diameter lines is testable. The system has two steam jets inductors that are used to transfer LLLW from WC-3 tank to the VP-3026. The suction lines from Tank WC-3 to the jets cannot be tested because they cannot be isolated. Line Segment 182 runs from node 1 to node 3 in Figure 31. Line Segment 186 connects Line Segment 29 and Tank WC-3 (node 7 to node 9).

Line Segments 95, 147, 29, 30, and 28 were successfully tested. Each of the line segments were tested by the EVB or GPD testing technique described in Section 3.2.1. The results of the leak testing are included in Section 7.9.4. The characteristics of each of the eight lines evaluated as part of Tank System WC-3 are given in Table 34. 
Table 34. Characteristics of Line Segments Evaluated as a Part of Tank System WC-3

\begin{tabular}{|c|c|c|c|c|c|c|c|c|c|}
\hline \multicolumn{2}{|c|}{ Line Segment } & 28 & 29 & 30 & 95 & 147 & 182 & 186 & 104 \\
\hline \multicolumn{2}{|c|}{ Node Numbers } & $\begin{array}{l}\text { S22-N9 to } \\
\text { VP-3026 }\end{array}$ & 9 to 6 & $\begin{array}{l}\text { S22-N9 to } \\
\text { S22-N8 }\end{array}$ & 4 to 5 & 3 to 6 & 1 to 3 & 7 to 8 & $\begin{array}{l}\text { S29-N1 } \\
\text { to } 12\end{array}$ \\
\hline \multicolumn{2}{|c|}{ Index Number } & P37 & P37 & P37 & G2 & P37 & * & * & P19 \\
\hline \multicolumn{2}{|c|}{ Diameter (in) } & 2 & 2 & 2 & 3 & 1 & 1 & 1 & 2 \\
\hline \multicolumn{2}{|c|}{ Material } & $347 \mathrm{SS}$ & $347 \mathrm{SS}$ & $347 \mathrm{SS}$ & $347 \mathrm{SS}$ & 347 SS & $347 \mathrm{SS}$ & $347 \mathrm{SS}$ & 347 SS \\
\hline \multicolumn{2}{|c|}{ Length ( $\mathrm{ft}$ ) } & 90 & 35 & 595 & 35 & 50 & 16 & 15 & 190 \\
\hline \multicolumn{2}{|c|}{ Volume (gal) } & 16 & 6 & 104 & 13 & 2 & 1 & 1 & 33 \\
\hline \multicolumn{2}{|c|}{$\begin{array}{l}\text { Transfer } \\
\text { Method }\end{array}$} & SJ & SJ & SJ & G & SJ & $\begin{array}{l}\text { SJ \& } \\
\text { Suct. }\end{array}$ & $\begin{array}{l}\text { SJ \& } \\
\text { Suct. }\end{array}$ & SJ \\
\hline \multicolumn{2}{|c|}{ Install Date } & 1951 & 1951 & 1951 & 1951 & 1951 & 1951 & 1951 & 1951 \\
\hline \multicolumn{10}{|c|}{\begin{tabular}{|ll}
$*$ & Transfer records available \\
G & Gravity \\
SJ & Steam jet pump \\
Suct. & Suction \\
SS & Stainless Steel \\
\end{tabular}} \\
\hline
\end{tabular}

\subsubsection{Corrosion Assessment of WC-3 Tank System}

Tank WC-3 presently serves only Building 3025. The solutions added to the tank are those associated with analytical and metallographic procedures and include etching and electropolishing solutions (highly acidic), acetone, alcohol, and decontaminating solutions, some of which include salts of citric acid. No chlorine-containing chemicals are used. None of the waste solution is neutralized before addition to the tank, but the lines are flushed with water after each addition. The $\mathrm{pH}$ of the tank solution is maintained at about 13 by adding a strong alkaline solution to the tank every time the waste is pumped out. Under the present conditions, attack on the interior tank walls should not be severe. How much damage may have occurred over the years when tank alkalinity may not have been maintained cannot be assessed.

The tank and associated piping are buried directly in the soil without benefit of coating or cathodic protection. However, based on information cited in Section 4, corrosion of stainless steel by ORNL soil is not believed to be severe.

\subsubsection{Results of Leak Tests on the WC-3 System}

This section summarizes the results of the leak detection tests conducted on Tank System WC-3 (the tank and its associated pipelines). Each element in the system was tested with a method appropriate for that element. Each method used has been demonstrated to detect a specified leak rate $(0.2 \mathrm{gal} / \mathrm{hr}$ for tank methods; $0.1 \mathrm{gal} / \mathrm{hr}$ for pipeline methods) with a PD no less than $95 \%$ and a Pra no greater than $5 \%$. 


\subsubsection{Tank}

Leak testing of Tank WC-3 for the current assessment period began in February 1995 and continued at routine intervals through December 1995, with a total of 13 leak test attempts during this reporting period. The results of these tests are summarized in Table 35, which shows the date of each test, the volume of LLLW in the tank at the time of the test, the percent of Tank WC-3's total volume the test represented ${ }^{8}$, the test result, and comments pertinent to particular tests. The table shows that Tank WC-3 recorded PASS results for 12 of the leak tests. One test was attempted while the tank was empty. The maximum volume for which the tank passed the leak testing during this reporting period was 490 gallons, or $43 \%$ of the total capacity. This is greater than the previously certified level of 412 gallons (36\%) for this tank and thus represents a new high level for certification purposes [DOE/OR/01-1385\&D2].

Table 35. Summary of Leak Tests Conducted on Tank WC-3

\begin{tabular}{|c|c|c|c|c||}
\hline Date & H or Gallons & \% Capacit & Test Result .7 & comment \\
\hline $02 / 03 / 95$ & 247 & 22 & PASS & \\
\hline $03 / 10 / 95$ & 277 & 24 & PASS & \\
\hline $04 / 07 / 95$ & 300 & 26 & PASS & \\
\hline $05 / 05 / 95$ & 303 & 26 & PASS & \\
\hline $06 / 06 / 95$ & 340 & 30 & PASS & \\
\hline $07 / 07 / 95$ & 334 & 29 & PASS & \\
\hline $07 / 25 / 95$ & 338 & 29 & PASS & \\
\hline $08 / 04 / 95$ & 339 & 30 & PASS & \\
\hline $09 / 01 / 95$ & 31 & N/A & EMPTY & \\
\hline $09 / 01 / 95$ & 169 & 15 & PASS & \\
\hline $10 / 06 / 95$ & 185 & 16 & PASS & \\
\hline $11 / 03 / 95$ & 247 & 22 & PASS & \\
\hline $12 / 01 / 95$ & 490 & 43 & PASS & \\
\hline
\end{tabular}

The 12 usable CVR data values from these leak tests were analyzed (1) to verify that the test method was performing properly in this application and (2) to confirm that during this assessment period the leak testing process had remained nominal; that is, that the use or performance of, the method as applied to this particular tank was not deteriorating. This analysis included a statistical examination of the CVR data, as well as a comparison of this year's assessment data with prior data. The analysis and the results are described in Section 7.7.4.3.

\subsubsection{WC-3 Pipelines}

The results of the leak detection test on the testable WC-3 pipelines are summarized in Section 7.7.4.2.1. An assessment of the integrity of the WC-3 pipelines that cannot be tested for leaks with existing approved methods is summarized in Section 7.7.4.2.2.

${ }^{8}$ WOCC look-up tables show $100 \%$ capacity for WC-3 as 1,148 gal. The percent capacity shown in the table is based on this number. 


\section{7.4.2.1 WC-3 Testable Pipelines}

There are three testable pipelines associated with the WC-3 tank system: one gravity line and two pressurized discharge lines. The gravity line (G2) leads from Building 3025 to Tank WC-3 (segment 95). The principal pressurized line (P37) is comprised of four Line Segments $28,29,30,147$, which are all part of the WC-3 to Valve Pit 3026 discharge system. This piping is also connected with the discharge piping from Tanks WC-19 and W-16. This pressurized piping system passed a leak test in September 1996. The other pressurized line (P19) leads from Valve Pit 3026 to VB2 (segment 404), but is not used and therefore not scheduled for leak testing. The gravity line, G2, was tested in November 1995, yielding a PASS result. Table 36 shows the results of the leak tests conducted on the WC-3 pipelines.

Table 36. Summary of Leak Test Results for the WC-3 Testable Lines.

\begin{tabular}{|c|c|c|c|c|}
\hline Element No & Line Segment & Test Date. & Test Result & Comment \\
\hline G2 & 95 & November 1995 & PASS & \\
\hline P37 & $28,29,30,147$ & September 1996 & PASS & \\
\hline P19 & 404 & N/T & N/A & not used; not tested \\
\hline
\end{tabular}

\subsection{WC-3 Untestable Pipelines}

The untestable portion of the WC-3 System consists of two suction lines (Line Segments 182 and 186) between Tank WC-3 and the jet pumps that are used to transfer LLLW from Tank WC-3 to Valve Box 1 and onto Tank W-22. Line Segment 186 (node 7 to node 9) is not used. Transfer logs show that during the period from January 1995 through December 1995, one transfer was made from WC-3 tank to W-22 tank. This transfer is summarized in the first four columns of Table 37. The difference between the volume sent (Column 3) and the volume received (Column 4) is shown in Column 5.

Table 37. Summary of Transfers between WC-3 and W-22 from January 1995 to December 1995

\begin{tabular}{|c|c|c|c|c|c|c|}
\hline Transfer & Transfer 109 & $\begin{array}{l}\text { Volime: } \\
\text { Sent } \\
\text { (Gar) }\end{array}$ & $\begin{array}{l}\text { Volune } \\
\text { Received } \\
\text { (Gal) }\end{array}$ & Bifference & $\begin{array}{l}\text { Maximum } \\
\text { Expected } \\
1(6 a)\end{array}$ & $\begin{array}{l}\text { Is difference } \\
\text { greaterthan } \\
\text { expected }\end{array}$ \\
\hline $8 / 18 / 95$ & WC-3 to W-22 & 426 & 450 & 24 & 141 & No \\
\hline
\end{tabular}

For the WC-3 tank to W-22 tank transfer, the expected error was 141 gallons. The recorded transfer showed an input output volume difference less than the maximum expected error; therefore, it is concluded that there were no significant differences during this assessment period. 


\subsubsection{Analysis of Tank WC-3 Leak Test Data}

During this assessment period, a total of 13 leak tests were attempted on Tank WC-3; of these, 12 tests resulted in conclusive decisions. Figure 32 shows a time series plot of the CVR data obtained from each of the useable test results. It can be seen from the plot that all 12 of the CVR values are within the INFLOW and OUTFLOW decision thresholds, and are thus consistent with the PASS results obtained from these tests.

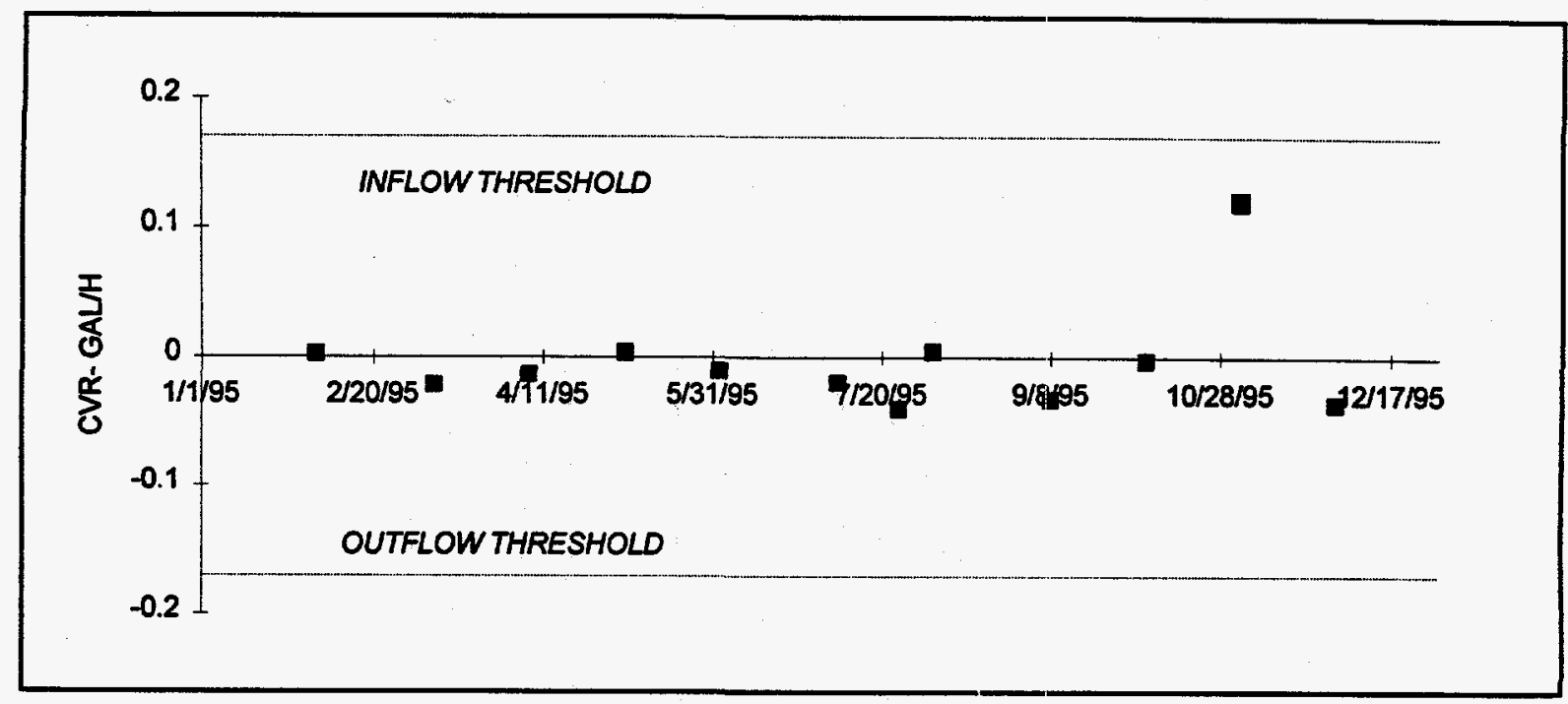

Figure 32. Time series plot of leak test CVRs from Tank WC-3.

A comparative analysis of the data shown in Figure 32 was performed. The analysis included using the Student's t- [Mendenhall, 1992], and the K-S [Benjamin and Cornell, 1970] statistical tests. The Student's $t$-test is used to determine the significance of the mean of the CVR data. The K-S analysis is used to determine if the population of CVR values from Tank WC-3 is significantly different than a reference set of CVRs. These statistical tests are fully described in Section 5.4.

As shown below, applying the t-test to the 12 data values shown above results in an absolute value of the $t$-statistic, $t_{\text {stat }}$ of 0.31 , while the critical value, $t_{\text {crit }}$, for a $99 \%$ level of confidence, is 3.11. Applying the K-S "goodness-of-fit" test to the WC-3 tank CVR data, using a $\mathrm{H} / \mathrm{V}$ weighted set of reference CVRs, results in a maximum ordinal difference, $\mathrm{KS}_{\text {stat, }}$ of 0.31 , while the critical value, $\mathrm{KS}_{\text {crit }}$ is 0.47 , for a $99 \%$ level of confidence. Based upon this analysis, we conclude that both the mean and the fluctuations of the 1995 CVR data from Tank WC-3 are entirely consistent with data expected from a non-leaking tank.

Figure 33 graphically illustrates the K-S test applied to the WC-3 data. The bold solid line in the figure shows the CDF obtained from the CVR data shown in Figure 32, after removing the mean from the data. The light dashed line in the figure shows the CDF obtained from the reference set of CVR values (See Section 5.4), after removing the mean from that data and scaling those values by the H/V coefficient of Tank WC-3 (14.72 gal/in.), divided by the $\mathrm{H} / \mathrm{V}$ of the (mean-removed) reference set (14.72 gal/in.). 
The similarity of the data sets defined by the two lines illustrated in Figure 33 is "tested" with the K-S "goodness-of-fit" test. Here, the test statistic, $\mathrm{KS}_{\text {stat }}$ is 0.31 , while the critical value, $\mathrm{KS}_{\text {crit }}$ is 0.47 . Since the maximum ordinal difference, $\mathrm{KS}_{\text {stat }}$, is less than $\mathrm{KS}_{\text {erit }}$, the two populations are deemed to be equivalent.

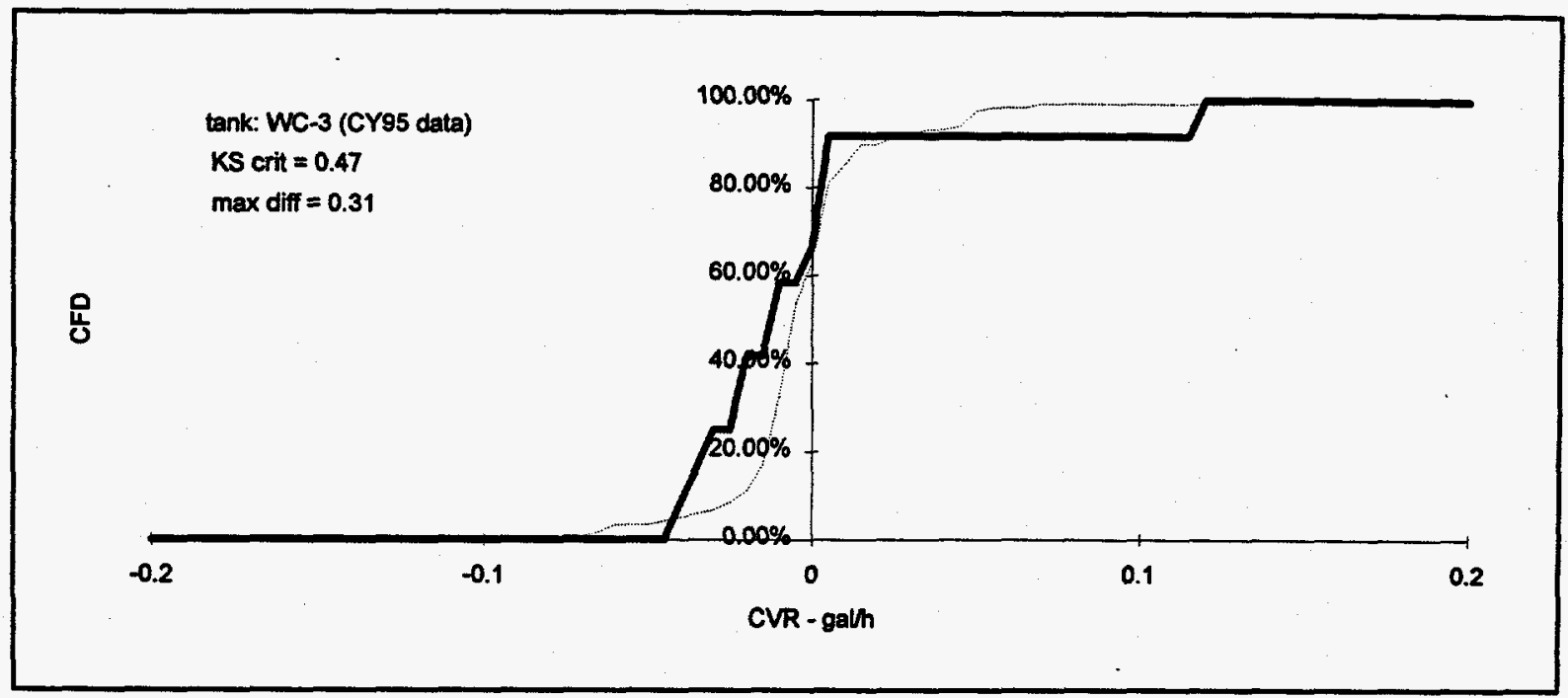

Figure 33. Cumulative frequency distribution from reference CVR data (light dashed line) and WC-2 data (CY95) (bold solid line).

Table 38 summarizes the statistical analysis of the Tank WC-3 CVR data. The table shows that the mean of the CY95 test data is equivalent to zero gal/h, and that the population of CY95 CVR values is not different than the population of CVR values in the reference, or comparison, data set.

Table 38. Summary of Statistical Analyses of Tank WC-3 CVR Data (H/V=14.72 gal/in)

\begin{tabular}{|c|c|c||}
\hline & Reference CVR data & '95 CVR data \\
\hline $\mathrm{N}$ & 118 & 12 \\
\hline Mean (gal/h) & 0.005 & -0.004 \\
\hline $\begin{array}{c}\text { Standard Deviation } \\
\text { (gal/h) }\end{array}$ & 0.031 & 0.042 \\
\hline t-statistic & & -0.31 \\
\hline t-critical (1\%) & mest Inference & 3.11 \\
\hline t-test & mean is same as 0 gal/h \\
\hline KS-statistic & 0.31 \\
\hline KS-critical (1\%) & r & 0.47 \\
\hline KS-test Inference & $\begin{array}{c}\text { Same population as } \\
\text { reference set }\end{array}$ \\
\hline
\end{tabular}




\subsubsection{Findings and Conclusions}

The findings of this report are based on (1) a review of available tank design drawings, (2) a qualitative assessment of corrosion on the tank and pipelines, and (3) leak testing results from the tank and testable pipelines.

Review of the design drawings indicated that the tank was designed in accordance with acceptable practices defined by ASTM and ASME. One concern noted was an abundance of nozzles into the tank that were not connected to pipelines. However, because the unused nozzles are located on the top of the tank, there is no concern that leakage could occur at those locations as long as the tank is operating at less than full capacity. The design drawings revealed a sound design of the tank.

During the corrosion assessment, it was determined that with the present use of the tank system, all forms of corrosion on the interior walls of the tank and associated piping should be nonexistent. Corrosion damage that may have occurred when the tank was used in past environments cannot be assessed. Furthermore, an analysis of the general aspects of corrosion at ORNL revealed that corrosion of stainless steel by ORNL soil is not believed to be severe.

Leak testing of Tank WC-3 was completed by the DP method in 1327 tests. The tank had PASS results for 12 of the leak tests, and was empty at the time of one test.

Five of the six testable line segments passed leak testing by methods discussed previously. Line Segment 404 is not used and will not be tested.

Transfer logs were used to qualitatively assess the pipelines which are untestable by currently approved methods. These transfer logs reveal that one transfer was made, during the period from January through December 1994. The difference between the measured volume sent from Tank WC-3 and the measured volume received in Tank W-22 was less than the maximum expected error. The successful transfer, coupled with the untestable line being a suction line, are a positive indication of the lines integrity. The volume of the transfer along with the latest qualitative assessment of the pipelines are reported to EPA and TDEC in the "Quarterly Highlights for LLLW Tank System Activities." Although a limited evaluation of the untestable pipelines can be made using transfer logs, this method of assessment, due to its limited accuracy, is not deemed valid for certification purposes.

All of these factors were considered in determining certification of the WC-3 Tank System components. Table 39 summarizes the elements of the tank system that were certified and the conditional limits on their certifications. 
Table 39. Summary of Tank System Certification for Tank WC-3

\begin{tabular}{|c|c|c|c|c|c|c|c|}
\hline \multicolumn{2}{|c|}{$\begin{array}{l}\text { System } \\
\text { Conponent }\end{array}$} & Vength & (Tested & $\begin{array}{l}\text { teal } \\
\text { rest } \\
\text { hethod }\end{array}$ & Result & Certification & Certification \\
\hline \multicolumn{2}{|c|}{ Tank WC-3 } & & Yes & DP & PASS & Yes & $43 \%$ \\
\hline \multicolumn{2}{|l|}{ LS-95 } & 35 & Yes & EVB & PASS & Yes & $32 \mathrm{gph}$ \\
\hline \multicolumn{2}{|l|}{ LS-28 } & 90 & Yes & GPD & PASS & Yes & Full Flow \\
\hline \multicolumn{2}{|l|}{ LS-29 } & 35 & Yes & GPD & PASS & Yes & Full Flow \\
\hline \multicolumn{2}{|l|}{ LS-30 } & 595 & Yes & GPD & PASS & Yes & Full Flow \\
\hline \multicolumn{2}{|c|}{ LS-147 } & 50 & Yes & GPD & PASS & Yes & Full Flow \\
\hline \multicolumn{2}{|c|}{ LS-182 } & 16 & No & $\mathrm{N} / \mathrm{T}^{*}$ & $\mathrm{~N} / \mathrm{T}$ & No & $\mathrm{N} / \mathrm{T}$ \\
\hline \multicolumn{2}{|c|}{ LS-186 } & 15 & No & $\mathrm{N} / \mathrm{T}^{*}$ & $\mathrm{~N} / \mathrm{T}$ & No & $\mathrm{N} / \mathrm{T}$ \\
\hline \multicolumn{2}{|c|}{ LS-404 } & 190 & No & $\mathrm{N} / \mathrm{T}$ & $\mathrm{N} / \mathrm{T}$ & No & $\mathrm{N} / \mathrm{T}$ \\
\hline \multicolumn{8}{|c|}{$\begin{array}{ll}* & \text { Trans } \\
\text { DP } & \text { Differ } \\
\text { EVB } & \text { Enhar } \\
\text { GPD } & \text { Gas p } \\
\text { gph } & \text { Gallo } \\
\text { LS } & \text { Line s } \\
\text { N/T } & \text { Not te } \\
\text { N/A } & \text { Not A } \\
\end{array}$} \\
\hline
\end{tabular}




\subsubsection{Certification}

Based on the results of the design drawings review, the qualitative corrosion assessment, and the results of the leak testing program, it is my professional opinion that Tank WC-3 retains sufficient structural integrity to contain liquids at operating levels up to the maximum level which achieved a PASS during the testing program. Also, based upon the results of the pipeline tests, it is my professional opinion that Line Segments $95,28,29,30$ and 147 retains sufficient integrity to contain liquids up to a flow rate of $32 \mathrm{gph}$. Table 39 provides a summary description of the certifications for the WC-3 Tank System. If future testing is conducted at larger pipeline flows and greater tank levels, then certification levels may also increase.

It is recommended that leak detection and line testing using the EPA and TDEC approved methods be continued, to support annual certification, until this system has been removed from operation or replaced.

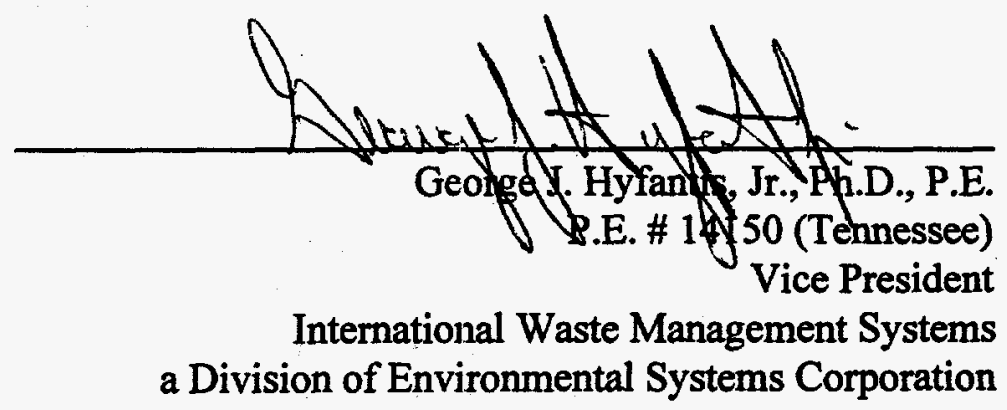




\subsection{WC-9 Tank System}

The WC-9 Tank System located in the Bethel Valley area south of Building 3503, as shown in Figure 1. The tank system is an active system, and collects rainwater from the WC-9 Pump Pit. It was also used to drain LLLW from Building 3503. The tank system is singly contained and is classified as Category $\mathrm{C}$.

\subsubsection{WC-9 Tank Description}

Tank WC-9 is a 2,150 gallon, buried, singly contained tank, and was installed in 1962. The tank is mounted vertically on four legs anchored to a concrete pad. The tank is constructed of 347 stainless steel with an outside diameter of 7'-0" and a length of 10'-9". The bottom of the tank is concave on an 84" radius and the top of the tank has a flanged dished head profile on an 84 " radius with a $1 / 8$ " minimum wall thickness. The top of the tank has four 2 " diameter flanged nozzles, three 2-1/2" diameter flanged nozzles, one 4" diameter-flanged nozzle, and one 18" diameter flanged manhole located at the top center of the tank. All of the flanged nozzles are located around a 3'-0" radius from the center of the tank. The manhole is fitted with a 16" I. D. extension constructed with $3 / 16^{\prime \prime}$ stainless steel walls. The manhole is capped with a 30" diameter-flanged inlet. The height of the extension is unknown. Two lifting lugs are provided located on opposite sides of the top of the tank. The operating volume of the tank is 1,500 gallons. The design drawing for Tank WC-9 is given in Figure 34. The tank is located in an earthen pit backfilled with crushed stone. The burial depth is 6'-6" to the top of the tank.

Tank WC-9 is capable of receiving material from three sources. The sources originate in Building 3503, an off-gas condensate drain trap located south of Building 3503, and a pump pit sump pump. A schematic of the tank system with numbered line segments is provided in Figure 35.

\subsubsection{WC-9 Pipeline Descriptions}

Nine separate line segments make up the portion of the LLLW pipeline system belonging to the WC-9 Tank System. Characteristics of the lines are listed in Table 40, and line segments numbers are shown in Figure 35.

The testable portion of the WC-9 pipeline system consists of two elements: the gravityfed inlet line from Building 3503 to Tank WC-9 and a portion of the pressurized discharge line between Tank WC-9 and Valve Box 2. The testable gravity-fed inlet line, Line Segment 97 (node 1 to node 2 in Figure 34), is 95' long, has a diameter of 3", and is made of 347 stainless steel. The testable pressurized line, index number P2 consists of two Line Segments, 301 and 27 (node 41 to node 10). Index number P2 includes a section of doubly contained pipeline which connects Tank WC-9 with the discharge line to Valve Box 2. Designated as Line Segment 301 , this line is $35^{\prime}$ long, and has an inner pipe diameter of $2^{\prime \prime}$ and an outer pipe diameter of 3". Line Segment 301 (node 41 to node 42) is made of stainless steel. Line Segment 27 (node 23 to node 10) is 1096' long and has a diameter of 2". Please note that nodes 6,23 , and 42 are all in one location and are only included for clarity of line identification. 


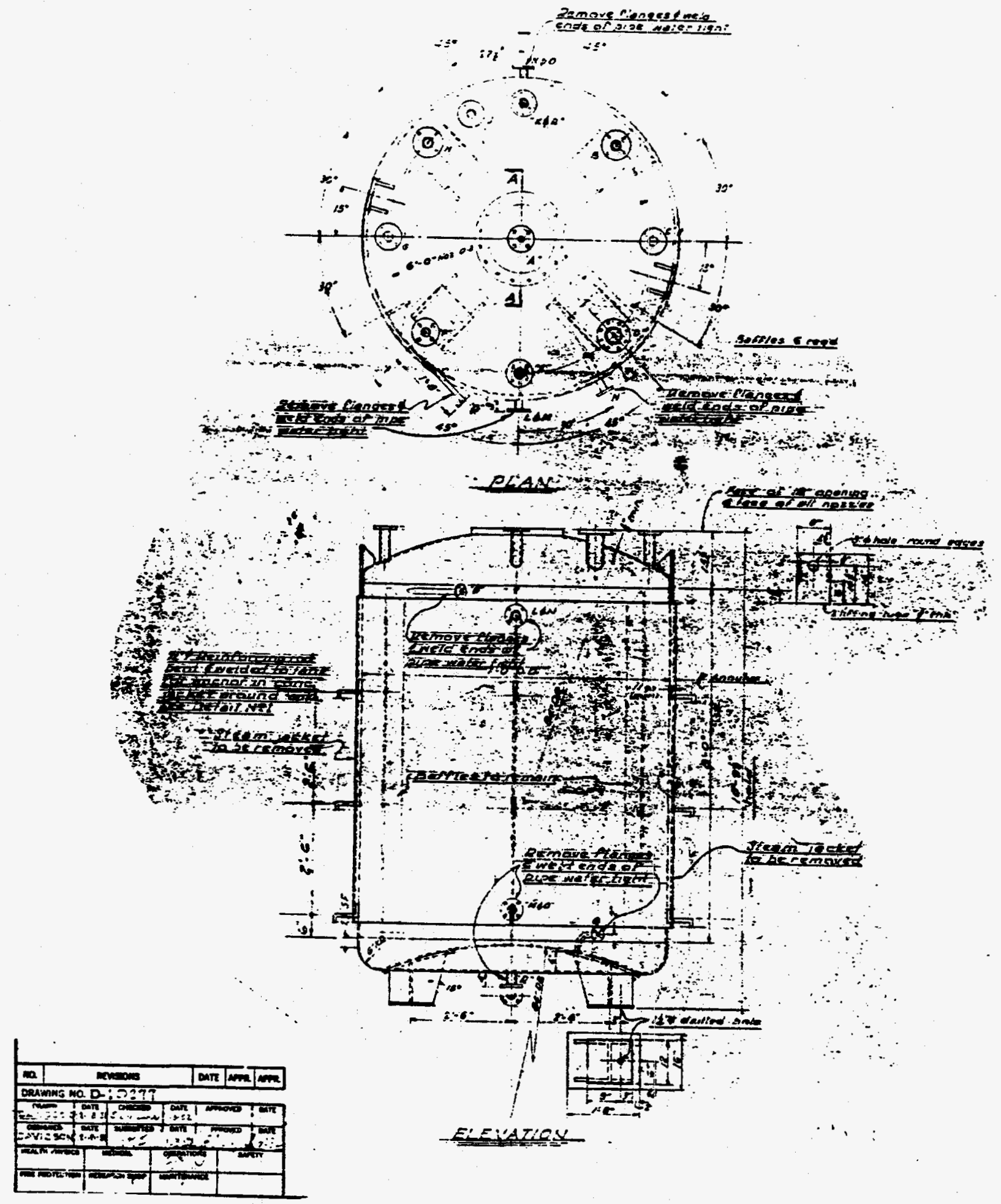

Figure 34. WC-9 Tank Design Drawing 

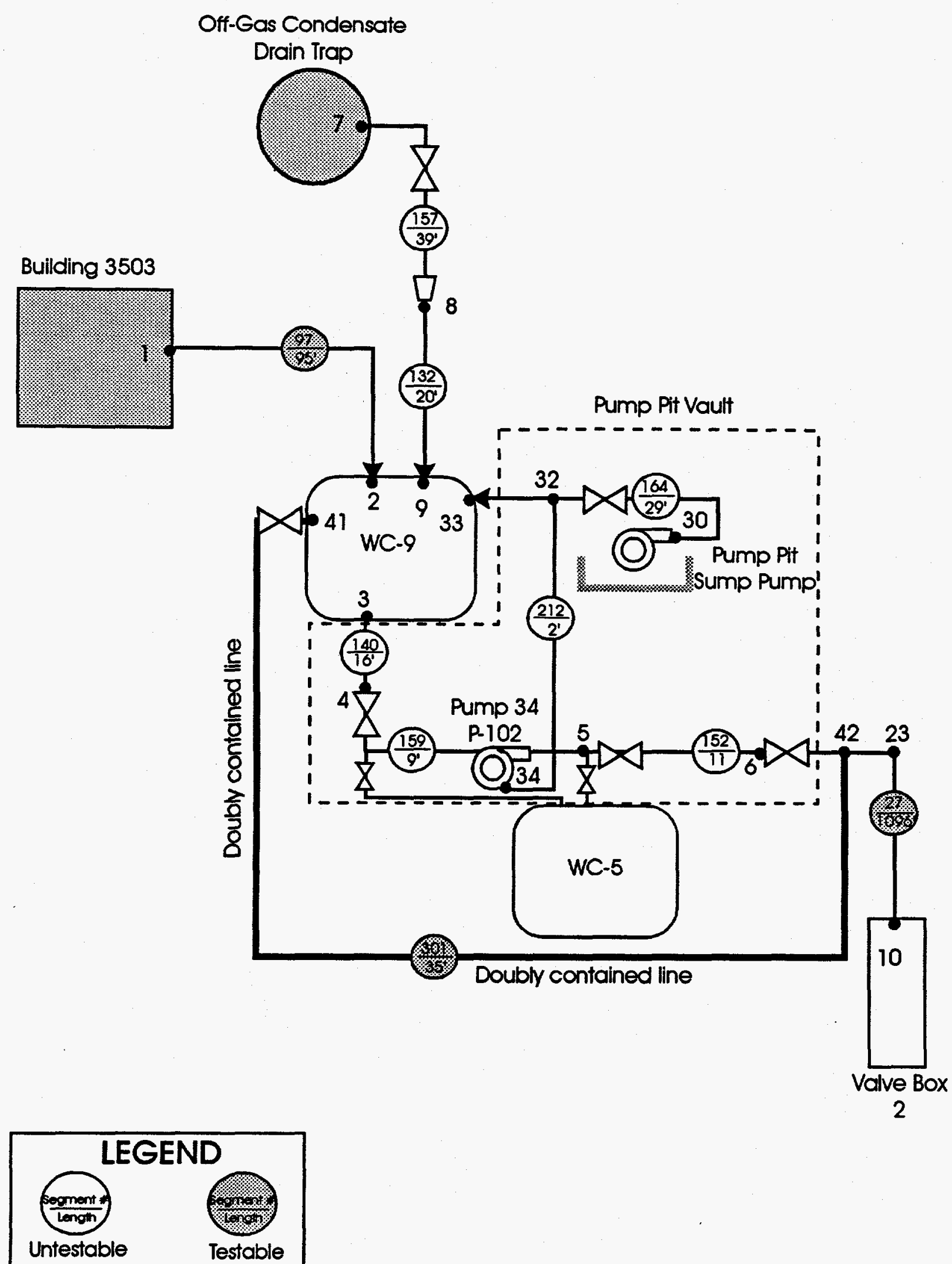

2 - Node Number

Figure 35. WC-9 Tank System 
There are four untestable pipeline elements associated with the WC-9 system. The first untestable pipeline element is the gravity-fed inlet line connecting an off-gas condensate drain trap to Tank WC-9. This pipeline element (node 7 to node 9) is comprised of two segments, Line Segments 132 and 157. The pipeline element is 59' long, and is comprised of 1" and 2" diameter sections, and is made of 347 stainless steel.

The second untestable pipeline element is the discharge line from a pump pit sump pump that empties the sump into WC-9 Tank. This element is made up of one stainless steel segment: Line Segment 164 (node 30 to node 33), which is 29 ' long, with a 1" diameter. The two remaining untestable elements are no longer used. This is a result of an upgrade program that installed a submersible pump in WC-9, and connected the submersible pump discharge to the WC-9 transfer piping via a section of doubly contained pipeline (Line Segment 301). One of the untestable elements is the (now-unused) suction piping between Tank WC-9 and Pump P102 and a short section of P-102 discharge piping. This line (node 3 to node 5) is comprised of two segments, Line Segments 140 and 159, and is $25^{\prime}$ long, with a 2" diameter. The other untestable element is the (now-unused) piping, Line Segment 212, (node 34 to node 32) which served to drain Pump P-102 back into Tank WC-9. This pipeline is 2' long, with a 1" diameter.

Table 40. Characteristics of Line Segments Evaluated as a Part of Tank System WC-9

\begin{tabular}{|c|c|c|c|c|c|c|c|c|c|c|}
\hline Segment & 27 & 97 & 132 & 140 & 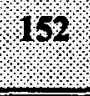 & 157 & 159 & 164 & 212 & 301 \\
\hline Node Numbers & $\begin{array}{c}23 \text { to } \\
10\end{array}$ & 1 to 2 & 8 to 9 & 3 to 4 & 5 to 6 & 7 to 8 & 4 to 5 & $\begin{array}{c}30 \text { to } \\
32\end{array}$ & $\begin{array}{c}32 \text { to } \\
34\end{array}$ & $\begin{array}{c}41 \text { to } \\
42\end{array}$ \\
\hline Index Number & P2 & G1 & & & & & & & & $\mathbf{P} 2$ \\
\hline Diameter (in) & 2 & 3 & 2 & 2 & 2 & 1 & 2 & 1 & 1 & \\
\hline Material & $\begin{array}{c}347 \\
\text { SS }\end{array}$ & $\begin{array}{l}347 \\
\text { SS }\end{array}$ & $\begin{array}{c}347 \\
\text { SS }\end{array}$ & $\begin{array}{c}347 \\
\text { SS }\end{array}$ & $\begin{array}{c}347 \\
\text { SS }\end{array}$ & $\begin{array}{c}347 \\
\text { SS }\end{array}$ & $\begin{array}{c}347 \\
\text { SS }\end{array}$ & $\begin{array}{c}347 \\
\text { SS }\end{array}$ & $\begin{array}{c}347 \\
\text { SS }\end{array}$ & \\
\hline Length (ft) & 1096 & 200 & 20 & 16 & 11 & 39 & 9 & 29 & 2 & 35 \\
\hline Volume (gal) & $\begin{array}{c}25042 \\
1\end{array}$ & 95 & 4 & 3 & 2 & 2 & 2 & 2 & $<1$ & \\
\hline Transfer Method & $\mathrm{CP}$ & G & G & $\mathrm{CP}$ & $\mathrm{CP}$ & G & $\mathrm{CP}$ & $\mathrm{CP}$ & $\mathrm{CP}$ & $\mathrm{CP}$ \\
\hline Install Date & 1952 & 1952 & 1952 & 1952 & 1952 & 1952 & 1952 & 1952 & 1952 & 1994 \\
\hline $\begin{array}{l}\text { Centri } \\
\text { Gravi } \\
\text { Stainl }\end{array}$ & $\begin{array}{l}\text { gal Pum } \\
\text { Steel }\end{array}$ & & & & & & & & & \\
\hline
\end{tabular}

\subsubsection{Corrosion Assessment of the WC-9 Tank System}

Tank WC-9 collects condensate from the hot off-gas system in Building 3503 and from the pump pit sump (rain water). The waste solution has not been characterized, but the $\mathrm{pH}$ in the tank solution is presently maintained near 13 which should minimize corrosion. Corrosion damage that may have occurred during periods when the $\mathrm{pH}$ of the solution was not maintained at a high value cannot be assessed. 
Based on information cited in Section 4, soil-side corrosion of the underground tank and associated piping is probably not severe, even though the tank and piping are neither coated nor cathodically protected.

\subsubsection{Results of Leak Tests on the WC-9 System}

This section summarizes the results of the leak detection tests conducted on Tank System WC-9 (the tank and its associated pipelines). Each element in the system was tested with a method appropriate for that element. Each method used has been demonstrated to detect a specified leak rate $(0.2 \mathrm{gal} / \mathrm{hr}$ for tank methods; $0.1 \mathrm{gal} / \mathrm{hr}$ for pipeline methods) with a probability of detection ( $\mathrm{PD}$ ) no less than $95 \%$ and a probability of false alarm (PFA) no greater than $5 \%$.

\subsubsection{Tank}

Leak testing of Tank WC-9 for the current assessment period began in February 1995 and continued at routine intervals through December 1995, with a total of 13 leak test attempts during this reporting period. The results of these tests are summarized in Table 41, which shows the date of each test, the volume of LLLW in the tank at the time of the test, the percent of Tank WC-9's total volume the test represented ${ }^{9}$, the test result, and comments pertinent to particular tests. The table shows that Tank WC-9 recorded PASS results for 11 of the leak tests, and INCONCLUSIVE results for the first two tests attempted early in the reporting period. The two inconclusives appear to have resulted from an addition of liquid during the test period. The maximum volume for which the tank passed the leak testing during this reporting period was 1,407 gallons, or $59 \%$ of the total capacity of the tank. This is greater than the previously certified level of 1,373 gallons $(57 \%)$ for this tank, and thus represents a new high level for certification purposes. [DOE/OR/01-1385\&D2]

Table 41. Summary of Leak Tests Conducted on Tank WC-9

\begin{tabular}{|c|c|c|c|c|}
\hline Date: & \# or Gallons & \% capacity & Test Result: & Conment \\
\hline $02 / 03 / 95$ & 1,408 & 59 & INCONCLUSIVE & addition during test? \\
\hline $02 / 17 / 95$ & 1,330 & 55 & INCONCLUSIVE & addition during test? \\
\hline $02 / 24 / 95$ & 1,407 & 59 & PASS & \\
\hline $03 / 10 / 95$ & 1,374 & 57 & PASS & \\
\hline $04 / 07 / 95$ & 818 & 34 & PASS & \\
\hline $05 / 05 / 95$ & 1068 & 45 & PASS & \\
\hline $06 / 02 / 95$ & 1,231 & 51 & PASS & \\
\hline $07 / 07 / 95$ & 963 & 40 & PASS & \\
\hline $08 / 04 / 95$ & 947 & 39 & PASS & \\
\hline $09 / 01 / 95$ & 1,057 & 44 & PASS & \\
\hline $10 / 06 / 95$ & 771 & 32 & PASS & \\
\hline $11 / 03 / 95$ & 1146 & 48 & PASS & \\
\hline $12 / 01 / 95$ & 1,200 & 50 & PASS & \\
\hline
\end{tabular}

${ }^{9}$ WOCC look-up tables show $100 \%$ capacity for WC-9 as 2,400 gal. The percent capacity shown in the table is based on this number. 
The 11 usable CVR data values from these leak tests were analyzed (1) to verify that the test method was performing properly in this application and (2) to confirm that during this assessment period the leak testing process had remained nominal; that is, that the use or performance of the method, as applied to this particular tank, was not deteriorating. This analysis included a statistical examination of the CVR data, as well as a comparison of this year's assessment data with prior data. The analysis and the results are described in Section 7.8.4.3.

\subsubsection{WC-9 Pipelines}

The results of the leak detection test on the testable WC-9 Pipelines are summarized in Section 7 8.4.2.1. An assessment of the integrity of the WC-9 Pipelines that cannot be tested for leaks with existing approved methods is summarized in Section 7.8.4.2.2.

\subsection{WC-9 Testable Pipelines}

There are two testable pipeline elements associated with the WC-9 System: a gravity-fed inlet line leading to WC-9 from Building 3503 (G1- segment 97) and a portion of the pressurized discharge line between the tank and VB-2. The gravity line was tested on August 10, 1995. The discharge line, P2, is comprised of Line Segments 27 and 301 . This line was tested in September 1996; the test yielded a PASS result. Table 42 shows the results of the leak tests conducted on the WC-9 pipelines.

Table 42. Summary of Leak Test Results for the WC-9 Testable Lines.

\begin{tabular}{|c|c|c|c|c|}
\hline Element No & Gine Segment & Test Date & Testresull & Comment \\
\hline G1 & 97 & 10-Aug-95 & PASS & \\
\hline P2 & 27,301 & September 1996 & PASS & \\
\hline
\end{tabular}

\subsection{WC-9 Untestable Pipelines}

There are seven untestable line segments associated with the WC-9 tank system. Four of the Line Segments, 140,152, 159, and 212 are no longer in service. Segments 157 and 132 make up the gravity line connecting the HOG pot to the WC-9 tank. While this line is used, there is no instrumentation to measure transfers. Line Segment 164 is a pump pit sump pump line which drains into WC-9 tank; this segment is also still in use but transfer data are not available.

\subsubsection{Analysis of Tank WC-9 Leak Test Data}

During this assessment period, a total of 13 leak tests were attempted on Tank WC-9; of these, 11 tests resulted in conclusive decisions. Figure 36 shows a time series plot of the CVR data obtained from each of the useable test results. It can be seen from the plot that all 11 of the CVR values are within the INFLOW and OUTFLOW decision thresholds, and are thus consistent 
with the PASS results obtained from these tests.

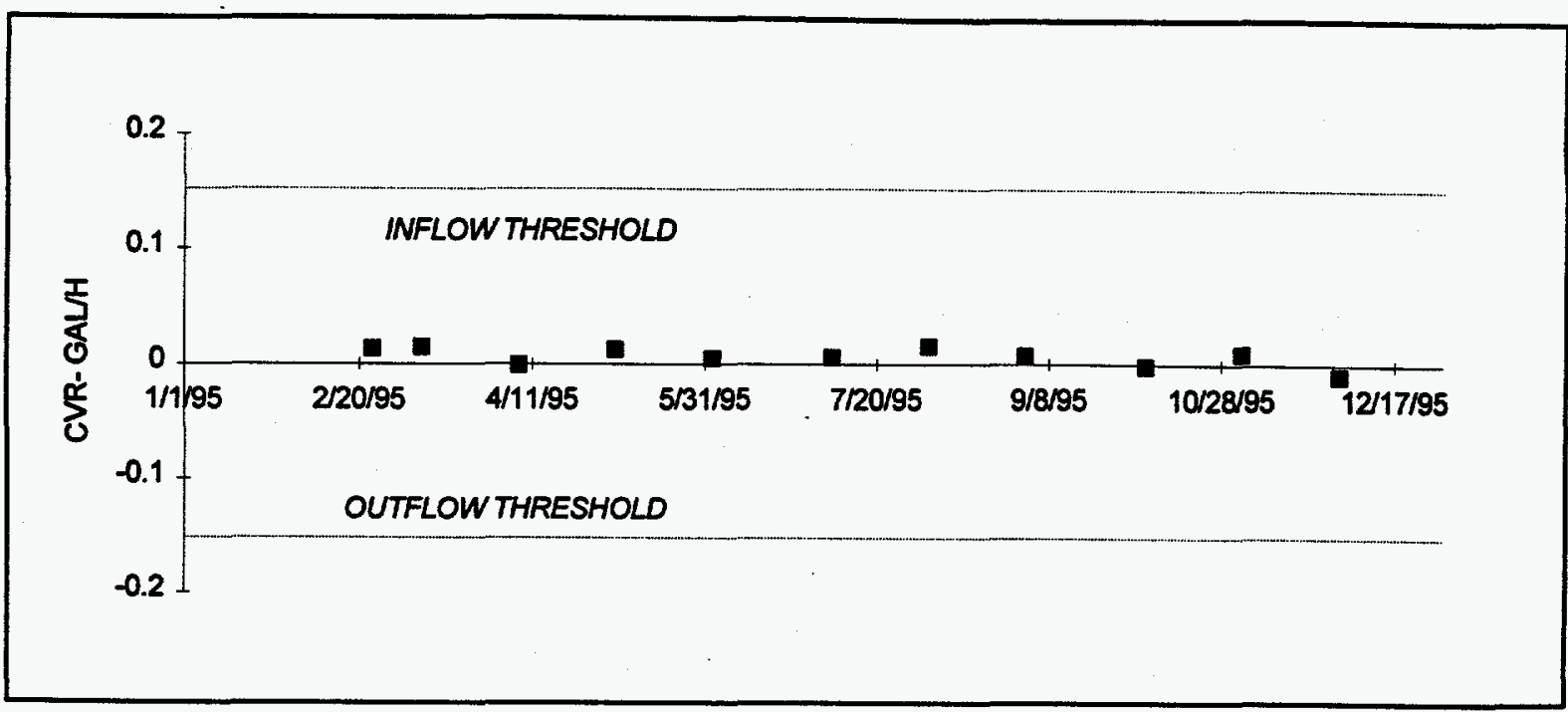

Figure 36. Time series plot of leak test CVRs from Tank WC-9.

A comparative analysis of the data shown in Figure 36 was performed. The analysis included using the Student's $t$ - [Mendenhall, 1992], and the K-S [Benjamin and Cornell, 1970] statistical tests. The Student's $t$-test is used to determine the significance of the mean of the CVR data. The K-S analysis is used to determine if the population of CVR values from Tank WC-9 is significantly different than a reference set of CVRs. These statistical tests are fully described in Section 5.4.

As shown below, applying the t-test to the 11 data values shown above results in a tstatistic, $t_{\text {stat }}$ of 2.86 , while the critical value, $t_{\text {crit }}$ is 3.17 , for a $99 \%$ level of confidence. Applying the K-S "goodness-of-fit" test to the WC-9 CVR data, using a H/V weighted set of reference CVRs, results in a maximum ordinal difference, $\mathrm{KS}_{\text {sat }}$ of 0.32 , while the critical value, $\mathrm{KS}_{\text {erit }}$ is 0.49 , for a $99 \%$ level of confidence. Based upon this analysis, we conclude that both the mean and the fluctuations of the 1995 CVR data from Tank WC-9 are entirely consistent with data expected from a non-leaking tank.

Figure 37 graphically illustrates the K-S test applied to the WC-9 data. The bold solid line in the figure shows the CDF obtained from the CVR data shown in Figure 36, after removing the mean from the data. The light dashed line in the figure shows the CDF obtained from the reference set of CVR values (See Section 5.4), after removing the mean from that data and scaling those values by the H/V coefficient of WC-9 (23.88 gal/in.), divided by the H/V of the (mean-removed) reference set (14.72 gal/in.).

The similarity of the data sets defined by the two lines illustrated in Figure 37 is "tested" with the K-S "goodness-of-fit" test. Here, the test statistic, $\mathrm{KS}_{\text {stat, }}$ is 0.32 , while the critical value, $\mathrm{KS}_{\text {crit }}$ is 0.49 . Since the maximum ordinal difference, $\mathrm{KS}_{\text {stat }}$, is less than $\mathrm{KS}_{\text {crit }}$, the two populations are deemed to be equivalent. 


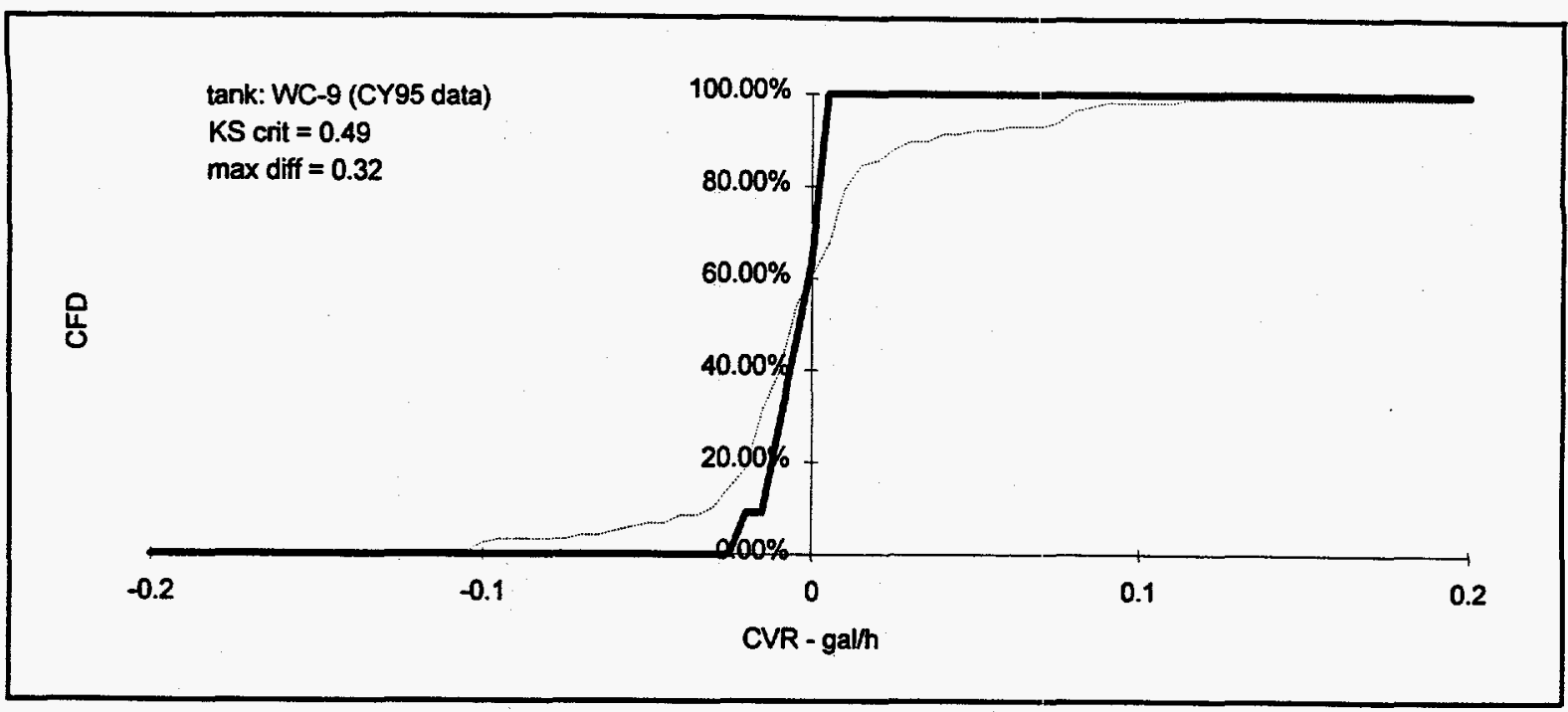

Figure 37. Cumulative frequency distribution from reference CVR data (light dashed line) and WC-9 data (CY95) (solid bold line).

Table 43 summarizes the statistical analyses of the Tank WC-9 CVR data. The table shows that the mean of the CY95 test data is equivalent to zero gal/h, and that the population of CY95 CVR values is not different than the population of CVR values in the reference, or comparison, data set.

Table 43. Summary of Statistical Analyses of Tank WC-9 CVR Data (H/V=23.88 gal/in)

\begin{tabular}{|c|c|c|}
\hline & Reference CVR data & '95 CVR data \\
\hline $\mathrm{N}$ & 118 & 11 \\
\hline Mean $(\mathrm{gal} / \mathrm{h})$ & 0.007 & 0.007 \\
\hline $\begin{array}{l}\text { Standard Deviation } \\
(\mathrm{gal} / \mathrm{h})\end{array}$ & 0.051 & 0.008 \\
\hline t-statistic & & 2.86 \\
\hline t-critical (1\%) & & 3.17 \\
\hline t-test Inference & & $\begin{array}{c}\text { mean is equivalent to } 0 \\
\mathrm{gal} / \mathrm{h}\end{array}$ \\
\hline KS-statistic & & 0.16 \\
\hline KS-critical (1\%) & & 0.53 \\
\hline KS-test Inference & & $\begin{array}{l}\text { Same population as } \\
\text { reference set }\end{array}$ \\
\hline
\end{tabular}




\subsubsection{Findings and Conclusions}

The findings of this report are based on (1) a review of available tank design drawings, (2) a qualitative assessment of corrosion on the tank and pipelines, and (3) leak testing results from the tank and testable pipelines.

Review of the design drawings indicated that the tank was designed with an abundance of inlets into the tank which were not connected to pipelines. However, because the unused inlets are located on the top of the tank, the concern of leakage from the ports is nonexistent when operating at less than full tank capacity. The design drawings revealed a sound design of the WC-9 tank.

During the corrosion assessment, it was determined that with the present use of the tank system, all forms of corrosion on the interior walls of the tank and associated piping should be nonexistent. Corrosion damage that may have occurred when the tank was used in past environments cannot be assessed. Furthermore, an analysis of the general aspects of corrosion at ORNL revealed that corrosion of stainless steel by ORNL soil is not believed to be severe.

Leak testing of Tank WC-9 was completed by the Volumetric DP method in 13 tests. The tank passed 11 of the tests and had INCONCLUSIVE results in two tests.

Three of the four testable line segments passed leak testing by methods discussed previously. The remaining testable segment, Line Segment 152, is no longer in use.

No transfer logs are available for the untestable line segments currently in use.

All of these factors were considered in determining certification of the WC-9 system components. Table 44 summarizes the elements of the tank systems which were certified and the conditional limits on their certifications.

Table 44. Summary of WC-9 Tank System Testing and Certification

\begin{tabular}{|c|c|c|c|c|c|c|}
\hline System & length. & $\begin{array}{l}\text { Tested } \\
\text { (Yesno) }\end{array}$ & $\begin{array}{l}\text { henll } \\
\text { meshod }\end{array}$ & Test Result? & Cerinifatio & Certification \\
\hline Tank WC-9 & & Yes & DP & PASS & Yes & $59 \%$ \\
\hline LS-27 & 1096 & Yes & GPD & PASS & Yes & Full Flow \\
\hline LS-97 & 200 & Yes & EVB & PASS & Yes & $32 \mathrm{gph}$ \\
\hline LS-132 & 20 & No & $\mathrm{N} / \mathrm{T}$ & N/A & No & N/A \\
\hline LS- 140 & 16 & No & $\mathrm{N} / \mathrm{T}$ & N/A & No & N/A \\
\hline LS-152 & 11 & No & $\mathrm{N} / \mathrm{T}$ & N/A & No & N/A \\
\hline LS-157 & 39 & No & $\mathrm{N} / \mathrm{T}$ & N/A & No & N/A \\
\hline
\end{tabular}




\begin{tabular}{|c|c|c|c|c|c|c|}
\hline Component & Iength & $\begin{array}{l}\text { Tested } \\
\text { (Yesno) }\end{array}$ & $\begin{array}{l}\text { Leak } \\
\text { Test } \\
\text { Method }\end{array}$ & Test Result & certificatio & Certirication \\
\hline LS-212 & 2 & No & $\mathrm{N} / \mathrm{T}$ & N/A & No & N/A \\
\hline LS-301 & 35 & Yes & GPD & PASS & Yes & Full Flow \\
\hline $\begin{array}{ll}\text { CVR } & \text { Co } \\
\text { DP } & \text { Di } \\
\text { EVB } & \text { En } \\
\text { gph } & \text { G } \\
\text { LS } & \text { Li } \\
\text { N/T } & \text { No } \\
\text { N/A } & \text { No } \\
\end{array}$ & $\begin{array}{l}\text { nsated vo } \\
\text { ced volum } \\
\text { is per hour } \\
\text { gment } \\
\text { table } \\
\text { plicable }\end{array}$ & $\begin{array}{l}\text { e rate } \\
\text { lancing }\end{array}$ & & & & \\
\hline
\end{tabular}




\subsubsection{Certification}

Based on the results of the design drawings review, the qualitative corrosion assessment, and the results of the leak testing program, it is my professional opinion that Tank WC-9 retains sufficient structural integrity to contain liquids at cperating levels up to the maximum level which achieved a PASS during the testing program. Also, based upon the results of the pipeline tests, it is my professional opinion that Line Segment 97 retains sufficient integrity to contain liquids up to a flow rate of $32 \mathrm{gph}$ and Line Segments 27 and 301 retain sufficient structural integrity to contain liquids at operating levels up to full flow conditions. Table 44 provides a summary description of the certifications for the WC-9 Tank System. If future testing is conducted at-large pipeline flows and greater tank levels, then certification levels may also increase.

It is recommended that leak detection and line testing using the EPA and TDEC approved methods be continued, to support annual certification, until this system has been removed from operation or replaced.

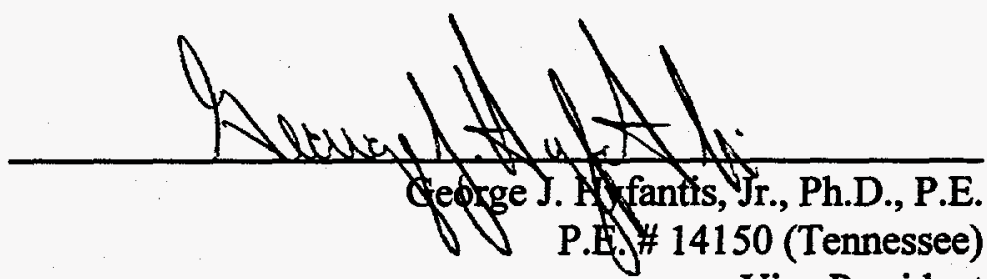

Vice President

International Waste Management Systems a Division of Environmental Systems Corporation 

The WC-10 Tank System is located south of Building 3587, as shown in Figure 1. The WC-10 Tank System collects LLLW and rainwater from the Isotope Circle area. The tank system is made up of Tank WC-10 and seven line segments connected to the system. Because the lines and tank are all singly contained, the tank system has been classified as Category $C$, according to the FFA.

\subsubsection{WC-10 Tank Description}

Tank WC-10 is a 2,300 gallon, buried, singly contained tank, installed in 1951. Tank WC-10 is mounted horizontally on two reinforced concrete pillars. The tank is constructed of stainless steel and has an unknown wall thickness. The outside diameter of the tank is $76^{\prime \prime}$ with a length of 124". The working volume of the tank is 1,650 gallons. The design drawing for Tank WC-10 is given in Figures 38 and 38A.

The tank is equipped with three 2 " diameter nozzles, one 3 " diameter nozzle, two $1 / 2$ " diameter sample nozzles, three unused nozzles, and one manhole. All of the nozzles, including the manhole, are located on top of the tank aligned with the tank centerline.

The tank is anchored to the support pillars which are anchored to a 34'-0" x 16'-9" reinforced concrete pad. The pad also supports six other tanks, one horizontally mounted, five vertically mounted. The tank pad and all of the tanks are placed in an earthen pit which has been backfilled with gravel to the top of the tanks. The gravel was then covered with earth. The top of tank WC-10 is 10'-2" below the surface elevation. The tank is equipped with a precision level sensor and can be tested for leaks.

\subsubsection{WC-10 Pipeline Descriptions}

Seven separate line segments make up the portion of the LLLW pipeline system belonging to Tank WC-10. Characteristics of the lines are listed in Table 45. A schematic of the tank system with numbered line segments is shown in Figure 39. All pipelines associated with the WC-10 Tank System are constructed of stainless steel and were installed in 1951. 


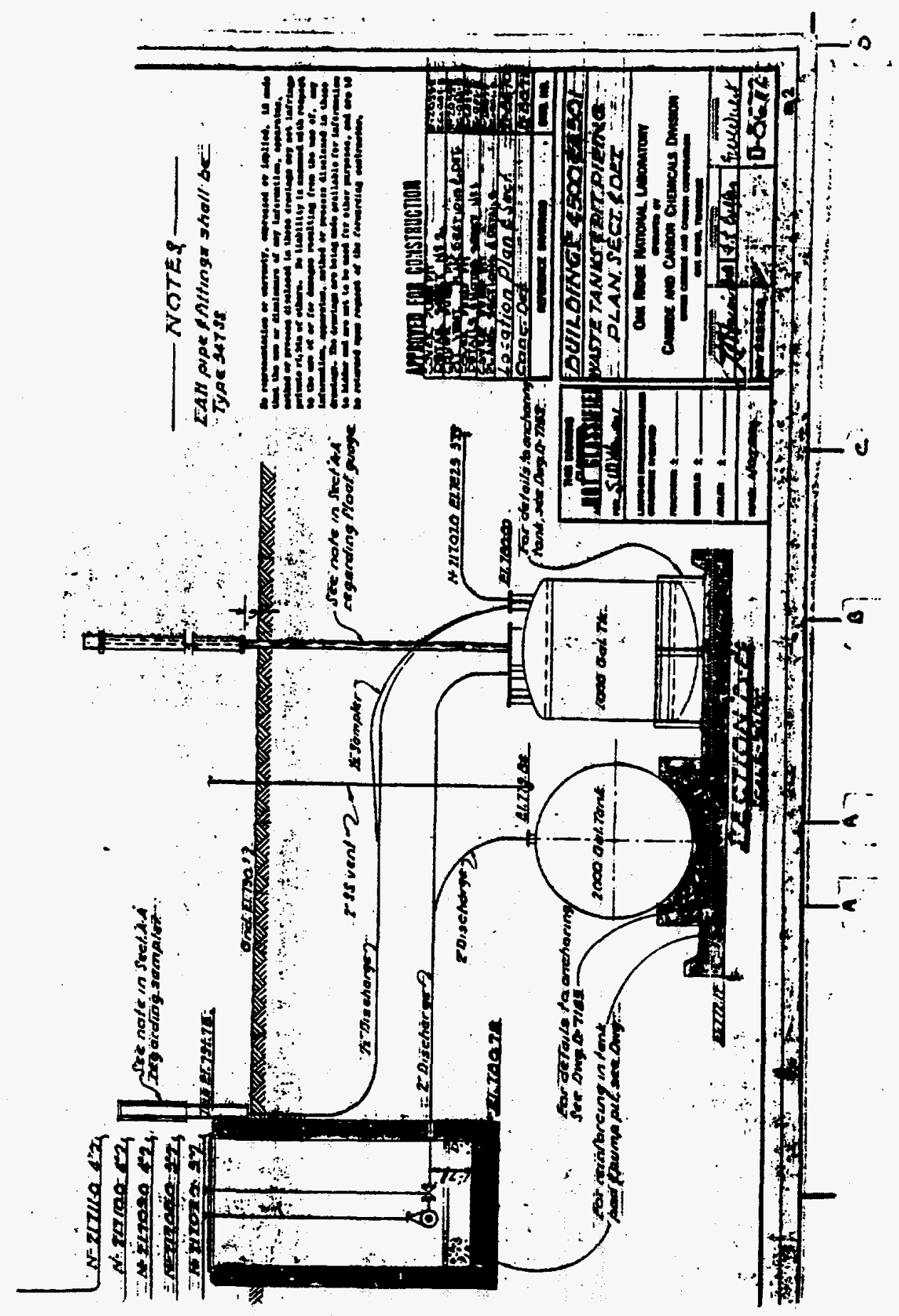

 


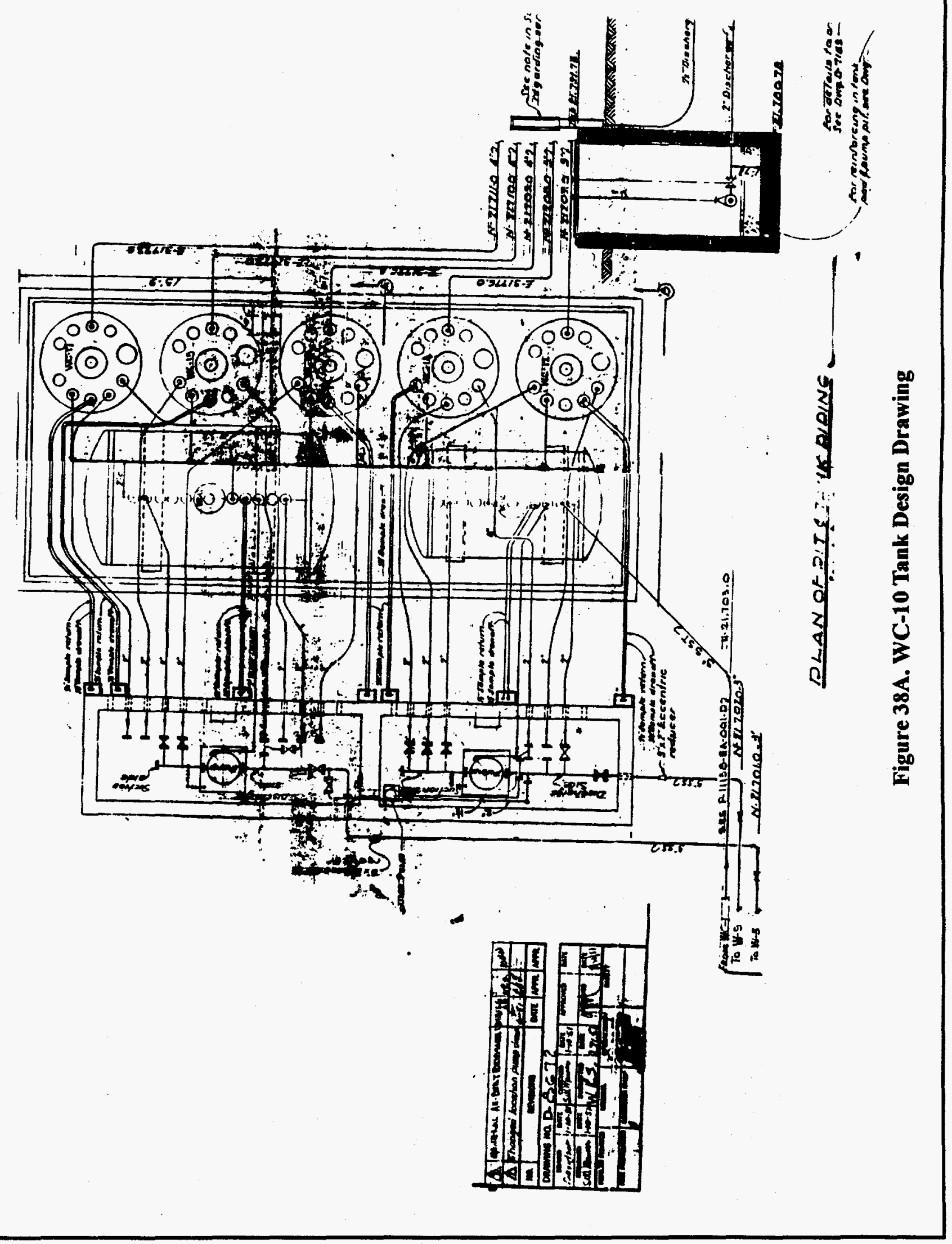




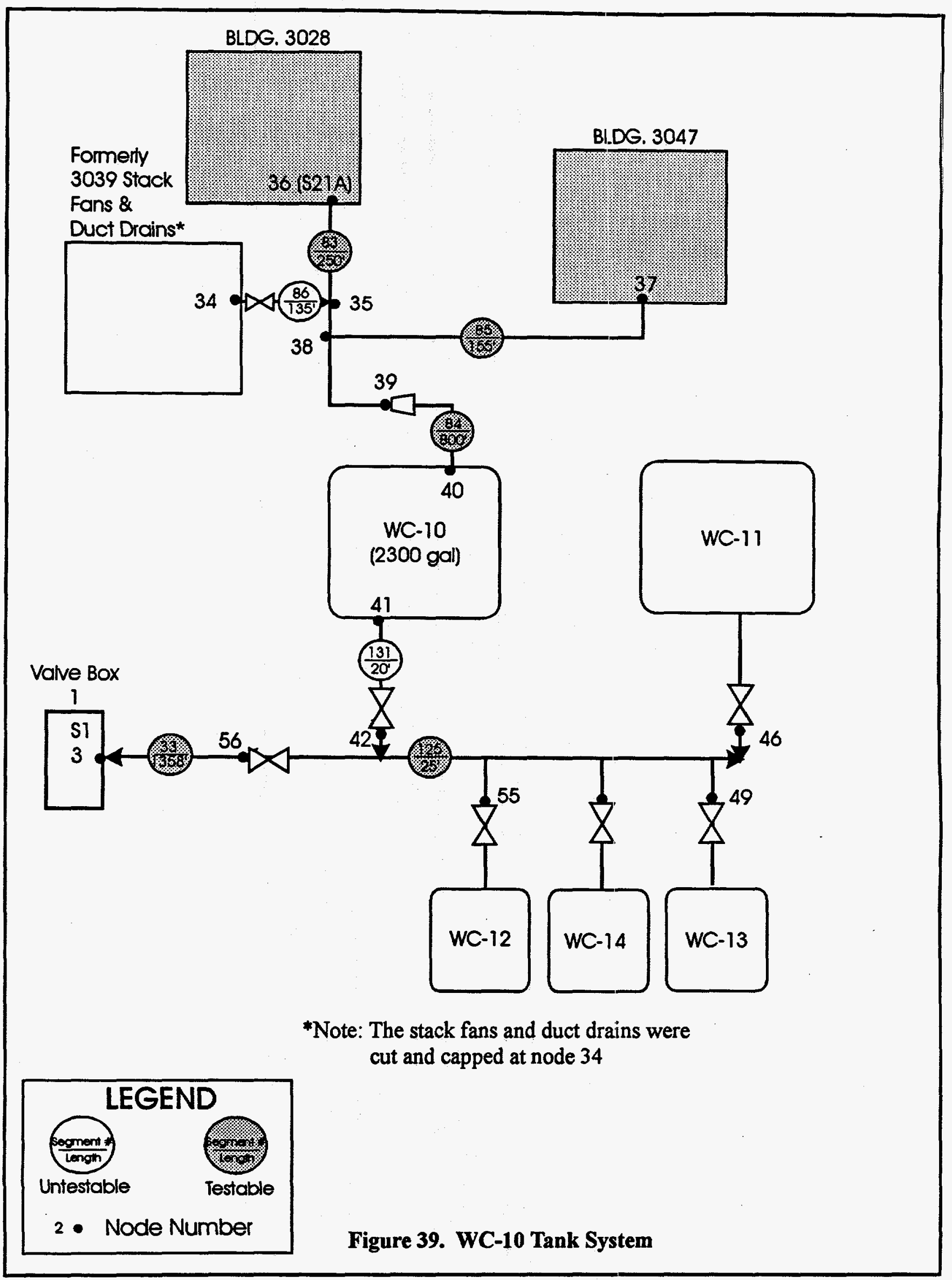


Table 45. Characteristics of Line Segments Evaluated as a Part of Tank System WC-10

\begin{tabular}{|c|c|c|c|c|c|c|c|c|}
\hline \multicolumn{2}{|c|}{ Hine Segment } & 33 & 83 & 84 & 85 & 86. & 125. & 131 \\
\hline \multicolumn{2}{|c|}{ Node Numbers } & $\begin{array}{c}56 \text { to } \\
\text { S1-N3 }\end{array}$ & $\begin{array}{c}\text { S21-N36 } \\
\text { to } 35\end{array}$ & 39 to 40 & 37 to 39 & 34 to 35 & 46 to 42 & 41 to 42 \\
\hline \multicolumn{2}{|c|}{ Index Number } & P6 & G29 & G32 & G32 & & P6 & * \\
\hline \multicolumn{2}{|c|}{ Diameter (in) } & 3 & 6 & 3 & 6 & 6 & 2 & 2 \\
\hline \multicolumn{2}{|c|}{ Material } & SS & SS & SS & SS & SS & SS & SS \\
\hline \multicolumn{2}{|c|}{ Length (ft) } & 1358 & 250 & 800 & 155 & 135 & 25 & 20 \\
\hline \multicolumn{2}{|c|}{ Volume (gal) } & 522 & 375 & 307 & 233 & 203 & 6 & 4 \\
\hline \multicolumn{2}{|c|}{$\begin{array}{l}\text { Transfer } \\
\text { Method }\end{array}$} & $\mathbf{P}$ & SJ\&G & G & G & G & $\mathbf{P}$ & $\mathbf{P}$ \\
\hline \multicolumn{2}{|c|}{ Install Date } & 1951 & 1951 & 1951 & 1951 & 1951 & 1951 & 1951 \\
\hline \multicolumn{9}{|c|}{$\begin{array}{ll}* & \text { Transfer records available } \\
\text { G } & \text { Gravity } \\
\text { P } & \text { Pressure } \\
\text { SJ } & \text { Steam jet pump } \\
\text { SS } & \text { Stainless Steel } \\
\end{array}$} \\
\hline
\end{tabular}

As shown in Figure 39, Tank WC-10 has one gravity-fed inlet line and one pressure discharge pipeline. The remaining five line segments are not directly connected to Tank WC10. There are three testable stainless steel pipeline elements associated with Tank System WC10. The first testable element is made up of two line segments. The first line segment of Element G32 is the gravity-fed line that drains from Building 3047 into Tank WC-10. The 3" diameter gravity-fed, inlet line is identified as Line Segment 84 . This line segment runs $800^{\prime}$ from a reducing valve (which converts Line Segment 83 from 6" diameter to 3" diameter), into Tank WC-10 (node 39 to node 40). Line Segment 85 is a testable gravity-fed line that runs 155' from Building 3047 to a reducing valve located in the inlet line (node 37 to node 39). Line Segments 85 and 84 both are testable, and were grouped together as Element G32 for testing purposes.

The second testable line of the WC-10 Tank System is identified as Element G29. The element is made up of Line Segments 83 and 84, and runs from Building 3028 to Tank WC-10. Line Segment 83 is a 6" diameter gravity-fed line that runs 250' from node 36 (S21A on Figure 39) at Building 3028 to node 38 . Line Segment 84 , also a part of the first testable element of WC-10, is described above.

The third testable element of the WC-10 Tank System is Element P6, and consists of Line Segments 33 and 125 . This element is a pressurized portion of the discharge line leading from Tanks WC-10 and WC-11 to Valve Box 1 . This element runs from nodes 46, 49, 52, 55, and 42 , to node 3 (S1). This element has a total length of 1383 , and has sections with diameters of $2 "$ and $3 "$. 
The pipeline identified as Line Segment 86 originates as a drain for stack fans and duct drains in Building 3039 and connects to the 6" diameter line, Line Segment 83 at node 35 . The duct drains have been cut and capped. Line Segment 86 is $135^{\prime}$ in length and has a 6 " diameter. Line Segment 86 is not used and therefore will not be leak tested. The second untestable line segment is a 20'-2" section of discharge line identified as Line Segment 131 (node 41 to 42). This segment cannot be tested because it cannot be isolated at the tank end of the line.

\subsubsection{Corrosion Assessment of the WC-10 Tank System}

Tank WC-10 collects waste from hot cells in Buildings 3028 through 3033, 3047, and 3118. For the past several years, most of the liquid materials added to the tank were decontaminating solutions including nitric acid, oxalic acid, potassium permanganate, and commercial cleansers such as Ajax and Mr. Clean. Only dilute solutions have been used, and these have been further diluted with large volumes of rinse water. After additions to the tank, drain lines are always flushed with water. As with the solutions in most waste tanks, the $\mathrm{pH}$ is maintained at a high value by adding a strong caustic to the tank after each emptying.

Under the present mode of operation, the interior surfaces of the tank should experience only slight corrosion. It is probable, however, that for some periods during the greater than 40 year life of the tank, the $\mathrm{pH}$ was neither neutral nor acid, and corrosion may have been appreciable.

In November 1993, an attempt was made to determine the cumulative damage to the interior tank walls during its life. A small video camera was inserted into the tank and a video cassette was made. Examination of the video indicated no evidence of gross corrosion damage. Most of the wetted surfaces were covered with a scale that in some areas appeared to contain iron (red) and in other areas seemed much lighter in color. It is possible that heavy scale may have obscured heavy attack beneath it. In some scaled areas, there appeared to be many pits, but these may be small areas where some of the scale had spalled. The resolution of the video was not sufficient to determine the thickness of the scale, the depth of the apparent pits, or the morphology of the surface.

Based on information cited in Section 4.0, corrosion damage to the exterior surfaces of the buried 347 stainless steel tank and pipelines associated with it are probably not extensive.

\subsubsection{Results of Leak Tests on the WC-10 System}

This section summarizes the results of the leak detection tests conducted on Tank System WC-10 (the tank and its associated pipelines). Each tested element in the system was tested with a method appropriate for that element. Each method used has been demonstrated to detect a specified leak rate $(0.2 \mathrm{gal} / \mathrm{hr}$ for the monthly tank testing; $0.1 \mathrm{gal} / \mathrm{hr}$ for the annual pipeline testing) with a probability of detection (PD) no less than $95 \%$ and a probability of false alarm (PFA) no greater than 5\%. 


\subsubsection{Tank}

Leak testing of Tank WC-10 for this assessment period began in January 1995 and continued at frequent intervals through December 1995, with a total of 43 leak test attempts during this reporting period. The results of these tests are summarized in Table 46, which shows the date of each test, the volume of LLLW in the tank at the time of the test, the percent of Tank WC-10's total volume the test represented ${ }^{10}$, the test result, and comments pertinent to particular tests. The table shows that there were no PASS results achieved due to a continuous and significant inflow into the tank. The testing recorded INFLOW results for 38 of the 43 leak tests attempted and INCONCLUSIVE results for the other five tests attempted. It is noted here that in April 1996, an inactive pipeline leading to Tank WC-10 was cut and capped. A section of this inactive piping upstream of the cap was observed to contain two small holes which allowed rain and other ground water sources to enter the tank, causing much of the observed inflows. Since the line was repaired, the inflow has decreased. The tank has undergone three monthly leak tests since the repair was completed, achieving a PASS results two times with one INCONCLUSIVE. These results will be documented in Quarterly Highlights and in the 1997 SIA report.

The 38 usable CVR data values from these leak tests were analyzed (1) to verify that the test method was performing properly in this application and (2) to confirm that during this assessment period the leak testing process had remained nominal; that is, the performance of the method as applied to this particular tank was not deteriorating. This analysis included a statistical examination of the CVR data, as well as a comparison of this year's assessment data with prior data. The analysis and the results are described in Section 7.9.4.3.

\subsubsection{WC-10 Pipelines}

The results of the leak detection test on the testable WC-10 pipelines are summarized in Section 7.9.4.2.1. An assessment of the integrity of the WC-10 pipelines that cannot be tested for leaks with existing approved methods is summarized in Section 7.9.4.2.2.

\subsection{WC-10 Testable Pipelines}

The testable portion of the WC-10 system consists of a gravity-fed inlet line from Building 3047 to Tank WC-10 (G32, Line Segments 84 and 85), the gravity-fed inlet line from Building 3028 to Tank WC-10 (G29, Line Segment 83), and a pressurized portion of the discharge piping leading from the tank to VB-1 (P6, Line Segments 33 and 125). The pressurized line (P6) passed a leak test in May 1996. An attempt was made to leak test gravity line G32 in January 1996. This test recorded an INCONCLUSIVE result due to the uncontrollable inflow into the tank. The other gravity line, G29 is not used and therefore will not be tested. Table 47 summarizes the results of the leak tests conducted on the WC-10 pipelines.

${ }^{10}$ WOCC look-up tables show $100 \%$ capacity for WC-10 as 2,300 gal. The percent capacity shown in the table is based on this number. 
Table 46. Summary of Leak Tests Conducted on Tank WC-10

\begin{tabular}{|c|c|c|c|c||}
\hline Date & H or Gallons & $\%$ Capacity & Test Result & Comment \\
\hline $01 / 13 / 95$ & 864 & $\mathrm{n} / \mathrm{a}$ & INCONCLUSIVE & \\
\hline $01 / 20 / 95$ & 1,095 & $\mathrm{n} / \mathrm{a}$ & INFLOW & \\
\hline $01 / 27 / 95$ & 1,004 & $\mathrm{n} / \mathrm{a}$ & INFLOW & \\
\hline $02 / 03 / 95$ & 587 & $\mathrm{n} / \mathrm{a}$ & INFLOW & \\
\hline $02 / 17 / 95$ & 993 & $\mathrm{n} / \mathrm{a}$ & INFLOW & \\
\hline $02 / 24 / 95$ & 498 & $\mathrm{n} / \mathrm{a}$ & INFLOW & \\
\hline $03 / 10 / 95$ & 1,142 & $\mathrm{n} / \mathrm{a}$ & INCONCLUSIVE & \\
\hline $03 / 17 / 95$ & 807 & $\mathrm{n} / \mathrm{a}$ & INFLOW & \\
\hline $03 / 24 / 95$ & 479 & $\mathrm{n} / \mathrm{a}$ & INFLOW & \\
\hline $03 / 31 / 95$ & 1,190 & $\mathrm{n} / \mathrm{a}$ & INFLOW & \\
\hline $04 / 07 / 95$ & 708 & $\mathrm{n} / \mathrm{a}$ & INFLOW & \\
\hline $04 / 21 / 95$ & 955 & $\mathrm{n} / \mathrm{a}$ & INFLOW & \\
\hline $04 / 28 / 95$ & 623 & $\mathrm{n} / \mathrm{a}$ & INFLOW & \\
\hline $05 / 05 / 95$ & 1,304 & $\mathrm{n} / \mathrm{a}$ & INFLOW & \\
\hline $06 / 02 / 95$ & 962 & $\mathrm{n} / \mathrm{a}$ & INFLOW & \\
\hline $06 / 09 / 95$ & 605 & $\mathrm{n} / \mathrm{a}$ & INFLOW & \\
\hline $06 / 16 / 95$ & 1,211 & $\mathrm{n} / \mathrm{a}$ & INFLOW & \\
\hline $06 / 23 / 95$ & 797 & $\mathrm{n} / \mathrm{a}$ & INFLOW & \\
\hline $06 / 30 / 95$ & 422 & $\mathrm{n} / \mathrm{a}$ & INFLOW & \\
\hline $07 / 07 / 95$ & 979 & $\mathrm{n} / \mathrm{a}$ & INFLOW & \\
\hline $07 / 14 / 95$ & 1,044 & $\mathrm{n} / \mathrm{a}$ & INCONCLUSIVE & \\
\hline $07 / 21 / 95$ & 915 & $\mathrm{n} / \mathrm{a}$ & INFLOW & \\
\hline $08 / 04 / 95$ & 377 & $\mathrm{n} / \mathrm{a}$ & INFLOW & \\
\hline $08 / 11 / 95$ & 295 & $\mathrm{n} / \mathrm{a}$ & INFLOW & \\
\hline $08 / 18 / 95$ & 1,004 & $\mathrm{n} / \mathrm{a}$ & INCONCLUSIVE & \\
\hline $08 / 25 / 95$ & 841 & $\mathrm{n} / \mathrm{a}$ & INFLOW & \\
\hline $09 / 01 / 95$ & 1,004 & $\mathrm{n} / \mathrm{a}$ & INCONCLUSIVE & \\
\hline $09 / 08 / 95$ & 726 & $\mathrm{n} / \mathrm{a}$ & INFLOW & \\
\hline $09 / 15 / 95$ & 374 & $\mathrm{n} / \mathrm{a}$ & INFLOW & \\
\hline $09 / 22 / 95$ & 913 & $\mathrm{n} / \mathrm{a}$ & INFLOW & \\
\hline $09 / 29 / 95$ & 400 & $\mathrm{n} / \mathrm{a}$ & INFLOW & \\
\hline $10 / 06 / 95$ & 958 & $\mathrm{n} / \mathrm{a}$ & INFLOW & \\
\hline $10 / 13 / 95$ & 442 & $\mathrm{n} / \mathrm{a}$ & INFLOW & \\
\hline $10 / 27 / 95$ & 450 & $\mathrm{n} / \mathrm{a}$ & INFLOW & addition during test? \\
\hline $11 / 03 / 95$ & 974 & $\mathrm{n} / \mathrm{a}$ & INFLOW & \\
\hline $11 / 10 / 95$ & 477 & $\mathrm{n} / \mathrm{a}$ & INFLOW & \\
\hline $11 / 17 / 95$ & 987 & $\mathrm{n} / \mathrm{a}$ & INFLOW & \\
\hline $11 / 24 / 95$ & 475 & $\mathrm{n} / \mathrm{a}$ & INFLOW & \\
\hline $12 / 01 / 95$ & 1,137 & $\mathrm{n} / \mathrm{a}$ & INFLOW & \\
\hline $12 / 08 / 95$ & 647 & $\mathrm{n} / \mathrm{a}$ & INFLOW & \\
\hline $12 / 15 / 95$ & 1,103 & $\mathrm{n} / \mathrm{a}$ & INFLOW & \\
\hline $12 / 22 / 95$ & 636 & $\mathrm{n} / \mathrm{a}$ & INFLOW & \\
\hline $12 / 29 / 95$ & 1,176 & $\mathrm{n} / \mathrm{a}$ & INFLOW & \\
\hline & & & & \\
\hline
\end{tabular}


Table 47. Summary of Leak Test Results for the WC-10 Testable Lines.

\begin{tabular}{|c|c|c|c|c|c|}
\hline Element No & Line Segment & Test Date & Test Result . & Comment \\
\hline \hline G32 & 84,85 & January '96 & INCONCLUSIVE & $\begin{array}{c}\text { irregular inflow during } \\
\text { test }\end{array}$ \\
\hline G29 & 83 & N/A & N/A & $\begin{array}{c}\text { not used; will not be } \\
\text { tested }\end{array}$ \\
\hline P6 & 33,125 & May '96 & PASS & \\
\hline
\end{tabular}

\subsection{WC-10 Untestable Pipelines}

The untestable portion of the WC-10 system (designated by index numbers 86 and 131) consists of the gravity-fed line between the building 3039 stack, fans, and duct drain and Tank WC-10, and a portion of the discharge line leading from Tank WC-10 to Valve Box 1. No WOCC transfer records are available for the gravity-fed line. However the discharge line carries transfers from Tank WC-10 through Valve Box 1 to Tank W-22 and the volume in both of these tanks is measured and recorded by WOCC. Transfer logs show that during the period from January 1995 through December 1995, 39 transfers were made from Tank WC-10 to Tank W-22. These transfers are summarized in the first four columns of Table 48. The difference between the volume sent (Column 3 ) and the volume received (Column 4) is shown in Column 5.

Table 48. Summary of Transfers between Tank WC-10 and Tank W-22 from January 1995 to December 1995

\begin{tabular}{|c|c|c|c|c|c|c|}
\hline Transfer & Transfer log & Volume & $\begin{array}{l}\text { rolume } \\
\text { Recerved } \\
(\mathrm{Ga})\end{array}$ & Difference & $\begin{array}{l}\text { Maximum } \\
\text { Expected } \\
\text { Error (Ga) }\end{array}$ & $\begin{array}{l}\text { ox orifference } \\
\text { greater than }\end{array}$ \\
\hline $1 / 6 / 95$ & $W C-10$ to $W-22$ & 1169 & 1200 & 31 & 141 & No \\
\hline $1 / 25 / 95$ & WC-10 to W-22 & 1031 & 1130 & 99 & 141 & No \\
\hline $2 / 2 / 95$ & WC-10 to W-22 & 1055 & 1055 & 0 & 141 & No \\
\hline $2 / 14 / 95$ & WC-10 to W-22 & 1085 & 1350 & 265 & 141 & Yes \\
\hline $2 / 14 / 95$ & WC-10 to W-22 & 1074 & 1190 & 116 & 141 & No \\
\hline $2 / 14 / 95$ & WC-10 to W-22 & 1031 & 1330 & 299 & 141 & Yes \\
\hline $2 / 14 / 95$ & WC- 10 to $W-22$ & 1089 & 1320 & 231 & 141 & Yes \\
\hline $2 / 15 / 95$ & WC- 10 to $W-22$ & 1263 & 1460 & 197 & 141 & Yes \\
\hline $2 / 15 / 95$ & WC- 10 to W-22 & 1144 & 1390 & 246 & 141 & Yes \\
\hline $2 / 15 / 95$ & WC- 10 to W-22 & 1193 & 1410 & 217 & 141 & Yes \\
\hline $2 / 15 / 95$ & WC- 10 to W-22 & 1017 & 1270 & 253 & 141 & Yes \\
\hline $2 / 15 / 95$ & WC- 10 to W-22 & 1144 & 1270 & 126 & 141 & No \\
\hline
\end{tabular}




\begin{tabular}{|c|c|c|c|c|c|c|}
\hline Transfer: & Transfer llog. & Volume & $\begin{array}{l}\text { volume } \\
\text { Received } \\
(G a l)\end{array}$ & $\begin{array}{l}\text { Difference } \\
\text { (Gal) }\end{array}$ & $\begin{array}{l}\text { Maximum } \\
\text { Expected } \\
\text { Eror (Gal) }\end{array}$ & $\begin{array}{l}\text { Is orffererrce } \\
\text { goreater than } \\
\text { expected error? }\end{array}$ \\
\hline $2 / 23 / 95$ & WC- 10 to W-22 & 1093 & 1100 & 7 & 141 & No \\
\hline $3 / 4 / 95$ & WC- 10 to W-22 & 1088 & 1234 & 146 & 141 & Yes \\
\hline $3 / 13 / 95$ & WC- 10 to W-22 & 1020 & 1153 & 133 & 141 & No \\
\hline $3 / 24 / 95$ & WC-10 to W-22 & 1094 & 1080 & -14 & 141 & No \\
\hline $4 / 3 / 95$ & WC-10 to W-22 & 1075 & 1080 & 5 & 141 & No \\
\hline $4 / 16 / 95$ & WC-10 to W-22 & 1084 & 1050 & -34 & 141 & No \\
\hline $4 / 26 / 95$ & WC- 10 to W-22 & 967 & 967 & 0 & 141 & No \\
\hline $5 / 17 / 95$ & WC- 10 to W-22 & 1067 & 1080 & 13 & 141 & No \\
\hline $5 / 28 / 95$ & WC- 10 to W-22 & 1080 & 1150 & 70 & 141 & No \\
\hline $6 / 9 / 95$ & WC- 10 to W-22 & 1160 & 1160 & 0 & 141 & No \\
\hline $6 / 19 / 95$ & WC-10 to W-22 & 1065 & 1150 & 85 & 141 & No \\
\hline $6 / 30 / 95$ & WC- 10 to W-22 & 1050 & 1130 & 80 & 141 & No \\
\hline $7 / 10 / 95$ & WC- 10 to W-22 & 850 & 775 & -75 & 141 & No \\
\hline $7 / 16 / 95$ & $W C-10$ to $W-22$ & 1062 & 570 & -492 & 141 & See Note 1 \\
\hline $7 / 27 / 95$ & WC- 10 to W- 22 & 1070 & 1130 & 60 & 141 & No \\
\hline $8 / 5 / 95$ & WC- 10 to W-22 & 940 & 870 & -70 & 141 & No \\
\hline $8 / 12 / 95$ & WC- 10 to W-22 & 1073 & 1004 & -69 & 141 & No \\
\hline $8 / 20 / 95$ & WC- 10 to W-22 & 580 & 580 & 0 & 141 & No \\
\hline 9/3/95 & WC- 10 to W-22 & 1064 & 1064 & 0 & 141 & No \\
\hline $9 / 16 / 95$ & WC- 10 to W-22 & 1061 & 1050 & -11 & 141 & No \\
\hline 9/29/95 & WC- 10 to W-22 & 1034 & 1034 & 0 & 141 & No \\
\hline $10 / 14 / 95$ & WC- 10 to W-22 & 1067 & 1070 & 3 & 141 & No \\
\hline $10 / 27 / 95$ & WC-10 to W-22 & 1013 & 1013 & 0 & 141 & No \\
\hline $11 / 9 / 95$ & WC- 10 to W-22 & 1045 & 1045 & 0 & 141 & No \\
\hline $11 / 23 / 95$ & WC- 10 to W-22 & 1030 & 1190 & 160 & 141 & Yes \\
\hline $12 / 5 / 95$ & WC-10 to W-22 & 1026 & 1030 & 4 & 141 & No \\
\hline $12 / 19 / 95$ & WC- 10 to W-22 & 1025 & 1028 & 3 & 141 & No \\
\hline
\end{tabular}

Note 1) Line was empty when transfer was made due to gas test for FFA.

For the Tank WC-10-to-Tank W-22 transfers, the expected error was 141 gallons. Ten 
of the 39 recorded transfers showed input/output volume differences greater than the maximum expected error. Nine of these ten transfers differences were positive, indicating that more liquid was measured going into Tank W-22 than was measured leaving Tank WC-10. These results suggest numerical errors in the volume balance, or unrecorded flush or prime water that was added to the system. The one transfer conducted on July 16 , recorded a negative difference. However, comments in the transfer logs indicated that this line was empty prior to the transfer. Part of the volume that was transferred out of WC-10 would be contained in the previously empty pipeline and would not contribute to the measured receive volume.

\subsubsection{Analysis of Tank WC-10 Leak Test Data}

During this assessment period, a total of 43 leak tests were attempted on Tank WC-10; of these, 38 tests resulted in conclusive decisions that the tank was experiencing an INFLOW. Figure 40 shows a time series plot of the CVR data obtained from each of the useable test results. It can be seen from the plot that all 38 of the CVR values are significant and positive, and are thus consistent with the INFLOW results obtained from these tests.

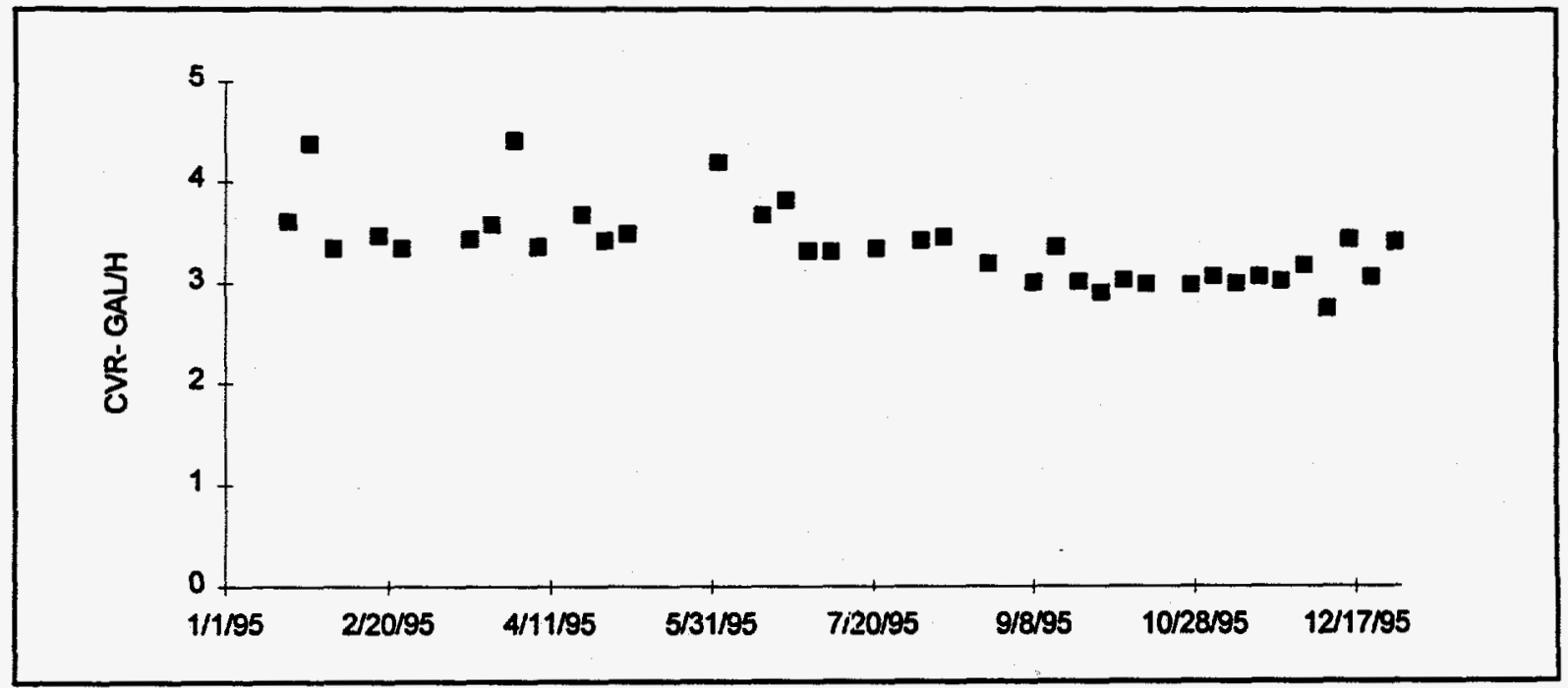

Figure 40. Time series plot of leak test CVRs from Tank WC-10.

A comparative analysis of the data shown in Figure 40 was performed. The analysis included using the Student's $t$ - [Mendenhall, 1992], and the K-S [Benjamin and Cornell, 1970] statistical tests. The Student's $t$-test is used to determine the significance of the mean of the CVR data. The K-S analysis is used to determine if the population of CVR values from Tank WC-10 is significantly different than a reference set of CVRs. These statistical tests are fully described in Section 5.4 .

Applying the $t$-test to the $\mathbf{3 8}$ data values shown above results in a t-statistic, $t_{\text {tat }}$ of 41.8 , while the critical value, $t_{\text {crit }}$ is 2.71 for a $99 \%$ level of confidence. Applying the K-S "goodnessof-fit" test to the Tank WC-10 CVR data, using a H/V weighted set of reference CVRs, results in a maximum ordinal difference, $\mathrm{KS}_{\text {stat }}$ of 0.36 , while the critical value, $\mathrm{KS}_{\text {erit }}$ is 0.26 . Based upon this analysis, we conclude that the observed mean CVR and the fluctuations about the 
mean are due to external influences, probably rain runoff that is entering the tank.

Figure 41 graphically illustrates the K-S test applied to the Tank WC-10 data. The light dashed line in the figure shows the CDF obtained from the reference set of CVR values (See Section 5.4), after removing the mean from that data and scaling those values by the $\mathrm{H} / \mathrm{V}$ coefficient of Tank WC-10 (38 gal/in.), divided by the H/V of the (mean-removed) reference set (14.72 gal/in.). The bold solid line in the figure shows the CDF obtained from the CVR data shown in Figure 40, after removing the mean from the data. This CDF shows that the total "spread" about the mean in the CVR data is large, and not at all consistent with the spread expected from measurement noise and other process-related effects.

The similarity of the data sets defined by the two lines illustrated in Figure 41 is "tested" with the K-S "goodness-of-fit" test. Here, the test statistic, $\mathrm{KS}_{\text {star }}$, is 0.36 , while the critical value, $\mathrm{KS}_{\text {crit }}$ is 0.26 . Since the maximum ordinal difference, $\mathrm{KS}_{\text {stat }}$, is greater than $\mathrm{KS}_{\text {crit }}$, the two populations are deemed to be different.

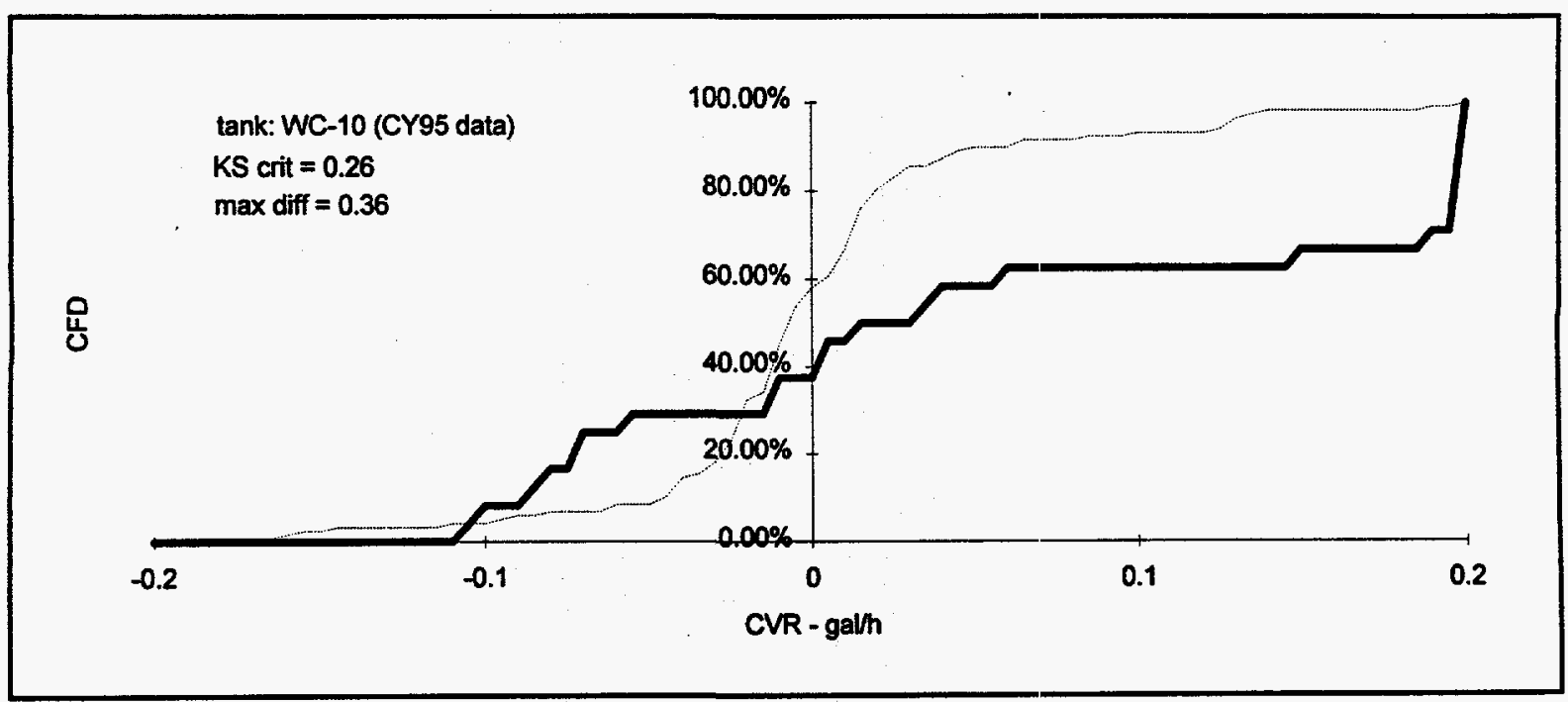

Figure 41. Cumulative frequency distribution from reference CVR data (light dashed line) and WC-10 CVR data (CY95) (solid bold line).

Table 49 summarizes the statistical analyses of the Tank WC-10 CVR data. The table shows that the mean of the CY95 test data is not equivalent to zero gal/h, and that the population of CY95 CVR values is different than the population of CVR values in the reference, or comparison, data set. 
Table 49. Summary of Statistical Analyses of Tank WC-10 CVR Data (H/V=38 gal/in)

\begin{tabular}{|c|c|c|}
\hline & Reference CVR data & '95 CVR data \\
\hline $\mathrm{N}$ & 118 & 38 \\
\hline Mean $(\mathrm{gal} / \mathrm{h})$ & 0.012 & 3.42 \\
\hline $\begin{array}{c}\text { Standard Deviation } \\
(\mathrm{gal} / \mathrm{h})\end{array}$ & 0.080 & 0.505 \\
\hline t-statistic & & 41.8 \\
\hline t-critical (1\%) & & 2.71 \\
\hline t-test Inference & & $\begin{array}{l}\text { mean of WC-10 CVR data } \\
\text { is different than } 0 \mathrm{gal} / \mathrm{h}\end{array}$ \\
\hline KS-statistic & & 0.36 \\
\hline KS-critical (1\%) & & 0.26 \\
\hline KS-test Inference & & $\begin{array}{l}\text { WC- } 10 \text { CVR population is } \\
\text { different than reference set }\end{array}$ \\
\hline
\end{tabular}

\subsubsection{Findings and Conclusions}

The findings of this report are based on (1) a review of available tank design drawings, (2) a qualitative assessment of corrosion on the tank and pipelines, and (3) leak testing results from the tank and testable pipelines.

Review of the design drawings indicated that the tank was designed in accordance with acceptable practices defined by ASTM and ASME. One concern noted was an abundance of inlets into the tank which were not connected to pipelines. However, because the unused inlets are located on the top of the tank, the concern of leakage out of the tank through the ports is nonexistent at operation levels of less than full tank capacity. The design drawings revealed a sound design of the WC-10 Tank.

During the corrosion assessment, it was determined that with the present use of the tank system, all forms of corrosion on the interior walls of the tank and associated piping should be nonexistent. However, corrosion damage that may have occurred when the tank was used in past environments cannot be assessed. An attempt to determine cumulative damage to the interior tank wells during its entire life revealed substantial iron containing scale on some areas of the tank. Heavy attack corrosion may be obscured beneath the scaled areas. An analysis of the general aspects of corrosion at ORNL revealed that corrosion of stainless steel by ORNL soil is not believed to be severe.

Leak testing of Tank WC-10 was completed by the Volumetric DP method in 43 tests. The tank had INCONCLUSIVE results in five test and INFLOW results for 38 tests. Although Tank WC- 10 cannot be certified on the basis of the leak test results reported here, the PASS results 
the potential of certifying the tank during the next reporting period.

Two of five testable line segments passed leak testing by EPA and TDEC approved methods and two pipelines segments yielded INCONCLUSIVE results due to an inflow into the tank. The remaining testable line segment is not used and will not be tested.

Transfer logs were used to qualitatively assess the pipelines which are untestable by currently approved methods. Transfer logs reveal that 39 transfers were made during the period from January 1995 through December 1995. The difference in the volume sent and the volume received exceeded the expected error in ten transfers. The volume of each of the transfer along with the latest qualitative assessment of the pipelines are reported to EPA and TDEC in the "Quarterly Highlights for LLLW Tank System Activities." Although a limited evaluation of the untestable pipelines can be made using transfer logs, this method of assessment is not deemed valid for certification purposes.

All of these factors were considered in determining certification of the WC-10 system components. Table 50 summarizes the elements of the tank system which were certified and the conditional limits on their certifications.

Table 50. Summary of Tank System Certification for Tank WC-10

\begin{tabular}{|c|c|c|c|c|c|c|}
\hline Systen & $\begin{array}{c}\text { Length } \\
\text { (ft) }\end{array}$ & $\begin{array}{l}\text { Tested? } \\
\text { (Yes/No) }\end{array}$ & $\begin{array}{l}\text { Leal Test } \\
\text { Method }\end{array}$ & Test Result & Cerfification & $\begin{array}{l}\text { Certification } \\
\text { Level }\end{array}$ \\
\hline Tank WC-10 & & Yes & DP & INCONCLUSIVE & No & $\mathrm{N} / \mathrm{T}$ \\
\hline LS-33 & 1358 & Yes & GPD & PASS & Yes & Full flow \\
\hline LS-83 & 250 & No & $\mathrm{N} / \mathrm{T}$ & $\mathrm{N} / \mathrm{T}$ & No & $\mathrm{N} / \mathrm{T}$ \\
\hline LS-84 & 800 & Yes & EVB & INCONCLUSIVE & No & $\mathrm{N} / \mathrm{T}$ \\
\hline LS-85 & 155 & Yes & EVB & INCONCLUSIVE & No & $\mathrm{N} / \mathrm{T}$ \\
\hline LS-86 & 135 & No & $\mathrm{N} / \mathrm{T}$ & $\mathrm{N} / \mathrm{T}$ & No & $\mathrm{N} / \mathrm{T}$ \\
\hline LS-125 & 25 & Yes & GPD & PASS & Yes & Full flow \\
\hline LS-131 & 20 & No & $\mathrm{N} / \mathrm{T}^{*}$ & $\mathrm{~N} / \mathrm{T}$ & No & $\mathrm{N} / \mathrm{T}$ \\
\hline $\begin{array}{l}{ }^{*} \\
\text { DP } \\
\text { EVB } \\
\text { LS } \\
\text { N/T } \\
\end{array}$ & $\begin{array}{l}\text { ords av } \\
\text { pressur } \\
\text { olume b } \\
\text { b }\end{array}$ & cing & & & & \\
\hline
\end{tabular}




\subsubsection{Certification}

Based on the results of the design drawings review, the qualitative corrosion assessment, and the results of the leak testing program, it is my professional opinion that Tank WC-10 cannot be certified at this time. However, based upon the results of the pipeline tests, it is my professional opinion that Line Segments 33 and 125 retain sufficient integrity to contain liquids up to the full flow potential of this line segment. Table 50 provides a summary description of the certifications for the WC-10 Tank System.

It is recommended that leak detection and line testing using the EPA and TDEC approved methods be continued, until this system has been removed from operation or replaced.

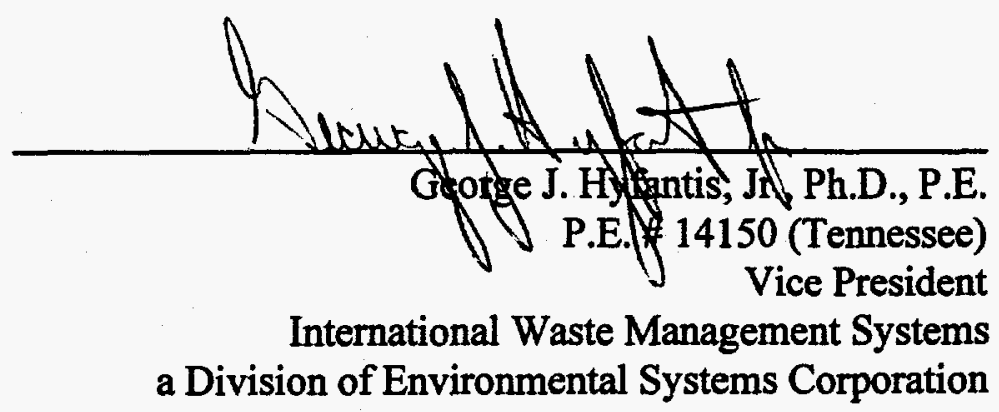





\subsection{WC-20 Tank System}

The WC-20 Tank System is located north of Building 7516, on the north side of Melton Valley Drive, as shown in Figure 1A. The WC-20 Tank System collects LLLW from the Radiochemical Engineering Development Center. The tank system is made up of Tank WC-20 and five line segments connected to the system. The WC-20 Tank System was classified as a Category $\mathrm{C}$, according to the FFA.

\subsubsection{WC-20 Tank Description}

Tank WC-20 is a 10,000 gallon tank located in a SS-lined concrete vault. Installed in 1976, Tank WC-20 is anchored in place, horizontally, by two 304L stainless steel shells conforming to the circumference of the tank and are secured to the floor by 1-1/8" anchored bolts. The tank is constructed of 304L stainless steel with a 3/4" wall thickness with 3/4" 304L stainless steel dished heads. The outside diameter of the tank is $10^{\prime}-0^{\prime \prime}$ with a length of $19^{\prime}$ $5-5 / 8$ ". The working volume of the tank is 7,000 gallons. The drawing for Tank WC-20 is provided as Figure 42.

The tank is equipped with three 6" diameter Schedule 40 stainless steel nozzles, five 2" diameter Schedule 40 stainless steel nozzles, two 1" diameter Schedule 40 stainless steel nozzles, two 1" diameter air spargers, one 2" diameter thermocoupler and one 20" diameter manhole. All of the nozzles including the manhole, air spargers, and thermocoupler, are located on top of the tank aligned along the tank centerline. The manhole is located in the center of the top of the tank.

The tank is located in a reinforced concrete vault lined with 16 gauge stainless steel having outside dimensions of $25^{\prime}-0^{\prime \prime} \times 18^{\prime}-0^{\prime \prime}$ with $2^{\prime}-0^{\prime \prime}$ thick walls. The floor of the vault is sloped to a sump 2'-0" × 2'-0" × 2'-0" in the southeast corner of the vault. The top of the vault is constructed to receive three inwardly stepped reinforced concrete plugs $5^{\prime}$ thick used for inspection and maintenance.

Tank WC-20 receives waste from Buildings 7920 and 7930. A schematic of the tank system with numbered line segments is provided as Figure 43.

\subsubsection{WC-20 Pipeline Descriptions}

Five separate lines make up the portion of the LLLW pipeline system belonging to Tank WC-20. Characteristics of the lines are listed in Table 50, and line segments are shown in Figure 43 of this report. All pipelines associated with the WC-20 tank system are constructed of stainless steel and were installed in 1976. As shown in Figure 43, Tank WC-20 has one inlet and one discharge pipeline. The remaining three line segments are not directly connected to Tank WC-20. 


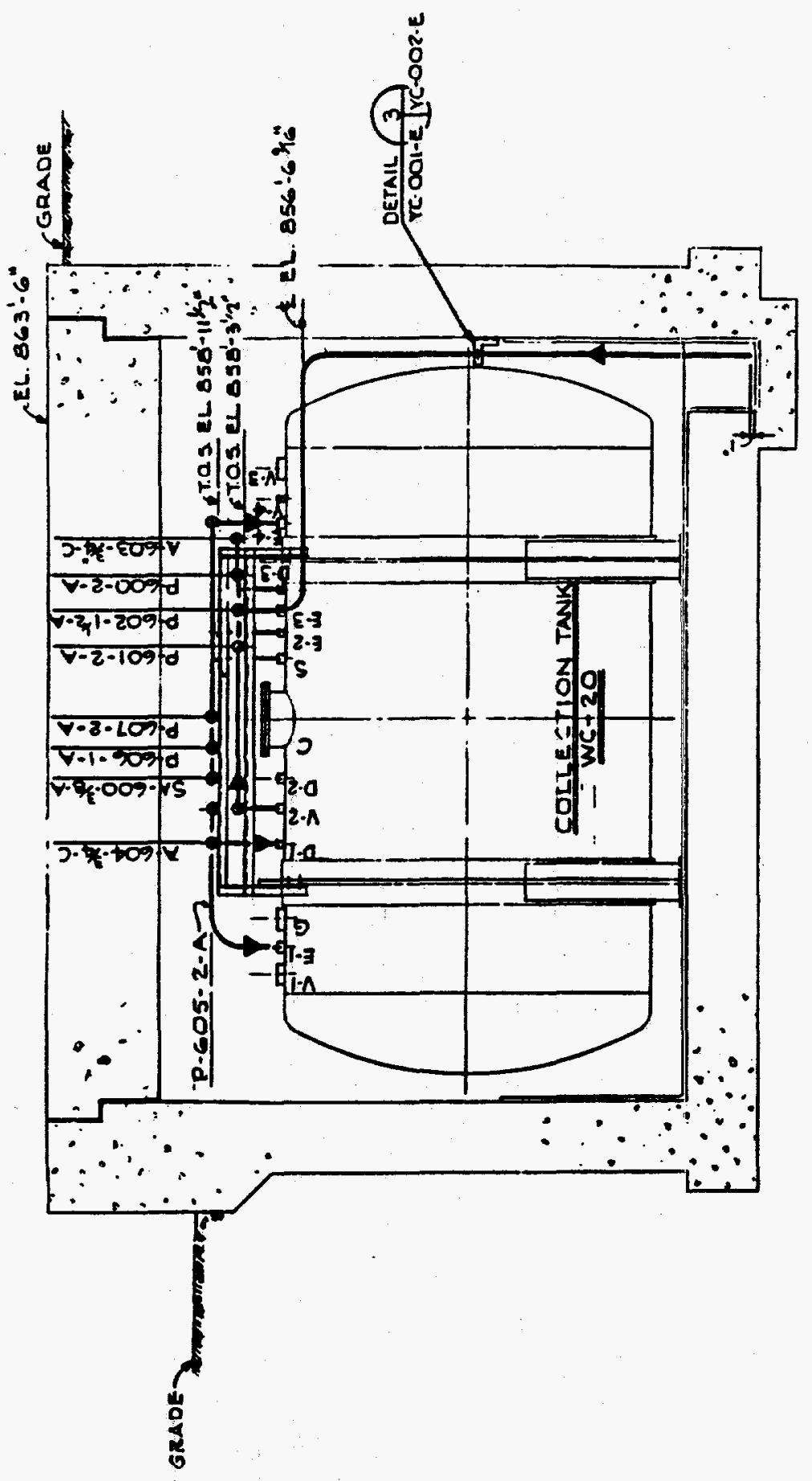

 


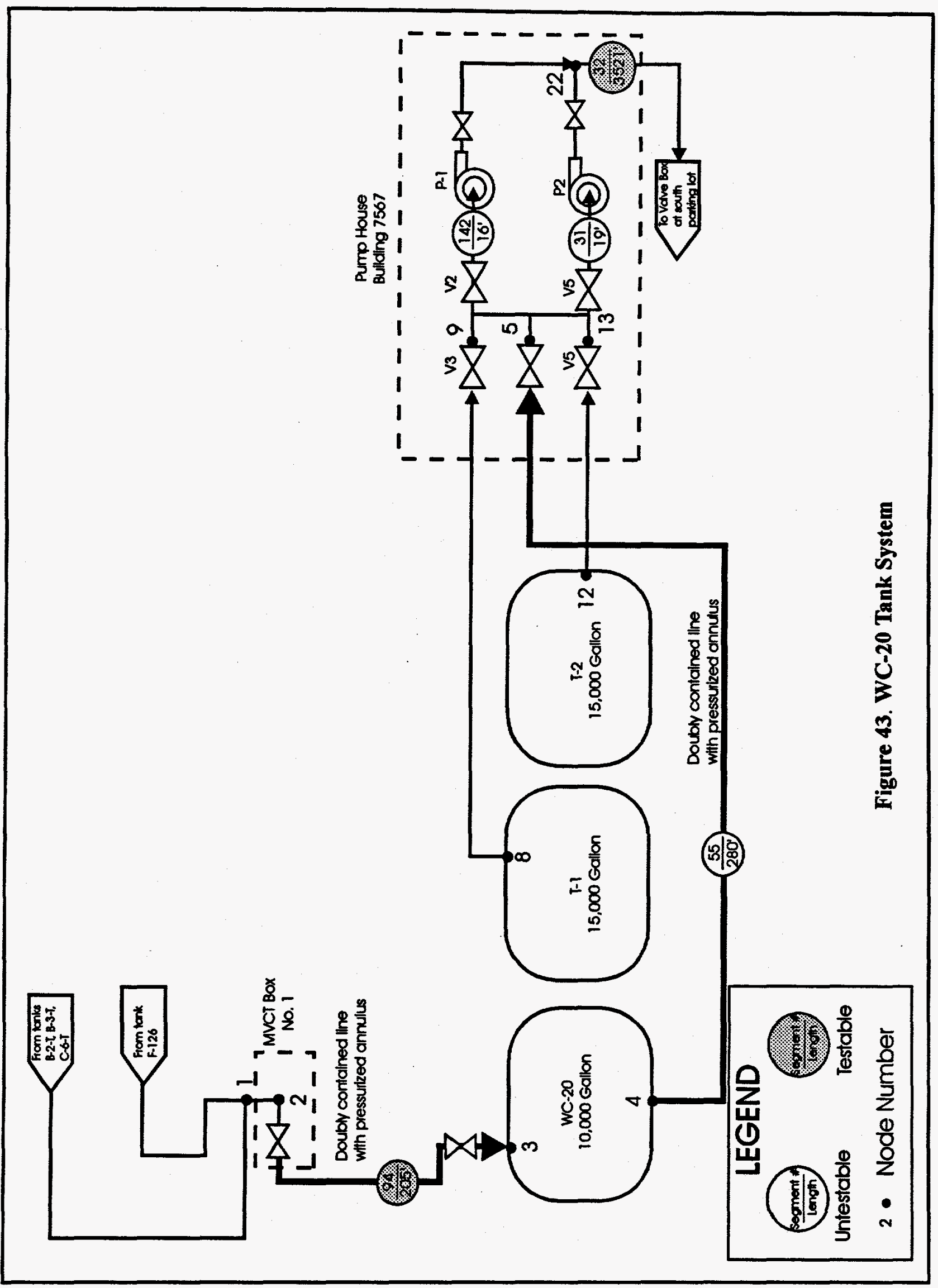


Line Segment 94 is the inlet for waste coming into Tank WC-20 (node 2 to node 3 on Figure 43). Line Segment 94 is a 205', 2" diameter steam jet pressurized pipeline connecting to lines leading from Tanks B-2-T, B-3-T, C-6-T, and F-126. Line Segment 55 is a 280' long, 2" diameter pipeline leading from Tank WC-20 to a manifold inside Pump House Building 7567 (node 4 to node 5).

This line serves as the suction line for the centrifugal purnp used to transfer waste out of Tank WC-20 and is doubly contained. Line Segments 31 and 142 are 19' long and 16' long sections of pipeline respectively, which connect the manifold from Line Segment 55 to the centrifugal transfer pumps located in Building 7567 (node 13 to node 22 and node 9 to node 22 respectively). Line Segment 31 has a 4" diameter while Line Segment 142 is a 2" diameter line. Line Segment 32 is a 3,521' long section of 2" diameter line leading from the pumps in Building 7567 to the Valve Box at the South Parking Lot in Bethel Valley (node 22 to south parking lot valve box).

Table 51. Characteristics of Line Segments Evaluated as a Part of Tank System WC-20

\begin{tabular}{|c|c|c|c|c|c|c|}
\hline \multicolumn{2}{|c|}{ Whe Serment } & 31 & 32 & 35 & 94 & 142 \\
\hline \multicolumn{2}{|c|}{ Node Number } & 13 to 22 & $\begin{array}{c}22 \text { to South Parking } \\
\text { Lot Valve Box }\end{array}$ & 4 to 5 & 2 to 3 & 9 to 22 \\
\hline \multicolumn{2}{|c|}{ Index Number } & $*$ & $\mathbf{P 2 1}$ & $*$ & P32 & $*$ \\
\hline \multicolumn{2}{|c|}{ Diameter (in) } & 4 & 2 & 2 & 2 & 2 \\
\hline \multicolumn{2}{|c|}{ Material } & 304 SS & 304 SS & 304 SS & 304 SS & 304 SS \\
\hline \multicolumn{2}{|c|}{ Length $(f)$} & 19 & 3,521 & 280 & 205 & 16 \\
\hline \multicolumn{2}{|c|}{ Volume (gal) } & 3 & 613 & 49 & 36 & 3 \\
\hline \multicolumn{2}{|c|}{ Transfer Method } & $\begin{array}{l}\text { CP and } \\
\text { CP Suct. }\end{array}$ & $\mathrm{CP}$ & CP Suct. & SJ & CP and CP Suct. \\
\hline \multicolumn{2}{|c|}{ Install Date } & 1976 & 1976 & 1976 & 1976 & 1976 \\
\hline \multicolumn{7}{|c|}{$\begin{array}{ll}\text { * } & \text { Transfer records available } \\
\text { CP } & \text { Centrifugal Pump } \\
\text { SJ } & \text { Steam jet pump } \\
\text { Suct. } & \text { Suction } \\
\text { SS } & \text { Stainless Steel } \\
\end{array}$} \\
\hline
\end{tabular}

\subsubsection{Corrosion Assessment of the WC-20 Tank System}

Tank WC-20 collects waste from Buildings 7920 and 7930, the Radiochemical Development Engineering Center. The major components in the process solutions from this facility are lithium chloride, hydrochloric acid, nitric acid, sodium nitrate, some organic material and traces of hydrogen peroxide, and Transuranium isotopes. Before entering the tank all solutions are neutralized with sodium hydroxide, and enough excess is added to make the solution $\mathrm{pH}$ at least 13 . Without the addition of sodium hydroxide, the solutions would rapidly corrode SS; with alkali present, these solutions should be compatible with stainless steel and any corrosion should be slight. 


\subsubsection{Results of Leak Tests on the WC-20 System}

This section summarizes the results of the leak detection tests conducted on Tank System WC-20 (the tank and its associated pipelines). Each element in the system was tested with a method appropriate for that element. Each method used has been demonstrated to detect a specified leak rate ( $0.2 \mathrm{gal} / \mathrm{hr}$ for tank methods; $0.1 \mathrm{gal} / \mathrm{hr}$ for pipeline methods) with a PD no less than $95 \%$ and a PFA no greater than $5 \%$.

\subsubsection{Tanks}

Leak testing of Tank WC-20 for the current assessment period began in September 1995, for this reporting period and continued through August 1996, with a total of 19 leak test attempts during this reporting period. The results of these tests are summarized in Table 52, which shows the date of each test, the volume of LLLW in the tank at the time of the test, the percent of Tank WC-20's total volume the test represented ${ }^{11}$, the test result, and comments pertinent to particular tests. The table shows that Tank WC-20 recorded INCONCLUSIVE results for ten of the test attempts, and PASS results for nine of the leak tests. The reason for the inconclusive results is spurious noise in the data- noise that is characteristic of atmospheric moisture that has condensed in the dip legs of the bubbler system causing erratic level indications. An air drier system was installed in January 1996 that appears to have remedied the noise problem. For this report, test data was included through August 1996 to conclusively demonstrate the integrity of WC-20. The maximum volume for which the tank passed the leak testing during this reporting period was 3,991 gallons, or $39 \%$ of the total capacity of the tank. This is greater than the previously certified level of 3,887 gallons (38\%) for this tank [DOE/OR/01-1385\&D2].

Table 52. Summary of Leak Tests Conducted on Tank WC-20

\begin{tabular}{||c|c|c|c|c||}
\hline Date & Hot Gallons & \% Capacity & Test Result & I Comment \\
\hline $09 / 01 / 95$ & 1,254 & 12 & PASS & \\
\hline $10 / 13 / 95$ & 2,716 & N/A & INCONCLUSIVE & \\
\hline $10 / 23 / 95$ & 2,763 & 27 & PASS & \\
\hline $11 / 14 / 95$ & 5,176 & N/A & INCONCLUSIVE & \\
\hline $11 / 21 / 95$ & 5,168 & N/A & INCONCLUSIVE & \\
\hline $11 / 27 / 95$ & 5,168 & N/A & INCONCLUSIVE & noise like H2O in \\
\hline $1202 / 95$ & 2,171 & N/A & INCONCLUSIVE & bubbler lines \\
\hline $12 / 04 / 95$ & 2,173 & N/A & INCONCLUSIVE & \\
\hline $12 / 06 / 95$ & 3,671 & N/A & INCONCLUSIVE & \\
\hline $12 / 20 / 95$ & 5,080 & N/A & INCONCLUSIVE & \\
\hline $12 / 29 / 95$ & 5,116 & N/A & INCONCLUSIVE & \\
\hline $01 / 05 / 96$ & 4,957 & N/A & INCONCLUSIVE & \\
\hline $02 / 23 / 96$ & 1,964 & 19 & PASS & new air drier installed \\
\hline $03 / 01 / 96$ & 1,964 & 19 & PASS & \\
\hline
\end{tabular}

${ }^{11}$ WOCC look-up tables show $100 \%$ capacity for WC- 20 as 10,336 gal. The percent capacity shown in the table is based on this number. 


\begin{tabular}{|c|c|c|c|c|}
\hline Date & \# of Gallons & \% Capacity & Test Result & Comment \\
\hline $04 / 02 / 96$ & 3,212 & 31 & PASS & \\
\hline $05 / 09 / 96$ & 2,727 & 26 & PASS & \\
\hline $06 / 01 / 96$ & 3,991 & 39 & PASS & \\
\hline $07 / 05 / 96$ & 1,655 & 16 & PASS & \\
\hline $08 / 02 / 96$ & 2,797 & 27 & PASS & \\
\hline
\end{tabular}

The nine usable compensated volume rate (CVR) data values from these leak tests were analyzed (1) to verify that the test method was performing properly in this application and (2) to confirm that during this assessment period the leak testing process had remained nominal; that is, that the use of, or performance of, the method as applied to this particular tank was not deteriorating. This analysis included a statistical examination of the CVR data, as well as a comparison of this year's assessment data with prior data. The analysis and the results are described in Section 7.10.4.3.

\subsubsection{WC-20 Pipelines}

The results of the leak detection test on the testable WC-20 pipelines are summarized in Section 7.10.4.2.1. An assessment of the integrity of the WC-20 pipelines that cannot be tested for leaks with existing approved methods is summarized in Section 7.10.4.2.2.

\subsection{WC-20 Testable Pipelines}

The testable portion of the WC-20 system consists of two pressurized line segments. One segment (segment 32, index P21) is the discharge line from the centrifugal pumps in Building 7567 to the valve box in the South Parking Lot. The other segment $(94, \mathrm{P} 32)$ is the transfer line from the Melton Valley Collection Transfer Valve Box (node 2) to Tank WC-20 (node 3). This segment is doubly contained, with a pressurized annulus. Since the annulus is maintaining the internal pressure, it will not be leak tested. Table 53 shows the results of the leak tests conducted on the WC-20 pipelines.

Table 53. Summary of Leak Test Results for the WC-20 Testable Lines.

\begin{tabular}{|c|c|c|c|c|}
\hline Element No & Sine Segnent & Test Date & Test Result & Comment \\
\hline P21 & 32 & 19-Jul-1996 & PASS & \\
\hline P32 & 94 & N/A & N/A & $\begin{array}{l}\text { doubly contained } \\
\text { pressurized annulus } \\
\text { that is maintaining } \\
\text { pressure }\end{array}$ \\
\hline
\end{tabular}




\subsection{WC-20 Untestable Pipelines}

There are three untestable line segments associated with the WC-20 system. Line Segment 55 is the suction line that joins the WC-20 tank vault with the transfer pumps manifold in the Building 7567 Pump House (node 4 to node 5 in Figure 43). Line Segments 31 and 142 are the discharge side of pumps $P 2$ and $P 1$, respectively (these line segments are also used on transfers from T-1 and T-2 to W-22). These lines are a portion of Tank WC-20 to Tank W-22 transfer line; the volume in the tank is measured and recorded by WOCC. Transfer logs show that during the period from January 1995 through December 1995, seven transfers were made from Tank WC-20 to Tank W-22. These transfers are summarized in the first four columns of Table 54. The difference between the volume sent (Column 3 ) and the volume received (Column 4) for each transfer is shown in Column 5.

Table 54. Summary of Transfers between Tank WC-20 and Tank W-22 from January 1995 to December 1995

\begin{tabular}{|c|c|c|c|c|c|c|}
\hline $\begin{array}{l}\text { Transfer } \\
\text { Date }\end{array}$ & Transfer log & $\begin{array}{l}\text { Volume } \\
\text { Sent } \\
\text { (Gal) }\end{array}$ & $\begin{array}{l}\text { Volume } \\
\text { Received } \\
\text { (Gal) }\end{array}$ & $\begin{array}{l}\text { Difference } \\
\text { (Gal) }\end{array}$ & $\begin{array}{l}\text { Maximun } \\
\text { Expeeted } \\
\text { Errot } \\
(\mathbf{G a l})\end{array}$ & $\begin{array}{l}\text { Is difference } \\
\text { greater than } \\
\text { erpected } \\
\text { errol? }\end{array}$ \\
\hline $1 / 13 / 95$ & WC-20 to W-22 & 2019 & 2000 & -19 & 144 & No \\
\hline $3 / 18 / 95$ & WC-20 to W-22 & 1002 & 2100 & 1098 & 143 & See Note 1 \\
\hline $4 / 25 / 95$ & WC-20 to W-22 & 3625 & 3625 & 0 & 152 & No \\
\hline $7 / 23 / 95$ & WC-20 to W-22 & 3180 & 3213 & 33 & 150 & No \\
\hline 9/1/95 & WC-20 to W-22 & 3520 & 5060 & 1540 & 160 & See Note 2 \\
\hline $11 / 11 / 95$ & WC- 20 to W-22 & 4228 & 4278 & 50 & 157 & No \\
\hline $12 / 2 / 95$ & WC-20 to W-22 & 3934 & 4630 & 696 & 158 & Yes \\
\hline
\end{tabular}

Note 1) FFA test required draining of line - 200 gal to refill.

Note 2) W-22 level lowered into sludge.

For the Tank WC-20 to Tank W-22 transfers, the expected errors are shown in Column 6. Three of the recorded Tank WC-20 to Tank W-22 transfers show input/output volume differences greater than the maximum error expected for each transfer; possible reasons for two of the differences are given in the transfer logs. The one unexplained difference was positive, indicating that more liquid was measured going into Tank W-22 than was measured leaving Tank WC-20. There were no unexplained significant negative differences, which, unlike positive differences, would warrant further investigation. In addition, because the untestable portion of this line is comprised of suction piping, it would be unlikely that the transfer pumps could be primed if the line lacked integrity. Therefore, the successful transfers are a positive indication of this line's integrity. 


\subsubsection{Analysis of Tank WC-20 Leak Test Data}

During the assessment period September 1995 through August 1996, a total of 19 leak tests were attempted on Tank WC-20. Nine of these tests resulted in conclusive decisions. Figure 44 shows a time series plot of the CVR data obtained from each of the useable test results. It can be seen from the plot that all nine of the CVR values are within the INFLOW and OUTFLOW decision thresholds, and are thus consistent with the PASS results obtained from these tests.

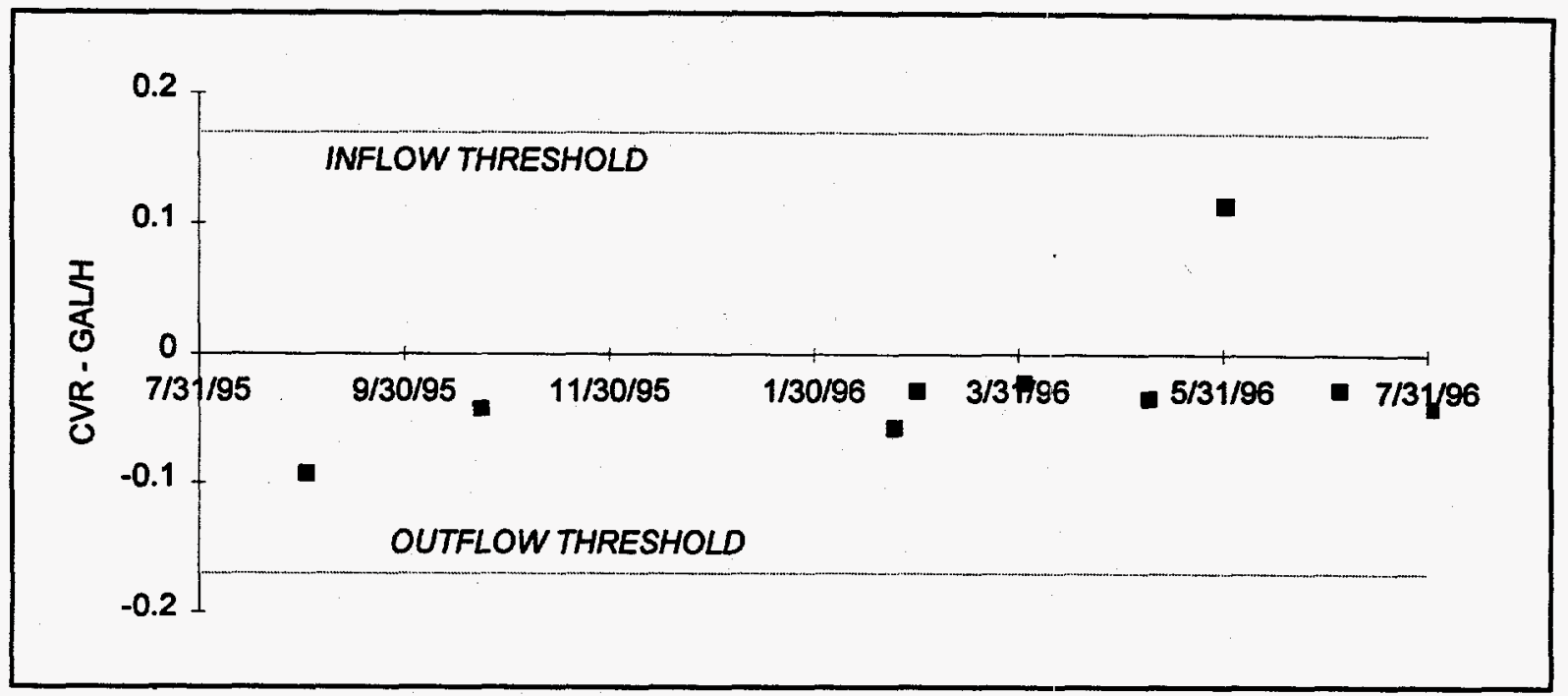

Figure 44. Time series plot of leak test CVRs from Tank WC-20 (note time scale).

A comparative analysis of the data shown in Figure 44 was performed. The analysis included using the Student's $t$ - [Mendenhall, 1992], and the K-S [Benjamin and Cornell, 1970] statistical tests. The Student's $t$-test is used to determine the significance of the mean of the CVR data. The K-S analysis is used to determine if the population of CVR values from WC20 is significantly different than a reference set of CVRs. These statistical tests are fully described in Section 5.4.

As shown below, applying the t-test to the nine data values shown above results in an absolute value of the $t$-statistic, $t_{\text {star }}$ of -1.36 , while the critical value, $t_{\text {trit }}$, is 3.36 , for a $99 \%$ level of confidence. Applying the K-S "goodness-of-fit" test to the Tank WC-20 CVR data, using a $\mathrm{H} / \mathrm{V}$ volume weighted set of reference CVRs, results in a maximum ordinal difference, $\mathrm{KS}_{\text {stat }}$, of 0.38 , while the critical value, $\mathrm{KS}_{\text {crit, }}$, is 0.56 , for a $99 \%$ level of confidence. Based upon this analysis, we conclude that both the mean and variance of the 1995 CVR data from Tank WC-20 is entirely consistent with data expected from non-leaking tanks.

Figure 45 graphically illustrates the K-S test applied to the Tank WC-20 data. The bold solid line in the figure shows the CDF obtained from the CVR data shown in Figure 44, after removing the mean from the data. The light dashed line in the figure shows the CDF 
obtained from the reference set of CVR values (See Section 5.4), after removing the mean from that data and scaling those values by the H/V coefficient of WC-20 (115 gal/in.), divided by the $\mathrm{H} / \mathrm{V}$ of the (mean-removed) reference set $(14.72 \mathrm{gal} / \mathrm{in}$.).

The similarity of the data sets defined by the two lines illustrated in Figure 45 is "tested" with the K-S "goodness-of-fit" test. Here, the test statistic, $\mathrm{KS}_{\text {stat }}$, is 0.38 , while the critical value, $\mathrm{KS}_{\text {crit, }}$ is 0.56 . Since the maximum ordinal difference, $\mathrm{KS}_{\text {stat }}$, is less than $\mathrm{Ks}_{\text {crit }}$, the two populations are deemed to be equivalent.

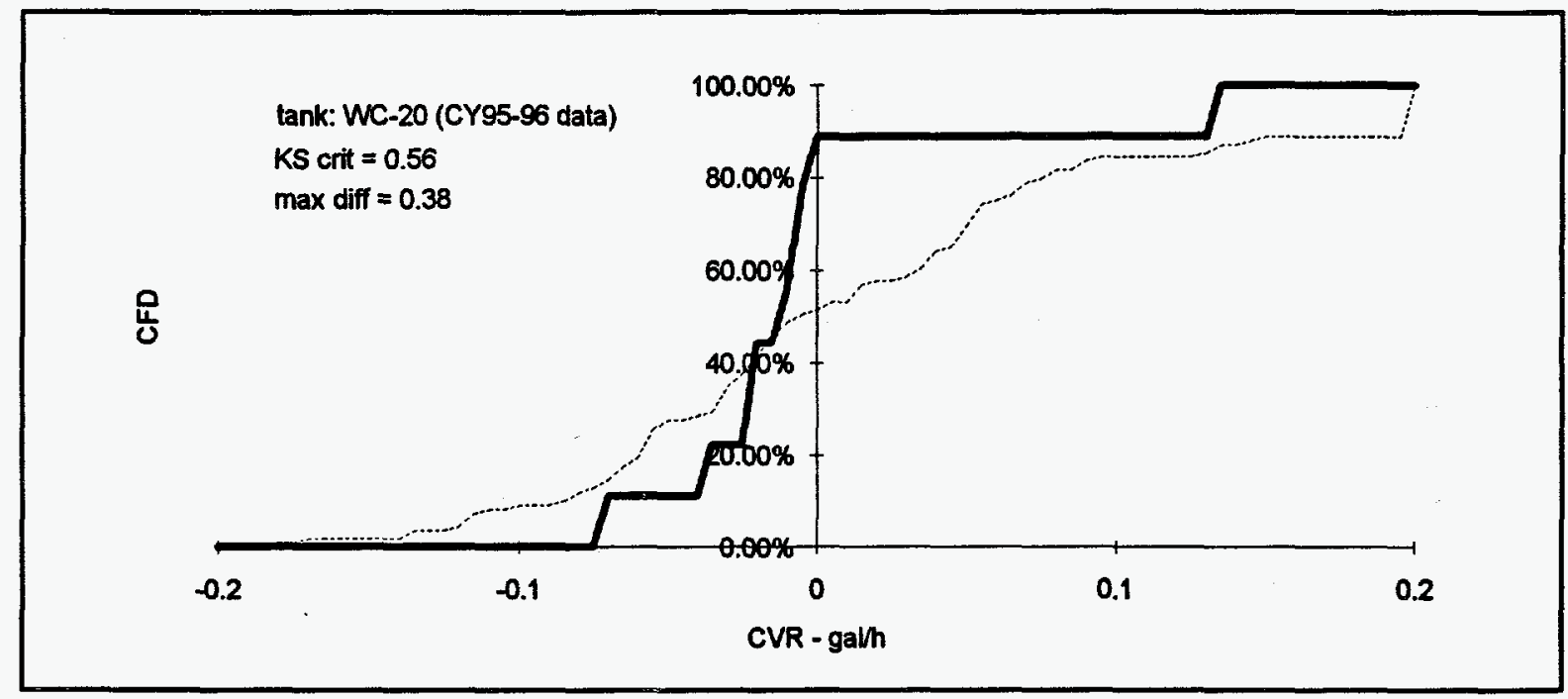

Figure 45. Cumulative frequency distribution from reference CVR data (light dashed line) and WC-20 data (CY95-96) (solid bold line).

Table 55 summarizes the statistical analyses of the Tank WC-20 CVR data. The table shows that the mean of the CY95 test data equivalent to zero gal/h. A "goodness-of-fit" test applied to the Tank WC-20 CVR data shows that the population of CY95 CVR values is not different than the population of CVR values in the reference, or comparison, data set.

Table 55. Summary of Statistical Analyses of Tank WC-20 CVR Data (H/V=115 gal/in)

\begin{tabular}{||c|c|c||}
\hline & Reference CVR data & 95 CVR data \\
\hline$N$ & 118 & 9 \\
\hline Mean (gal/h) & 0.036 & -0.026 \\
\hline $\begin{array}{c}\text { Standard Deviation } \\
\text { (gal/h) }\end{array}$ & 0.243 & 0.057 \\
\hline t-statistic & & -1.36 \\
\hline$t$-critical (1\%) & & 3.36 \\
\hline t-test Inference & & $\begin{array}{c}\text { mean is equivalent to a } \\
\text { zero gal/h leak rate }\end{array}$ \\
\hline
\end{tabular}




\begin{tabular}{|c|c|c|}
\hline & Reference CVR data & '95 CVR data \\
\hline KS-statistic & & 0.38 \\
\hline KS-critical (1\%) & & 0.56 \\
\hline KS-test Inference & & $\begin{array}{c}\text { Same population as } \\
\text { reference set }\end{array}$ \\
\hline
\end{tabular}

\subsubsection{Findings and Conclusions}

The findings of this report are based on (1) a review of available tank design drawings, (2) a qualitative assessment of corrosion on the tank and pipelines, and (3) leak testing results from the tank and testable pipelines.

Review of the design drawings revealed a sound design of the WC-20 Tank System. One concern noted was an abundance of nozzles into the tank that were not connected to pipelines. However, because the nozzles are located on the top of the tank, there is no concern that leakage could occur at those locations as long as the tank is operating at less than full capacity.

During the corrosion assessment it was determined that with the present use of the tank system, all forms of corrosion on the interior walls of the tank and associated piping should be nonexistent. Corrosion damage that may have occurred when the tank was used in past environments cannot be assessed. This tank is located in a stainless steel lined concrete vault and corrosion damage to the tank should be nil. All underground stainless steel piping associated with this tank are cathodically protected, and if the cathodic protection system is properly installed and maintained, corrosion on the exterior pipe surfaces should also be essentially nil.

Leak testing of Tank WC-20 was completed by the volunaetric DP method in 16 tests. Six tests resulted in PASS decisions. One of the two testable line segments passed leak testing by an EPA and TDEC approved method. The second testable line segment is doubly contained and has a pressurized annulus that has maintained pressure. Three remaining pipeline segments are untestable by current approved testing methods.

Transfer logs were used to qualitatively assess the pipelines which are untestable by currently approved methods. These transfer logs reveal that seven transfers were made between January and December 1995. The difference between the measured volume sent from Tank WC-20 and the measured volume received in Tank W-22 was greater than expected on two events. Each of the differences were explained. The successful transfers, coupled with the untestable line being a suction line, are a positive indication of the lines integrity. The volume of these transfers along with the latest qualitative assessment of the pipelines are reported to EPA and TDEC in the "Quarterly Highlights for LLLW Tank System Activities." Although a limited evaluation of the untestable pipelines can be made using transfer logs, this method of assessment, due to limited accuracy, is not deemed valid for certification purposes. 
All of these factors were considered in determining certification of the WC-20 System components. Table 56 summarizes the elements of the tank system which were certified and the conditional limits on their certifications.

Table 56. Summary of WC-20 Tank System Testing and Certification

\begin{tabular}{|c|c|c|c|c|c|c|c|}
\hline \multicolumn{2}{|c|}{ Component } & length & $\begin{array}{l}\text { Tested } \\
\text { Yes/No) } \\
\end{array}$ & $\begin{array}{l}\text { Leak Test } \\
\text { Method } \\
\end{array}$ & $\begin{array}{l}\text { Test: } \\
\text { Result } \\
\end{array}$ & Certirication & $\begin{array}{l}\text { Certincation } \\
\end{array}$ \\
\hline \multicolumn{2}{|c|}{ Tank WC-20 } & & Yes & MDP & PASS & Yes & $39 \%$ \\
\hline \multicolumn{2}{|l|}{ LS-31 } & 19 & No & $\mathrm{N} / \mathrm{T}^{*}$ & $\mathrm{~N} / \mathrm{T}$ & No & $\mathrm{N} / \mathrm{T}$ \\
\hline \multicolumn{2}{|l|}{ LS-32 } & 3,521 & Yes & GPD & PASS & Yes & Full flow \\
\hline \multicolumn{2}{|l|}{ LS-94 } & 205 & ** & & & Yes & Full flow \\
\hline \multicolumn{2}{|c|}{ LS-142 } & 16 & No & $\mathrm{N} / \mathrm{T}^{*}$ & $\mathrm{~N} / \mathrm{T}$ & No & $\mathrm{N} / \mathrm{T}$ \\
\hline \multicolumn{2}{|l|}{ LS-55 } & 280 & No & $\mathrm{N} / \mathrm{T}^{*}$ & $\mathrm{~N} / \mathrm{T}$ & No & $\mathrm{N} / \mathrm{T}$ \\
\hline \multicolumn{8}{|c|}{\begin{tabular}{|ll}
$*$ & Transfer records available \\
$* *$ & Pressurized annulus is monitor \\
GPD & Gas pressure decay method \\
LS & Line segment \\
MDP & Modified differential pressure \\
N/T & Not testable
\end{tabular}} \\
\hline
\end{tabular}




\subsubsection{Certification}

Based on the results of the design drawings review, the qualitative corrosion assessment and the results of the leak testing program, it is my professional opinion that Tank WC-20 retains sufficient structural integrity to contain liquids at operating levels up to those achieving a PASs during the testing program. Furthermore, Line Segments 32 and 94 of the WC-20 Tank System retains sufficient structural integrity to contain liquids up to full flow conditions. Table 56 provides a summary description of the certifications for the WC-20 Tank System. If future testing is conducted at greater tank levels, then certification levels may also increase.

It is recommended that leak detection and line testing using EPA and TDEC approved methods be continued, to support annual certification, until this system has been removed from operation or replaced.

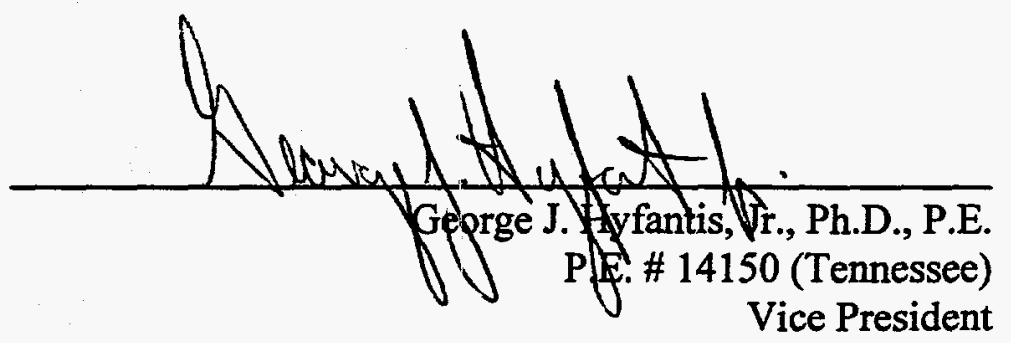

International Waste Management Systems a Division of Environmental Systems Corporation 


\section{REFERENCES}

Douglas, D. G., J. W. Starr, T. M. Juliano, J. W. Maresca, Jr., and R. A. Bennahmias, "Detailed Leak Detection Test Plan and Schedule for the Oak Ridge National Laboratory LLLW Active Pipelines," Report No. DOE/OR/01-1167\&D2, prepared for U.S. DOE, Office of Environmental Restoration and Waste Management, Oak Ridge National Laboratory, Oak Ridge, Tennessee, prepared by Vista Research, Inc., Mountain View, California (August 1994).

U.S. Environmental Protection Agency, " 40 CFR 280 - Technical Standards and Corrective Action Requirements for Owners and Operators of Underground Storage Tanks," Federal Register, Vol. 53, No. 185 (23 September 1988).

Bucholz, C. S., Trans. AM. Inst. of Electr. Eng., Vol. 78, Part 2, No. 46 (1960) pp. $394-399$

Gerhold, W. F., E. Esclante and B. T. Sanderson, "The Corrosion Behavior of Selected Stainless Steels in Soil Environments," NBSIR 81-2228 (Feb. 1981).

Lechkie, H. P. and H. H. Uhlig, J. of Electrochem. Soc., Vol 113, No. 12, pp. 1262-1267 (1966

Ondrejcin, R., Savannah River Plant, telephone conversation with author, 1991.

Romanoff, M. "Underground Corrosion," National Bureau of Standards Circular 579 (1957).

Shreir, L. L., R. A. Jarman and G. T. Brunson eds., Corrosion, Vol. 1, 3rd ed., ButterworthHeinemann, Oxford, 1994.

Douglas, D. G., R. F. Wise, J. W. Starr, and J. W. Maresca, Jr., "Leak Testing Plan for the Oak Ridge National Laboratory Liquid Low-Level-Waste System (Active Tanks)," Volumes I, II and III, Report No. ORNL/ER/Sub/92-SK263/1, prepared for Martin Marietta Energy Systems, Inc., Oak Ridge, Tennessee (June 1992).

Summers, G., W. Peters, and C. Armstrong, Basic Statistics in Business and Economics, 2nd ed.,Belmont, California: Wadsworth Publishing Company, Inc. (1977).

Mendenhall, W. and T. Sinchick, Statistics for Engineering and the Sciences, 3rd ed., San Francisco: Dellen Publishing Company (1992).

Benjamin, Jack R. and C. Allin Cornell, "Probability, Statistics, and Decision for Civil Engineers", McGraw-Hill Book Company (1970) 
"Structural Integrity Assessments for the Category C Liquid Low-Level Waste Tank Systems at the Oak Ridge National Laboratory", DOE/OR/01-1385\&D2, prepared by International Waste Management Systems, Knoxville, Tennessee, prepared for US Department of Energy, Oak Ridge National Laboratory, September 1995. 


\title{
1996 STRUCTURAL INTEGRITY ASSESSMENTS FOR THE CATEGORY C LIQUID LOW-LEVEL WASTE TANK SYSTEMS AT ORNL
}

\author{
RESPONSE TO COMMENTS
}

The following matrix provides the DOE responses to EPA comments on the 1996 Structural Integrity Assessments for the Category C Liquid Low-Level Waste Tank Systems at ORNL (DOE/OR/01-1512\&D1).

\section{EPA COMMENTS}

\section{General}

Appendix F of the FFA must be updated to reflect the transfer of F-201 and WC-19 to Category D.

\section{Response}

DOE is in the process of notifying EPA and TDEC in writing that Tanks F-201 and WC-19 are to be transfered to Category D. This change is expected to be on the agenda at the next FFA managers meeting.

\section{General}

It is not clear how the structural integrity assessments of the transfer lines from Buildings 2533/2534 is being established and reported. These lines are listed as Category $\mathrm{C}$ in the Annual Implementation Plan.

\section{Response}

The transfer lines from Buildings 2533/2534 formerly tied into the discharge line from Tank WC-7 to Valve Box No. 1. When Tank WC-7 was remediated, the discharge line was capped at the point where it tied into the discharge line from Bldgs 2533/2534. However, the 2533/2534 transfer line continues to transfer LLLW from the Evaporator Complex to Valve Box No. 1. Because it is still active and singlycontained, it continues to be leak tested annually. The leak test result for FY 96 was reported in the FFA Quarterly Highlights ( the test was conducted in June 1996 and reported in the Third and Fourth Quarter reports). The pipeline now serves a Category B System, and is in the process of being replaced by a system which meets all Category B requirements. Construction is scheduled to be complete in FY 97 . This pipeline is tested and reported in the same manner as the discharge pipelines for Tanks L-11, S-223, and F126.

\section{Page 1. Supplemental Information. Tanks, First Paragraph}

It is unclear how the two small holes in the drain line resulted in the tank failing previous leak tests. Was the drain line below the groundwater table? What investigations were done in connection with previous releases from that drain line through the holes? Were contaminated soils removed?

\section{Response}

Prior to cutting and capping the section of pipe downgradient of the section that contained the two holes, tests conducted on Tank WC-10 frequently resulted in INFLOW decisions and occasionally in INCONCLUSIVE decisions. (A decreasing trend - indicating a FAIL result - was never observed in the data.) The decision to excavate the pipeline in the area where the holes were found was made based on sprinkler tests (simulating rainfall) conducted in the immediate area which showed a definite increase in inflows in to Tank WC-10. The pipeline in the Isotopes Circle area is above the groundwater table. Therefore, tank testing conducted after the capping of the line (April '96) continued to show steady 
inflows, but not the rainfall related unsteady inflows. Before work was completed in the area of the excavation, a cleanout/inspection port was discovered to have a poorly sealed piping joint. This joint was re-sealed on May 30, 1996. The cleanout port is located in a 12" vitrified pipe encasement. The area inside the virified pipe was found to have standing water in it. Tank testing performed after the cleanout port was re-sealed on May 30, showed that the nearly steady inflow (approximately 4 gal/hour) has ceased. Tank WC-10 now routinely passes monthly leak tests. It is suspected that a water supply line in the area is leaking causing the ground around the cleanout to be wet. Prior work was done in which sections of the water supply network were valved out and levels at WC-10 were observed. Closing the valve to the section of line closest to the LLLW line cleanout port showed a decrease of inflows to the tank.

Prior to excavating down to the LLLW pipeline, soil samples were collected at two depths from two locations. Analysis showed trace amounts of Cesium in each sample. Soil was monitored during the excavation, and was found to be below $5 \mathrm{mrem} / \mathrm{hr}$ until soil was taken from directly surrounding the pipeline. Two 55-gallon drums of Category 3 soil (greater than $5 \mathrm{mrem} / \mathrm{hr}$ ) were removed from the area.

\section{Page 139, Tank WC-20, t-statistic}

The discussion on page 139 indicates that the $t$-statisitic for WC-20 is -1.36 and that the mean is consistent with a non-leaking tank. On page 140 it is stated that the mean is equivalent to a zero gal/hr leak rate. However, the table states that the mean is not equivalent to a zero gal/hr leak rate. Please clarify what the analysis of the data set indicates.

\section{Response}

The text is correct and the table contains an error. The table should have stated, " mean is equivalent to a 0 $\mathrm{gal} / \mathrm{hr}$ leak rate". The table on page 140 will be revised via a change page to correct this error and the subsequent document number will be DOE/OR/01-1512\&D2. 
$-\quad+$ 


\section{DISTRIBUTION}

1. L. V. Asplund

2. W. R. Clark

3. C. E. Devore

4-6. J. T. Ethridge

5. H. R. Gaddis

6. H. A. Glovier

7. J. H. Hooyman

8. J. M. Keller

9. M. W. Kohring

10-12. D. M. Matteo

13. K. A. Morgan

14. T. W. Morris

15. P. T. Owen

16. B. D. Patton

17-18. M. R. Peet

19. S. T. Rudell

20. P. A. Schrandt

21. C. B. Scott

22. R. C. Stewart

23. L. J. Turner

24. Central Research Library

25. Engineering Document Management Center

26. ER Document Management Center-RC

27. Laboratory Records Department

28. R. C. Sleeman, Director, Environmental Restoration Division, DOE Oak Ridge Operations Office, P.O. Box 2001, Oak Ridge, TN 37831-8541

29. Vista Research, 100 View St., P.O.Box 998 Mountain View, CA 94042

30. George Hyfantis, International Waste Management Systems, 200 Tech Center Dr., Knoxville, TN 37912

31. Office of Scientific and Technical Information, P.O. Box 62, Oak Ridge, TN 37831 


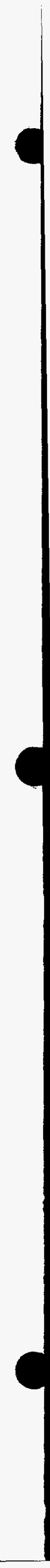

